\title{
De novo apoA-I production : regulation and nutritional effects
}

Citation for published version (APA):

Dullens, S. P. J. (2008). De novo apoA-I production : regulation and nutritional effects. [Doctoral Thesis, Maastricht University]. Universitaire Pers Maastricht. https://doi.org/10.26481/dis.20081112sd

Document status and date:

Published: 01/01/2008

DOI:

10.26481/dis.20081112sd

Document Version:

Publisher's PDF, also known as Version of record

\section{Please check the document version of this publication:}

- A submitted manuscript is the version of the article upon submission and before peer-review. There can be important differences between the submitted version and the official published version of record.

People interested in the research are advised to contact the author for the final version of the publication, or visit the DOI to the publisher's website.

- The final author version and the galley proof are versions of the publication after peer review.

- The final published version features the final layout of the paper including the volume, issue and page numbers.

Link to publication

\footnotetext{
General rights rights.

- You may freely distribute the URL identifying the publication in the public portal. please follow below link for the End User Agreement:

www.umlib.nl/taverne-license

Take down policy

If you believe that this document breaches copyright please contact us at:

repository@maastrichtuniversity.nl

providing details and we will investigate your claim.
}

Copyright and moral rights for the publications made accessible in the public portal are retained by the authors and/or other copyright owners and it is a condition of accessing publications that users recognise and abide by the legal requirements associated with these

- Users may download and print one copy of any publication from the public portal for the purpose of private study or research.

- You may not further distribute the material or use it for any profit-making activity or commercial gain

If the publication is distributed under the terms of Article $25 \mathrm{fa}$ of the Dutch Copyright Act, indicated by the "Taverne" license above, 


\section{de novo apoA-I production:}

regulation and nutritional effects 

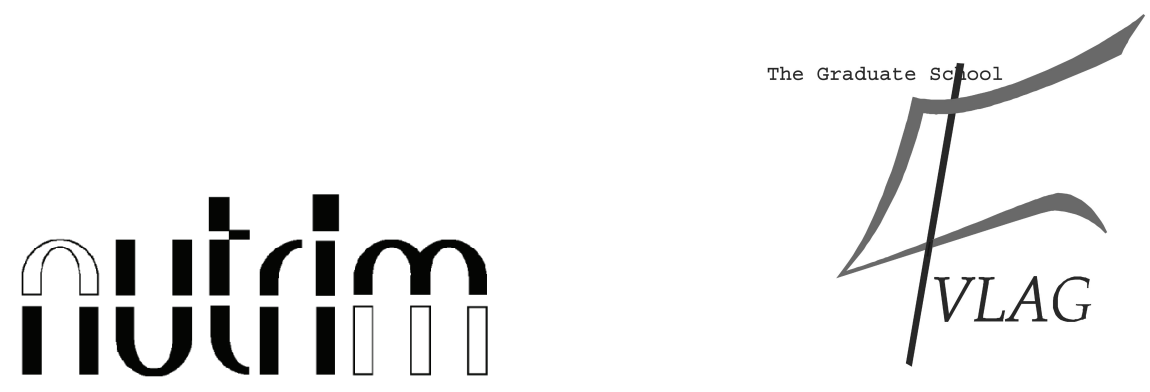

The studies in this thesis were performed within the Nutrition and Toxicology Research Institute Maastricht (NUTRIM), which participates in the Graduate School VLAG (Food Technology, Agrobiotechnology, Nutrition and Health Sciences), accredited by the Royal Netherlands Academy of Arts and Sciences.

Cover design: Eric Limpens

Layout: Stefan Dullens

Printed by: Datawyse, Universitaire Pers Maastricht

(C) Stefan Dullens, Maastricht 2008

ISBN 978-90-5278-750-3 


\title{
de novo apoA-I production:
}

\section{regulation and nutritional effects}

\author{
Proefschrift \\ Ter verkrijging van de graad van doctor \\ aan de Universiteit Maastricht, \\ op gezag van de Rector Magnificus, \\ Prof. mr. G.P.M.F. Mols, \\ volgens het besluit van het College van Decanen, \\ in het openbaar te verdedigen \\ op woensdag 12 november 2008 om 14.00 uur. \\ door \\ Stefan Philomina Joseph Dullens
}

geboren op 12 augustus 1978 te Heerlen 


\section{Promotors:}

Prof. dr. E.C.M. Mariman

Prof. dr. ir. R.P. Mensink

\section{Co-promotor:}

Dr. J. Plat

\section{Beoordelingscommissie:}

Prof. dr. ir. W.H.M. Saris (voorzitter)

Prof. dr. J.F.C. Glatz

Prof. dr. em. G. Hornstra

Prof. dr. F. Kuipers

Dr. ir. P.L. Zock

Financial support by the Netherlands Heart Foundation and Fonds van het Hart for the publication of this thesis is gratefully acknowledged

Printing of this thesis was financially supported by AB Diets, AstraZeneca B.V., Corning B.V., Greiner Bio-One GmbH, Pfizer B.V., and Sigma-Aldrich Chemie B.V. 


\section{Abbreviations}

$\begin{array}{ll}\text { AA } & \text { arachidonic acid }(\mathrm{C} 20: 4 \mathrm{n}-6) \\ \text { ABCA1 } & \text { adenosine triphosphate-binding cassette transporter A1 } \\ \text { ABCG1 } & \text { adenosine triphosphate-binding cassette transporter G1 } \\ \text { ABCG4 } & \text { adenosine triphosphate-binding cassette transporter G4 } \\ \text { ACS } & \text { acute coronary syndromes } \\ \text { ALA } & \text { alpha-linolenic acid } \\ \text { apoA-I } & \text { apolipoprotein A-I } \\ \text { apoA-IV } & \text { apolipoprotein A-IV } \\ \text { apoB } & \text { apolipoprotein B } \\ \text { apoC-III } & \text { apolipoprotein C-III } \\ \text { AARE } & \text { amino acid response element } \\ \text { ARE } & \text { antioxidant response element } \\ \text { ARP-1 } & \text { apoA-I regulatory protein } 1 \\ \text { ASBT } & \text { apical sodium dependent bile acid } \\ \text { ATF3 } & \text { activating transcription factor } 3 \\ \text { ATP } & \text { adenosine triphosphate } \\ \text { BMI } & \text { body mass index } \\ \text { BSA } & \text { bovine serum albumine } \\ \text { CaCo-2 } & \text { human colon adenocarcinoma-derived cell line; differentiated } \\ & \text { small intestinal cell line } \\ \text { CDCA } & \text { chenodeoxycholic acid } \\ \text { CETP } & \text { cholesterol ester transfer protein } \\ \text { CE } & \text { cholesterol ester } \\ \text { C/EBP } & \text { CCAAT enhancer binding protein } \\ \text { CHD } & \text { coronary heart disease } \\ \text { CLA } & \text { conjugated linoleic acid } \\ \text { Ct } & \text { threshold cycle } \\ \text { CVD } & \text { cardiovascular diseases } \\ \text { DDIT3 } & \text { DNA damage-inducible transcript 3 } \\ \text { de novo } & \text { nieuw } \\ \text { DHA } & \text { docosahexaenoic acid (C22:6n-3) } \\ \text { DNA } & \text { deoxyribonucleic acid } \\ \text { EAR-3 } & \text { vERB-A-related protein 3 } \\ \text { EGF1 } & \text { early growth factor } 1 \\ \text { EL } & \text { endothelial lipase } \\ \text { ELISA } & \text { enzyme-linked immunosorbent assay } \\ \text { En\% } & \text { energy percentage } \\ \text { EPA } & \text { eicosapentaenoic acid (C20:5n-3) } \\ \text { ER } \alpha & \text { estrogen receptor } \alpha \\ \text { ER } \beta & \text { estrogen receptor } \beta \\ & \end{array}$




\begin{tabular}{ll} 
FBS & foetal bovine serum \\
FCR & fractional catabolic rate \\
FED & fish eye disease \\
FFA & free fatty acid \\
FeAC & fenofibric acid (PPAR $\alpha$ agonist) \\
FHA & familial hypoalphalipoproteinemia \\
FLD & familial LCAT deficiency \\
FMD & brachial artery dilation \\
FXR & farnesoid X receptor \\
GDF15 & growth/differentiation factor 15 precursor \\
GW7647 & synthetic PPAR agonist \\
HDL & high-density lipoprotein \\
HDL-C & high-density lipoprotein cholesterol \\
HepG2 & human hepatoma-derived cell line \\
HL & hepatic lipase \\
HMG CoA & hepatocyte 3 -hydroxy-3-methylglutaryl coenzyme A \\
HNF-4 & hepatic nuclear factor 4 \\
HNF-3 $\alpha$ & hepatic nuclear factor $3 \alpha$ \\
HNF-3 $\beta$ & hepatic nuclear factor $3 \beta$ \\
HRE & hormone response element \\
IDL & intermediate-density lipoprotein \\
INT407 & small intestinal carcinoma cell line \\
In vitro & in een reageerbuisje \\
In vivo & levend op of in het lichaam zelf \\
IMT & intima-media thickness \\
IRCE & insulin response core element \\
LA & linoleic acid (C18:2n-6) \\
LCAT & lecithin:cholesterol acyltransferase \\
LDL & low-density lipoprotein \\
LDL-C & low-density lipoprotein cholesterol \\
LDLr & low-density lipoprotein receptor \\
Lesstanol & natural policosanol mixture \\
LPS & lipopolysaccharide \\
LXR & liver $X$ receptor \\
MCP-1 & monocyte chemotaxic protein 1 \\
MUFA & monounsaturated fatty acid \\
NEAA & non-essential amino acids \\
NFIL3A & Nuclear factor interleukin-3-regulated protein \\
NF-kB & nuclear factor kappa B \\
NMR & nuclear magnetic resonance \\
NSAID & non-steroidal anti-inflammatory drug \\
OA & oleic acid \\
\hline
\end{tabular}




$\begin{array}{ll}\text { OXLDL } & \text { oxidized LDL } \\ \text { PAF-AH } & \text { platelet-activating factor acetyl-hydrolase } \\ \text { PBS } & \text { phosphate buffered saline } \\ \text { PC } & \text { phosphatidylcholine } \\ \text { PE } & \text { phosphatidylethanolamine } \\ \text { PI } & \text { phosphatidylinositol } \\ \text { PLTP } & \text { phospholipid transfer protein } \\ \text { PON } & \text { paraoxonase } \\ \text { PPAR } & \text { peroxisome proliferator-activated receptor } \\ \text { PPRE } & \text { PPAR response element } \\ \text { PUFA } & \text { polyunsaturated fatty acid } \\ \text { PXR } & \text { pregnane } X \text { receptor } \\ \text { RA } & \text { 9-cis retinoid acid } \\ \text { RAR } \alpha & \text { retinoid acid receptor } \alpha \\ \text { RCT } & \text { reverse cholesterol transport } \\ \text { RNA } & \text { ribonucleic acid } \\ \text { RTq-PCR } & \text { real time quantitative polymerase chain reaction } \\ \text { RXR } \alpha & \text { retinoid } X \text { receptor } \alpha \\ \text { SAA } & \text { serum amyloid A } \\ \text { SAFA } & \text { saturated fatty acid } \\ \text { SD } & \text { standard deviation } \\ \text { SEM } & \text { standard error of mean } \\ \text { SPLA } 2 & \text { secretory phospholipase A2 } \\ \text { SR-BI } & \text { scavenger receptor BI } \\ \text { SP-1 } & \text { specific protein } 1 \\ \text { TAG } & \text { triacylglycerol } \\ \text { TC } & \text { total cholesterol } \\ \text { TCA } & \text { taurocholate } \\ \text { TD } & \text { tangier disease } \\ \text { TNF } & \text { tumor necrosis factor } \\ \text { T }{ }_{3} R \beta & \text { thyroid hormone receptor } \beta \\ \text { VCAM-1 } & \text { vascular cell adhesion molecule 1 } \\ \text { VLDL } & \text { very-low-density lipoprotein } \\ & \end{array}$





\section{Contents}

\section{Chapter 1}

General introduction

\section{Chapter 2}

Increasing apoA-I production as a target for $\mathrm{CHD}$ risk reduction

\section{Chapter 3}

Differentiated CaCo- 2 cells as an in vitro model to evaluate de novo apoA-I production of the small intestine

\section{Chapter 4}

Differential effects of individual fatty acids on de novo

small intestinal apoA-I production

\section{Chapter 5}

Effects of emulsified policosanols with different chain-lengths on cholesterol metabolism in heterozygous LDL-receptor

deficient mice

\section{Chapter 6}

Identification of regulatory factors for apoA-I production by enterocytes and hepatocytes

\section{Chapter 7}

General discussion

Summary/Samenvatting

Dankwoord

List of publications 

Chapter 1

General introduction 


\section{Introduction}

In the Netherlands, but also in other western countries, the imbalance between energy intake and energy expenditure in combination with a diet that does not meet recommended dietary intakes is a main cause for the increasing incidence of typical western-associated diseases, such as obesity, type II diabetes mellitus, metabolic syndrome, and cardiovascular diseases (CVD). These diseases have become our main health concern, and challenge researchers to develop interventions to counteract the undesirable effects or to change these unhealthy lifestyle patterns. With respect to the recommended dietary intake, the Dutch population consume, for example, too much saturated fatty acids (on average 14en\% (percent of energy) instead of less than $10 \mathrm{en} \%$ as recommended), too less carbohydrates (45en\% versus 55en\%, in which more complex carbohydrates should be consumed), and too less dietary fibres (2.4g/MJ versus $3 \mathrm{~g} / \mathrm{MJ}))^{1}$.

CVD are the world's leading cause of mortality and morbidity in developed countries. In the Netherlands, CVD also has the highest mortality (32\%) of all Western-associated diseases and leads to approximately 42500 deaths per year ${ }^{2}$. CVD mainly includes coronary heart disease (CHD) and cerebrovascular diseases. In 2006, CHD had the highest mortality of $69 \%$ (29315 deaths), whereas cerebrovascular diseases had a mortality of $23 \%$ (9976 deaths). The prevalence of CHD is equally distributed between women en men (in 2006: 14977 men, and 14338 women). However, the average age of CHD mortality is 10 years lower in men than in women. Moreover, CHD (myocardial infarction and/or angina pectoris) is predominantly caused by atherosclerosis, which is a multi-factorial progressive inflammatory disease of the arterial wall ${ }^{3}$. In more detail, atherosclerosis is primarily triggered by an injury of the endothelial layer of a blood vessel, followed by a broad range of complex interactions that finally leads to the development of an atherosclerotic plaque in the vessel wall. This progressive process, atherogenesis, is affected by many predisposing risk factors, such as diabetes, dyslipidemia, hypertension, and obesity. In addition, life-style factors, such as smoking, a high saturated fat diet, stress, and physical inactivity are also positively associated with atherogenesis ${ }^{2,4,5}$. One of these risk factors, dyslipidemia, is characterised by increased serum triacylglycerol and low-density lipoprotein cholesterol (LDL-C) concentrations, and decreased serum high-density lipoprotein cholesterol (HDL-C) concentrations. LDL-C and HDL-C, also known as the 'bad' cholesterol (LDL-C) and the 'good' cholesterol (HDL-C), respectively, are both cholesterol-rich vehicles, and are both important players within the process of atherosclerosis (atherogenesis). Therefore, pharmacological and/or nutritional compounds that decrease serum LDL-C and/or increase HDL-C and apoA-I concentrations are potential 
agents in CHD risk reduction. However, research in the past decades has predominantly focussed on the development of pharmacological and nutritional agents to lower serum LDL-C concentrations. Although this antiatherogenic strategy is still relevant, elevating serum HDL-C and/or apoA-I concentrations is of additional importance, with respect to the treatment or prevention of CHD.

The studies described in this thesis focus on the process of de novo apoA-I production to elevate concentrations of new-formed HDL particles in humans as an anti-atherogenic strategy. In this chapter, the process of atherogenesis will be described briefly, thereby especially describing the position of LDL-C, HDL-C, and apoA-I. Next, the potential effects of fatty acids and policosanols on cholesterol metabolism will be described. Finally, the outline of the thesis will be presented.

\section{Atherogenesis}

The process of atherogenesis is a continuum that already starts during infancy. During these early stages, the disease is still clinically silent. At later ages, when plaque formation is more severe, a plaque may become unstable. Rupture of an atherosclerotic plaques consequently leads to a thrombus that may cause a myocardial or cerebro-vascular infarct ${ }^{6}$.

A disturbance within the cholesterol metabolism can trigger the atherosclerotic process. Cholesterol is not only an important constituent of our cell membranes, but also is a precursor for the synthesis of bile acids, steroid hormones, and vitamin $D^{7}$. However, when serum total cholesterol (TC) concentrations are elevated, cholesterol may accumulate into the intima layers of the arteries, which ultimately leads to a reduced arterial flexibility. A reduced flexibility of the arterial wall makes the (coronary) artery more vulnerable for injuries, caused, for example, by high blood pressure. As shown in figure $\mathbf{1}$, in this process particularly small dense LDL particles, which are prone to oxidation, are involved and contribute to endothelial injury. This is the premature stage of atherogenesis. Moreover, oxidised LDL (oxLDL) stimulates injured endothelial cells to express adhesion molecules, such as vascular cell-adhesion molecule 1 (VCAM-1) and to secrete chemoattractants, for example, monocyte chemotaxic protein 1 (MCP-1). Consequently, these adhesion molecules attract monocytes to the site of arterial wall damage. When monocytes arrive via the blood circulation at the endothelial layer of the damaged artery, they bind to adhesion molecules and transmigrate through the endothelial layer into the intima. After a monocyte enters the intima, it transforms into a macrophage, hereby expressing large numbers of scavenger receptors at their membrane-surface. Because 
macrophages present scavenger receptors, they are capable to phagocytose large amounts of oxLDLs. Due to the lack of a feedback regulation of these scavenger receptors, the macrophage becomes overloaded with oxLDL particles and transforms into a 'foam cell'. During this process the macrophage 1) produces cytokines, which attract more monocytes and macrophages, 2) activates endothelial cells to produce adhesion molecules, and 3) activates smooth muscle cells to proliferate towards the luminal side of the arterial wall. At that moment, smooth muscle cells start synthesizing an extracellular matrix, in particular collagen. The relocation of smooth muscle cells and the accumulation of new matrix components result in the formation of a fibrous 'cap'. This fibrous 'cap' covers the lipid pool and consists of collagen-rich fibrous tissue, smooth muscle cells, macrophages, thrombocytes, and T-lymphocytes. This is a mature atherosclerotic plaque. When a plaque becomes unstable, rupture of this plaque might lead to a thrombus in the circulation. When the thrombus blocks a coronary or cerebral artery, this can lead to a myocardial or cerebrovascular infarct, respectively.

Although atherogenesis is a progressive process, it is - at least partly reversible. Reversibility of this atherosclerotic process is obviously easier at earlier stages. In this reversible process HDL particles have a major role, which has been clearly demonstrated in a human intervention study ${ }^{8}$. In this study, recombinant apoA-I $\mathrm{I}_{\text {Milano }}$ was intravenously infused and ultimately resulted in an absolute reduction in atheroma volume of $-14.1 \mathrm{~mm}^{3}$ (or $4.2 \%)$ from baseline. HDL particles are able to accept cholesterol from the atherosclerotic plaque, via the activity of specific transporter proteins (ABCA1, ABCG1, and ABCG4) located at macrophages and/or endothelial cells of peripheral tissues ${ }^{9,10}$. When HDL particles are loaded with cholesterol esters, they transport and deliver cholesterol esters to the liver. In the liver, cholesterol esters can be metabolized into bile acids and as such excreted out of the body. This whole process is called the reverse cholesterol transport, which is described in more detail in chapter 2 . Besides this enhancing effect on reverse cholesterol transport, many other anti-atherosclerotic properties have been ascribed to HDL particles, which are described in the next section. 


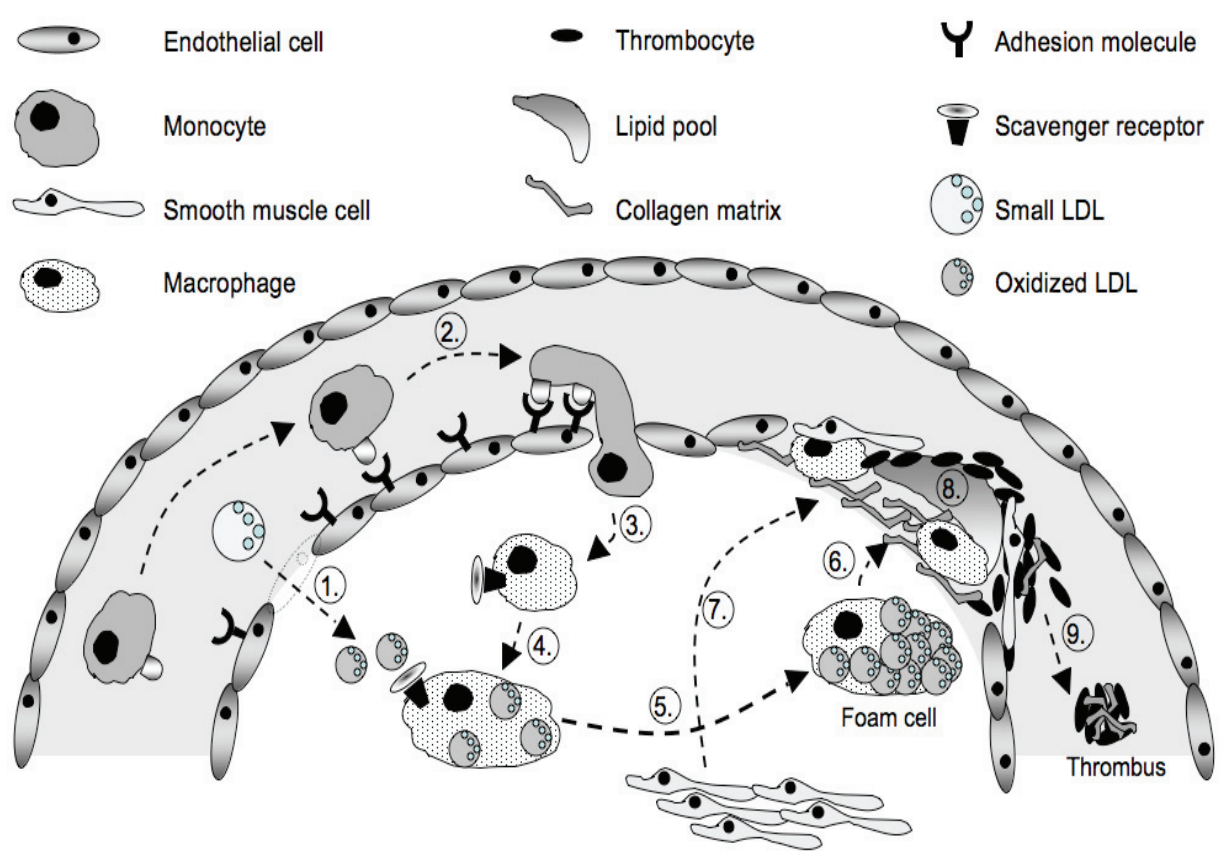

Figure 1. Atherogenesis.

When the endothelial layer becomes damaged, small (oxidised) LDL particles can migrate through this damaged endothelial layer (1). Monocytes, attracted by adhesion molecules produced by endothelial cells, transmigrate through the endothelial layer (2), and differentiate into macrophages (3). Macrophages present scavenger receptors and phagocytose oxLDLs (4). Next, when a macrophage becomes overloaded with oxLDLs, it transforms into a "foam cell" (5). Accumulation of foam cells in the endothelial layer (6), together with migrated smooth muscle cells (7), monocytes, a collagen matrix, and thrombocytes, results into a mature atherosclerotic plaque (8). Ultimately, rupture of an unstable atherosclerotic plaque leads to a thrombus (9) that may result in a myocardial or cerebrovascular infarct. 


\section{Evidence of anti-atherogenic properties of HDL-C and apoA-I}

Numerous epidemiological studies have demonstrated an inverse association between serum HDL-C and/or apoA-I concentrations with $\mathrm{CHD}$ risk ${ }^{11-17}$. It has been estimated that each $1 \%$ increase in serum HDL-C concentrations is associated with a $2 \%$ reduction in the risk to develop $\mathrm{CHD}{ }^{18,19}$. A metaanalysis of long-term population studies even suggested that in women a $1 \%$ increase of HDL-C lowered CHD risk by $3 \%{ }^{11}$. However, the strength of the association between serum HDL-C concentrations and cardiovascular risk also depends on the presence of additional risk factors, such as diabetes mellitus, smoking, hypertension, and a family history of myocardial infarction. Obviously, the CHD risk will increase when a low HDL-C concentration is combined with one (or more) of the above-mentioned risk factors ${ }^{20}$.

The anti-atherogenic properties of HDL-C are ascribed to several characteristics of the HDL particle or its main protein constituent apoA-I. Examples of these characteristics are: 1) HDL has anti-inflammatory effects 21 , 2) it protects against endothelial dysfunction 22,3 ) it inhibits the synthesis of platelet-activating factor by endothelial cells ${ }^{23}$, 4) it protects erythrocytes against the generation of pro-coagulant activity 24,5 ) has antioxidant capacities ${ }^{25}$, and finally, 6) HDL is a key player within the reverse cholesterol transport ${ }^{26}$. With respect to reverse cholesterol transport, the capacity of circulating HDL particles to accept cholesterol from the vessel wall of peripheral tissues is higher for premature (cholesterol-poor) HDL particles (i.e. pre- $\beta_{1} \mathrm{HDL}$, and pre $\beta_{2} \mathrm{HDL}$ ) than mature (cholesterol-rich) HDL particles (i.e. $\mathrm{HDL}_{2}$, and $\left.\mathrm{HDL}_{3}\right)^{27}$. Therefore, the reverse cholesterol transport capacity theoretically depends on the production of de novo (premature) HDL particles. Premature HDL particles can be generated in two different manners as described in chapter $\mathbf{3}$ (figure 1. HDL metabolism). First, when apoA-I is secreted into the circulation by the liver and/or by the small intestine, premature HDL can be formed. Secondly, by HDL remodelling of small spherical HDL particles, in which these particles fuse together and lead to a de novo premature and a large HDL particle ${ }^{28}$. The remodelling of spherical HDL particles takes place in the blood circulation and is facilitated by various lipases ${ }^{29}$, whereas de novo produced apoA-I is predominantly derived from the liver and the small intestine. Conclusively, besides HDL remodelling, elevating hepatic and/or small intestinal de novo apoA-I production might be a potential anti-atherogenic strategy. This assumption has been confirmed in several animal studies. For example, the finding that human apoA-I transgenic mice were protected against the development of diet-induced atherosclerosis as compared to their wild-type littermates is convincing ${ }^{30-33}$. In addition, in a study with the apoA-I knockout mice that received a high-fat 
high-cholesterol diet, HDL-C levels were minimally raised and showed the essential role of apoA-I in diet induced HDL-C production ${ }^{34}$. These apoA-I knockout mice had however no peripheral total cholesterol accumulation, and did not develop atherosclerotic plaques, which was explained by the fact that both HDL-C and LDL-C levels were decreased in this mice model. Furthermore, in C57BL/6] or LDLreceptor-knockout mice, intravenous infusions with synthetic mimetic human apoA-I proteins, like D-4F or 5F, protected against diet-induced atherosclerosis 35,36 . In addition, recent findings showed that intravenous infusion of recombinant apoA- $\mathrm{I}_{\text {Milano }}$ phospholipid complexes (ETC-216) significantly reduced atherosclerosis progression in mice and rabbits ${ }^{37}$. This latter finding was recently confirmed in patients with acute coronary syndromes ${ }^{8}$.

In summary, increasing apoA-I concentrations via elevating de novo apoA-I production is a promising approach to lower CHD risk. Therefore, detailed knowledge is needed concerning apoA-I synthesis and underlying regulatory pathways. In addition, there is an urgent need to identify (dietary) components that have the capacity to elevate apoA-I production. In this respect, certain fatty acids and policosanols are of potential interest. 


\section{Fatty acids}

\section{Structure of fatty acids}

Fatty acids are important energy suppliers of a cell, but have also an important role in several physiological processes. The involvement in regulation of physiological processes can be ascribed to the metabolites formed from individual fatty acids. In this view, certain fatty acids are precursors of a wide variety of signalling agents, such as eicosanoids, prostagladines, thromboxanes, and leukotrienes ${ }^{38}$. The regulatory effects of fatty acids or their metabolites might be related to their structure. The fatty acid structure consists of a skeleton of carbon (C) atoms with a methyl-group $\left(\mathrm{CH}_{3}\right)$ at one end, and a carboxyl-group $(\mathrm{COOH})$ at the other end. The skeleton of C-atoms can vary in chain-length, in degree of saturation indicated as a double bond -, or in cis or trans configuration - depending on the configuration of the double bond - (figure 2). According to their structure, fatty acids are denoted as $C a: b(n-c)$, in which ' $a$ ' indicates the number of $C$-atoms within the chain of the skeleton, ' $b$ ' the number of double bonds, and ' $\mathrm{c}$ ' the position of the first double bond as counted from the methyl-group. For example, C18:2(n-6) stands for linoleic acid, which is a fatty acid with eighteen $\mathrm{C}$-atoms, two double bonds of which the first double bond starts from $\mathrm{C}$-atom number six counted from the methyl-group end.

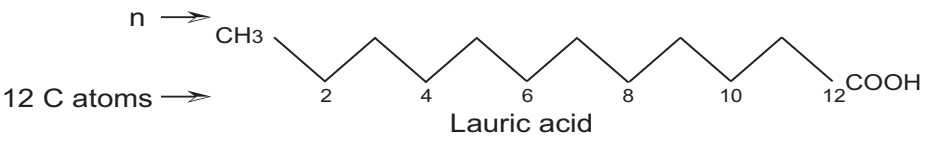

(12:0)
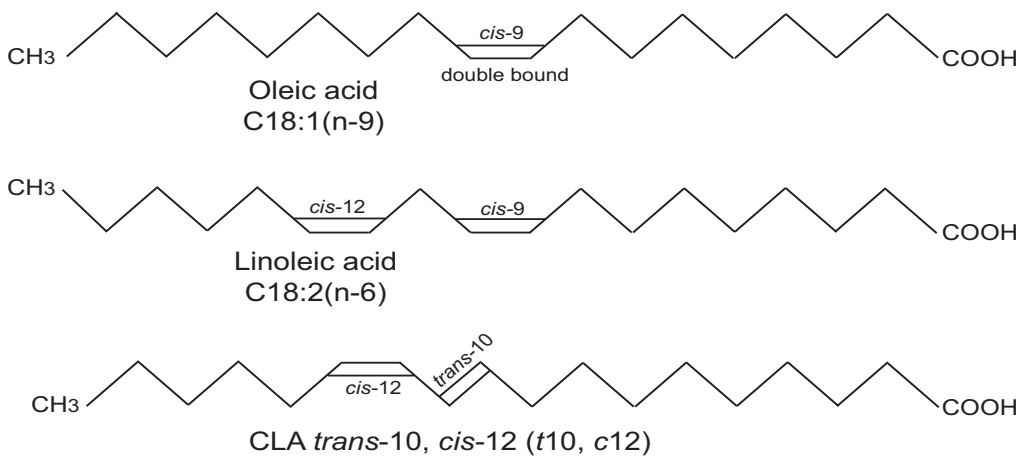

Figure 2. Nomenclature of various fatty acids.

Saturated fatty acid (SAFA) lauric acid (C12:0), monounsaturated fatty acid (MUFA) oleic acid (C18:1(n-9)) -the main fatty acid in daily diet of the Dutch population-, and polyunsaturated fatty acid (PUFAs) linoleic acid $(C 18: 2(n-6))$ with its isomer $C_{2} A_{t 10, c 12}$ are examples of different structures of fatty acids. 
With respect to the degree of saturation, saturated fatty acids (SAFAs) do not contain double bonds, whereas mono-unsaturated fatty acids (MUFAs) have one and polyunsaturated fatty acids (PUFAs) contain two or more double bonds. For example, lauric acid (C12:0) is a SAFA, oleic acid $(\mathrm{C} 18: 1(n-9))$ is a MUFA, and linoleic acid $(C 18: 2(n-6))$ is a PUFA. According to the position of the first double bond ( $n$-designation), fatty acids can either belong to $n-3, n-6, n-7$, or $n-9$ families. Next to fatty acids from diet, they can also be formed endogenously. In humans, de novo fatty acid biosynthesis is predominantly active in the liver and in adipose tissue, but also in mammary glands during lactation ${ }^{39}$. Unlike SAFAs and MUFAs, PUFA linoleic acid (LA: C18:2n-6) and $\alpha$-linolenic acid (ALA: C18:3n-3) can not be synthesised de novo by humans, and in addition are required in many biological processes, such as vascular and cerebral development. Therefore, linoleic acid and $\alpha$-linolenic acid are essential fatty acids. When PUFAs linoleic acid and $\alpha$-linolenic acid are provided by the diet, linoleic acid and $\alpha$-linolenic acid can be endogenously modulated by desaturases and elongases in which long-chain PUFAs are generated. Because these enzymes can only change the chemical structure of a fatty acid between the carboxyl-group and the first double bond, the biosynthesis of a fatty acid into another de novo fatty acid always results in a processed fatty acid of the same fatty acid family.

\section{Fatty acids and CHD}

With respect to CHD risk, effects on total cholesterol of different categories of fatty acids are already known since the fifties and sixties of the previous century 40,41. A meta-analysis of 60 well-controlled interventions, in which the effects of individual SAFAs, MUFAs, and PUFAs, on total cholesterol and (apo)lipoproteins were evaluated, showed the effects of individual and/or categories of fatty acids ${ }^{42}$. From this meta-analysis, it was estimated that a mixture of SAFAs elevates serum HDL-C concentrations as compared to the MUFA oleic acid (table 1). Oleic acid is the main fatty acid in daily diet of the Dutch population. When the effects of individual SAFAs (lauric acid, myristic acid, palmitic acid, and stearic acid) are compared to the MUFA oleic acid, we can conclude that lauric acid is most strongly associated with elevated serum HDL-C levels. With respect to serum apoA-I concentrations, lauric acid, myristic acid, and palmitic acid - but not stearic acid - have elevating effects as compared to oleic acid. Furthermore, trans MUFAs have decreasing effects on both serum HDL-C and apoA-I levels as compared to oleic acid. In line with trans MUFAs, PUFAs (mainly linoleic acid and $\alpha$-linolenic acid) do not elevate HDL-C or apoA-I levels as compared to oleic acid. In this view, the SAFA lauric acid might have the most favourable effects on serum HDL-C and apoA-I levels as compared to oleic acid and the PUFAs linoleic acid and $\alpha$ - 
linolenic acid. However, it has to be mentioned that long-chain PUFAs, such as n-3 PUFA eicosapentaenoic acid (EPA: C20:5n-3) and docosahexaenoic acid (DHA: C22:6n-3) - present in fatty fish -, may contain other health beneficial effects, such as anti-inflammatory properties. Therefore, a high dietary intake of these PUFAs is strongly recommended to reduce CHD risk ${ }^{43}$.

Table 1. The effects of SAFAs, trans MUFAs, and PUFAs on serum lipids and apoA-I presented as estimated regression coefficients for mean changes $(\Delta)$, compared to the effects of MUFA oleic acid ${ }^{42}$.

\begin{tabular}{|c|c|c|c|c|c|}
\hline & $\begin{array}{c}\Delta \text { Total } \\
\text { cholesterol: } \\
\text { HDL-C }\end{array}$ & $\begin{array}{c}\Delta \text { Total } \\
\text { cholesterol } \\
(\mathrm{mmol} / \mathrm{L})\end{array}$ & $\begin{array}{c}\Delta \mathrm{HDL}-\mathrm{C} \\
(\mathrm{mmol} / \mathrm{L})\end{array}$ & $\begin{array}{c}\Delta \mathrm{LDL}-\mathrm{C} \\
(\mathrm{mmol} / \mathrm{L})\end{array}$ & $\begin{array}{c}\Delta a p o A-I \\
(\mathrm{mg} / \mathrm{L})\end{array}$ \\
\hline SAFAs & $0.029 \Uparrow$ & $0.042 \Uparrow \Uparrow$ & $0.002=$ & $0.041 \Uparrow \Uparrow$ & $0.5 \Uparrow$ \\
\hline $\begin{array}{l}\text { Lauric acid } \\
(\mathrm{C} 12: 0)\end{array}$ & $-0.011 \Downarrow$ & $0.075 \Uparrow \Uparrow$ & $0.019 \Uparrow$ & $0.061 \Uparrow \Uparrow$ & $8.6 \Uparrow \Uparrow$ \\
\hline $\begin{array}{l}\text { Myristic acid } \\
(\text { C14:0) }\end{array}$ & $0.023 \Uparrow$ & $0.065 \Uparrow \Uparrow$ & $0.010 \Uparrow$ & $0.057 \Uparrow \Uparrow$ & $5.2 \Uparrow \Uparrow$ \\
\hline $\begin{array}{l}\text { Palmitic acid } \\
(\text { C16:0) }\end{array}$ & $0.031 \Uparrow$ & $0.047 \Uparrow \Uparrow$ & $0.002=$ & $0.048 \Uparrow \Uparrow$ & $2.3 \Uparrow$ \\
\hline $\begin{array}{l}\text { Stearic acid } \\
(\mathrm{C} 18: 0)\end{array}$ & $0.013 \Uparrow$ & $-0.040 \Downarrow \Downarrow$ & $-0.006 \Downarrow$ & $0.005=$ & $-6.8 \Downarrow \Downarrow$ \\
\hline Trans MUFAs & $0.048 \Uparrow \Uparrow$ & $0.037 \Uparrow \Uparrow$ & $-0.008 \Downarrow$ & $0.049 \Uparrow \Uparrow$ & $-3.0 \Downarrow \Downarrow$ \\
\hline PUFAs & $-0.006 \Downarrow$ & $-0.015 \Downarrow$ & $-0.002=$ & $-0.010 \Downarrow$ & $-3.0 \Downarrow \Downarrow$ \\
\hline
\end{tabular}

In conclusion, individual fatty acids have different effects on serum HDL-C and apoA-I concentrations, in which the effects of the SAFA lauric acid seems to be most pronounced. However, the relation between individual fatty acids and CHD risk has to be estimated carefully, since lauric acid not only elevates HDL-C but also serum LDL-C concentrations. However, it has been estimated that dietary intake of the SAFA lauric acid significantly decreased the ratio total cholesterol to HDL-C compared to oleic acid (regression coefficient of -0.011 compared to oleic acid), which is comparable to the effect of diets enriched with PUFAs (regression coefficient of -0.006) ${ }^{42}$. Nevertheless, the effects and optimal intakes of dietary PUFAs have been frequently studied and PUFAs are generally considered as healthy, whereas the optimal lauric acid concentration in daily diet is not yet known, and needs further study. 


\section{Policosanols}

\section{Structure of policosanols}

A natural mixture of aliphatic primary alcohols - policosanols - can be isolated from sugar cane wax (Saccharum officinarum $L$ ), but can also be found in wheat germ, rice bran, or beeswax ${ }^{44-46}$. The natural policosanol source contains alcohols, very long chain aliphatic alkanes, and fatty aldehydes, of which all policosanol types can vary in carbon skeleton length of C24 to C34 (see figure 3). The most abundant constituent within natural policosanol mixtures is octacosanol ( $\mathrm{C} 28$ alcohol). Although, health favourable effects were claimed for the natural policosanol mixture, it is composed of different policosanol constituents. Therefore, it is not known which single policosanol is the most effective component in the natural policosanol mixture.

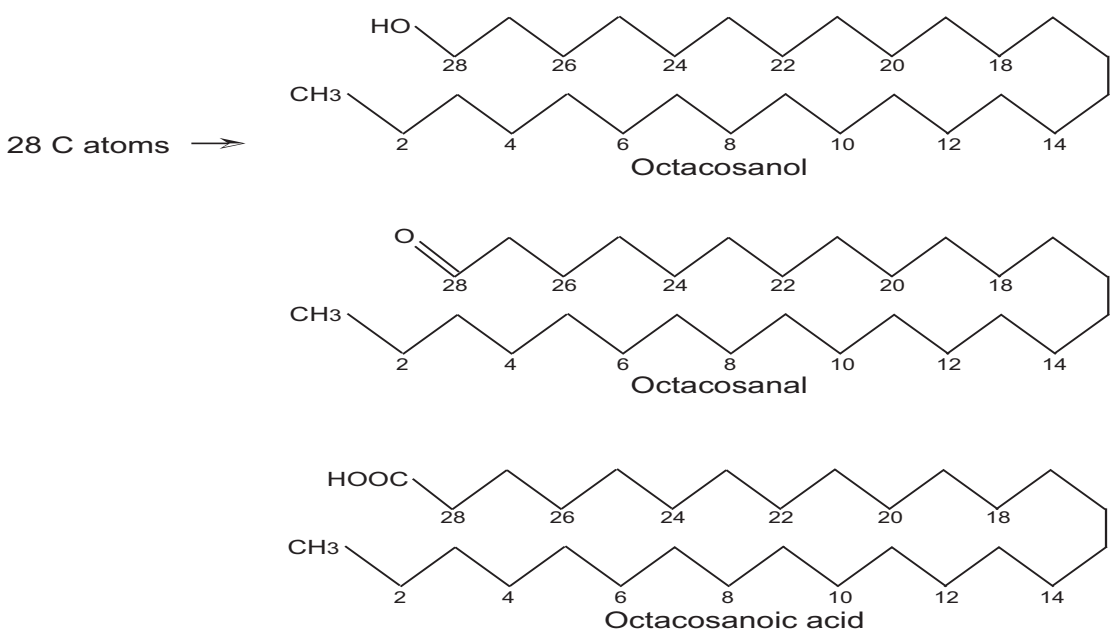

Figure 3. Nomenclature of policosanols.

Policosanols with a carbon skeleton length of C28 can be divided in a very long-chain fatty alcohol (octacosanol), a fatty aldehyde (octacosanal), and a fatty acid (octacosanoic acid). 


\section{Policosanols and CHD}

In humans, the effects of a mixture of policosanols derived from sugar cane on serum lipoprotein profiles have been studied extensively by a research group in Cuba. As reviewed by Gouni-Berthold and Berthold 47 , policosanols have strong reducing effects both on serum LDL-C $(-17 \%$ to $-21 \%)$ and TC ($21 \%$ to $-29 \%$ ) concentrations, whereas elevating effects have been demonstrated on serum HDL-C $(+8 \%$ to $+15 \%)$ concentrations. These favourable effects are comparable to those achieved by statin treatments ${ }^{47}$, which implicates that policosanols are highly interesting candidates as a functional food ingredient to lower the CHD risk in humans. Especially, the effects described on serum HDL-C are promising. However, more recent human intervention studies, others than performed by research groups outside Cuba, were not able to confirm these effects ${ }^{48-51}$. One possible explanation for this discrepancy is the difference in composition between the original Cuban product and the policosanol mixtures used in those other studies. Therefore, more research is needed to estimate the effectiveness of the constituents in the natural policosanol mixtures. 


\section{Outline of the Thesis}

This thesis presents the effects of various pharmacological and nutritional compounds on de novo apoA-I production of the liver and/or the small intestine in humans. The physiological relevance of increasing de novo apoA-I production and consequently elevating numbers of small HDL particles to reduce $\mathrm{CHD}$ risk is extensively described in chapter $\mathbf{2}$. With respect to apoAI elevating components, we were especially interested in de novo apoA-I production of the small intestine. However, effects of components on de novo apoA-I production in enterocytes have only been scarcely reported. Therefore, in chapter $\mathbf{3}$ we demonstrated the suitability of differentiated CaCo-2 cells as an in vitro model to study effects of various pharmacological model agents that are known to interfere with de novo apoA-I production. In that study, we demonstrated that differentiated $\mathrm{CaCo}-2$ cells are a suitable enterocyte-like cell model, in which effects of other (nutritional) agents on de novo apoA-I production can be investigated. Therefore, effects of individual fatty acids on de novo apoA-I production in differentiated $\mathrm{CaCo}-2$ cells were evaluated in chapter $\mathbf{4}$, in which the potential influence of fatty acid chainlength, degree of saturation, and cis/trans configuration were studied. Further, we evaluated the effects of a natural policosanol mixture in a sideby-side comparison with several individual policosanols to identify the effective component of the natural policosanol mixture, both in cell models as well as in heterozygous $\mathrm{LDLr}^{+/-}$mice, as described in chapter $\mathbf{5}$.

PPAR $\alpha$ agonists have been postulated to elevate serum HDL-C and apoA-I concentrations in humans. However, in our in vitro hepatic and enterocyte cell models fenofibric acid (FeAc) decreased the apoA-I production, whereas PPAR $\alpha$ agonist GW7647 elevated apoA-I culture medium concentrations. To elucidate the mechanism behind this discrepancy, we searched for additional transcriptional (co)factors involved in de novo apoA-I production. Therefore, we evaluated gene expression profiles induced by fenofibric acid and GW7647 in HepG2 cells and in differentiated CaCo-2 cells, as described in chapter $\mathbf{6}$. Finally, chapter $\mathbf{7}$ discusses the most important findings and conclusions based on the studies described in this thesis. In addition, recommendations for further research are addressed in this final chapter. 


\section{References}

1. RIVM. Internet: http://www.rivm.nl. Assessed on April 2008.

2. Nederlandse, Internet:http://www.hartstichting.nl. Assessed on April 2008.

3. Berliner JA, Navab M, Fogelman AM, et al. (1995). Atherosclerosis: basic mechanisms. Oxidation, inflammation, and genetics. Circulation (91):2488-96.

4. Fruchart JC, Nierman MC, Stroes ES, Kastelein JJ, Duriez P. (2004). New risk factors for atherosclerosis and patient risk assessment. Circulation (109):III15-9.

5. Tegos TJ, Kalodiki E, Sabetai MM, Nicolaides AN. (2001). The genesis of atherosclerosis and risk factors: a review. Angiology (52):89-98.

6. Fuster V, Badimon L, Badimon JJ, Chesebro $\mathrm{JH}$. (1992). The pathogenesis of coronary artery disease and the acute coronary syndromes (1). N Engl J Med (326):24250,310-318

7. Danielsson H, Sjovall J. (1975). Bile acid metabolism. Annu Rev Biochem (44):23353

8. Nissen SE, Tsunoda T, Tuzcu EM, et al. (2003). Effect of recombinant ApoA-I Milano on coronary atherosclerosis in patients with acute coronary syndromes: a randomized controlled trial. Jama (290):2292-300.

9. Wang $N$, Lan D, Chen W, Matsuura F, Tal AR. (2004). ATP-binding cassette transporters $\mathrm{G} 1$ and $\mathrm{G} 4$ mediate cellular cholesterol efflux to high-density lipoproteins. Proc Natl Acad Sci U S A (101):9774-9.

10. Denis $M$, Bissonnette $R$, Haidar B, Krimbou L, Bouvier M, Genest J. (2003). Expression, regulation, and activity of ABCA1 in human cell lines. Mol Genet Metab (78):265-74.

11. Gordon DJ, Knoke J, Probstfield JL, Superko R, Tyroler HA. (1986). High-density lipoprotein cholesterol and coronary heart disease in hypercholesterolemic men: the Lipid Research Clinics Coronary Primary Prevention Trial. Circulation (74):1217-25.

12. Enger SC, Hjermann I, Foss OP, et al. (1979). High density lipoprotein cholesterol and myocardial infarction or sudden coronary death: a prospective case-control study in middle-aged men of the Oslo study. Artery (5): 170-81.

13. Miller $\mathrm{NE}$, Thelle DS, Forde $\mathrm{OH}$, Mjos OD. (1977). The Tromso heart-study. Highdensity lipoprotein and coronary heartdisease: a prospective case-control study. Lancet (1):965-8.

14. Gordon T, Castelli WP, Hjortland MC, Kannel WB, Dawber TR. (1977). High density lipoprotein as a protective factor against coronary heart disease. The Framingham Study. Am J Med (62):707-14.
15. Jacobs DR, Jr., Mebane IL, Bangdiwala SI, Criqui MH, Tyroler HA. (1990). High density lipoprotein cholesterol as a predictor of cardiovascular disease mortality in men and women: the follow-up study of the Lipid Research Clinics Prevalence Study. Am J Epidemiol (131):32-47.

16. Pekkanen J, Linn S, Heiss G, et al. (1990). Ten-year mortality from cardiovascular disease in relation to cholesterol level among men with and without preexisting cardiovascular disease. N Engl J Med (322):1700-7.

17. Luc G, Bard JM, Ferrieres J, et al. (2002). Value of HDL cholesterol, apolipoprotein A-I, lipoprotein A-I, and lipoprotein A-I/A-II in prediction of coronary heart disease: the PRIME Study. Prospective Epidemiological Study of Myocardial Infarction. Arterioscler Thromb Vasc Biol (22):1155-61.

18. Castelli WP. (1988). Cholesterol and lipids in the risk of coronary artery disease--the Framingham Heart Study. Can J Cardiol (4 Suppl A):5A-10A.

19. Gordon DJ, Probstfield JL, Garrison RJ, et al. (1989). High-density lipoprotein cholesterol and cardiovascular disease. Four prospective American studies. Circulation (79):8-15.

20.von Eckardstein A, Assmann G. (2000). Prevention of coronary heart disease by raising high-density lipoprotein cholesterol? Curr Opin Lipidol (11):627-37.

21. Levine DM, Parker TS, Donnelly TM, Walsh A, Rubin AL. (1993). In vivo protection against endotoxin by plasma high density lipoprotein Proc Natl Acad Sci U S A (90):12040-4.

22. Murugesan G, Sa G, Fox PL. (1994). Highdensity lipoprotein stimulates endothelial cell movement by a mechanism distinct from basic fibroblast growth factor. Circ Res (74): 1149-56

23. Sugatani J, Miwa $M$, Komiyama $Y$, Ito $S$. (1996). High-density lipoprotein inhibits the synthesis of platelet-activating factor in human vascular endothelial cells. J Lipid Mediat Cell Signal (13):73-88

24. Epand RM, Stafford A, Leon B, et al. (1994). $\mathrm{HDL}$ and apolipoprotein A-I protect erythrocytes against the generation of procoagulant activity. Arterioscler Thromb (14): $1775-83$.

25. Kontush A, Chantepie S, Chapman MJ. (2003). Small, dense HDL particles exert potent protection of atherogenic LDL against oxidative stress. Arterioscler Thromb Vasc Biol (23): 1881-8

26. Rader DJ. (2006). Molecular regulation of HDL metabolism and function: implications for novel therapies. J Clin Invest (116):3090100. 
27. Norata GD, Pirillo A, Catapano AL. (2006). Modified HDL: biological and physiopathological consequences. Nutr Metab Cardiovasc Dis (16):371-86.

28. Rye KA, Barter PJ. (2004). Formation and metabolism of prebeta-migrating, lipid-poor apolipoprotein A-I. Arterioscler Thromb Vasc Biol (24):421-8.

29. Jin W, Marchadier D, Rader DJ. (2002). Lipases and HDL metabolism. Trends Trends Endocrinol Metab (13):174-8.

30. Li H, Gu S, Cao X, Wang Z, She M. (2000). Suppression of induced atherosclerosis in $\mathrm{h}$ apo AI transgenic mice by overexpression of human apo AI in the aortic wall. Chin Med J (Engl) (113):657-61.

31. Rubin EM, Krauss RM, Spangler EA, Verstuyft JG, Clift SM. (1991). Inhibition of early atherogenesis in transgenic mice by human apolipoprotein AI. Nature (353):265-7.

32. Baroukh $\mathrm{N}$, Ostos MA, Vergnes $\mathrm{L}$, et al. (2001). Expression of human apolipoprotein A-I/C-III/A-IV gene cluster in mice reduces atherogenesis in response to a high fat-high cholesterol diet. FEBS Lett (502):16-20.

33. Benoit $P$, Emmanuel $F$, Caillaud JM, et al. (1999). Somatic gene transfer of human ApoA-I inhibits atherosclerosis progression in mouse models. Circulation (99):105-10.

34. Plump AS, Azrolan N, Odaka $\mathrm{H}$, et al. (1997). ApoA-I knockout mice: characterization of HDL metabolism in homozygotes and identification of a post-RNA mechanism of apoA-I up-regulation in heterozygotes. J Lipid Res (38):1033-47.

35. Navab M, Anantharamaiah GM, Hama S, et al. (2002). Oral administration of an Apo A-I mimetic Peptide synthesized from D-amino acids dramatically reduces atherosclerosis in mice independent of plasma cholesterol. Circulation (105):290-2.

36. Ou J, Ou Z, Jones DW, et al. (2003). L-4F, an apolipoprotein A-1 mimetic, dramatically improves vasodilation in hypercholesterolemia and sickle cell disease. Circulation (107):2337-41.

37. Chiesa G, Monteggia E, Marchesi M, et al. (2002). Recombinant apolipoprotein AI(Milano) infusion into rabbit carotid artery rapidly removes lipid from fatty streaks. Circ Res (90): 974-80.

38. Huggins KW, Curtiss LK, Gebre AK, Parks JS. (1998). Effect of long chain polyunsaturated fatty acids in the sn-2 position of phosphatidylcholine on the interaction with recombinant high density lipoprotein apolipoprotein A-I. J Lipid Res (39):2423-31.

39. Leonard $A E$, Pereira $S L$, Sprecher $H$, Huang YS. (2004). Elongation of long-chain fatty acids. Prog Lipid Res (43):36-54.
40. Keys A, Anderson JT, Grande F. (1957). Prediction of serum-cholesterol responses of man to changes in fats in the diet. Lancet (273):959-66.

41. Hegsted DM, McGandy RB, Myers ML, Stare FJ. (1965). Quantitative effects of dietary fat on serum cholesterol in man. Am J Clin Nutr (17):281-95

42. Mensink RP, Zock PL, Kester AD, Katan MB. (2003). Effects of dietary fatty acids and carbohydrates on the ratio of serum total to HDL cholesterol and on serum lipids and apolipoproteins: a meta-analysis of 60 controlled trials. Am J Clin Nutr (77):114655.

43. Calder PC. (2006). n-3 polyunsaturated fatty acids, inflammation, and inflammatory diseases. Am J Clin Nutr (83):1505S-1519S.

44. Marinangeli $C P$, Kassis $A N$, Jain D, Ebine $N$, Cunnane SC, Jones PJ. (2007). Comparison of composition and absorption of sugarcane policosanols. Br J Nutr (97):381-8.

45. Irmak S, Dunford NT. (2005). Policosanol contents and compositions of wheat varieties. J Agric Food Chem (53):5583-6.

46. Hargrove JL, Greenspan P, Hartle DK. (2004). Nutritional significance and metabolism of very long chain fatty alcohols and acids from dietary waxes. Exp Biol Med (Maywood) (229):215-26.

47. Gouni-Berthold I, Berthold HK. (2002) Policosanol: clinical pharmacology and therapeutic significance of a new lipidlowering agent. Am Heart J (143):356-65.

48. Berthold HK, Unverdorben S, Degenhardt R, Bulitta M, Gouni-Berthold I. (2006). Effect of policosanol on lipid levels among patients with hypercholesterolemia or combined hyperlipidemia: a randomized controlled trial. Jama (295):2262-9.

49. Cubeddu LX, Cubeddu RJ, Heimowitz $T$, Restrepo B, Lamas GA, Weinberg GB. (2006). Comparative lipid-lowering effects of policosanol and atorvastatin: a randomized, parallel, double-blind, placebo-controlled trial. Am Heart J (152):982 e1-5.

50. Lin $Y$, Rudrum $M$, van der Wielen RP, et al. (2004). Wheat germ policosanol failed to lower plasma cholesterol in subjects with normal to mildly elevated cholesterol concentrations. Metabolism (53):1309-14.

51. Greyling A, De Witt C, Oosthuizen W, Jerling JC. (2006). Effects of a policosano supplement on serum lipid concentrations in hypercholesterolaemic and heterozygous familial hypercholesterolaemic subjects. $\mathrm{Br}$ J Nutr (95): 968-75. 



\section{Chapter 2}

\section{Increasing apoA-I production as a target for CHD risk reduction}

Stefan P.J. Dullens, Jogchum Plat, Ronald P. Mensink

Department of Human Biology, Nutrition and Toxicology Research Institute Maastricht, Maastricht University, Maastricht, The Netherlands

Based on Nutr. Metab. Cardiovasc. Dis. 2007 Oct:17(8):616-28 


\section{Introduction}

Coronary heart disease (CHD), still the world's leading cause of mortality and morbidity, is causally related to increased serum low-density lipoproteins cholesterol (LDL-C) concentrations. The first anti-atherogenic strategies were therefore focused on lowering serum LDL-C concentrations. CHD however has a multifactorial origin, which has opened venues to prevent or treat CHD by other strategies.

Unlike LDL-C, elevated high-density lipoprotein cholesterol (HDL-C) concentrations may protect against the development of CHD as demonstrated in numerous large-scale epidemiological studies ${ }^{1,2}$. This inverse association between HDL-C and CHD risk is most likely explained by reverse cholesterol transport, although many other anti-atherogenic properties have been ascribed to $\mathrm{HDL}^{3}$. Strategies to elevate HDL-C concentrations can roughly be divided into two different approaches. The first, approach targets pre- $\beta$ HDL elevations of which apoA-I $\mathrm{I}_{\text {Milano }}$ infusions, apoA-I-mimetic peptides, and delipidation of $\alpha$-HDL particles are promising examples to be applied in acute coronary events. The second approach focuses merely on elevating $\alpha-\mathrm{HDL}$ particles for example by cholesterol ester transfer protein (CETP) inhibition and is more applicable chronically. In this review, we describe that besides the above-mentioned applications, elevating de novo apoA-I production may be a suitable target to functionally increase HDL-C concentrations. Since the synthesis-rate of HDL particles depends on the production of apolipoprotein A-I (apoA-I), it can be argued that de novo apoA-I production is an important key-player within HDL metabolism. However, pre- $\beta$ HDL particles can also be generated after fusion of surface fragments or scavenger receptor B1 (SR-BI) mediated HDL-C clearance, which implicates a role for catabolism in the regulation of pre- $\beta$ HDL generated particles. Although the relevance of catabolism within HDL metabolism is certainly acknowledged, the aim of this review is to further discuss the rational for choosing de novo apoA-I production as anti-atherogenic strategy. First, HDL metabolism will be described briefly, followed by a detailed description of the current knowledge concerning apoA-I synthesis and underlying molecular pathways. Next, effects of pharmacological and nutritional compounds on apoA-I synthesis, but also the interrelation between HDL and inflammatory processes will be discussed. 


\section{Ins and outs of HDL-C \& apoA-I}

\section{HDL Metabolism}

In humans, apoA-I is synthesized as a pre-pro-protein in hepatocytes and in small intestinal cells ${ }^{4}$. After intracellular cleavage of the pre-peptide, the proproteins are secreted into the plasma or lymphatic system ${ }^{5}$, as shown in figure 1. As demonstrated by Pyle and coworkers (2000), the subsequent cleavage of the pro-peptide of apoA-I seems to be essential for the conversion of nascent HDL (pre- $\beta \mathrm{HDL}$ ) into a mature HDL ( $\alpha-\mathrm{HDL}$ ) particle. After cleavage of the pro-segment, mature apoA-I can interact directly with the adenosine triphosphate-binding cassette transporter A1 (ABCA1), which is present - at least in humans - at the membranes of macrophages, and hepatic, small intestinal, and endothelial cells ${ }^{6}$. In support, blocking $A B C A 1$ did not inhibit apoA-I secretion by HepG2 cells, whereas apoA-I lipidation and HDL formation was reduced ${ }^{7}$. Thus, apoA-I synthesis and secretion seems to be $A B C A 1$ independent. When lipid-free apoA-I binds to $A B C A 1$, small amounts of free cholesterol, phospholipids (phosphatidylcholine), and sphingomyelin become associated with the apoA-I protein. In this way, a lipid-poor apoA-I particle is generated, also known as nascent or pre- $\beta_{1} \mathrm{HDL}$. This lipid-poor apoA-I particle can be lipidated into more spherical HDL particles $\left(\mathrm{HDL}_{3}\right)$, but it can also be catabolized in which apoA-I protein is cleared by the kidney ${ }^{8}$. Lipid-poor apoA-I can however also be incorporated into already existing $\mathrm{HDL}$ particles ${ }^{9}$. Further, free cholesterol and phospholipids can easily be taken up by lipid-poor apoA-I, which results into the formation of pre- $\beta_{2} \mathrm{HDL}$ and finally into pre- $\beta_{3}$ discoid HDL particles. These particles become spherical $\left(\mathrm{HDL}_{3}\right)$ after esterification of cholesterol, which is facilitated by lecithin:cholesterol acyltransferase (LCAT). When a discoid pre- $\beta_{3}$ particle is converted into an $\mathrm{HDL}_{3}$ particle, it can exchange cholesteryl ester (CE) for triacylglycerol (TAG) with apoB-containing lipoproteins, like very-low-density lipoprotein (VLDL), LDL, and intermediatedensity lipoprotein (IDL), which is facilitated by CETP. Furthermore, ATPbinding cassette transporter G-1 receptor (ABCG1), which is highly expressed in macrophages present in the vessel-wall, is essential for cellular cholesterol efflux to $\mathrm{HDL}_{3}$ acceptor particles and consequently results in the transformation of $\mathrm{HDL}_{3}$ into $\mathrm{HDL}_{2}$ particles ${ }^{10}$. This suggests that cholesterol from macrophage foam cells, which are present in the endothelial layer, can be delivered to $\mathrm{HDL}_{3}$ particles. Besides this active reverse cholesterol process, results of in vitro experiments have also suggested that $\mathrm{HDL}_{3}$ particles can absorb unesterified cholesterol from other lipoproteins or cell membranes through a passive process ${ }^{11}$. If representative for the in vivo situation, $\mathrm{HDL}$ enrichment with cholesterol might not always require $A B C$ transporters. 


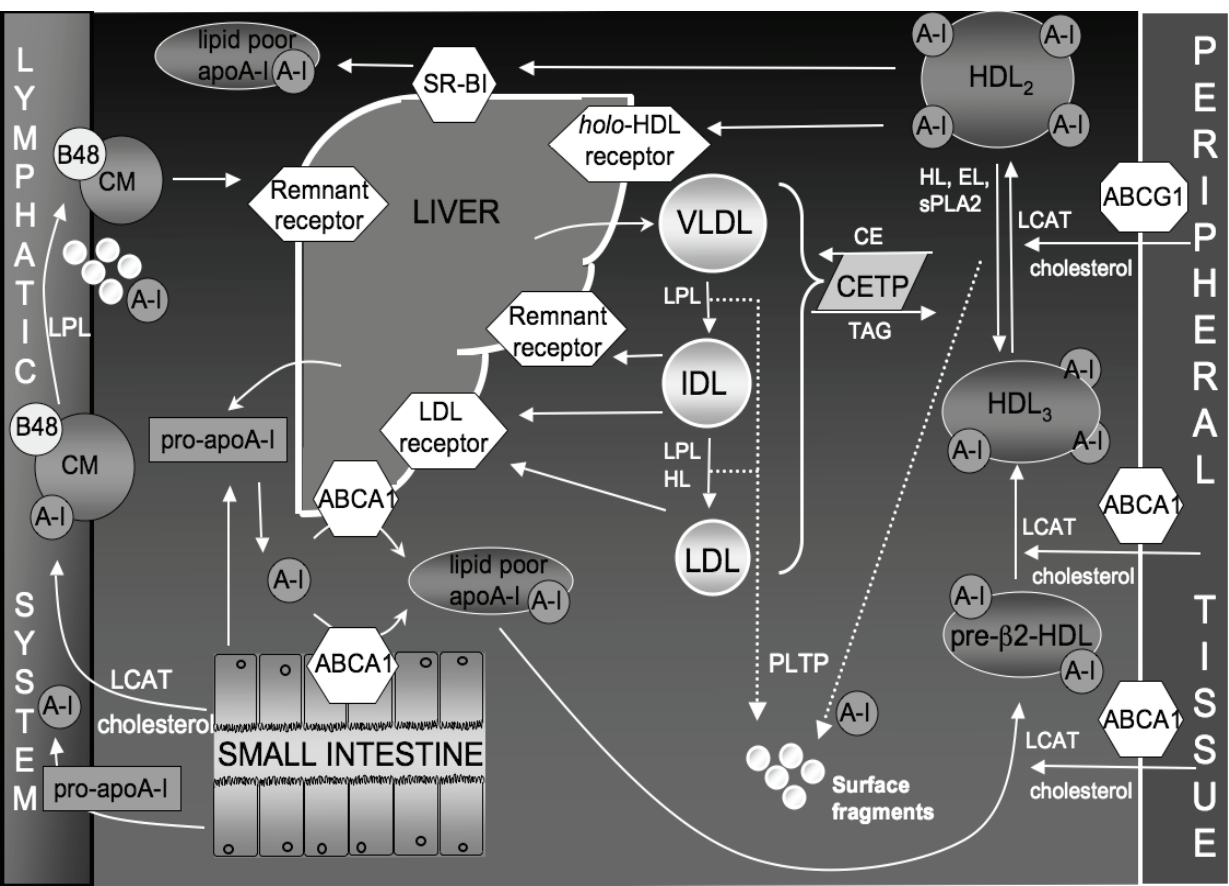

Figure 1. Schematic HDL metabolism.

ApoA-I is predominantly synthesized as a pre-pro-protein in liver and small intestine, and secreted as a pro-apoA-I protein into the blood circulation or the lymphatic system. After cleavage of the pro-segment, mature apoA-I probably binds to the hepatic or small intestinal $A B C A 1$ receptor, which facilitates the uptake of phospholipids and sphingomyelin. This process converts mature apoA-I into a lipid-poor apoA-I particle, however, in addition to this process lipid-poor apoA-I particles can also generated after fusion of $\mathrm{HDL}_{3}$ particles, which is facilitated by PLTP. Next, lipid-poor apoA-I particles convert into pre- $\beta 2-H D L$ particles, which proceeds after absorption of free cholesterol from peripheral tissues. After lipid-poor apoA-I particles absorb free cholesterol, LCAT rapidly esterifies cholesterol into cholesteryl esters, which results in larger $\mathrm{HDL}$ particles $\left(\mathrm{HDL}_{3}\right)$. CETP facilitates the exchange of $\mathrm{CE}$ for TAG between apoB-containing lipoproteins (VLDL, IDL, and $L D L$ ) and $\mathrm{HDL}_{3}$ particles, whereas $A B C G 1$ seems to be essential to transform $\mathrm{HDL}_{3}$ into $\mathrm{HDL}_{2}$. Further, $\mathrm{HDL}_{2}$ particles can bind to SR-BI, whereby CE and TAG are selectively absorbed from the $\mathrm{HDL}_{2}$ particle into the liver. In addition, $\mathrm{HDL}_{2}$ particles can also bind to an holo-HDL receptor. Binding to the holo-HDL receptor leads to complete incorporation of $\mathrm{HDL}_{2}$ particles into the hepatic cell. 
$\mathrm{HDL}_{2}$ particles can be recognized by the SR-BI, which is located at the hepatic cell membrane. When an $\mathrm{HDL}_{2}$ particle binds to SR-BI, CE and TAG are transported into the hepatic intracellular matrix, while - at least in mice extracellular a lipid-poor apoA-I/pre- $\beta$ HDL particle remains. In contrast to this selective lipid uptake, substantial evidence exists for the presence of an holo-HDL-receptor at the membrane of human hepatocytes ${ }^{12}$. In this process, HDL endocytosis is probably indirectly triggered by apoA-I. It has been proposed that apoA-I binds to ATPase, resulting in ATP cleavage and generation of ADP, which in turn binds and activates nucleotide receptor $P 2 Y$ 13. Next, this receptor leads to activation of a yet unknown endocytic HDL receptor ${ }^{14}$. Furthermore, $\mathrm{HDL}_{2}$ particles can be converted into $\mathrm{HDL}_{3}$ particles through the action of extracellular lipases such as hepatic lipase $(H L)$, endothelial lipase (EL), or secretory phospholipase $A 2\left(s P L A_{2}\right)$. HL hydrolyzes TAG and phospholipids of $\mathrm{HDL}_{2}$ particles, whereas $\mathrm{EL}$ and $\mathrm{SPLA}$ hydrolyze only the phospholipids ${ }^{15}$. Another extracellular lipase, LPL is also involved in HDL metabolism. LPL hydrolyzes TAG from chylomicrons and VLDL. Consequently, surface phospholipids and several apolipoproteins will remain, which can be transferred to pre- $\beta$ HDL and $\alpha-H D L$ particles by phospholipid transfer protein (PLTP). PLTP is also involved in the fusion of $\mathrm{HDL}_{3}$ particles, whereby $\mathrm{HDL}_{2}$ particles and lipid-poor apoA-I particles are formed ${ }^{16}$.

\section{Composition and classification of HDL particles}

HDL particles are small plasma lipoproteins (7.0-12 $\mathrm{nm}$ diameter) with a density between $1.063<d<1.21 \mathrm{~g} / \mathrm{mL}^{17}$. An HDL particle consists of a hydrophilic outer layer and a hydrophobic core. Like any other lipoprotein, the hydrophilic outer layer is composed of free cholesterol, phospholipids and apolipoproteins, whereas the hydrophobic core mainly consists of cholesteryl esters and a small amount of TAG.

A small part of the HDL total protein mass consists of the apolipoproteins apoA-IV, apoA-V, apoC-I, apoC-II, apoC-III, apoD, apoE, apoF, apoJ, apoL, and apoM 18-25. The exact function of all these apolipoproteins is not known, but they may fulfil crucial roles. Recently, for example, it was shown that apoM was essential for pre $\beta$-HDL formation in mice and was involved in cholesterol efflux by a so far unknown mechanism 26, however the relevance in humans needs to be proven. Further, upregulation of apoM gene expression inhibited the formation of atherosclerotic lesions in LDL receptor knockout mice fed a cholesterolenriched diet. The two major apolipoproteins are however apoA-I and apoAII, which constitute respectively about $70 \%$ and $20 \%$ of the total protein mass of an HDL particle ${ }^{27}$. Besides apolipoproteins, various other proteins within or attached to HDL are also involved in HDL metabolism, such as 
CETP, LCAT, PLTP, platelet-activating factor acetyl-hydrolase (PAF-AH), and paraoxonase (PON) ${ }^{3}$ and serum amyloid A (SAA) ${ }^{28}$.

Within the circulation, the composition of an HDL particle can be modulated. This results in various HDL particle (sub)classes, which all have their own specific role within HDL metabolism. Characterization of these HDL (sub)classes can be carried out by focusing on differences in density, size, shape, charge, and protein composition (table 1). Based on particle sizes, $\mathrm{HDL}$ particles can be separated with 1-D gradient electrophoresis into five subpopulations, which are $\mathrm{HDL}_{2 b}(12.9-9.7 \mathrm{~nm}), \mathrm{HDL}_{2 \mathrm{a}}(9.7-8.8 \mathrm{~nm}), \mathrm{HDL}_{3 \mathrm{a}}$ $(8.8-8.2 \mathrm{~nm}), \mathrm{HDL}_{3 \mathrm{~b}}(8.2-7.8 \mathrm{~nm})$, and $\mathrm{HDL}_{3 \mathrm{c}}(7.8-7.2 \mathrm{~nm})^{29}$. A more advanced technique is non-denaturing two-dimensional gel electrophoresis, which separates $\mathrm{HDL}$ particles by surface charge (first dimension) and size (second dimension) ${ }^{30}$. Most $\mathrm{HDL}$ particles have $\alpha$-mobility $\left(\mathrm{HDL}_{3}, \mathrm{HDL}_{2}\right.$ ), which means that these lipoproteins are large spherical particles. This contrasts $\beta$-mobility, which is associated with small HDL particles. These small (pre- $\beta$ ) HDL particles are discoid lipid-poor particles, which consist of two apoA-I molecules together with phospholipids and possibly a small amount of unesterified cholesterol ${ }^{31}$. In addition, $\gamma$-HDL particles can be determined with 2-D gradient electrophoresis, which are HDL particles that contain only apoE (HDL-LpE) ${ }^{32}$. With 2-D gradient electrophoresis, HDL particles can be separated into the following classes: pre- $\beta_{1 a, b}-H D L$ (5.79, $5.38 \mathrm{~nm}) \rightarrow$ pre- $\beta_{2 a, b, c}-\mathrm{HDL}(13.74,12.85,12.17 \mathrm{~nm}) \rightarrow \alpha-\mathrm{HDL}_{1,2,3}$ (10.97, $9.20,7.62 \mathrm{~nm}) \rightarrow$ pre- $\alpha \mathrm{HDL}_{1-4}(11.05,9.42,8.40,7.67 \mathrm{~nm})^{30}$. 
Table 1. Classification of HDL particles by different separation techniques.

\begin{tabular}{|c|c|c|}
\hline Technique & Characteristic & HDL (sub)classes \\
\hline $\begin{array}{l}\text { 1-D gradient } \\
\text { electrophoresis }\end{array}$ & Particle size interval (nm) & $\begin{array}{l}\mathrm{HDL}_{2 \mathrm{~b}}(12.9-9.7), \mathrm{HDL}_{2 \mathrm{a}}(9.7- \\
8.8), \mathrm{HDL}_{3 \mathrm{a}}(8.8-8.2), \mathrm{HDL} \text { b } \\
(8.2-7.8), \mathrm{HDL}_{3 \mathrm{c}}(7.8-7.2)\end{array}$ \\
\hline $\begin{array}{l}\text { 2-D gradient } \\
\text { electrophoresis }\end{array}$ & $\begin{array}{l}1^{\text {ste }} \text { dimension surface charge, } \\
2^{\text {de }} \text { dimension particle size }(\mathrm{nm})\end{array}$ & 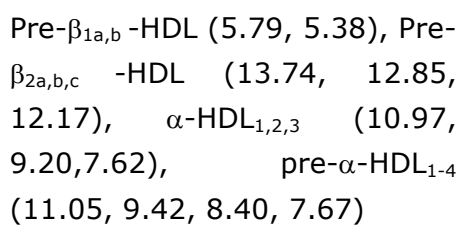 \\
\hline $\begin{array}{l}\text { Gradient } \\
\text { ultracentrifugation }\end{array}$ & Particle density $(\mathrm{g} / \mathrm{mL})$ & $\begin{array}{l}\mathrm{HDL}_{2}(1.063-1.125), \mathrm{HDL}_{3} \\
(1.125-1.21), \mathrm{VHDL}(1.21- \\
1.25)\end{array}$ \\
\hline NMR & $\begin{array}{l}\text { Particle size based on terminal } \\
\text { methyl groups }(\mathrm{nm})\end{array}$ & $\begin{array}{l}\text { Small HDL }(7.3-7.7) \text { and }(7.8 \\
-8.2) \text {, intermediate HDL }(8.2- \\
8.8) \text { and }(8.8-10) \text {, large HDL } \\
(10-13)\end{array}$ \\
\hline $\begin{array}{l}\text { Immunoaffinity } \\
\text { chromatography }\end{array}$ & $\begin{array}{l}\text { ApoA-I/apoA-II protein } \\
\text { composition }\end{array}$ & $L p(A-I), L p(A-I I)$ \\
\hline
\end{tabular}

Gradient ultracentrifugation techniques, which are based on differences in density, can also be used to separate HDL particles. Two major subfractions are $\mathrm{HDL}_{2}(1.063<\mathrm{d}<1.125 \mathrm{~g} / \mathrm{mL})$ and $\mathrm{HDL}_{3}(1.125<\mathrm{d}<1.21$ $\mathrm{g} / \mathrm{mL})^{33}$. However, further subcategorisation into $\mathrm{HDL}_{2 a}, 2 \mathrm{~b}, 3 \mathrm{a}, 3 \mathrm{~b}$, and $3 \mathrm{c}$ is possible ${ }^{34}$.

Nuclear magnetic resonance (NMR)-spectroscopy is less laborious and time-consuming than traditional ultracentrifugation methods. With this technique, five different $\mathrm{HDL}$ subclasses are identified: i.e. small HDL

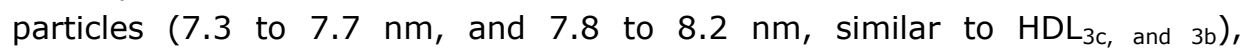
intermediate HDL ( 8.2 to $8.8 \mathrm{~nm}$, and 8.8 to $10 \mathrm{~nm}$, similar to $\mathrm{HDL}_{3 a}$, and $\mathrm{HDL}_{2 \mathrm{~b}}$ ), and large $\mathrm{HDL}$ particles (10 to $13 \mathrm{~nm}$, similar to $\mathrm{HDL}_{2 \mathrm{a}}$ ) ${ }^{35}$. Size ranges identified by NMR are comparable to those measured by gradient gel electrophoresis techniques 36, 37. However, there are indications that the accuracy to quantify different plasma lipoprotein subclasses needs improvement ${ }^{38}$. In addition, NMR spectroscopy has also another disadvantage. Identification is based on terminal methyl groups. Because a cholesterol ester and a TAG molecule each have three terminal methyl groups, NMR-spectrometry does not discriminate between lipid particles that have an "abnormal" cholesteryl esters to TAG ratio ${ }^{39}$. On the other hand, NMR-derived values reflect the absolute amount of lipids compared to those 
measured chemically, which suggest that NMR-spectrometry might predict CHD risk better than traditional chemical techniques ${ }^{39}$.

Finally, immuno-affinity chromatography is used to distinguish HDL classes in apoA-I and apoAI/apoA-II-containing particles. One subpopulation comprises particles that contain apoA-I but no apoA-II ( $L p(A-I))$, while the other class comprises particles containing both apoA-I and apoA-II (Lp(A-I/AII)) ${ }^{40}$. Most of the $L p(A-I / A-I I)$ is found in the $H_{D L}$ density range, while $\mathrm{Lp}(\mathrm{A}-\mathrm{I})$ is traced in both $\mathrm{HDL}_{3}$ and $\mathrm{HDL}_{2}$ density ranges ${ }^{41}$. 


\section{HDL and apoA-I: genetic as well as inflammatory relations with CHD risk}

\section{Epidemiological evidence for HDL and apoA-I protective effects}

Epidemiological studies estimated that each $1 \%$ increase in HDL-C is associated with a $2 \%$ reduction in the risk to develop $\mathrm{CHD}^{42}$. A meta-analysis of long-term population studies even suggested that in women $1 \%$ increase of $\mathrm{HDL}-\mathrm{C}$ lowered CHD risk by $3 \%{ }^{43}$. Moreover, this inverse association is stronger in presence of additional risk factors, such as diabetes mellitus, smoking, hypertension, and a family history of myocardial infarction ${ }^{44}$. Further evidence for the protective effects of elevated serum HDL-C and apoA-I concentrations comes from studies on the impact of mutations or polymorphisms in genes encoding for proteins involved in HDL metabolism ${ }^{45}$, 46. Typical examples are Tangier disease (TD), familial hypoalphalipoproteinemia, and analphalipoproteinemia, which will be briefly described in the next Section 47, 48. Finally, a strong inverse correlation between HDL-C concentrations and $\mathrm{CHD}$ risk can be found in patients suffering from inflammatory disorders, which will be illustrated in more into detail in Section "Inflammation and HDL".

\section{Genetic variations and the anti-atherogenicity of HDL}

In addition to large-scale prospective epidemiological studies, evidence for the protective effects of elevated serum HDL-C and apoA-I concentrations to CVD risk can be found in genetics variations - mutations or polymorphisms in genes encoding for regulatory proteins involved in HDL metabolism. Typical examples of HDL deficiency caused by genetic mutations and associated with increased CHD risk are Tangier disease (TD), familial hypoalphalipoproteinemia, and analphalipoproteinemia 47, 48 .

TD, a rare autosomal recessive disease, is characterized by a dramatic reduction of serum HDL-C concentrations or in some cases even in a total HDL deficiency ${ }^{49}$. The structure of apoA-I as well as apoA-I synthesis rate is however normal. TD patients have a defect in the ABCA1 receptor, which leads to a disturbed apoA-I mediated cholesterol efflux 50, 51 and a consequent impaired capacity to transform pre- $\beta$ HDL particles into $\mathrm{HDL}_{3}$ particles ${ }^{52-54}$. Now, at least 50 ABCA1 mutations and/or single nucleotide polymorphisms in the ABCA1 gene have been identified ${ }^{55,56}$. Although many ABCA1 mutations/SNPs have been identified, of which not all are shown functional, heterozygous carriers of the ABCA1 mutation (K776N) conferred for example a two- to three-fold risk of ischemic heart disease (IHD) in participants in the Copenhagen City Heart study ${ }^{57}$. Besides this mutation, other mutations in ABCA1 have been shown important modulators of $\mathrm{HDL}$ metabolism. For example, homozygosity for a few other ABCA1 mutations, 
resulted in TD, whereas heterozygous carriers of these mutations showed a milder phenotype, also known as familial hypoalphalipoproteinemia (reviewed by Singaraja and coworkers ${ }^{58}$ ). TD and familial hypoalphalipoproteinemia patients also differ in their serum HDL subclass profiles. Concentrations of larger $\alpha$ and pre- $\beta$ HDL particles are strongly decreased in familial hypoalphalipoproteinemia patients, whereas in serum of TD patients only a low concentration of pre- $\beta$ HDL particles is detectable ${ }^{59}$.

Patients who suffer from analphalipoproteinemia have decreased HDL$\mathrm{C}$ concentrations and are often at increased risk to develop CHD, as in most TD and hypoalphalipoproteinemia patients. Analphalipoproteinemia can be caused by several apoA-I gene mutations, which results in a disturbed cellular cholesterol efflux ${ }^{60-62}$. On the other hand, apoA-I gene mutations apoA-I $\mathrm{I}_{\text {Milano, }}$ apoA-I $\mathrm{I}_{\text {Paris, }}$ and apoA-I $\mathrm{I}_{\text {Sasebo }}$ cause analphalipoproteinemia, but are not associated with increased $\mathrm{CHD}$ risk ${ }^{63,64}$. This apparent paradox might be explained by a higher clearance rate of mature HDL particles and not by a disturbance in HDL formation like in analphalipoproteinemia patients ${ }^{65}$. In addition, it has been suggested that apoA- $\mathrm{I}_{\text {Milano }}$ and apoA- $\mathrm{I}_{\text {Paris }}$ mutations increases the antioxidant activity of HDL particles.

Mutations in the gene encoding for LCAT are associated with low serum HDL-C concentrations. Depending on the severity, certain mutations result in partial or complete LCAT deficiency, leading to fish eye disease (FED) or familial LCAT deficiency (FLD), respectively ${ }^{66,67}$. Despite markedly decreased serum HDL-C and apoA-I concentrations, FED and FLD patients hardly develop CVD. This unexpected observation might be related to the concomitant decreased serum apoB and/or LDL-C concentrations in these patients, however the underlying mechanism is not clear ${ }^{68}$. Moreover, in a recent kinetic study an increased LDL catabolism and an upregulated LDLr gene expression was found in LCAT deficient patients ${ }^{69}$.

CETP deficiency - due to functional mutations in the CETP gene - is associated with hyperalphalipoproteinemia (HALP), due to abnormally high concentrations of HDL-C, as only observed in Japanese subpopulations ${ }^{70-72}$. In this view, CETP inhibitors have been suggested to increase serum HDL-C concentrations, which should consequently resulted in a decreased CHD risk. However, findings on the impact of CETP deficiency and CETP polymorphisms in relation to $\mathrm{CHD}$ risk are inconsistent ${ }^{73}$. Recently, Hovingh and coworkers have even shown that the progression of the carotid intima media thickness (IMT) over age - a modest increase in IMT substantially increases the risk for myocardial infarction and stroke - did not differ between CETP deficient $\left(\right.$ IVS7+1) patients and controls ${ }^{74}$. This novel CETP mutation leads to a CETP null allele and consequently reduced CETP activity (-50\%) and increased serum HDL-C concentrations $(+36 \%)$ in a Caucasian family. In addition, many other CETP mutations have been described. In this respect, 
homozygous carriers of the CETP Taq1B polymorphism was were not only characterized by lower serum HDL-C concentrations but also by an increased risk of $\mathrm{CHD}^{75}$.

\section{Inflammation and HDL metabolism}

Besides strong epidemiological and genetical evidence of anti-atherosclerotic effects by HDL-C and apoA-I, additional supporting data can be found in patients suffering from inflammatory disorders. More generally, there is a close inversely correlation between HDL-C and acute as well as chronic inflammatory stimuli ${ }^{76,77}$. For example, simulation of an acute (systemic) inflammatory situation, by intraperitoneal injection of lipopolysaccharide (LPS) in C57BL/6 mice, severely reduced serum HDL-C and apoA-I concentrations ${ }^{78}$. Unexpectedly, intraperitoneal injection of LPS had no significant effect on serum human apoA-I or HDL-C concentrations in human apoA-I transgenic mice, whereas mouse apoA-I was lowered in wild-type littermates ${ }^{79}$. This might suggest that the acute phase response, induced by LPS injection, does not influence human apoA-I expression. However, when in addition to human apoA-I also human SPLA $_{2}$ gene was expressed (human apoA-I/sPLA 2 double transgenic mice), serum HDL-C and human apoA-I concentrations were reduced after LPS treatment ${ }^{79}$. These reductions were ascribed to an increased apoA-I catabolic rate mediated by SPLA2. Finally, in vitro studies also suggest an interrelation between inflammation and apoA-I or/and HDL-C serum concentrations, since pro-inflammatory cytokines, like tumor necrosis factor alpha (TNF $\alpha)$, IL-1 $\beta$, or LPS decreased apoA-I secretion by HepG2 cells ${ }^{80,81}$. Furthermore, besides a reduction in HDL-C and apoA-I concentrations during inflammation, HDL composition seems affected. During severe sepsis, HDL particles are depleted of CE and apoA-I. Moreover, during acute sepsis, serum amyloid A (SAA) was the main protein of HDL, which was slowly replaced by apoA-I throughout recovery ${ }^{82}$. In addition, many other regulatory proteins in $\mathrm{HDL}$ metabolism are affected during inflammation, which altogether result in a decreased ability of HDL particles to reduce CHD risk ${ }^{83}$.

In line with effects of these acute stimulatory stimuli, HDL metabolism is also affected in chronic inflammatory conditions. It was, for example, recently reported that patients with Crohn's disease had a disturbed endothelial function, as measured by ultrasound flow-mediated brachial artery dilatation (FMD) ${ }^{84}$. Interestingly, this disturbance was associated with low serum HDL-C and apoA-I concentrations. This observation is reflected in a validated mouse model (interleukin-10 knockout mouse) to study Crohn's disease ${ }^{85}$. This illustrates that local intestinal inflammation affects HDL metabolism, and ultimately results in enhanced lesion development. Not only decreased (local) IL-10, HDL-C, and apoA-I concentrations are characteristics 
of Crohn's disease, but also elevated serum C-reactive protein (CRP) concentrations ${ }^{86}$. Indeed, a strong inverse correlation was found between hs-CRP and HDL-C or apoA-I serum concentrations ${ }^{87}$. Conclusively, chronic inflammation seems to be associated with reduced serum HDL-C and apoA-I concentrations, and therefore can be regarded as a risk factor to develop CHD.

\section{ApoA-I key target for elevating HDL-C}

Since de novo apoA-I production is an important driving force behind HDL-C elevation, it became one of the anti-atherogenic target proteins, which currently receive a lot of interest. Several approaches have been used to prove that elevating serum apoA-I concentrations are causally related to a lower CHD risk ${ }^{88-90}$. In this respect, the finding that human apoA-I transgenic mice were protected against the development of diet-induced atherosclerosis was very important ${ }^{91,92}$. In addition, studies with apoA-I knockout mice fed a high-fat, high-cholesterol diet stressed the importance of apoA-I ${ }^{93}$. HDL-C concentrations were minimally elevated in apoA-I knockout mice compare to littermates, which show the essential role of apoA-I in diet induced HDL-C changes. Furthermore, intravenous infusions of synthetic mimetic human apoA-I proteins, like $\mathrm{D}-4 \mathrm{~F}$ or $5 \mathrm{~F}$, protect against diet-induced atherosclerosis as demonstrated in C57BL/6] or LDL receptor-null mice ${ }^{94,95}$. In addition, although somewhat different that elevating endogenous apoA-I production, recent findings showed that intravenous infusion of recombinant

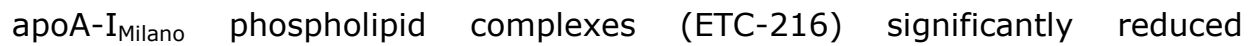
atherosclerosis progression in mice, rabbits ${ }^{96}$, and in patients with acute ACS 97. In summary, increased de novo apoA-I production is a promising target to lower CHD risk. Therefore, detailed knowledge concerning apoA-I synthesis and underlying regulatory pathways is needed.

However, it should be mentioned that other anti-atherogenic strategies to influence HDL metabolism might also be protective. For example, increasing ABCA1 gene expression via tissue-specific LXR activation is a possible strategy. Another strategy could be (pharmacological) CETP inhibition. Although the first results from phase 1 trails were promising ${ }^{98}$, the recent decision to stop all activities around the CETP inhibitor torcetrapid, is a potential problem for further research activities into this direction. Moreover, a recent long-term intervention trial by Kastelein and coworkers ${ }^{99}$ showed that in patients with familial hypercholesterolemia that combination therapy of torcetrapid plus atorvastatin indeed elevated serum HDL-C concentrations (predominantly $\mathrm{HDL}_{2}$ particles) and lowered serum TAG and LDL-C levels as compared to atorvastatin monotherapy. However, despite these beneficial changes in lipid profile, changes in the maximum carotid IMT were similar between the two groups. In fact, torcetrapid-atorvastatin therapy even 
caused progression of disease in the common carotid artery and increased in systolic blood pressure. However, an important aspect in this matter is the current discussion, whether it was the mechanism or the molecule that made torcetrapid unsuccessful ${ }^{100}$. 


\section{ApoA-I synthesis}

\section{ApoA-I transcription}

The apoA-I gene, which consists of four exons, is located at chromosome 11 in a gene cluster with the genes that code for apoC-III and apoA-IV. This cluster spans approximately $11 \mathrm{~Kb}$ (figure 2) ${ }^{101}$. ApoA-I gene expression is not only regulated by activation of regulatory response elements as present in the apoA-I promoter and enhancer, but also by response elements in the apoC-III enhancer. In humans, apoA-I is predominantly expressed in the liver and in the small intestine. Recently, however, apoA-I gene expression and secretion was also found in human heart cells in vitro ${ }^{102}$. Unfortunately, how expression levels relate to those in hepatic or small intestinal cells was not studied.

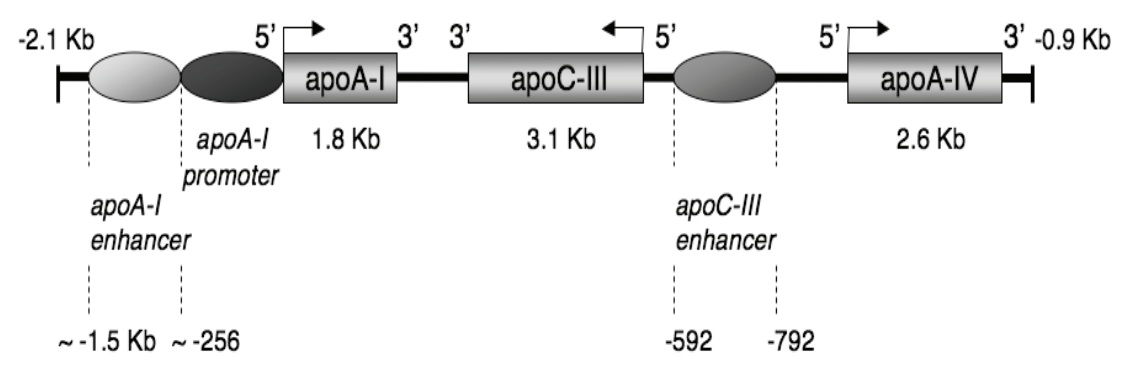

Figure 2. ApoA-I/apoC-III/apoA-IV-cluster.

\section{ApoA-I transcription regulation}

In vitro cell systems, such as hepatic (HepG2) cells and small intestinal (differentiated CaCo-2) cells are commonly used to investigate tissue-specific regulatory pathways of apoA-I transcription. Because the apoA-I promoter is a relatively weak promoter, apoA-I transcription depends on several, distally and proximally located, tissue-specific enhancer response elements as will be discussed later. Full apoA-I gene expression is only achieved in the presence of the proximal apoA-I promoter (-256bp to apoA-I), the apoA-I enhancer (between -256bp and -1500bp to apoA-I), and the apoC-III enhancer (between -592bp and -792bp to apoC-III), which altogether results in a synergistic regulatory effect ${ }^{103}$. These regions are particularly important for intestinal apoA-I gene expression, while hepatic apoA-I gene expression already takes place in the presence of the apoA-I promoter alone. 


\section{The apoA-I promotor/enhancer}

With respect to the promoter region of apoA-I, at least two different apoA-I promoter models have been proposed. Zannis and coworkers have described a model, in which the regulatory elements $B, C$, and D (figure 3 ) were essential to induce apoA-I gene expression ${ }^{104}$. Element $A(-22 \mathrm{bp}$ to $+17 \mathrm{bp})$ was not recognized as an apoA-I regulatory element. In this model, element B (-128bp to $-77 \mathrm{bp})$ and D (-220bp to $-190 \mathrm{bp})$ each contain an hormone response element (HRE) - a binding site for many different types of nuclear receptors -, while element $C(-175 b p$ to $-148 b p)$ contains a binding site for CCAAT enhancer binding protein (C/EBP). In addition, element $D$ contains a PPAR $\alpha$ response element (PPRE). HRE in element $D$ and $B$ can bind hepatocyte nuclear factor 4 (HNF-4), but also other orphan nuclear receptors - nuclear receptors without an identified ligand - e.g. vErb-A-related protein (EAR-3), and a variety of ligand-dependent nuclear receptors ${ }^{105}$.

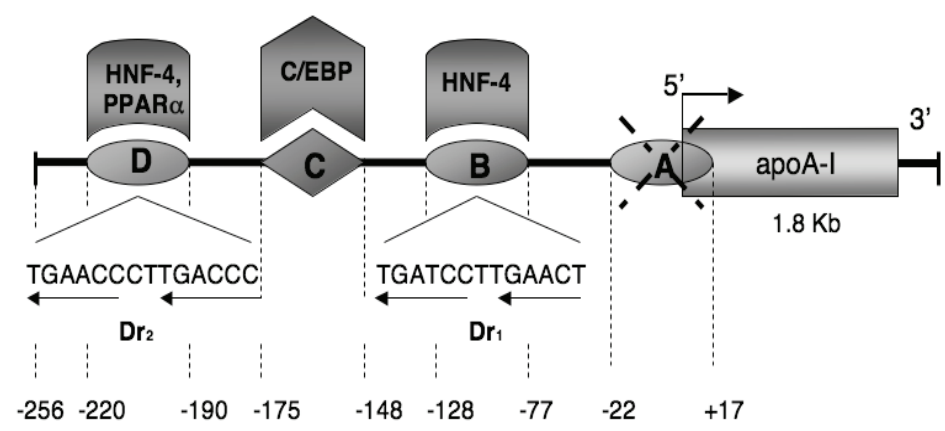

Figure 3. The first apoA-I promoter model as described by Zannis et al.

In addition to this model, a second apoA-I promoter model (-1500bp to apoA-I) has been described, although in the literature this model has also been described as an apoA-I enhancer (figure 4) ${ }^{106,107}$. To avoid some confusion of the nomenclature of this region, we will define the 256bp proximal region to the apoA-I gene as apoA-I promoter and the proximally located region between $1500 \mathrm{bp}$ and $256 \mathrm{bp}$ as apoA-I enhancer. The second model has three cis-acting elements within the apoA-I promoter (site $A$, 214bp to $-192 \mathrm{bp}$; site $\mathrm{B},-169 \mathrm{bp}$ to $-146 \mathrm{bp}$; and site $\mathrm{C},-134 \mathrm{bp}$ to $-119 \mathrm{bp}$ ). Although somewhat different in location, a substantial overlap has been shown in regulatory functions exists between sites A and C from model 2, and elements $D$ and $B$ from model 1 . Therefore, sites $A$ and $C$ contain HREs, which recognize homodimers of HNF-4 ${ }^{108}$, apoA-I regulatory protein 1 (ARP1) 106,109 , and other orphan nuclear receptors ${ }^{110}$ as shown in table 2. 
Interestingly, despite the similarity in sequence between the HRE at sites A and $C$, the heterodimer RXR/PPAR $\alpha$ only binds to the HRE at site A (i.e. element $D$ in model 1$)^{111}$.

Not only PPAR $\alpha$ but also the transcription factor PPAR $\delta$ can affect apoAI gene expression. Although the exact binding site for the PPAR $\delta / R X R$ heterodimer is not known, GW501516 (a PPAR $\delta$ agonist) increased serum apoA-I concentrations in obese rhesus male monkeys ${ }^{112}$. But also shown in wild type mice, PPAR $\delta$ activation (GW610742) elevated serum HDL-C concentrations ${ }^{113}$. Examples of other nuclear receptors, which bind to sites $A$ or $\mathrm{C}$, are overall members of the ligand-dependent steroid/thyroid receptor super family nuclear receptors such as farnesoid $X$ receptor ( $F X R)$, retinoid $X$ receptor $\alpha(R X R \alpha)$, retinoic acid receptor $\alpha(R A R \alpha)$, and thyroid hormone receptor $\beta\left(T_{3} R \beta\right)$.

In addition, not only the nuclear receptor homodimers, but also their heterodimers, such as $R X R \alpha / R A R \alpha$, can bind to sites $A$ and $C{ }^{105},{ }^{114}$. Another transcription factor, FXR represses apoA-I gene expression, as demonstrated in taurocholic acid (a FXR agonist) treated human apoA-I transgenic mice ${ }^{115}$. This effect can be explained by the presence of a negative FXR response element specifically mapped on site $\mathrm{C}$, as shown in HepG2 cells. 


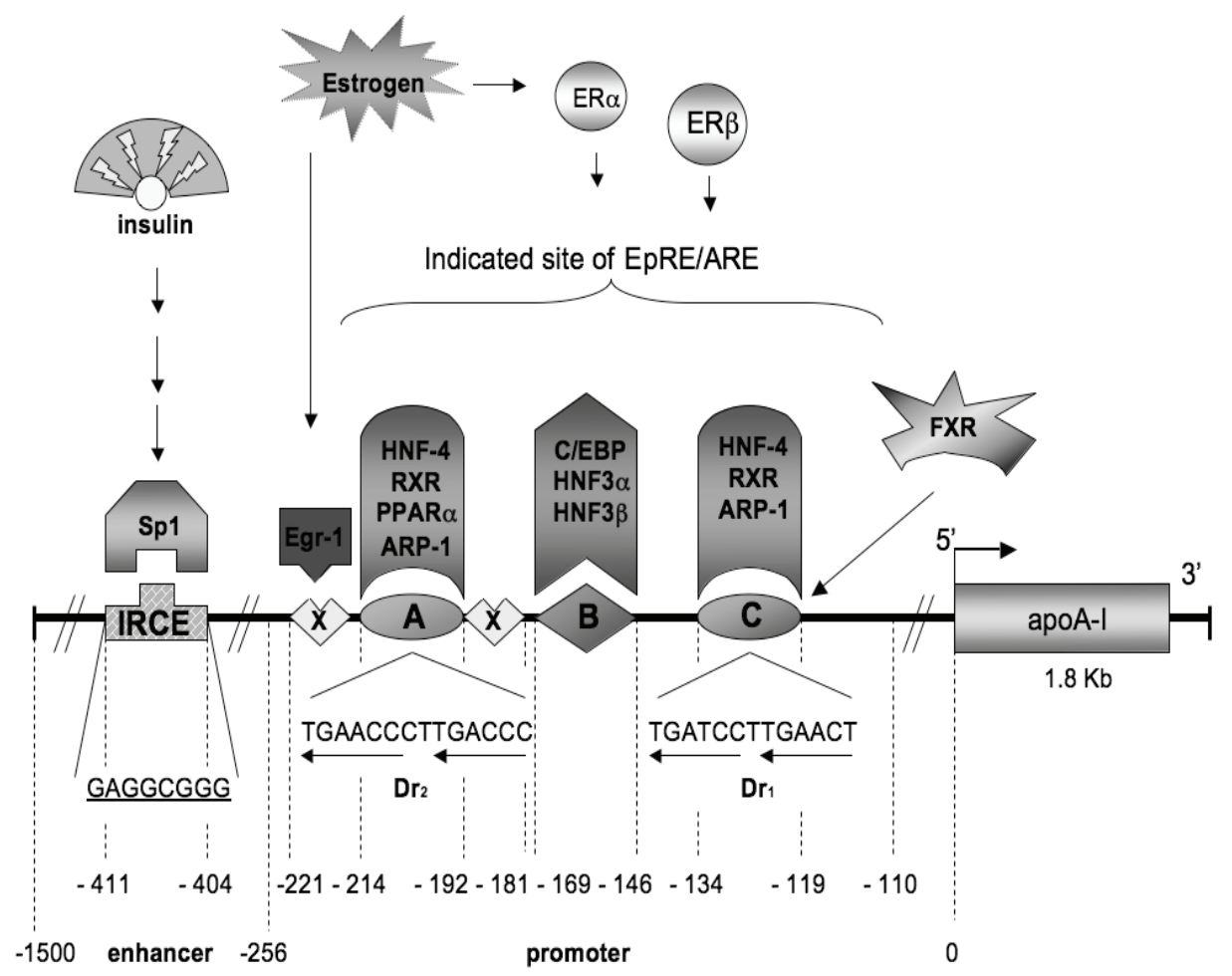

Figure 4. The second apoA-I promoter/enhancer model with selective activators or inhibitors.

Site $B$, which region is comparable to element $C$ in model 1 , can bind hepatic nuclear factor $3 \alpha(\mathrm{HNF}-3 \alpha), \mathrm{HNF}-3 \beta^{116}$ and CCAAT enhancer binding protein $(C / E B P){ }^{117}$. Although a prominent role for site $B$ in the regulation of apoA-I gene expression has not yet been defined, apoA-I elevating effects of estrogen-like compounds, such as 17- $\beta$-estradiol or genistein, are however associated with site $B$, and early growth response factor 1 (Egr-1) response elements (between $-221 b p$ and $-214 b p,-192 b p$ and $-181 b p$ to apoA-I) as shown in HepG2 cells ${ }^{118}$. Furthermore, estrogen-like compounds do not only affect site $B$, but also influence MAP kinase pathways. Activation of MAP kinase pathways can lead to activation of specific protein 1 (Sp1), which binds to insulin response core element (IRCE). IRCE is a GC-rich region, which is located at the apoA-I enhancer, between -404bp and -411bp of the apoA-I gene. Interestingly, IRCE activation elevates apoA-I transcription ${ }^{119}$. Moreover, insulin-related pathways, such as the Ras-MAP kinase, phosphatidylinositol 3 kinase (PI3K), and phospholipase $\mathrm{C} \gamma$ cascades, might also be involved in apoA-I synthesis, although exact mechanisms have to be 
elucidated ${ }^{120}$. Till now, Ras-raf and PI3K, which are involved in the insulinsignalling pathway, are effective in activating Sp1 ${ }^{119}$, which suggests a role in apoA-I synthesis.

Another pathway that affects the apoA-I promoter region is estrogen receptor (ER) signaling. This signaling pathway is regulated by estrogen receptor $\alpha(E R \alpha)$, which induces apoA-I gene expression through activation of electrophile response elements (EpREs) ${ }^{121}$. EpREs are present somewhere at the apoA-I promoter (-256bp to apoA-I). Besides ER $\alpha, E R \beta$ - the most potent - can also activate EpRE elements, although ER $\alpha$ and ER $\beta$ differ in ligandbinding characteristics and probably also in element binding sites ${ }^{122}$. Finally, in HepG2 cells also antioxidant response elements (AREs) have been identified in the apoA-I promoter (-256bp to apoA-I) ${ }^{123,124}$. 
Table 1. Regulatory elements at the apoA-I promoter/enhancer with selective ligands.

\begin{tabular}{|c|c|c|c|}
\hline $\begin{array}{l}\text { Response } \\
\text { element }\end{array}$ & $\begin{array}{l}\text { Location region to } \\
\text { apoA-I gene }\end{array}$ & $\begin{array}{l}\text { Transcription } \\
\text { factor }\end{array}$ & Ligand \\
\hline $\begin{array}{l}\text { Site A or } \\
\text { element D } \\
(\text { HRE) }\end{array}$ & $\begin{array}{l}-214 b p \text { to }-192 b p \\
\text { or } \\
-220 b p \text { to }-190 b p\end{array}$ & $\begin{array}{l}\text { HNF-4 } \\
\text { EAR-3 } \\
\text { RXR } \alpha \\
\text { RAR } \\
\text { RXR } \alpha / R A R \\
\text { RXR } \alpha / T 3 R \beta \\
\text { RXR } \alpha / P P A R \alpha \\
\text { RXR } \alpha / P P A R \delta \\
\text { (?) } \\
\text { ARP-1 } \\
\text { RXR } \alpha / A R P-1\end{array}$ & $\begin{array}{l}\text { Orphan } \\
\text { Orphan } \\
\text { 9-cis retinoid acid (RA) } \\
\text { all trans retinoids } \\
\text { RA/all trans retinoid } \\
\text { RA/thyroid hormone } \\
\text { RA/GW7647, WY14643, fibrates } \\
\text { RA/GW501516, GW610742 } \\
\text { Orphan } \\
\text { RA/orphan }\end{array}$ \\
\hline $\begin{array}{l}\text { Site B or } \\
\text { element C }\end{array}$ & $\begin{array}{l}-169 b p \text { to }-146 b p \\
\text { or } \\
-175 b p \text { to }-148 b p\end{array}$ & $\begin{array}{l}\text { C/EBP } \\
\text { HNF-3 } \alpha \\
\text { HNF-3 } \beta\end{array}$ & $\begin{array}{l}\text { Orphan } \\
\text { Orphan } \\
\text { Orphan }\end{array}$ \\
\hline $\begin{array}{l}\text { Site C or } \\
\text { element B } \\
\text { (HRE) }\end{array}$ & $\begin{array}{l}-134 b p \text { to }-119 b p \\
\text { or } \\
-128 b p \text { to }-77 b p\end{array}$ & $\begin{array}{l}\text { HNF-4 } \\
\text { EAR-3 } \\
\text { RXR } \alpha \\
\text { RAR } \\
\text { RXR } \alpha / \text { RAR } \\
\text { RXR } \alpha / T 3 R \beta \\
\text { RXR } \alpha / \text { PPAR } \delta \\
(?) \\
\text { ARP-1 } \\
\text { RXR } \alpha / A R P-1 \\
\text { FXR }\end{array}$ & $\begin{array}{l}\text { Orphan } \\
\text { Orphan } \\
\text { 9-cis retinoid acid (RA) } \\
\text { all trans retinoids } \\
\text { RA/all trans retinoid } \\
\text { RA/thyroid hormone } \\
\text { RA/GW0742, GW610742 } \\
\text { Orphan } \\
\text { RA/orphan } \\
\text { GW4064 }\end{array}$ \\
\hline $\begin{array}{l}\text { Egr-1 } \\
\text { response } \\
\text { element }\end{array}$ & $\begin{array}{l}-221 b p \text { to }-214 b p \text {, } \\
\text { and } \\
-192 b p \text { to }-181 b p\end{array}$ & Egr-1 & $17-\beta$ estradiol, genistein \\
\hline IRCE & $-404 b p$ to $-411 b p$ & Sp1 & Orphan \\
\hline EpRE & $-256 b p$ to $0 b p$ & $\begin{array}{l}E R \alpha \\
E R \beta\end{array}$ & Estrogen \\
\hline ARE & $-256 b p$ to $0 b p$ & Unknown & Gramoxome, DMSO \\
\hline
\end{tabular}




\section{Regulation by the apoC-III promotor/enhancer}

As already mentioned, intestinal apoA-I gene expression is not only regulated by the apoA-I promotor/enhancer but also by the apoC-III enhancer. More interestingly, since tissue-specific apoC-III enhancer effects on apoA-I gene expression have been discovered both in vitro and in vivo ${ }^{104}$, tissue-specific treatment regimens can be suggested. As shown in figure 5, the apoC-III enhancer contains two HREs that are located in regions $\mathrm{G}$ and $\mathrm{I}_{4}$, three Sp1 binding sites (element $\mathrm{F}, \mathrm{H}$, and $\mathrm{I}$ ), and one response element $\mathrm{J}$, which function is unknown so far. Despite the fact that the HREs in region $\mathrm{G}$ and $\mathrm{I}_{4}$ are almost identical, HNF-4 can only bind to HRE $\mathrm{I}_{4}$. However, region $\mathrm{G}$ and $\mathrm{I}_{4}$ are both important in hepatic and small intestinal apoA-I gene expression, as demonstrated in HepG2 and CaCo-2 cells. In general, HRE and Sp1 regions in the apoC-III promotor and enhancer are activated in a similar manner as described for the apoA-I promoter.

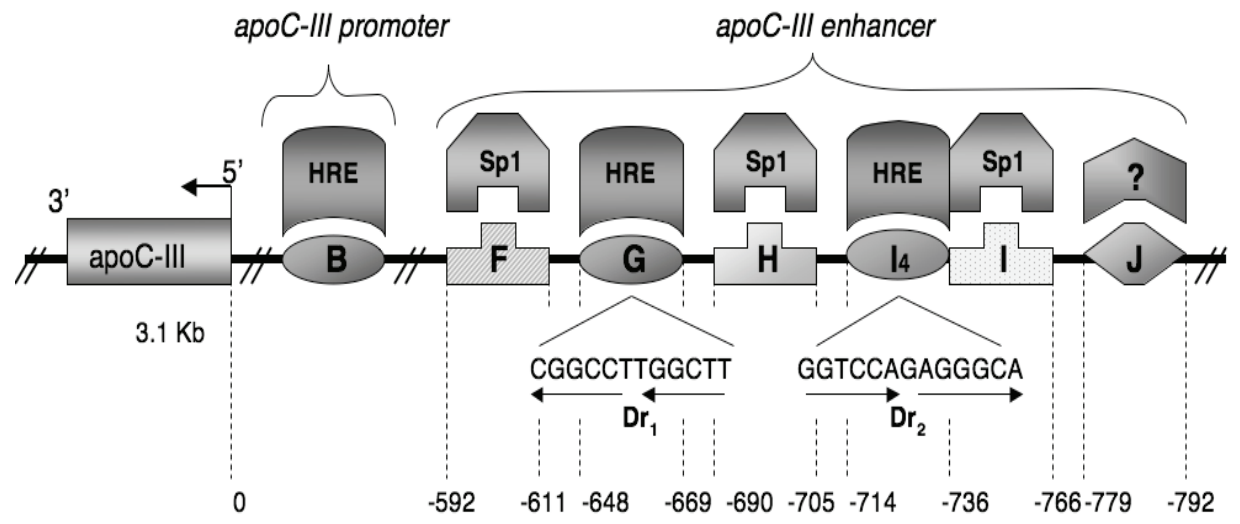

Figure 5. The apoC-III gene cluster. 


\section{Tissue-specific regulation}

There are clear indications that regulation of apoA-I transcription is generally the same in the liver as well as in the small intestine, however there are also some differences. These differences might be interesting to enhance apoA-I production in a tissue-specific manner. For example, mice with a mutation in the HRE $\mathrm{I}_{4}$ of the apoC-III enhancer showed a completely abolished intestinal apoA-I expression, while hepatic apoA-I expression was still $20 \%$ as compared to transgenic mice without this mutation ${ }^{125}$. Another example relates to the differences in estrogen receptor expression patterns. ER $\alpha$ is only expressed in the liver, whereas ER $\beta$ is predominantly expressed in the small intestine (CaCo-2, T84, and SW1116 cells) ${ }^{126}$.

\section{ApoA-I protein synthesis and secretion}

ApoA-I is synthesized as a pre-pro-protein consisting of 267 amino acids. The pre-peptide is 18 amino acids long (MKAAVLTLAVLFLTGSQA) and the propeptide 6 amino acids (RHFWQQ). During translocation of pre-pro-apoA-I, the pre-peptide segment is cleaved off by a signal peptidase and the remaining pro-apoA-I is secreted into plasma or lymph ${ }^{5,127}$. The pro-apoA-I binds directly to ABCA1 and the pro-segment is removed by an unidentified metallo-enzyme.

With respect to intestinal apoA-I secretion, pre-apoA-I is secreted both into the lymphatic system and directly into the blood circulation. Although it is not clear whether pre-apoA-I secretion into the lymph is involved in chylomicron formation, secretion of pre-apoA-I into the circulation results in formation of pre- $\beta$ HDL (as described in Section "HDL metabolism"). Moreover, the small intestine is compartmentalized into a proliferative undifferentiated zone (crypts) and a nonproliferative differentiated zone (villi), which renews the epithelium layer in crypt-to-villus axis. Therefore, expression patterns of villus specific proteins, such as apolipoproteins, are regulated along the crypt-to-villus axis. Although the mechanisms involved are poorly understood, the apoA-IV promoter has been demonstrated to increase apoA-IV as well as apoC-III gene expression in a crypt-to-villus direction. This suggests that apoA-IV promoter also regulates intestinal apoAI gene expression, because it belongs to the same gene cluster, and is regulated by common transcription factors ${ }^{128}$. Because apoA-IV is mainly expressed in the small intestine, it probably has no regulatory function in the liver ${ }^{129}$. 


\section{Pharmacological and nutritional compounds affecting apoA-I production: effects and mechanisms}

Numerous in vivo and in vitro experiments have been carried out to examine the effects of a wide variety of pharmacological and nutritional compounds on apoA-I concentrations. However, findings have not always been consistent when different models are compared.

\section{Pharmacological agents}

Statins are the most frequently used evidence-based lipid-lowering and antiatherogenic regimens, while there are indications that fibrate-treatment might also be effective. At least a part of these anti-atherogenic effects might be ascribed to the observed increased serum HDL-C and apoA-I concentrations.

Fenofibrate, of which fenofibric acid is the active metabolite, has been shown to elevate serum HDL-C as well as apoA-I concentrations in dyslipidemic patients ${ }^{130}$. However, no significant reduction in the risk of primary outcome of coronary events could be found in the FIELD study - a large clinical-endpoint trial that evaluated the long-term effects of fenofibrate treatment in type 2 diabetes mellitus patients -, despite an improved lipidprofile ${ }^{131}$. Although the clinical benefit in the FIELD study was unexpectedly low, the general conclusion after reviewing five large placebo-controlled trials with second-generation fibrates (i.e. HHS, VA-HIT, BIP, LEADER and FIELD) is that CHD reduction will most likely occur in patients with a metabolic syndrome profile (i.e. overweight, and insulin resistance) and not specifically in dyslipidemic patients ${ }^{132}$. Even more important, gemfibrozil, might have more beneficial effects on major cardiovascular outcomes than fenofibrate 132. Moreover, the fibrate induced CHD risk reduction by for example gemfibrozil might at least be explained by favourable changes in lipoprotein particle sizes and particle concentrations as measured by NMR ${ }^{133}$. Moreover, HDL particle and particularly the small HDL subclass particles numbers were significantly increased. This indicates that (1) fibrates are still potential HDL elevating compounds and (2) the efficiency of fibrate-therapy should be further evaluated.

The mechanism, by which fibrates increase apoA-I synthesis, relates to their PPAR $\alpha$ ligand activity, as already describe in Section "ApoA-I synthesis: The apoA-I promoter/enhancer". Although the mechanism by which fibrates act is similar, the efficacy in elevating apoA-I concentrations depends on whether they act as full or partial PPAR $\alpha$ agonists. The difference between full and partial PPAR $\alpha$ agonists relates to their capacity to recruit or activate essential co-activators or co-repressors, which play a regulatory role in gene transcription. For example, Duez and coworkers ${ }^{134}$ have shown that in 
contrast to gemfibrozil, fenofibrate is a full PPAR $\alpha$ agonist, as it can activate coactivator DRIP205 as demonstrated in mice. Interestingly, fibrates also activate the PKC signalling pathway. Recently, it has been shown that in HepG2 cells, PKC inhibition impaired the ligand-activated PPAR $\alpha$ transcriptional activity, and consequently PPAR $\alpha$ target gene expression ${ }^{135}$. These observations therefore suggest that PKC regulates the (de)phosphorylation switch of PPAR $\alpha$, and hereby modulates the effects of fibrates on apoA-I gene expression.

Statin-treatment lowers CHD risk, myocardial events, and mortality, as demonstrated in different large-scale controlled clinical trails ${ }^{136}$. Like fibrates, statins not only lower concentrations of the atherogenic lipoproteins, but elevate at the same time those of serum HDL-C and apoA-I ${ }^{137}$. Although there is no consensus on how statins elevate serum apoA-I concentrations, it has been suggested that de novo apoA-I synthesis is increased. In line with fibrates, statins (at least as shown for cerivastatin and pitavastatin) also regulate the apoA-I production by effecting PPAR $\alpha$ activity ${ }^{138}$. More into detail, statins effectively decrease de novo cholesterol synthesis by inhibiting the rate-limiting enzyme hepatocyte 3-hydroxy-3-methylglutaryl coenzyme $A$ (HMG-CoA) reductase. An additional effect of this decrease in de novo cholesterol synthesis, is that the geranylgeranylation of small G proteins, such as Rho and Rac enzymes is reduced. Since these small G proteins act as PPAR $\alpha$ inhibitors, this latter finding may ultimately lead to a reduced inhibition of PPAR $\alpha$ activity. Consequently, expression of PPAR $\alpha$ target genes, like apoA-I, becomes elevated.

In conclusion, although underlying pathways are different, fibrates as well as certain statins may increase apoA-I serum concentrations. Although statins as well as fibrates have beneficial effects on apoA-I production, their therapeutic effect on lipid profiles is different. Statins are effective in decreasing serum LDL-C concentrations as well as levels of total cholesterol, and therefore very useful in controlling serum LDL-C concentrations ${ }^{139}$, while fibrates on the other hand, prominently lower serum TAG and increase serum HDL-C concentrations ${ }^{140}$. Because of these additional effects on lipid profiles, beneficial effects of statin-fibrate combination therapies might be expected and useful. Therefore, several promising statin-fibrate combinations are now under investigation ${ }^{141,142}$. 


\section{Nutritional compounds}

Beside pharmacological agents, different studies have demonstrated that nutritional compounds affect serum apoA-I and/or HDL-C concentrations. Compared to an iso-energetic amount of carbohydrates, fat increases serum HDL-C and/or apoA-I concentrations ${ }^{143}$. More interestingly are the effects of the different individual fatty acids. From a meta-analysis, which included 60 well-controlled clinical trials, it was concluded that saturated fatty acids (SAFAs) and cis-monounsaturated fatty acids (cis-MUFAs) increase serum apoA-I and HDL-C concentrations significantly, when compared to an isoenergetic amount of carbohydrates ${ }^{144}$. For the effects of the individual SAFAs on apoA-I concentrations, these effects were in particular evident for lauric acid (C12:0), myristic acid (C14:0), and palmitic acid (C16:0), but not for stearic acid (C18:0). Despite this knowledge, the metabolic routes by which SAFAs affect apoA-I concentrations are not fully understood. Effects cannot be explained through the well-known effects of fatty acids on PPAR $\alpha$-activity, as this is particularly true for the long chain (unsaturated) fatty acids and their derivatives, which do not have the strongest effects on apoA-I. As described in Section "ApoA-I synthesis: The apoA-I promoter/enhancer", activation of transcription factor Sp1 can lead to an enhanced apoA-I gene expression. In HepG2 cells, Sp1 activity was indeed affected by the SAFAs stearic acid, myristic acid, or palmitic acid ${ }^{145}$. However, rather unexpectedly, Sp1 activity was repressed, and therefore apoA-I gene expression was reduced. It must however be realized that very high (non-physiological) concentrations $(250 \mu \mathrm{M})$ of fatty acids were used in this study and it remains to be determined what effects of lower concentrations will be. In addition, unsaturated fatty acids (oleic, linoleic or $\alpha$-linolenoic acid) had no effect in this study. In conclusion, at this moment there is no consistent picture concerning the mechanism by which specific fatty acids affect circulating apoA-I and HDL cholesterol concentrations, and therefore more studies should be performed to elucidate fatty acid related apoA-I regulation.

Alcohol, at least when consumed in moderate amounts is associated with elevated serum apoA-I and HDL-C concentrations and a reduced CHD risk ${ }^{146}$. Although again the exact mechanism by which ethanol elevates serum apoA-I and HDL-C concentrations is unclear, it has been suggested that the microsomal ethanol oxidizing system (MEOS) plays a central role ${ }^{147}$.

Beside these energy-delivering nutrients, like fat, glucose and alcohol, different micronutrients, such as minerals (e.g. zinc, magnesium, and vanadate) and vitamins (e.g., vitamin C (ascorbic acid), vitamin D, vitamin $E$ ( $\alpha$-tocopheral), and vitamin A), might also enhance apoA-I synthesis ${ }^{148}$. For example, vitamin $B_{3}$ (nicotinic acid or niacin) strongly elevated serum HDL-C concentrations ${ }^{149}$. Niacin-induced HDL-C elevations could not be explained through effects on de novo apoA-I synthesis, but by a reduced hepatic holo- 
HDL particle uptake and HDL catabolism ${ }^{136}$. This ultimately lowered the FFA flux to the liver, and resulted in a lowered VLDL production, serum TAG concentrations, CETP activity, and consequently a reduced apoA-I fractional catabolic rate (FCR). Another important micronutrient is vitamin A derivative 9-cis retinoid acid, which induces $R X R \alpha$ activation - the partner of PPAR $\alpha$ in heterodimer formation - and clearly upregulates apoA-I gene expression in HepG2 cells ${ }^{105,150}$. Whether these findings also hold for the in vivo situation, and which is the optimal amount that establishes this effect, remains to be confirmed.

An interesting nutritional compound is soy protein. Recently, Reynolds and coworkers performed a meta-analysis, and concluded that soy protein and soy isoflavones significantly increased serum HDL-C concentrations ${ }^{151}$. In contrast, members of the American Heart Association Nutrition Committee concluded that soy protein and isoflavones do not have important favourable effects on total cholesterol, HDL-C and TAG concentrations ${ }^{152}$. Besides protein and isoflavones, soy also contains lecithin. Soy lecithin extracted from processed soybean oil consists of three phospholipids; phosphatidylcholine $(P C)$, phosphatidylethanolamine (PE), and phosphatidylinositol (PI). In humans, PI - but not PC - can stimulate reverse cholesterol transport in two different ways. First, by enhancing the flux of endothelial cholesterol into HDL particles, and second, by enhancing the cholesterol transport derived from HDL particles towards the liver and bile ${ }^{153}$. These effects might be explained by the increased serum apoA-I concentrations. Interestingly, effects were already evident during a low intake, and it was recently claimed, that PI may have a comparable therapeutic value as niacin. In conclusion, the precise mechanism by which PI (and maybe soy isoflavones and protein) elevates HDL-C and whether this also involves apoA-I concentrations is unfortunately unknown.

Like for soy lecithin, there are other nutritional compounds claiming elevations in serum HDL-C concentrations of which effects on serum apoA-I concentrations or pathways responsible for increased apoA-I concentrations are unknown. For example, policosanols - a natural mixture of aliphatic primary alcohols isolated from purified sugar cane wax - have been reported as a powerful new agent to increase HDL-C concentration in humans ${ }^{154}$. However, more recent intervention studies did not confirm these findings ${ }^{155}$, 156. At the moment there is no consensus why there is a discrepancy between the studies with a positive and a negative outcome, which demands further study. 


\section{General conclusion}

In this review, we have illustrated several lines of evidence that elevated HDL-C concentrations may protect against the development of CHD. More importantly, we have outlined that interfering in HDL metabolism, with the approach to elevate circulating HDL-C concentrations and related enhanced reverse cholesterol transport, is possible by aiming at different targets. Furthermore, we have focussed on the possibilities of elevating de novo apoA-I production as a promising strategy to elevate serum HDL-C concentrations. By describing the current knowledge concerning apoA-I synthesis and underlying molecular pathways in detail, we have illustrated that there are several possibilities by either pharmacological or nutritional interventions to elevate (tissue-specific) apoA-I production. This knowledge may ultimately be used in developing dietary intervention strategies to elevate de novo apoA-I production, serum HDL-C concentrations and to enhance reverse cholesterol efflux, which should consequently lower CHD risk. 


\section{References}

1. Luc G, Bard JM, Ferrieres J, et al. (2002). Value of HDL cholesterol, apolipoprotein A-I, lipoprotein A-I, and lipoprotein A-I/A-II in prediction of coronary heart disease: the PRIME Study. Prospective Epidemiological Study of Myocardial Infarction. Arterioscler Thromb Vasc Biol (22):1155-61.

2. Assmann G, Schulte $H$, von Eckardstein $A$, Huang Y. (1996). High-density lipoprotein cholesterol as a predictor of coronary heart disease risk. The PROCAM experience and pathophysiological implications for reverse cholesterol transport. Atherosclerosis (124 Suppl):S11-20.

3. Nofer JR, Kehrel B, Fobker M, Levkau B, Assmann G, von Eckardstein A. (2002). HDL and arteriosclerosis: beyond reverse cholesterol transport. Atherosclerosis (161):1-16.

4. Eggerman $T L$, Hoeg JM, Meng MS, Tombragel A, Bojanovski D, Brewer HB, Jr. (1991). Differential tissue-specific expression of human apoA-I and apoA-II. J Lipid Res (32):821-8.

5. Pyle LE, Sviridov D, Fidge NH. (2001). Characterization of the maturation of human pro-apolipoprotein A-I in an in vitro model. Biochemistry (40):3101-8.

6. Basso F, Freeman L, Knapper CL, et al. (2003). Role of the hepatic ABCA1 transporter in modulating intrahepatic cholesterol and plasma HDL cholesterol concentrations. J Lipid Res (44):296-302.

7. Tsujita M, Wu CA, Abe-Dohmae S, Usui S, Okazaki M, Yokoyama S. (2005). On the hepatic mechanism of HDL assembly by the ABCA1/apoA-I pathway. J Lipid Res (46):15462.

8. Horowitz BS, Goldberg IJ, Merab J, Vanni TM, Ramakrishnan R, Ginsberg HN. (1993). Increased plasma and renal clearance of an exchangeable pool of apolipoprotein A-I in subjects with low levels of high density lipoprotein cholesterol. J Clin Invest (91):1743-52.

9. Settasatian N, Duong M, Curtiss LK, et al. (2001). The mechanism of the remodeling of high density lipoproteins by phospholipid transfer protein. J Biol Chem (276):26898905.

10. Wang N, Lan D, Chen W, Matsuura F, Tall AR. (2004). ATP-binding cassette transporters G1 and G4 mediate cellular cholesterol efflux to high-density lipoproteins. Proc Natl Acad Sci U S A (101):9774-9.
11. Johnson WJ, Mahlberg $\mathrm{FH}$, Rothblat $\mathrm{GH}$, Phillips MC. (1991). Cholesterol transport between cells and high-density lipoproteins. Biochim Biophys Acta (1085):273-98.

12. Barbaras $R$, Collet $X$, Chap $H$, Perret $B$. (1994). Specific binding of free apolipoprotein A-I to a high-affinity binding site on HepG2 cells: characterization of two high-density lipoprotein sites. Biochemistry (33):2335-40.

13. Jacquet S, Malaval C, Martinez LO, et al. (2005). The nucleotide receptor P2Y(13) is a key regulator of hepatic High-Density Lipoprotein (HDL) endocytosis. Cell Mol Life Sci.

14. Martinez LO, Jacquet S, Esteve JP, et al. (2003). Ectopic beta-chain of ATP synthase is an apolipoprotein A-I receptor in hepatic HDL endocytosis. Nature (421):75-9.

15. Jin W, Marchadier D, Rader DJ. (2002). Lipases and HDL metabolism. Trends Endocrinol Metab (13):174-8.

16. Huuskonen J, Olkkonen VM, Jauhiainen $M$, Ehnholm C. (2001). The impact of phospholipid transfer protein (PLTP) on HDL metabolism. Atherosclerosis (155):269-81.

17. Asztalos BF, Roheim PS, Milani RL, et al. (2000). Distribution of ApoA-I-containing $\mathrm{HDL}$ subpopulations in patients with coronary heart disease. Arterioscler Thromb Vasc Biol (20):2670-6.

18. Shore B, Shore V. (1969). Isolation and characterization of polypeptides of human serum lipoproteins. Biochemistry (8):45106.

19. Kostner G, Alaupovic P. (1972). Studies of the composition and structure of plasma lipoproteins. Separation and quantification of the lipoprotein families occurring in the high density lipoproteins of human plasma. Biochemistry (11):3419-28.

20. Morrisett JD, Jackson RL, Gotto AM, Jr. (1975). Lipoproteins: structure and function. Annu Rev Biochem (44):183-207.

21. Albers JJ, Cheung MC, Ewens SL, Tollefson JH. (1981). Characterization and immunoassay of apolipoprotein D. Atherosclerosis (39):395-409.

22. Olofsson SO, McConathy WJ, Alaupovic P. (1978). Isolation and partial characterization of a new acidic apolipoprotein (apolipoprotein F) from high density lipoproteins of human plasma. Biochemistry (17):1032-6.

23. de Silva HV, Stuart WD, Park YB, et al. (1990). Purification and characterization of apolipoprotein J. J Biol Chem (265):14292-7 
24. Duchateau PN, Pullinger CR, Orellana RE, et al. (1997). Apolipoprotein $L$, a new human high density lipoprotein apolipoprotein expressed by the pancreas. Identification, cloning, characterization, and plasma distribution of apolipoprotein L. J Biol Chem (272):25576-82.

25. Luo G, Zhang $X$, Nilsson-Ehle $P, X u \quad N$. (2004). Apolipoprotein M. Lipids Health Dis (3):21.

26. Wolfrum C, Poy MN, Stoffel M. (2005). Apolipoprotein $M$ is required for prebeta-HDL formation and cholesterol efflux to HDL and protects against atherosclerosis. Nat Med (11):418-22.

27.Tall AR. (1990). Plasma high density lipoproteins. Metabolism and relationship to atherogenesis. J Clin Invest (86):379-84.

28. Cai $L$, de Beer MC, de Beer FC, van der Westhuyzen DR. (2005). Serum amyloid A is a ligand for scavenger receptor class B type I and inhibits high density lipoprotein binding and selective lipid uptake. J Biol Chem (280):2954-61.

29. Nichols AV, Krauss RM, Musliner TA. (1986). Nondenaturing polyacrylamide gradient gel electrophoresis. Methods Enzymol (128):41731.

30. Asztalos BF, Sloop CH, Wong L, Roheim PS. (1993). Two-dimensional electrophoresis of plasma lipoproteins: recognition of new apo A-I-containing subpopulations. Biochim Biophys Acta (1169):291-300.

31. Thomas MJ, Bhat S, Sorci-Thomas MG. (2006). The use of chemical cross-linking and mass spectrometry to elucidate the tertiary conformation of lipid-bound apolipoprotein AI. Curr Opin Lipidol (17):214-20.

32. Krimbou L, Marcil M, Chiba H, Genest J, Jr. (2003). Structural and functional properties of human plasma high density-sized lipoprotein containing only apoE particles. J Lipid Res (44):884-92.

33. Redgrave TG, Roberts DC, West CE. (1975). Separation of plasma lipoproteins by densitygradient ultracentrifugation. Anal Biochem (65):42-9.

34. Kontush A, Chantepie S, Chapman MJ. (2003). Small, dense HDL particles exert potent protection of atherogenic LDL against oxidative stress. Arterioscler Thromb Vasc Biol (23):1881-8.

35. Freedman DS, Otvos JD, Jeyarajah EJ, Barboriak JJ, Anderson AJ, Walker JA. (1998). Relation of lipoprotein subclasses as measured by proton nuclear magnetic resonance spectroscopy to coronary artery disease. Arterioscler Thromb Vasc Biol (18): 1046-53.
36. Blake GJ, Otvos JD, Rifai N, Ridker PM. (2002). Low-density lipoprotein particle concentration and size as determined by nuclear magnetic resonance spectroscopy as predictors of cardiovascular disease in women. Circulation (106):1930-7.

37. Grundy SM, Vega GL, Otvos JD, Rainwater DL, Cohen JC. (1999). Hepatic lipase activity influences high density lipoprotein subclass distribution in normotriglyceridemic men. Genetic and pharmacological evidence. J Lipid Res (40):229-34.

38. Ala-Korpela M, Lankinen $\mathrm{N}$, Salminen A, et al. (2006). The inherent accuracy of (1)H NMR spectroscopy to quantify plasma lipoproteins is subclass dependent. Atherosclerosis.

39. Otvos JD, Jeyarajah EJ, Cromwell WC. (2002). Measurement issues related to lipoprotein heterogeneity. Am J Cardiol (90): $22 \mathrm{i}-29 \mathrm{i}$.

40. Cheung MC, Albers J]. (1984). Characterization of lipoprotein particles isolated by immunoaffinity chromatography. Particles containing A-I and A-II and particles containing A-I but no A-II. J Biol Chem (259):12201-9.

41. James RW, Proudfoot A, Pometta D. (1989). Immunoaffinity fractionation of high-density lipoprotein subclasses 2 and 3 using antiapolipoprotein A-I and A-II immunosorbent gels. Biochim Biophys Acta (1002):292-301.

42. Castelli WP. (1988). Cholesterol and lipids in the risk of coronary artery disease--the Framingham Heart Study. Can J Cardiol (4 Suppl A):5A-10A

43. Gordon DJ, Probstfield JL, Garrison RJ, et al. (1989). High-density lipoprotein cholesterol and cardiovascular disease. Four prospective American studies. Circulation (79):8-15.

44. von Eckardstein A, Assmann G. (2000). Prevention of coronary heart disease by raising high-density lipoprotein cholesterol? Curr Opin Lipidol (11):627-37.

45. Norata GD, Pirillo A, Catapano AL. (2006). Modified HDL: biological and physiopathological consequences. Nutr Metab Cardiovasc Dis (16):371-86.

46. Miltiadous G, Hatzivassiliou M, Liberopoulos $\mathrm{E}$, et al. (2005). Gene polymorphisms affecting HDL-cholesterol levels in the normolipidemic population. Nutr Metab Cardiovasc Dis (15):219-24.

47. Brooks-Wilson A, Marcil M, Clee SM, et al. (1999). Mutations in ABC1 in Tangier disease and familial high-density lipoprotein deficiency. Nat Genet (22):336-45. 
48. Moriyama K, Sasaki J, Takada Y, et al. (1996). A cysteine-containing truncated apo A-I variant associated with HDL deficiency. Arterioscler Thromb Vasc Biol (16):1416-23.

49.von Eckardstein A. (2006). Differential diagnosis of familial high density lipoprotein deficiency syndromes. Atherosclerosis (186):231-9.

50. Bodzioch M, Orso E, Klucken J, et al. (1999). The gene encoding ATP-binding cassette transporter 1 is mutated in Tangier disease. Nat Genet (22):347-51.

51. Rust S, Rosier M, Funke H, et al. (1999). Tangier disease is caused by mutations in the gene encoding ATP-binding cassette transporter 1. Nat Genet (22):352-5.

52. Kastelein JJ, Haines JL, Hayden MR. (1990). The gene causing familial hypoalphalipoproteinemia is not caused by a defect in the apo AI-CIII-AIV gene cluster in a Spanish family. Hum Genet (84):396-400.

53. Hovingh GK, Van Wijland MJ, Brownlie $A$, et al. (2003). The role of the ABCA1 transporter and cholesterol efflux in familial hypoalphalipoproteinemia. J Lipid Res (44):1251-5.

54. Glickman RM, Green PH, Lees RS, Tall A. (1978). Apoprotein A-I synthesis in normal intestinal mucosa and in Tangier disease. N Engl J Med (299):1424-7.

55. Cohen JC, Kiss RS, Pertsemlidis A, Marcel YL, McPherson R, Hobbs HH. (2004). Multiple rare alleles contribute to low plasma levels of HDL cholesterol. Science (305):869-72.

56. Probst MC, Thumann $\mathrm{H}$, Aslanidis $\mathrm{C}$, et al. (2004). Screening for functional sequence variations and mutations in ABCA1. Atherosclerosis (175):269-79.

57. Frikke-Schmidt R, Nordestgaard BG, Schnohr P, Steffensen R, Tybjaerg-Hansen A. (2005). Mutation in ABCA1 predicted risk of ischemic heart disease in the Copenhagen City Heart Study Population. J Am Coll Cardiol (46):1516-20.

58. Singaraja RR, Brunham LR, Visscher $H$, Kastelein JJ, Hayden MR. (2003). Efflux and Atherosclerosis. Arterioscler Thromb Vasc Biol.

59. Asztalos BF, Brousseau ME, McNamara JR, Horvath KV, Roheim PS, Schaefer EJ. (2001). Subpopulations of high density lipoproteins in homozygous and heterozygous Tangier disease. Atherosclerosis (156):217-25.

60. Ordovas JM, Cassidy DK, Civeira F, Bisgaier CL, Schaefer EJ. (1989). Familial apolipoprotein A-I, C-III, and A-IV deficiency and premature atherosclerosis due to deletion of a gene complex on chromosome 11. J Biol Chem (264):16339-42.
61. Ng DS, Leiter LA, Vezina C, Connelly PW, Hegele RA. (1994). Apolipoprotein A-I Q[-2]X causing isolated apolipoprotein A-I deficiency in a family with analphalipoproteinemia. J Clin Invest (93):223-9.

62. Norum RA, Lakier JB, Goldstein S, et al. (1982). Familial deficiency of apolipoproteins A-I and C-III and precocious coronary-artery disease. N Engl J Med (306):1513-9.

63. Bielicki JK, Oda MN. (2002). Apolipoprotein A-I(Milano) and apolipoprotein A-I(Paris) exhibit an antioxidant activity distinct from that of wild-type apolipoprotein A-I. Biochemistry (41):2089-96.

64. Sirtori CR, Calabresi L, Franceschini G, et al. (2001). Cardiovascular status of carriers of the apolipoprotein A-I(Milano) mutant: the Limone sul Garda study. Circulation (103):1949-54.

65. Shah PK, Yano J, Reyes O, et al. (2001). High-dose recombinant apolipoprotein AI(milano) mobilizes tissue cholesterol and rapidly reduces plaque lipid and macrophage content in apolipoprotein e-deficient mice. Potential implications for acute plaque stabilization. Circulation (103):3047-50.

66. Kuivenhoven JA, Pritchard H, Hill J, Frohlich J, Assmann G, Kastelein J. (1997). The molecular pathology of lecithin:cholesterol acyltransferase (LCAT) deficiency syndromes. J Lipid Res (38):191-205.

67. Calabresi L, Pisciotta L, Costantin A, et al. (2005). The molecular basis of lecithin:cholesterol acyltransferase deficiency syndromes: a comprehensive study of molecular and biochemical findings in 13 unrelated Italian families. Arterioscler Thromb Vasc Biol (25):1972-8.

68. Santamarina-Fojo S, Lambert G, Hoeg JM, Brewer HB, Jr. (2000). Lecithin-cholesterol acyltransferase: role in lipoprotein metabolism, reverse cholesterol transport and atherosclerosis. Curr Opin Lipidol (11):267-75.

69. Nishiwaki M, Ikewaki K, Bader G, et al. (2006). Human lecithin:cholesterol acyltransferase deficiency: in vivo kinetics of low-density lipoprotein and lipoprotein-X. Arterioscler Thromb Vasc Biol (26):1370-5.

70.Koizumi J, Inazu A, Yagi K, et al. (1991). Serum lipoprotein lipid concentration and composition in homozygous and heterozygous patients with cholesteryl ester transfer protein deficiency. Atherosclerosis (90):189-96. 
71. Inazu A, Brown ML, Hesler CB, et al. (1990). Increased high-density lipoprotein levels caused by a common cholesteryl-ester transfer protein gene mutation. N Engl J Med (323):1234-8.

72. Akita $\mathrm{H}$, Chiba $\mathrm{H}$, Tsuchihashi $\mathrm{K}$, et al. (1994). Cholesteryl ester transfer protein gene: two common mutations and their effect on plasma high-density lipoprotein cholesterol content. J Clin Endocrinol Metab (79): 1615-8.

73. de Grooth GJ, Klerkx AH, Stroes ES, Stalenhoef AF, Kastelein JJ, Kuivenhoven JA. (2004). A review of CETP and its relation to atherosclerosis. J Lipid Res (45):1967-74.

74. Hovingh GK, de Groot E, van der Steeg W, et al. (2005). Inherited disorders of HDL metabolism and atherosclerosis. Curr Opin Lipidol (16):139-45.

75. Boekholdt SM, Sacks FM, Jukema JW, et al. (2005). Cholesteryl ester transfer protein TaqIB variant, high-density lipoprotein cholesterol levels, cardiovascular risk, and efficacy of pravastatin treatment: individual patient meta-analysis of 13,677 subjects. Circulation (111):278-87.

76. Park YB, Lee SK, Lee WK, et al. (1999). Lipid profiles in untreated patients with rheumatoid arthritis. J Rheumatol (26):1701-4.

77. Choi HK, Seeger JD. (2005). Lipid profiles among US elderly with untreated rheumatoid arthritis--the Third National Health and Nutrition Examination Survey. J Rheumatol (32):2311-6.

78. Khovidhunkit W, Duchateau PN, Medzihradszky KF, et al. (2004). Apolipoproteins A-IV and A-V are acutephase proteins in mouse HDL. Atherosclerosis $(176): 37-44$.

79. Tietge UJ, Maugeais C, Lund-Katz S, Grass D, deBeer FC, Rader DJ. (2002). Human secretory phospholipase A2 mediates decreased plasma levels of HDL cholesterol and apoA-I in response to inflammation in human apoA-I transgenic mice. Arterioscler Thromb Vasc Biol (22):1213-8.

80. Haas MJ, Horani M, Mreyoud A, Plummer B, Wong NC, Mooradian AD. (2003). Suppression of apolipoprotein AI gene expression in HepG2 cells by TNF alpha and IL-1beta. Biochim Biophys Acta (1623):1208.

81. Morishima A, Ohkubo N, Maeda N, Miki T, Mitsuda N. (2003). NFkappaB regulates plasma apolipoprotein A-I and high density lipoprotein cholesterol through inhibition of peroxisome proliferator-activated receptor alpha. J Biol Chem (278):38188-93.
82. van Leeuwen $\mathrm{HJ}$, Heezius EC, Dallinga GM, van Strijp JA, Verhoef J, van Kessel KP. (2003). Lipoprotein metabolism in patients with severe sepsis. Crit Care Med (31):135966.

83. Khovidhunkit W, Memon RA, Feingold KR, Grunfeld C. (2000). Infection and inflammation-induced proatherogenic changes of lipoproteins. J Infect Dis (181 Suppl 3):S462-72.

84. Duivenvoorden R, Butzelaar JY, Elsen BM, et al. (2004). A low dose of oral fat load impairs endothelial function in healthy males. Drugs Affecting Lipid Metabolism 69.

85. Mallat Z, Besnard S, Duriez M, et al. (1999). Protective role of interleukin-10 in atherosclerosis. Circ Res (85):e17-24.

86. Hezemans $R$, Levels $H$, Hommes $D$, van Deventer S, Kasteleijn JJP, de Grooth E. (2004). Patients with crohn's disease and the causal relationships between inflammation, $\mathrm{HDL}$ levels and atherosclerosis progression. Drugs Affecting Lipid Metabolism 69.

87. Sampietro T, Bigazzi F, Dal Pino B, et al. (2002). Increased plasma C-reactive protein in familial hypoalphalipoproteinemia: a proinflammatory condition? Circulation (105):11-4.

88. Newton RS, Krause BR. (2002). HDL therapy for the acute treatment of atherosclerosis. Atheroscler Suppl (3):31-8.

89. Li HH, Lyles DS, Pan W, Alexander E, Thomas MJ, Sorci-Thomas MG. (2002). ApoA-I structure on discs and spheres. Variable helix registry and conformational states. J Biol Chem (277):39093-101.

90. Klon AE, Segrest JP, Harvey SC. (2002). Molecular dynamics simulations on discoidal HDL particles suggest a mechanism for rotation in the apo A-I belt model. J Mol Biol (324):703-21.

91. Rubin EM, Krauss RM, Spangler EA, Verstuyft JG, Clift SM. (1991). Inhibition of early atherogenesis in transgenic mice by human apolipoprotein AI. Nature (353):265-7.

92. Benoit P, Emmanuel F, Caillaud JM, et al. (1999). Somatic gene transfer of human ApoA-I inhibits atherosclerosis progression in mouse models. Circulation (99):105-10.

93. Plump AS, Azrolan N, Odaka H, et al. (1997). ApoA-I knockout mice: characterization of $\mathrm{HDL}$ metabolism in homozygotes and identification of a post-RNA mechanism of apoA-I up-regulation in heterozygotes. J Lipid Res (38): 1033-47. 
94. Navab M, Anantharamaiah GM, Hama S, et al. (2002). Oral administration of an Apo AI mimetic Peptide synthesized from Damino acids dramatically reduces atherosclerosis in mice independent of plasma cholesterol. Circulation (105):2902.

95. Ou J, Ou Z, Jones DW, et al. (2003). L-4F, an apolipoprotein A-1 mimetic, dramatically improves vasodilation in hypercholesterolemia and sickle cell disease. Circulation (107):2337-41.

96. Chiesa G, Monteggia E, Marchesi M, et al. (2002). Recombinant apolipoprotein AI(Milano) infusion into rabbit carotid artery rapidly removes lipid from fatty streaks. Circ Res (90):974-80.

97. Nissen SE, Tsunoda T, Tuzcu EM, et al. (2003). Effect of recombinant ApoA-I Milano on coronary atherosclerosis in patients with acute coronary syndromes: a randomized controlled trial. Jama (290):2292-300.

98. Brousseau ME, Schaefer EJ, Wolfe ML, et al. (2004). Effects of an inhibitor of cholesteryl ester transfer protein on HDL cholesterol. N Engl J Med (350):1505-15.

99. Kastelein JJ, van Leuven SI, Burgess L, et al. (2007). Effect of torcetrapib on carotid atherosclerosis in familial hypercholesterolemia. N Engl J Med (356): 1620-30.

100. Tall AR, Yvan-Charvet L, Wang N. (2007). The failure of torcetrapib: was it the molecule or the mechanism? Arterioscler Thromb Vasc Biol (27):257-60.

101. Zannis VI, Kan HY, Kritis A, Zanni E, Kardassis D. (2001). Transcriptional regulation of the human apolipoprotein genes. Front Biosci (6):D456-504.

102. Baroukh N, Lopez CE, Saleh MC, et al. (2004). Expression and secretion of human apolipoprotein A-I in the heart. FEBS Lett (557):39-44.

103. Zannis VI, Liu T, Zanni M, Kan HY, Kardassis D. (2003). Regulatory gene mutations affecting apolipoprotein gene expression: functions and regulatory behavior of known genes may guide future pharmacogenomic approaches to therapy. Clin Chem Lab Med (41):411-24.

104. Zannis VI, Kan HY, Kritis A, Zanni EE, Kardassis D. (2001). Transcriptional regulatory mechanisms of the human apolipoprotein genes in vitro and in vivo. Curr Opin Lipidol (12):181-207.
105. Tzameli I, Zannis VI. (1996). Binding specificity and modulation of the ApoA-I promoter activity by homo- and heterodimers of nuclear receptors. J Biol Chem (271):8402-15.

106. Ladias JA, Karathanasis SK. (1991). Regulation of the apolipoprotein AI gene by ARP-1, a novel member of the steroid receptor superfamily. Science (251):561-5.

107. Berthou L, Duverger N, Emmanuel F, et al. (1996). Opposite regulation of human versus mouse apolipoprotein A-I by fibrates in human apolipoprotein A-I transgenic mice. J Clin Invest (97):2408-16.

108. Chan J, Nakabayashi H, Wong NC. (1993). HNF-4 increases activity of the rat Apo A1 gene. Nucleic Acids Res (21):1205-11.

109. Ge R, Rhee M, Malik S, Karathanasis SK. (1994). Transcriptional repression of apolipoprotein AI gene expression by orphan receptor ARP-1. J Biol Chem (269):13185-92.

110. Malik S, Karathanasis S. (1995). Transcriptional activation by the orphan nuclear receptor ARP-1. Nucleic Acids Res (23):1536-43.

111. Vu-Dac N, Schoonjans K, Laine B, Fruchart JC, Auwerx J, Staels B. (1994). Negative regulation of the human apolipoprotein A-I promoter by fibrates can be attenuated by the interaction of the peroxisome proliferator-activated receptor with its response element. J Biol Chem (269):31012-8.

112. Oliver WR, Jr., Shenk JL, Snaith MR, et al. (2001). A selective peroxisome proliferatoractivated receptor delta agonist promotes reverse cholesterol transport. Proc Natl Acad Sci U S A (98):5306-11.

113. van der Veen JN, Kruit JK, Havinga R, et al. (2005). Reduced cholesterol absorption upon PPARdelta activation coincides with decreased intestinal expression of NPC1L1. J Lipid Res (46):526-34.

114. Kliewer SA, Umesono K, Noonan DJ, Heyman RA, Evans RM. (1992). Convergence of 9-cis retinoic acid and peroxisome proliferator signalling pathways through heterodimer formation of their receptors. Nature (358):771-4.

115. Claudel T, Sturm E, Duez H, et al. (2002). Bile acid-activated nuclear receptor FXR suppresses apolipoprotein A-I transcription via a negative FXR response element. J Clin Invest (109): 961-71.

116. Harnish DC, Malik S, Karathanasis SK. (1994). Activation of apolipoprotein AI gene transcription by the liver-enriched factor HNF-3. J Biol Chem (269):28220-6. 
117. Kan HY, Georgopoulos S, Zanni M, et al. (2004). Contribution of the HormoneResponse Elements of the Proximal ApoA-I Promoter, ApoCIII Enhancer, and C/EBP Binding Site of the Proximal ApoA-I Promoter to the Hepatic and Intestinal Expression of the ApoA-I and ApoCIII Genes in Transgenic Mice. Biochemistry (43): 5084-93.

118. Lamon-Fava S, Micherone D. (2004). Regulation of apoA-I gene expression: mechanism of action of estrogen and genistein. J Lipid Res (45):106-12.

119. Lam JK, Matsubara S, Mihara K, Zheng XL, Mooradian AD, Wong NC. (2003). Insulin induction of apolipoprotein AI, role of Sp1. Biochemistry (42):2680-90.

120. Zheng XL, Matsubara S, Diao C, Hollenberg MD, Wong NC. (2001). Epidermal growth factor induction of apolipoprotein A-I is mediated by the Ras-MAP kinase cascade and Sp1. J Biol Chem (276):13822-9.

121. Zhang X, Jiao JJ, Bhavnani BR, Tam SP. (2001). Regulation of human apolipoprotein A-I gene expression by equine estrogens. J Lipid Res (42):1789-800.

122. Mosselman S, Polman J, Dijkema R. (1996). ER beta: identification and characterization of a novel human estrogen receptor. FEBS Lett (392):49-53.

123. Tam SP, Zhang X, Cuthbert C, Wang Z, Ellis T. (1997). Effects of dimethyl sulfoxide on apolipoprotein A-I in the human hepatoma cell line, HepG2. J Lipid Res (38):2090-102.

124. Cuthbert C, Wang Z, Zhang X, Tam SP. (1997). Regulation of human apolipoprotein A-I gene expression by gramoxone. J Biol Chem (272): 14954-60.

125. Georgopoulos S, Kan HY, Reardon-Alulis C, Zannis V. (2000). The SP1 sites of the human apoCIII enhancer are essential for the expression of the apoCIII gene and contribute to the hepatic and intestinal expression of the apoA-I gene in transgenic mice. Nucleic Acids Res (28):4919-29.

126. Campbell-Thompson M, Lynch IJ, Bhardwaj B. (2001). Expression of estrogen receptor (ER) subtypes and ERbeta isoforms in colon cancer. Cancer Res (61):632-40.

127. Zannis VI, Karathanasis SK, Keutmann HT, Goldberger G, Breslow JL. (1983). Intracellular and extracellular processing of human apolipoprotein A-I: secreted apolipoprotein A-I isoprotein 2 is a propeptide. Proc Natl Acad Sci U S A (80):2574-8.
128. Sauvaget D, Chauffeton V, Citadelle D, et al. (2002). Restriction of apolipoprotein AIV gene expression to the intestine villus depends on a hormone-responsive element and parallels differential expression of the hepatic nuclear factor 4alpha and gamma isoforms. J Biol Chem (277):34540-8.

129. Le Beyec J, Chauffeton V, Kan HY, et al. (1999). The -700/-310 fragment of the apolipoprotein A-IV gene combined with the $-890 /-500$ apolipoprotein C-III enhancer is sufficient to direct a pattern of gene expression similar to that for the endogenous apolipoprotein A-IV gene. J Biol Chem (274):4954-61.

130. Ikewaki K, Tohyama J, Nakata Y, Wakikawa T, Kido T, Mochizuki S. (2004). Fenofibrate effectively reduces remnants, and small dense $L D L$, and increases $H D L$ particle number in hypertriglyceridemic men - a nuclear magnetic resonance study. J Atheroscler Thromb (11):278-85.

131. Keech A, Simes RJ, Barter P, et al. (2005). Effects of long-term fenofibrate therapy on cardiovascular events in 9795 people with type 2 diabetes mellitus (the FIELD study): randomised controlled trial. Lancet (366): 1849-61.

132. Robins SJ, Bloomfield HE. (2006). Fibric acid derivatives in cardiovascular disease prevention: results from the large clinical trials. Curr Opin Lipidol (17):431-9.

133. Otvos JD, Collins D, Freedman DS, et al. (2006). Low-density lipoprotein and highdensity lipoprotein particle subclasses predict coronary events and are favorably changed by gemfibrozil therapy in the Veterans Affairs High-Density Lipoprotein Intervention Trial. Circulation (113):155663.

134. Duez $H$, Lefebvre $B$, Poulain $P$, et al. (2005). Regulation of human apoA-I by gemfibrozil and fenofibrate through selective peroxisome proliferator-activated receptor alpha modulation. Arterioscler Thromb Vasc Biol (25):585-91.

135. Blanquart $C$, Mansouri $R$, Paumelle $R$, Fruchart JC, Staels B, Glineur C. (2004). The protein kinase $C$ signaling pathway regulates a molecular switch between transactivation and transrepression activity of the peroxisome proliferator-activated receptor alpha. Mol Endocrinol (18):190618.

136. Toth PP. (2005). High-density lipoprotein as a therapeutic target: clinical evidence and treatment strategies. Am J Cardiol (96):50K-58K; discussion 34K-35K. 
137. Mauger JF, Couture $P$, Paradis ME, Lamarche B. (2005). Comparison of the impact of atorvastatin and simvastatin on apoA-I kinetics in men. Atherosclerosis (178):157-63.

138. Martin G, Duez H, Blanquart C, et al. (2001). Statin-induced inhibition of the Rho-signaling pathway activates PPARalpha and induces $\mathrm{HDL}$ apoA-I. J Clin Invest (107):1423-32.

139. Schaefer EJ, Asztalos BF. (2006). The effects of statins on high-density lipoproteins. Curr Atheroscler Rep (8):41-9.

140. Fazio S, Linton MF. (2004). The role of fibrates in managing hyperlipidemia: mechanisms of action and clinical efficacy. Curr Atheroscler Rep (6):148-57.

141. Athyros VG, Papageorgiou AA, Athyrou VV, Demitriadis DS, Pehlivanidis AN, Kontopoulos AG. (2002). Atorvastatin versus four statin-fibrate combinations in patients with familial combined hyperlipidaemia. J Cardiovasc Risk (9):339.

142. Athyros VG, Papageorgiou AA, Athyrou VV, Demitriadis DS, Kontopoulos AG. (2002). Atorvastatin and micronized fenofibrate alone and in combination in type 2 diabetes with combined hyperlipidemia. Diabetes Care (25):1198-202.

143. Meksawan K, Pendergast DR, Leddy JJ, Mason M, Horvath PJ, Awad AB. (2004). Effect of low and high fat diets on nutrient intakes and selected cardiovascular risk factors in sedentary men and women. J Am Coll Nutr (23):131-40.

144. Mensink RP, Zock PL, Kester AD, Katan MB. (2003). Effects of dietary fatty acids and carbohydrates on the ratio of serum total to HDL cholesterol and on serum lipids and apolipoproteins: a meta-analysis of 60 controlled trials. Am J Clin Nutr (77):114655.

145. Haas MJ, Horani MH, Wong NC, Mooradian AD. (2004). Induction of the apolipoprotein AI promoter by $\mathrm{Sp} 1$ is repressed by saturated fatty acids. Metabolism (53):1342-8.

146. van der Gaag MS, van Tol A, Vermunt SH, Scheek LM, Schaafsma G, Hendriks HF. (2001). Alcohol consumption stimulates early steps in reverse cholesterol transport. J Lipid Res (42):2077-83.

147. Tam SP. (1992). Effect of ethanol on lipoprotein secretion in two human hepatoma cell lines, HepG2 and Hep3B. Alcohol Clin Exp Res (16):1021-8.
148. Mooradian AD, Haas MJ, Wong NC. (2006). The Effect of Select Nutrients on Serum High-Density Lipoprotein Cholesterol and Apolipoprotein A-I Levels. Endocr Rev.

149. Ganji SH, Kamanna VS, Kashyap ML. (2003). Niacin and cholesterol: role in cardiovascular disease (review). J Nutr Biochem (14):298-305.

150. Haghpassand M, Moberly JB. (1995). 9-cisretinoic acid increases apolipoprotein AI secretion and mRNA expression in HepG2 cells. Atherosclerosis (117): 199-207.

151. Reynolds K, Chin A, Lees KA, Nguyen A, Bujnowski D, He J. (2006). A meta-analysis of the effect of soy protein supplementation on serum lipids. Am J Cardiol (98):633-40.

152. Sacks FM, Lichtenstein A, Van Horn L, Harris W, Kris-Etherton $P$, Winston $M$. (2006). Soy protein, isoflavones, and cardiovascular health: an American Heart Association Science Advisory for professionals from the Nutrition Committee. Circulation (113):1034-44.

153. Burgess JW, Neville TA, Rouillard $P$, Harder Z, Beanlands DS, Sparks DL. (2005). Phosphatidylinositol increases HDL-C levels in humans. J Lipid Res (46):350-5.

154. Gouni-Berthold I, Berthold HK. (2002). Policosanol: clinical pharmacology and therapeutic significance of a new lipidlowering agent. Am Heart J (143):356-65.

155. Kassis AN, Jones PJ. (2006). Lack of cholesterol-lowering efficacy of Cuban sugar cane policosanols in hypercholesterolemic persons. Am J Clin Nutr (84):1003-8.

156. Berthold HK, Unverdorben S, Degenhardt R, Bulitta M, Gouni-Berthold I. (2006). Effect of policosanol on lipid levels among patients with hypercholesterolemia or combined hyperlipidemia: a randomized controlled trial. Jama (295):2262-9. 



\section{Chapter 3}

\section{Differentiated CaCo-2 cells as an in vitro model to evaluate de novo apoA-I production of the small intestine}

Stefan P.J. Dullens, Ronald P. Mensink, Edwin C.M. Mariman, Jogchum Plat

Department of Human Biology, Nutrition and Toxicology Research Institute Maastricht, Maastricht University, Maastricht, The Netherlands 


\section{Abstract}

Increasing high-density lipoprotein cholesterol (HDL-C) concentrations by stimulating de novo apolipoprotein A-I (apoA-I) production in the liver and/or in the small intestine is a potential strategy to reduce coronary heart disease (CHD) risk. Although there is quite some knowledge concerning regulatory effects in the liver, less is known concerning potential agents that could elevate de novo apoA-I production in the small intestine. Therefore, we compared side-by-side effects of various PPAR $\alpha, P P A R \gamma, R X R \alpha$, and FXR agonists on de novo apoA-I production in differentiated CaCo-2 and HepG2 cells. For PPAR $\alpha$ agonists, we showed that GW7647 elevated apoA-I concentrations in the medium of both cell models, while WY14643 only elevated de apoA-I concentrations in differentiated $\mathrm{CaCo}-2$ cells. Unexpectedly, fenofibric acid (FeAc) lowered apoA-I medium concentrations in both cell lines, which could not be explained by a lack of PPAR transactivation or a lack of RXR a activation. For FXR agonists, chenodeoxycholic acid strongly reduced apoA-I concentrations both in differentiated CaCo-2 and in HepG2 cells, while GW4064 and taurocholate only lowered apoA-I in CaCo-2 cells (GW4064) or in HepG2 cells (taurocholate). Overall, however, effects of all individual components on apoA-I production in differentiated $\mathrm{CaCo}-2$ and $\mathrm{HepG} 2$ cells were highly correlated $(r=0.68 ; \mathrm{P}=0.037 ; \mathrm{N}=9)$. Therefore, we conclude that differentiated $\mathrm{CaCo}-2$ cells are a suitable model to study de novo small intestinal apoA-I production in vitro enabling the possibility to screen for potential bioactive dietary components. This cell model may also determine small intestinal specific effects, since some discrepancy was found between both cell models. 


\section{Introduction}

In the past decade, strategies to reduce the risk for coronary heart diseases (CHD) were mostly focused on lowering serum low-density lipoprotein cholesterol (LDL-C) levels. Nowadays, however, increasing high-density lipoprotein cholesterol (HDL-C) concentrations is becoming more and more an additional target in CHD risk reduction ${ }^{1}$. Indeed, many epidemiological studies have shown a negative relationship between serum concentrations of HDL-C, as well as of its main protein apolipoprotein A-I (apoA-I) with CHD risk ${ }^{2,3}$. To elevate HDL-C concentrations, different strategies can be chosen, of which cholesterol ester transfer protein (CETP) inhibition was by far the most promising. In this respect, convincing data came from studies in rabbits in which CETP inhibition resulted in marked reductions of atherosclerotic lesions ${ }^{4,5}$. However, despite these effects, the effectiveness of this approach is now reconsidered. CETP inhibition mainly increases concentrations of large $\alpha$-HDL particles, which in theory do not have the possibility to further incorporate large amounts of cholesterol from the vessel wall, and consequently lack the capacity to enhance reverse cholesterol transport. Indeed, CETP inhibition did not lower the overall removal of cholesterol esters from the arterial wall in rabbits ${ }^{6}$, and the impact of CETP inhibition on reverse cholesterol transport (RCT) is therefore still uncertain ${ }^{7}$. In addition, the recent disappointing effects from the trials with the CETP inhibitor torcetrapid ${ }^{8,9}$, for which there is so far no conclusive explanation, has questioned the effects of CETP inhibition on CHD risk ${ }^{10}$. However, indications that the undesirable effects of torcetrapid might relate to characteristics other than effects on CETP opens venues for other CETP inhibitors, which are currently evaluated. Another approach, namely a selective increase in the production of pre $\beta$-HDL particles by elevating de novo apoA-I production ${ }^{11}$ might result in increased concentrations of functional HDL particles that have the capacity to incorporate large amounts of cholesterol and consequently enhance RCT. In humans, one of the strongest indications that elevating de novo apoA-I production reduces CHD risk can be deduced from the finding that intravenous administration of apoA- $\mathrm{I}_{\text {Milano, }}$ lowered atheroma burden areas by $4.2 \%$ within 5 weeks as observed in humans ${ }^{12}$. This finding is in line with observations in transgenic mice producing the human apoA-I protein, which were protected against diet-induced atherosclerosis ${ }^{13,14}$.

In humans, apoA-I is mainly produced in hepatocytes and enterocytes, but also in smaller amounts in heart cells ${ }^{15},{ }^{16}$. Most studies have now focused on the transcriptional regulation in hepatocytes, although there are indications that apoA-I production is regulated in a tissue-specific manner ${ }^{17}$. In addition, apoA-I is highly expressed in enterocytes and the small intestine is therefore an interesting target tissue to stimulate apoA-I production and 
elevate serum HDL-C levels ${ }^{18}$. Thus, components that are able to elevate apoA-I in the small intestine might be interesting candidates in relation to HDL-elevating approaches and CHD risk reduction.

To evaluate involvement of specific previously defined transcription factors on de novo apoA-I production, pharmacological agents with consistent and strong effects are attractive agents to compare effects in hepatic and enterocyte cell models. In this view, fibrates such as fenofibric acid (FeAc), can be seen as model components since they effectively elevate serum HDLC concentrations as demonstrated in cell, animal, and human studies ${ }^{19-22}$. Mechanistically, fibrates are known as peroxisome proliferator-activator receptor alpha (PPAR $\alpha$ ) agonists and, as demonstrated in human apoA-I transgenic/PPAR $\alpha$ knockout mice, PPAR $\alpha$ is a crucial transcription factor in apoA-I synthesis ${ }^{23}$. However, a frequently used human apoA-I transgenic mouse model only produces human apoA-I in the liver ${ }^{13}$, and consequently, the effects of PPAR $\alpha$ stimulation on small intestinal human apoA-I production are less known.

We therefore evaluated side-by-side the involvement of PPAR $\alpha$ in the production of apoA-I in human hepatoma cells (HepG2) versus human enterocytes (fully differentiated CaCo-2 cells). Furthermore, other studies have suggested a regulatory role for transcription factors peroxisome proliferators-activated receptor $\gamma$ (PPAR $\gamma$ ), retinoid-X-receptor (RXR), and farnesoid-X-receptor (FXR) ${ }^{24-26}$. Therefore, we studied the involvement of the these transcription factors on apoA-I synthesis in HepG2 and in differentiated $\mathrm{CaCo}-2$ cells, with the ultimate aim to illustrate the suitability of fully differentiated $\mathrm{CaCo}-2$ cells as a small intestinal cell model to elucidate the effects of (nutritional) components on de novo apoA-I production. 


\section{Material and methods}

\section{Cells}

CaCo-2 cells were purchased from European Collection of Cell Cultures (ECACC, Poole, UK) and cultured in growth medium DMEM at $37{ }^{\circ} \mathrm{C}$ in a humidified atmosphere of $5 \% \mathrm{CO}_{2} / 95 \% \mathrm{O}_{2}(\mathrm{v} / \mathrm{v})$. Medium was supplemented with $10 \%(\mathrm{v} / \mathrm{v})$ FBS, $1 \%(\mathrm{v} / \mathrm{v})$ non essential amino acids (NEAA), $1 \%(\mathrm{v} / \mathrm{v}$ ) sodium pyruvate, and $1 \%(\mathrm{v} / \mathrm{v})$ penicillin/streptomycin. All supplements were obtained from Invitrogen Life Technologies (Carlsbad, CA, USA). For each experimental condition, $\mathrm{CaCo}-2$ cells were seeded in 6-well-tissue-culture plates (Corning, Aston, MA, USA) at a density of $5 \times 10^{5}$ cells per well. Every 2 or 3 days cell culture medium was renewed. After 21 days, culture medium was again renewed and the confluent and fully differentiated cell monolayers were exposed to the components of interest for incubation periods as indicated. HepG2 cells were kindly provided by Mabtech (Nacka Strand, Sweden) and grown in MEM (Invitrogen Life Technologies, Carlsbad, CA, USA), supplemented with $10 \%(\mathrm{v} / \mathrm{v})$ FBS, $1 \%(\mathrm{v} / \mathrm{v})$ NEAA, $1 \%(\mathrm{v} / \mathrm{v})$ penicillin/streptomycin, and $2 \mathrm{mM}$ L-glutamine. HepG2 cells were also grown in 6-well tissue-culture plates, in which $5 \times 10^{5}$ cells were seeded per well. When monolayers of HepG2 cells reached a confluence of approximately $90 \%$, cells were exposed to the component of interest. In contrast to the other components, FeAc did not dissolve in culture medium. Therefore, FeAc was first added to culture medium and sonificated for 30 minutes at $47 \mathrm{kHz}$ (Branson 2000, Danbury, CL, USA) to obtain a well-homogenized suspension before it was supplied to the cells.

The concentrations of the components used in this study were based on previous in vitro experiments, which confirmed these amounts as being optimal and nontoxic ${ }^{26-31}$. In line with these results, also in our experiments incubating both HepG2 and $\mathrm{CaCo}-2$ cells with the used components for 48 hours did not show any sign of toxicity based on morphology of the cells.

Cell culture medium of both differentiated CaCo-2 cells and HepG2 cells was collected and analyzed for human apoA-I protein concentrations with an apoA-I sandwich ELISA (Mabtech, Nacka Strand, Sweden). This human apoA-I sandwich ELISA had no cross-activity with bovine apoA-I presented in culture medium (data not shown). The apoA-I calibration curve was obtained with purified human apoA-I (Sigma, St. Louis, MO, USA). The detection limit of this sandwich ELISA was $1.3 \mathrm{ng} / \mathrm{mL}$ and the between run variation coefficient was less than $5 \%$. Samples from each experiment were always analyzed in duplo on one ELISA plate. 


\section{PPAR transactivation assay}

To determine PPAR activation by components, monolayers (a confluence of approximately $80 \%$ ) of CaCo-2 cells and HepG2 cells were transiently transfected using FuGENE 6 reagent (Roche, Basel, Switzerland) with $0.2 \mu \mathrm{g}$ of a luciferase reporter pGL3 vector (PPRE-luc) that contained PPAR responsive elements (PPREs) enabling measurement of PPAR transcriptional activity, as described previously ${ }^{32}$. In addition, a reporter eGFP vector was used to determine the transfection efficiency in both cell lines. One day prior to the transfection, CaCo-2 cells or HepG2 cells were plated in 24-well tissue culture plates at a density of $2 \times 10^{5}$ cells per well and maintained further as described above. One hour before the transfection, standard culture medium was replaced by medium without serum and antibiotics. Six hours after transfection, culture medium was renewed and the cells were maintained as described above. Transfected CaCo-2 cells were maintained for 21 days to differentiate into enterocytes. After differentiation of $\mathrm{CaCo}-2$ cells (at day 21), the control vector eGFP was equally expressed as observed at day 3 after transfection. After 48 hours of incubation with the indicated component, cells were washed once in ice cold PBS following lysis with reporter lysis buffer (Promega, Madison, WI, USA). The cell lysate was then used to measure luciferase expression with the luciferase reporter assay (Promega, Madison, WI, USA).

\section{Reagents}

Fenofibric acid was kindly provided by Fournier Laboratories (Dijon, France). GW7647, WY14643, chenodeoxycholic acid (CDCA), taurocholate (TCA), and 9-cis retinoid acid (RA) were purchased from Sigma-Aldrich (St. Louis, MO, USA). GW4064 was kindly provided by Prof F. Kuipers (Center for Liver, Digestive and Metabolic Diseases, University Medical Centre Groningen, Groningen, The Netherlands). Troglitazone was purchased from Biomol International L.P. (Exeter, UK), and guggulsteron (4, 17(20)-(trans)pregnadien-3, 16-dione) was obtained from Steraloids Inc. (Newport, Rhode Island, USA).

\section{Statistical analysis}

All experimental conditions were performed in duplo and values are shown as mean \pm SEM. Effects of experimental conditions, of which components were dissolved in dimethylsulfoxide (DMSO) were compared to the control condition ( $0.01 \%$ DMSO) and effects were defined as being different when more or less than $10 \%$ from control values. To examine the relationship between the responsiveness of fully differentiated CaCo-2 and HepG2 cells, the Spearman correlation coefficient between the responses to the various components of both cell lines was calculated. 


\section{Results}

De novo apoA-I production in differentiated CaCo-2 and HepG2 cells Without addition of specific stimulating agents, fully differentiated CaCo-2 cells continuously secreted apoA-I in culture medium in a time-dependent manner (figure 1). In HepG2 cells, constitutive de novo apoA-I production was comparable, although quantitatively at lower amounts than in differentiated CaCo-2 cells.

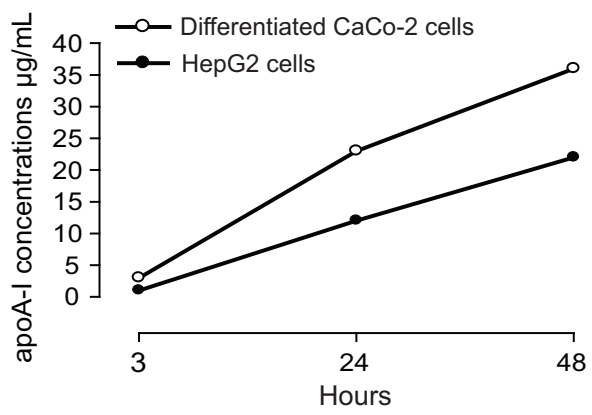

Figure 1. Time-dependent constitutive de novo apoA-I production in differentiated $\mathrm{CaCo}-2$ and HepG 2 cells.

\section{Effects of PPAR $\alpha$ and PPAR $\gamma$ agonists on de novo apoA-I production}

As shown in figure 2, GW7647 (100 nM) - a selective PPAR $\alpha$ agonist strongly elevated de novo apoA-I production in differentiated CaCo-2 cells after 48 hours incubation ( $+46 \%)$. In HepG2 cells, apoA-I production was also elevated $(+13 \%)$ by GW7647, but less prominent as compared to the effects observed in differentiated CaCo- 2 cells. In differentiated CaCo-2 cells, the PPAR $\alpha$ agonist WY14643 $(50 \mu \mathrm{M})$ elevated apoA-I production by $16 \%$. However, in HepG2 cells, WY14643 had no effect $(+2 \%)$ on apoA-I medium concentrations. Unexpectedly, FeAc $(0.6 \mathrm{mM})$ lowered apoA-I medium concentrations both in differentiated CaCo-2 cells $(-14 \%)$ as well as in HepG2 cells $(-39 \%)$ after 48 hours incubation. 


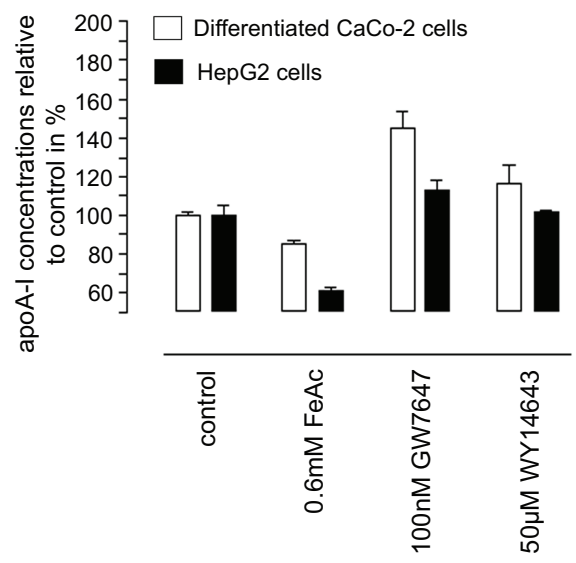

Figure 2. Effects of different PPAR $\alpha$ agonists on de novo apoA-I production in differentiated CaCo-2 and HepG2 cells (48 hours incubation).

Values are presented as mean $\pm \mathrm{SEM}$, as percentage compared to the control.

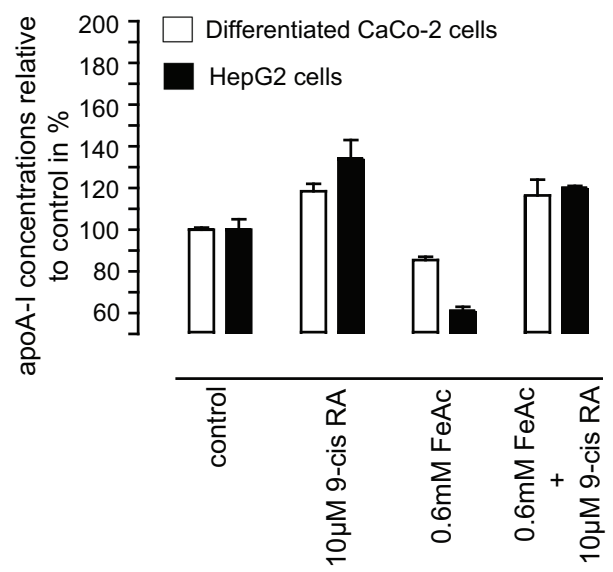

Figure 3. Effects of the PPAR $\alpha$ agonist fenofibric acid, the RXR $\alpha$ agonist 9-cis retinoid acid, and their combination on de novo apoA-I production (48 hours incubation).

Values are presented as mean \pm SEM, as percentage compared to the control.

Since this effect of FeAc was unexpected, we evaluated whether FeAc and GW7647 transactivated PPAR $\alpha$. In PPRE-luc transiently transfected differentiated CaCo-2 cells, luciferase activity was increased with $500 \%$ by FeAc $(0.6 \mathrm{mM})$ and $25 \%$ by GW7647 (100nM). Also in PPRE-luc transient transfected HepG2 cells, $0.6 \mathrm{mM}$ FeAc and 100nM GW7647 increased luciferase activity via PPRE by $60 \%$ and $20 \%$, respectively (data not shown). 
Therefore, it is not likely that the lack of increasing apoA-I production by FeAc relates to a lack of PPAR $\alpha$ activation in both cell lines. Next, we evaluated whether simultaneous activation of RXR $\alpha$ and PPAR $\alpha$ resulted in FeAc-induced apoA-I production. When RA and FeAc were added simultaneously, there was no additional effect on apoA-I production as compared to RA alone (figure 3). More specifically, the apoA-I lowering effect of FeAc was counteracted through addition of RA in both HepG2 and differentiated $\mathrm{CaCo}-2$ cells. Since the combined effects of FeAc and RA still did not result in elevated apoA-I production, this finding can be interpreted as an indication that the lack of enhancing de novo apoA-I production by FeAc cannot be ascribed to a lack of RXR $\alpha$ activation. Therefore, other factors besides RXR $\alpha$ or PPAR $\alpha$ activation, which are obviously differentially regulated by the used PPAR agonists, seem crucial for elevating apoA-I production in both HepG2 and differentiated CaCo-2 cells.

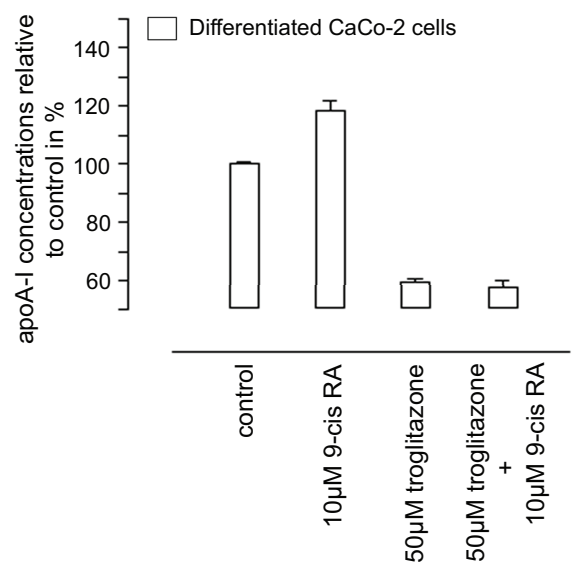

Figure 4. Effects of the PPAR $\gamma$ agonist troglitazone, the RXR $\alpha$ agonist 9-cis retinoid acid, and their combination on de novo apoA-I production stimulation in differentiated CaCo-2 cells (48 hours incubation).

Values are presented as mean \pm SEM, as percentage compared to the control.

We also examined whether PPAR $\gamma$ activation affected de novo apoA-I production by incubating the cells with the selective PPAR $\gamma$ agonist troglitazone $(50 \mu \mathrm{M})$. Either in combination with RA $(-42 \%)$ or without RA ($40 \%$ ), apoA-I concentrations in culture medium were strongly reduced in differentiated $\mathrm{CaCo}-2$ cells (figure 4). Effects on apoA-I production were not evaluated in HepG2 cells, because troglitazone is hepatotoxic ${ }^{33}$. 


\section{Effects of FXR agonists on de novo apoA-I production}

To evaluate the effects of FXR activation - which is known to inhibit apoA-I transcription by binding to site $\mathrm{C}$ at the apoA-I promoter ${ }^{26}$ - on de novo apoA-I production, differentiated CaCo-2 and HepG2 cells were incubated with $5 \mu \mathrm{M}$ GW 4064 for 48 hours. As shown in figure 5, apoA-I concentrations in culture medium were indeed decreased by GW4064 in differentiated CaCo2 cells $(-16 \%)$, but not in HepG2 cells $(-4 \%)$. Besides the effects of the synthetic FXR agonist GW4064, effects of the natural FXR agonists chenodeoxycholic acid (CDCA) and taurocholate (TCA) were also evaluated. In line with the effects of GW4064, CDCA-treated $(100 \mu \mathrm{M}) \mathrm{CaCo}-2$ cells showed a strong reduction in apoA-I production $(-28 \%)$, whereas exposure to $50 \mu \mathrm{M}$ TCA did not $(-6 \%)$. Also in HepG2 cells, CDCA $(-31 \%)$ strongly reduced apoA-I concentrations. In contrast to effects in differentiated $\mathrm{CaCo}-2$ cells, apoA-I production was also reduced in TCA-treated HepG2 cells $(-18 \%)$ (figure 5). In line with the experiments using FeAc and troglitazone, effects were not related to a lack of RXR $\alpha$ activation (data not shown).

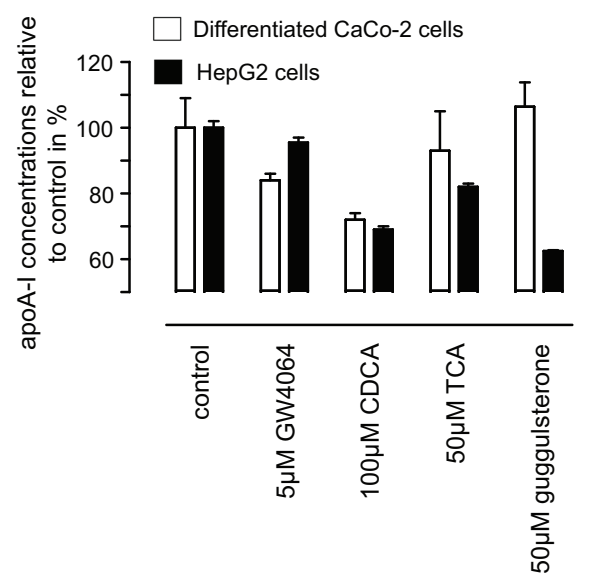

Figure 5. Effects of FXR agonists on de novo apoA-I stimulation in differentiated CaCo-2 and HepG 2 cells (48 hours incubation).

Values are presented as mean $\pm \mathrm{SEM}$, as percentage compared to the control.

Finally, Z-guggulsterone $(50 \mu \mathrm{M})$ - known as a FXR-antagonist ${ }^{34}$, but also as an agonist to the pregnane $X$ receptor (PXR) ${ }^{35}$ and an oestrogen receptor alpha $(E R \alpha)^{36}$ - did not change apoA-I medium concentrations in differentiated $\mathrm{CaCo}-2$ cells $(+7 \%)$, whereas these concentrations were decreased in HepG2 cells $(-37 \%)$. 


\section{Correlation between the responses in differentiated CaCo-2 and HepG2 cells}

Since the apoA-I production depends in both enterocytes and hepatocytes on the apoA-I promoter/enhancer ${ }^{37}$, we expected at least some consistency between responses to the different model components in both cell models. Indeed, the Spearman correlation coefficient between the responses in fully differentiated $\mathrm{CaCo}-2$ cells and HepG2 cells was statistically significant $(r=0.68 ; P=0.037$, figure 6).

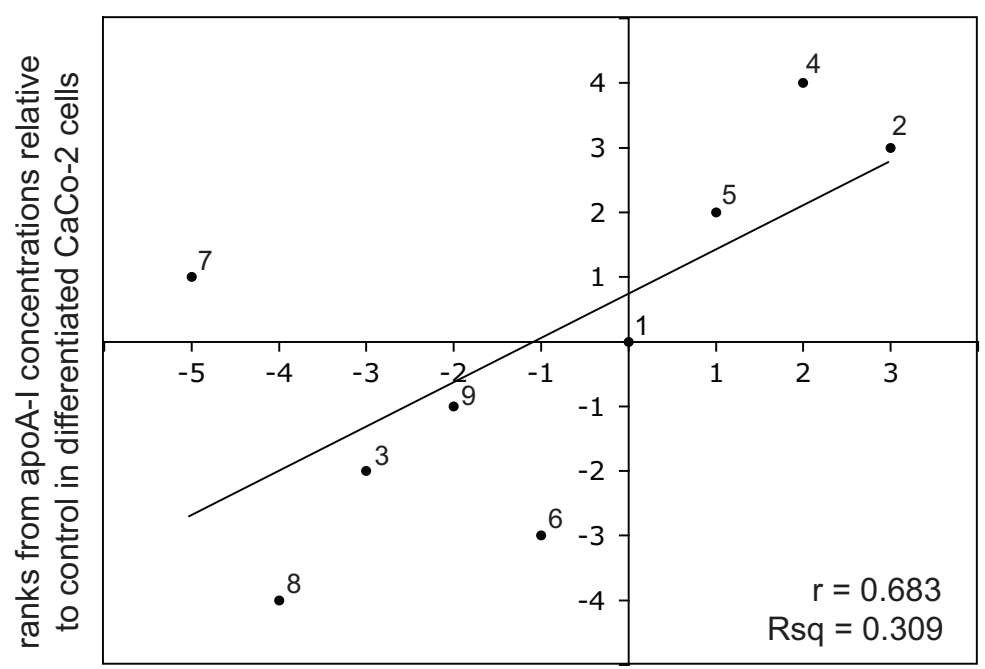

$1=$ control

$2=9-\operatorname{cis} \mathrm{RA}$

$3=$ fenofibric acid

$4=\mathrm{GW} 7647$

$5=W Y 14643$

$6=$ GW4064

7 = guggulsterone

$8=$ TCA

$9=\mathrm{CDCA}$

ranks from apoA-I concentrations relative to control in HepG2 cells

Figure 6. Scatter-plot of ranks and Spearman correlation coefficient of the effects induced by different components in differentiated $\mathrm{CaCo-2}$ and HepG 2 cells. 


\section{Discussion}

Since apoA-I is a PPAR $\alpha$ target gene, effects of several known PPAR $\alpha$ agonists (GW7467, WY14643, and FeAc) were evaluated in differentiated CaCo-2 cells and HepG2 cells side-by-side. As expected, GW7647 elevated de novo apoA-I production in both cell lines as measured in culture medium after 48 hours incubation. In contrast, the PPAR $\alpha$ agonist FeAc strongly reduced apoA-I concentrations in culture medium in both cell lines after 48 hours incubation. This was an unexpected finding, since a previous study in human apoA-I transgenic/PPAR $\alpha^{-/-}$versus human apoA-I transgenic/PPAR $\alpha^{+/+}$ mice demonstrated that FeAc, in contrast to gemfibrozil, was a full PPAR $\alpha$ agonist and elevated plasma human apoA-I levels ${ }^{23}$. Furthermore, other fibrates (gemfibrozil and ciprofibrate) elevated apoA-I medium levels in monkey hepatocytes in vitro ${ }^{38}$. Because PPAR $\alpha$ activation depends on the formation of a PPAR $\alpha / R X R \alpha$ heterodimer, we incubated both cell lines also simultaneously with FeAc and the RXR $\alpha$ agonist 9-cis RA. Results, however, did not indicate that the decreased apoA-I concentrations by FeAc could be ascribed to a lack of $R X R \alpha$ activation. This conclusion is supported by the finding that the increase in apoA-I production by GW7467, which is also a PPAR $\alpha$ agonist, was evident without additional RXR activation. In addition, FeAc clearly increased PPAR transactivation, which illustrated that FeAc was taken up by the cells. A more plausible explanation for the differential effects of the PPAR $\alpha$ agonists GW7647 and FeAc on apoA-I production might be found in the lack of activation or inhibition of additional regulatory factors that are involved. Further research is however needed to confirm this suggestion. Both cell lines however responded in a comparable way to the different PPAR agonists, suggesting that HepG2 cells and differentiated CaCo2 cells share a common apoA-I regulatory mechanism. Furthermore, the fact that FeAc did not elevate apoA-I production is in line with a recent large-scale intervention study (FIELD) in type 2 diabetic subjects, which showed no effects of fenofibrate on serum HDL-C ${ }^{39}$. It should be emphasized however that several smaller human interventional studies did see such effects ${ }^{40,41}$. It should be considered that fibrates may influence serum HDL-C concentrations in humans by affecting other mechanisms as well. For example, in vitro experiments indicated that FeAc enhanced ABCA1 expression in macrophages and fibroblasts ${ }^{42}$, which may increase cholesterol efflux and consequently HDL-C concentrations. Finally, the recent suggestion that fibrates elevate HDL-C concentrations in apoE*3-Leiden.CETP transgenic mice by decreasing CETP-activity is noteworthy ${ }^{43}$.

Rong and coworkers ${ }^{24}$ have proposed that activation of PPAR $\gamma$ by 15 -deoxy- ${ }^{\Delta 12,14}$ prostagladin $\mathrm{J}_{2}(15 \mathrm{~d}$-PGj2) increased apoA-I production in 14 days differentiated CaCo-2 cells after 20 hours incubation. In our study, 
however, PPAR $\gamma$ activation by another PPAR $\gamma$ agonist, troglitazone, decreased de novo apoA-I production in fully differentiated CaCo-2 cells (21 days) after 48 hours. Although troglitazone and $15 \mathrm{~d}-\mathrm{PGj} 2$ are both PPAR $\gamma$ agonists, component specific effects on other (transcription) factors might explain the different effects on apoA-I production. Furthermore, as reviewed by Goldberg and coworkers, thiazolidenediones (TZD) clearly elevated HDL-C concentrations in human intervention trials. However, these effects were not ascribed to a changed apoA-I production, but to a possible reduction in hepatic lipase activity and an increase in ABCA1 activity ${ }^{44}$.

Besides PPARs, FXR is an important transcription factor in $\mathrm{HDL}$ cholesterol homeostasis. In human apoA-I transgenic mouse, a TCA-enriched diet resulted in a remarkable reduction of human as well as mouse apoA-I concentrations ${ }^{26}$. This effect was ascribed to a negative regulatory response element mapped in site $\mathrm{C}$ of the apoA-I promoter, as concluded from studies in HepG2 cells ${ }^{26}$. In view of these findings, effects of the synthetic FXR agonist GW4064 as well as of the natural agonists CDCA and TCA were evaluated. Although the inhibitory effects of the specific FXR agonist GW4064 on de novo apoA-I production was only evident in differentiated CaCo-2 cells, we did find a strong reduction after 48 hours incubation with the natural FXR agonist CDCA in both cell lines. This may suggest that the presence of the negative regulatory response element mapped in site $C$ of the apoA-I promoter, as demonstrated in HepG2 cells, is also functional in differentiated CaCo- 2 cells. The finding that TCA had no effect in differentiated $\mathrm{CaCo}-2$ cells, but did lower apoA-I production in HepG2 cells, can probably not be explained by an inefficient TCA uptake, since a functional apical sodium dependent bile acid (ASBT) transporter was previously identified in differentiated CaCo-2 cells ${ }^{45}$. Therefore, we currently have no good explanation for the observed difference in response to TCA treatment of differentiated CaCo-2 and HepG2 cells.

Earlier in vitro studies have suggested that E- and Z-guggulsterone are potent and specific FXR-antagonists ${ }^{31,34}$. More recently, however, it was shown that E- and Z-guggulsterone are also agonists of other transcription factors such as the pregnane $X$ receptor (PXR) ${ }^{35}$, the estrogen receptor alpha $(E R \alpha)$, and the progesterone receptor ${ }^{36}$. In our experiments, guggulsteron treatment decreased apoA-I concentrations in culture medium of HepG2 cells. However, this decreasing effect could not be observed in differentiated CaCo2 cells, which is not in line with effects described for the FXR agonist GW4064, which did lower the apoA-I production in our enterocyte cell model. This suggest that - at least - in HepG2 cells, guggelsterone is a rather nonspecific agonist, and effects may as well be mediated via PXR, ER $\alpha$ or the progesterone receptor. Furthermore, as reviewed by Ulbricht and coworkers ${ }^{46}$ guggulsterone is postulated as a functional candidate in reducing TC and 
LDL-C levels, whereas it elevates HDL-C levels. However, the relevance of these findings is questionable since treatment of hypercholesterolemic patients with a standardized guggul extract (guggullipid) had no effects on serum HDL-C levels or other lipoproteins ${ }^{47}$. Unfortunately, effects on serum apoA-I concentrations were not measured in that study.

Our results show that the enterocyte $\mathrm{CaCo}-2$ cell line responds to several agonists, which are involved in apoA-I metabolism, in a comparable way as HepG2 cells do. Using differentiated CaCo-2 cells instead of HepG2 cells may be of specific importance for dietary agents with a low bioavailability. Sometimes these components are taken up by the enterocytes, giving rise to high local concentrations, but do not appear in the circulation, since they are secreted back into the lumen, or end up in the faeces after renewal of the mucosal enterocyte lining. In this case, the component may still affect transcriptional regulation of for example apoA-I within the enterocyte and as such influence serum HDL-C concentrations. In addition, despite similarities, apoA-I transcription can be tissue-specific and regulatory effects in the small intestine may be missed when only HepG2 cells are used.

In conclusion, differentiated $\mathrm{CaCo}-2$ cells and $\mathrm{HepG} 2$ cells both secrete continuously apoA-I in culture medium. Interestingly, de novo apoA-I production in response to known players in HDL metabolism (i.e. PPAR $\alpha$, $\mathrm{RXR} \alpha$, and FXR agonist(s)) was highly comparable between both cell lines. Although differences existed, we nonetheless conclude that besides HepG2 cells, differentiated $\mathrm{CaCo}-2$ cells are an additional cell model to evaluate effects induced by components or compounds of interest on de novo apoA-I production. 


\section{References}

1. Brewer HB, Jr. (2004). Focus on high-density lipoproteins in reducing cardiovascular risk. Am Heart J (148):S14-8.

2. Schaefer EJ, Lamon-Fava S, Ordovas JM, et al. (1994). Factors associated with low and elevated plasma high density lipoprotein cholesterol and apolipoprotein A-I levels in the Framingham Offspring Study. J Lipid Res (35):871-82.

3. Luc G, Bard JM, Ferrieres J, et al. (2002). Value of HDL cholesterol, apolipoprotein A-I, lipoprotein A-I, and lipoprotein A-I/A-II in prediction of coronary heart disease: the PRIME Study. Prospective Epidemiological Study of Myocardial Infarction. Arterioscler Thromb Vasc Biol (22):1155-61.

4. Sugano M, Makino N, Sawada $S$, et al. (1998). Effect of antisense oligonucleotides against cholesteryl ester transfer protein on the development of atherosclerosis in cholesterol-fed rabbits. J Biol Chem (273):5033-6.

5. Rittershaus CW, Miller DP, Thomas LJ, et al. (2000). Vaccine-induced antibodies inhibit CETP activity in vivo and reduce aortic lesions in a rabbit model of atherosclerosis. Arterioscler Thromb Vasc Biol (20):2106-12.

6. Kee $P$, Caiazza $D$, Rye $K A$, Barrett $P H$ Morehouse LA, Barter PJ. (2006). Effect of inhibiting cholesteryl ester transfer protein on the kinetics of high-density lipoprotein cholesteryl ester transport in plasma: in vivo studies in rabbits. Arterioscler Thromb Vasc Biol (26):884-90.

7. Rensen PC, Havekes LM. (2006). Cholesteryl ester transfer protein inhibition: effect on reverse cholesterol transport? Arterioscler Thromb Vasc Biol (26):681-4

8. Kastelein JJ, van Leuven SI, Burgess L, et al. (2007). Effect of torcetrapib on carotid atherosclerosis in familia hypercholesterolemia. N Engl J Med (356): 1620-30.

9. Tall AR, Yvan-Charvet L, Wang N. (2007). The failure of torcetrapib: was it the molecule or the mechanism? Arterioscler Thromb Vasc Biol (27):257-60.

10. Bots ML, Visseren FL, Evans GW, et al. (2007). Torcetrapib and carotid intima-media thickness in mixed dyslipidaemia (RADIANCE 2 study): a randomised, double-blind trial. Lancet (370): 153-60.

11. Rader DJ. (2006). Molecular regulation of HDL metabolism and function: implications for novel therapies. J Clin Invest (116):3090100 .

12. Nissen SE, Tsunoda T, Tuzcu EM, et al. (2003). Effect of recombinant ApoA-I Milano on coronary atherosclerosis in patients with acute coronary syndromes: a randomized controlled trial. Jama (290):2292-300.

13. Rubin EM, Krauss RM, Spangler EA, Verstuyft JG, Clift SM. (1991). Inhibition of early atherogenesis in transgenic mice by human apolipoprotein AI. Nature (353):265-7.
14. Vergnes L, Baroukh N, Ostos MA, et al. (2000). Expression of human apolipoprotein A-I/C-III/A-IV gene cluster in mice induces hyperlipidemia but reduces atherogenesis. Arterioscler Thromb Vasc Biol (20):2267-74.

15. Zannis VI, Cole FS, Jackson CL, Kurnit DM, Karathanasis SK. (1985). Distribution of apolipoprotein A-I, C-II, C-III, and E mRNA in fetal human tissues. Time-dependent induction of apolipoprotein $E$ mRNA by cultures of human monocyte-macrophages. Biochemistry (24):4450-5.

16. Baroukh N, Lopez CE, Saleh MC, et al. (2004). Expression and secretion of human apolipoprotein A-I in the heart. FEBS Lett (557):39-44

17. Zannis VI, Liu T, Zanni M, Kan HY, Kardassis D. (2003). Regulatory gene mutations affecting apolipoprotein gene expression: functions and regulatory behavior of known genes may guide future pharmacogenomic approaches to therapy. Clin Chem Lab Med (41):411-24.

18. Eggerman TL, Hoeg JM, Meng MS, Tombragel A, Bojanovski D, Brewer HB, Jr. (1991). Differential tissue-specific expression of human apoA-I and apoA-II. J Lipid Res (32):821-8.

19. Hahn SE, Goldberg DM. (1992). Modulation of lipoprotein production in Hep G2 cells by fenofibrate and clofibrate. Biochem Pharmacol (43):625-33.

20. Berthou L, Duverger N, Emmanuel F, et al. (1996). Opposite regulation of human versus mouse apolipoprotein A-I by fibrates in human apolipoprotein A-I transgenic mice. J Clin Invest (97):2408-16.

21. Hennuyer N, Poulain P, Madsen L, et al. (1999). Beneficial effects of fibrates on apolipoprotein A-I metabolism occur independently of any peroxisome proliferative response. Circulation (99):2445-51.

22. Adkins JC, Faulds D. (1997). Micronised fenofibrate: a review of its pharmacodynamic properties and clinical efficacy in the management of dyslipidaemia. Drugs (54):615-33.

23. Duez H, Lefebvre B, Poulain $P$, et al. (2005). Regulation of human apoA-I by gemfibrozil and fenofibrate through selective peroxisome proliferator-activated receptor alpha modulation. Arterioscler Thromb Vasc Biol (25): 585-91.

24. Rong R, Ramachandran S, Penumetcha $M$, Khan N, Parthasarathy S. (2002). Dietary oxidized fatty acids may enhance intestinal apolipoprotein A-I production. J Lipid Res (43):557-64

25. Giller T, Hennes U, Kempen HJ. (1995). Regulation of human apolipoprotein A-I expression in Caco-2 and HepG2 cells by alltrans and 9-cis retinoic acids. J Lipid Res (36):1021-8. 
26. Claudel T, Sturm E, Duez H, et al. (2002). Bile acid-activated nuclear receptor FXR suppresses apolipoprotein A-I transcription via a negative FXR response element. J Clin Invest (109): 961-71.

27. Vu-Dac N, Schoonjans K, Laine B, Fruchart JC, Auwerx J, Staels B. (1994). Negative regulation of the human apolipoprotein A-I promoter by fibrates can be attenuated by the interaction of the peroxisome proliferatoractivated receptor with its response element. J Biol Chem (269):31012-8.

28. Trivedi NR, Cong Z, Nelson AM, et al. (2006). Peroxisome proliferator-activated receptors increase human sebum production. J Invest Dermatol (126):2002-9.

29. Hsu MH, Savas U, Griffin KJ, Johnson EF. (2001). Identification of peroxisome proliferator-responsive human genes by elevated expression of the peroxisome proliferator-activated receptor alpha in HepG2 cells. J Biol Chem (276):27950-8.

30. Tirmenstein MA, $\mathrm{Hu} \mathrm{CX,} \mathrm{Gales} \mathrm{TL,} \mathrm{et} \mathrm{al.}$ (2002). Effects of troglitazone on HepG2 viability and mitochondrial function. Toxicol Sci (69):131-8.

31. Cui J, Huang L, Zhao A, et al. (2003). Guggulsterone is a farnesoid $X$ receptor antagonist in coactivator association assays but acts to enhance transcription of bile salt export pump. J Biol Chem (278):10214-20.

32. Gilde AJ, van der Lee KA, Willemsen $\mathrm{PH}$, et al. (2003). Peroxisome proliferator-activated receptor (PPAR) alpha and PPARbeta/delta, but not PPARgamma, modulate the expression of genes involved in cardiac lipid metabolism.[see comment]. Circulation Research (92):518-24.

33. Graham DJ, Green L, Senior JR, Nourjah P. (2003). Troglitazone-induced liver failure: a case study. Am J Med (114):299-306.

34. Urizar NL, Liverman AB, Dodds DT, et al. (2002). A natural product that lowers cholesterol as an antagonist ligand for FXR. Science (296): 1703-6.

35. Brobst DE, Ding $X$, Creech $\mathrm{KL}$, Goodwin $B$, Kelley B, Staudinger JL. (2004). Guggulsterone activates multiple nuclear receptors and induces CYP3A gene expression through the pregnane $X$ receptor. J Pharmacol Exp Ther (310):528-35.

36. Burris TP, Montrose C, Houck KA, et al. (2005). The hypolipidemic natural product guggulsterone is a promiscuous steroid receptor ligand. Mol Pharmacol (67):948-54.

37. Zannis VI, Kan HY, Kritis A, Zanni EE, Kardassis D. (2001). Transcriptional regulatory mechanisms of the human apolipoprotein genes in vitro and in vivo. Curr Opin Lipidol (12):181-207.

38. Kockx M, Princen HM, Kooistra T. (1998). Fibrate-modulated expression of fibrinogen, plasminogen activator inhibitor-1 and apolipoprotein A-I in cultured cynomolgus monkey hepatocytes -- role of the peroxisome proliferator-activated receptoralpha. Thromb Haemost (80):942-8.
39. Keech A, Simes RJ, Barter P, et al. (2005). Effects of long-term fenofibrate therapy on cardiovascular events in 9795 people with type 2 diabetes mellitus (the FIELD study): randomised controlled trial. Lancet (366):1849-61.

40. Bilz S, Wagner S, Schmitz M, Bedynek A, Keller U, Demant T. (2004). Effects of atorvastatin versus fenofibrate on apoB-100 and apoA-I kinetics in mixed hyperlipidemia. J Lipid Res (45):174-85.

41. Ikewaki K, Tohyama J, Nakata Y, Wakikawa T, Kido T, Mochizuki S. (2004). Fenofibrate effectively reduces remnants, and small dense LDL, and increases $\mathrm{HDL}$ particle number in hypertriglyceridemic men - a nuclear magnetic resonance study. J Atheroscler Thromb (11):278-85.

42. Arakawa R, Tamehiro N, Nishimaki-Mogami T, Ueda K, Yokoyama S. (2005). Fenofibric acid, an active form of fenofibrate, increases apolipoprotein A-I-mediated high-density lipoprotein biogenesis by enhancing transcription of ATP-binding cassette transporter $\mathrm{A} 1$ gene in a liver $\mathrm{X}$ receptordependent manner. Arterioscler Thromb Vasc Biol (25):1193-7.

43. van der Hoogt CC, de Haan W, Westerterp M, et al. (2007). Fenofibrate increases HDLcholesterol by reducing cholesteryl ester transfer protein expression. J Lipid Res (48): 1763-71.

44. Goldberg RB. (2006). Impact of thiazolidenediones on serum lipoprotein levels. Curr Atheroscler Rep (8):397-404.

45. Thomas C, Landrier JF, Gaillard D, et al. (2006). Cholesterol dependent downregulation of mouse and human apical sodium dependent bile acid transporter (ASBT) gene expression: molecular mechanism and physiological consequences. Gut (55):1321-31.

46. Ulbricht C, Basch E, Szapary P, et al. (2005). Guggul for hyperlipidemia: a review by the Natural Standard Research Collaboration. Complement Ther Med (13):279-90.

47. Szapary PO, Wolfe ML, Bloedon LT, et al. (2003). Guggulipid for the treatment of hypercholesterolemia: a randomized controlled trial.[see comment]. JAMA (290): $765-72$ 


\section{Chapter 4}

\section{Differential effects of individual fatty acids on de novo apoA-I production by differentiated CaCo-2 cells}

Stefan P.J. Dullens ${ }^{1}$, Herman E. Popeijus ${ }^{1,2}$, Ronald P. Mensink ${ }^{1}$, Jogchum Plat ${ }^{1}$

\footnotetext{
${ }^{1}$ Department of Human Biology, Nutrition and Toxicology

Research Institute Maastricht, Maastricht University, Maastricht, The Netherlands

${ }^{2}$ Nutrigenomics Consortium, Top Institute Food and Nutrition, Wageningen, The Netherlands
} 


\section{Abstract}

Metabolic syndrome subjects have low concentrations of high-density lipoprotein cholesterol (HDL-C) and of its main protein constituent apolipoprotein A-I (apoA-I), which may contribute to their increased risk for cardiovascular disease. In humans, saturated fatty acids (SAFAs) increase, whereas polyunsaturated fatty acids (PUFAs) lower serum apoA-I concentrations, when compared to an iso-energetic amount of the cis monounsaturated fatty acid (MUFA) oleic acid (OA). Whether these effects originate from differences in small intestinal de novo apoA-I production is unknown. To examine the effects of individual fatty acids, which vary in degree of saturation, chain-length, or cis/trans configuration, on de novo apoA-I production in differentiated CaCo-2 cells. As compared to $160 \mu \mathrm{M} \mathrm{OA}$, $2 \mu \mathrm{M}$ lauric acid plus $158 \mu \mathrm{M}$ OA significantly elevated apoA-I concentrations (+15\%; $P=0.05)$, whereas a similar isomolar exchange of caprylic acid, myristic acid, palmitic acid, or stearic acid did not. Also no significant effects on apoA-I concentrations were observed for the n-3 PUFA $\alpha$-linolenic acid and the n-6 PUFA linoleic acid, as well as for the trans-MUFA C18:1(n-9) and the trans-PUFAs of C18:2(n-6). Furthermore, $2 \mu \mathrm{M}$ lauric acid plus $158 \mu \mathrm{M} O A$ (fold change of $+2.8 ; \mathrm{P}=0.002$ ), but also $100 \mathrm{nM} \mathrm{GW7647}(+2.3 ; \mathrm{P}=0.008)$ or an isomolar exchange of stearic acid $(+2.2 ; \mathrm{P}=0.003)$ and linoleic acid $(+2.5 ; P=0.003)$, elevated PPAR transactivation as compared to OA only in PPRE-luc differentiated CaCo-2 cells. ApoA-I elevating effects of the SAFA lauric acid are - at least partly - related to an increased de novo apoA-I production in enterocytes. Mechanistically, PPAR activation might be involved, but is apparently not the only necessary transactivation signal. The PUFAs linoleic acid and $\alpha$-linolenic acid as well as trans fatty acids did not change de novo apoA-I production of differentiated CaCo-2 cells. 


\section{Introduction}

The metabolic syndrome, an increasing health threat in western societies, is positively associated with an increased risk for coronary heart disease (CHD) ${ }^{1}$. For this, a cluster of metabolic abnormalities is responsible ${ }^{2}$. Among others, a typical and important characteristic is dyslipidemia, in which serum triacylglycerol (TAG) concentrations are elevated, whereas those of highdensity lipoprotein cholesterol (HDL-C) are reduced 2. Nowadays, it is therefore accepted that future interventions to reduce the burden of CHD should not only be aimed at reducing atherogenic low-density lipoprotein cholesterol (LDL-C) concentrations, but also at elevating those of the antiatherogenic HDL-C ${ }^{3}$.

There is indeed a wealth of evidence from both in vitro and in vivo studies that increased serum HDL-C concentrations, or its main protein constituent apolipoprotein A-I (apoA-I), lowers CHD risk ${ }^{4-6}$. Besides intervening with pharmacological agents, interventions with dietary compounds should be considered. For example, certain fatty acids have more favourable effects on serum apoA-I concentrations than other fatty acids. Convincing data in this respect comes from a meta-analysis, which included carefully selected placebo-controlled intervention studies ${ }^{7}$. When effects of various fatty acids were compared to those of an iso-energetic amount of the cis monounsaturated fatty acid (MUFA) oleic acid (C18:1(n-9)), it was found that a mixture of saturated fatty acids (SAFAs) increased, while polyunsaturated fatty acids (PUFAs) lowered serum apoA-I concentrations. However, differences in effects existed between the four most common dietary SAFAs: lauric acid (C12:0), myristic acid (C14:0), and palmitic acid (C16:0), but not stearic acid (C18:0), were associated with higher serum apoA-I concentrations (estimated regression coefficients in $\mathrm{mg} / \mathrm{L}$ per percent of energy of $8.6,5.2,2.3$, and -6.8 , respectively) as compared to an isoenergetic amount of oleic acid. Furthermore, cis PUFAs (mainly linoleic acid and some $\alpha$-linolenic acid) as well as trans MUFAs both had negative effects (estimated regression coefficients of $-3.0 \mathrm{mg} / \mathrm{L}$ ) on serum apoA-I concentrations, when iso-energetically exchanged for oleic acid. The mechanisms underlying these effects are however unclear.

Serum HDL-C concentrations can be elevated by affecting different steps in HDL metabolism, such as for example inhibiting CETP activity ${ }^{8}$, tissue-specific activation of LXR to elevate ABCA1 transporter expression ${ }^{9}$, or increasing de novo apoA-I production in the liver and/or in the small intestine 10. Actually, there are strong indications that the small intestine contributes substantially to serum apoA-I levels in humans ${ }^{11}$ and in wild type mice ${ }^{12}$. In this respect, we have earlier demonstrated that an enterocyte cell model (fully differentiated $\mathrm{CaCo}-2$ cells) was highly responsive to pharmacological 
and nutritional agents concerning de novo apoA-I production (see chapter 3). We therefore decided to evaluate systematically the effects of isomolar exchanges of individual fatty acids, varying in degree of saturation, chainlength, or cis/trans configuration on de novo apoA-I production by enterocytes. In addition, since PPAR $\alpha$ is a well-defined player in apoA-I transcription and fatty acids are natural PPAR ligands, we also examined a possible role for PPAR $\alpha$ transactivation in the process of fatty acid induced intestinal apoA-I production by enterocytes. By this approach, we tried to elucidate whether effects of individual fatty acids on serum apoA-I concentrations could be explained by a (PPAR mediated) change in de novo apoA-I production in the intestine. 


\section{Material and methods}

\section{Reagents}

The SAFAs caprylic acid, lauric acid, myristic acid, palmitic acid, and stearic acid as well as the MUFAs oleic acid, elaidic acid, and vaccenic acid, and the PUFAs linoleic acid, and $\alpha$-linolenic acid, were obtained from Sigma-Aldrich (St. Louis, MO, USA). Cis-9, trans-11 (c9,t11) conjugated linoleic acid (CLA), and trans-11, cis-12 (t10, c12) CLA were purchased from Cayman Chemical Company (Ann Arbor, MI, USA).

\section{Cell cultures}

CaCo-2 cells were purchased from European Collection of Cell Cultures (Poole, UK) and cultured in growth medium DMEM at $37{ }^{\circ} \mathrm{C}$ in a humidified atmosphere of $5 \% \mathrm{CO}_{2} / 95 \% \mathrm{O}_{2}(\mathrm{v} / \mathrm{v})$. Medium was supplemented with $10 \%$ (v/v) FBS, $1 \%(\mathrm{v} / \mathrm{v})$ non essential amino acids (NEAA), 1\% ( $/ \mathrm{v}$ ) sodium pyruvate, and $1 \%(\mathrm{v} / \mathrm{v})$ penicillin/streptomycin. All supplements were obtained from Invitrogen Life Technologies (Carlsbad, CA, USA). For each experimental condition, $\mathrm{CaCo}-2$ cells were seeded in 6-well-tissue-culture plates (Corning, Aston, MA, USA) at a density of $5 \times 10^{5}$ cells per well. Every 2 or 3 days cell culture medium was renewed. After 21 days, the confluent and fully differentiated cell monolayers were exposed to a total amount of $160 \mu \mathrm{M}$ or $250 \mu \mathrm{M}$ fatty acids for an incubation period of 3 or 48 hours. A total amount of $160 \mu \mathrm{M}$ oleic acid in culture medium is approximately 4 times higher than normally available to differentiated CaCo-2 cells, while the normal physiological concentration of oleic acid in mixed micelles obtained from the human intestinal lumen can even reach concentrations of $500 \mu M^{13}$. Several concentrations of lauric acid or linoleic acid were tested to determine the optimal fatty acid concentration to increase apoA-I concentrations in culture medium. For this, lauric acid or linoleic acid was added to the enterocytes at concentrations of $2,4,8,32$, or $128 \mu \mathrm{M}$ in an isomolar manner by exchanging lauric acid or linoleic acid for oleic acid. The total concentration of added fatty acids was $160 \mu \mathrm{M}$ and the condition with $160 \mu \mathrm{M}$ oleic acid served as control. Before adding the fatty acids to the cell culture medium, they were pre-incubated with fatty acid-free BSA (Sigma-Aldrich, St. Louis, MO, USA) for $30 \mathrm{~min}$ at $37^{\circ} \mathrm{C}$. After the experimental period, cell lysate and cell culture medium were collected for further analysis. All cell experiments were performed at least in duplo.

\section{ApoA-I ELISA}

Human apoA-I protein concentrations were analyzed in culture medium with an apoA-I sandwich ELISA (Mabtech, Nacka Strand, Sweden). The apoA-I calibration curve was obtained with purified human apoA-I from Sigma (St. 
Louis, MO, USA). The detection limit of this sandwich ELISA was $1.3 \mathrm{ng} / \mathrm{mL}$, and the variation coefficient was less than $5 \%$. Samples from an experiment were always analyzed in duplo on one ELISA plate.

\section{PPAR transactivation assay}

To evaluate whether the fatty acids used were able to transactivate the PPAR system, CaCo-2 cells were transiently transfected using FuGENE 6 reagent (Roche, Basel, Switzerland) with $0.2 \mu \mathrm{g}$ of a luciferase reporter pGL3 vector (PPRE-luc) that contained PPAR responsive elements (PPREs) enabling measurement of PPAR transcriptional activity, as described by Gilde and coworkers ${ }^{14}$. One day prior to the transfection, CaCo- 2 cells were plated in 24-well plates at a density of $2 \times 10^{5}$ cells per well and maintained further as described above. One hour before the transfection, standard culture medium was replaced by medium without serum and antibiotics. Six hours after transfection, culture medium was renewed and the transfected CaCo-2 cells were maintained for 21 days to differentiate into enterocytes. Thereafter, cells were incubated with different isomolar fatty acid combinations in line with the experiments described above, or with the synthetic PPAR $\alpha$ agonist GW7647 (100nM; Sigma-Aldrich, St. Louis, MO, USA). After 48 hours of incubation, cells were washed once in ice cold PBS following lysis with reporter lysis buffer (Promega, Madison, WI, USA). The cell lysate was then used to measure luciferase expression with the luciferase reporter assay (Promega, Madison, WI, USA).

\section{Real-time quantitative PCR}

RNA isolation and synthesis of cDNA was performed as described before [ref model]. After cDNA was obtained, RT quantitative PCR reactions were performed using Taqman gene expression assays (Applied Biosystems, Foster City, CA, USA) for the genes of interest. Taqman gene expression assays (Taqman MGB probe (FAM ${ }^{\mathrm{TM}}$ dye-labeled)) of apoA-I (Hs00163641_m1), PPAR $\alpha$ (Hs00231882_m1), and housekeeping gene cyclophillin A (Hs99999904_m1) were used. Elevating effects at gene expression level were indicated at a cut-off comparative threshold cycle-value of 1.2 or higher, whereas decreasing effects were denoted at a cut-off comparative threshold cycle-value of 0.8 or lower. mRNA expression was expressed as comparative threshold cycle-values as described by others ${ }^{15}$.

\section{Statistical analysis}

All values are shown as means \pm SEM. Differences between the various conditions were tested by the non-parametric Mann-Whitney $U$ test. 


\section{Results}

Dose-response relationship of fatty acids on de novo apoA-I production

Lauric acid (C12:0) and linoleic acid (C18:2(n-6)) were dose-dependently added to differentiated CaCo- 2 cells by exchanging $\mathrm{C} 12: 0$ or $\mathrm{C} 18: 2(n-6)$ for an isomolar amount of oleic acid. As shown in figure 1, $2 \mu \mathrm{M}$ lauric acid combined with $158 \mu \mathrm{M}$ oleic acid resulted in a strong apoA-I elevating effect ( $+50 \%$ versus oleic acid). Moreover, a further isomolar exchange of lauric acid for oleic acid (i.e. $4 \mu \mathrm{M}, 8 \mu \mathrm{M}, 32 \mu \mathrm{M}$, and $128 \mu \mathrm{M}$ ) did not result in a further increase. In fact, at a concentration of $128 \mu \mathrm{M}$ lauric acid apoA-I concentrations in culture medium were even comparable to those of $160 \mu \mathrm{M}$ oleic acid only. In line with lauric acid, the optimal elevating effect of linoleic acid on apoA-I concentrations in culture medium was found at a concentration of $2 \mu \mathrm{M}$. This effect ( $+8 \%$ versus oleic acid) was less than that of lauric acid at the same isomolar concentration of $2 \mu \mathrm{M}$. At higher concentrations of linoleic acid, apoA-I concentrations in culture medium were decreased as compared with oleic acid only. Furthermore, compared to 250 $\mu \mathrm{M}$ oleic acid, $250 \mu \mathrm{M}$ of lauric acid ( $-1 \%$ versus oleic acid) as well as linoleic acid $(-11 \%$ versus oleic acid) did not result in significant changes in apoA-I concentrations.

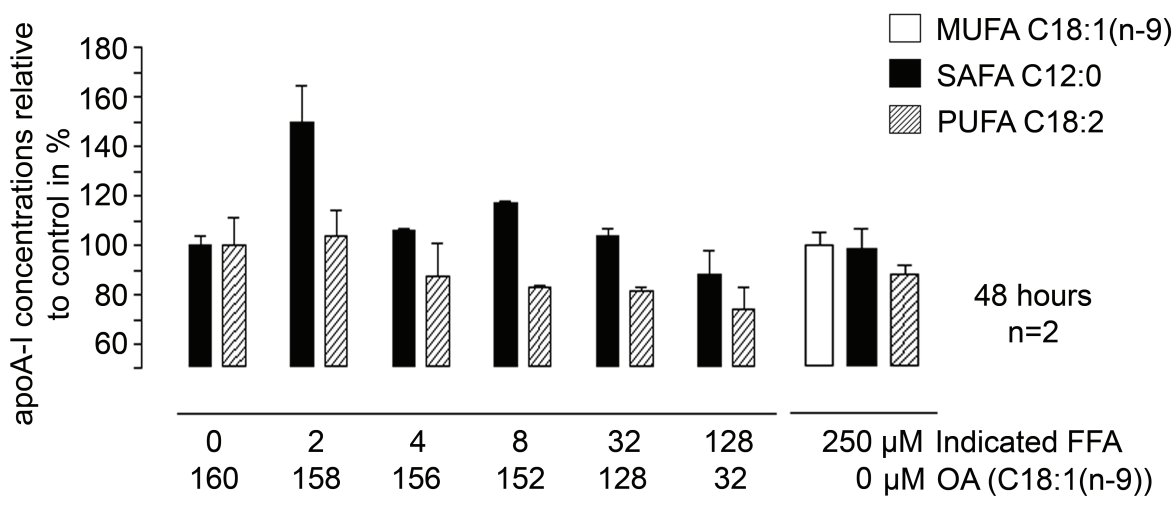

Figure 1. Dose-dependent effects of isomolar exchanged lauric acid or linoleic acid on apoA-I concentrations relative to oleic acid by differentiated $\mathrm{CaCo-2}$ cells after 48 hours incubation.

Values are presented as mean \pm SEM, and relatively compared to $160 \mu \mathrm{M}$ or $250 \mu \mathrm{M}$ oleic acid.

$\mathrm{N}=2$ of each individual condition. 


\section{Differential effects of individual fatty acids on de novo apoA-I production}

Since an isomolar exchange of $2 \mu \mathrm{M}$ of lauric acid or linoleic acid combined with $158 \mu \mathrm{M}$ oleic acid resulted in the highest elevation of apoA-I concentrations in culture medium, this condition was used in further experiments.

The next step was to evaluate the effects of fatty acid chain-length of SAFAs. For this, the following SAFAs were examined: caprylic acid (C8:0), lauric acid (C12:0), myristic acid (C14:0), palmitic acid (C16:0), or stearic acid (C18:0). Also the degree of fatty acid saturation of eighteen carbon fatty acids was evaluated. In this respect, stearic acid (C18:0), oleic acid $(\mathrm{C} 18: 1(n-9))$, linoleic acid $(C 18: 2(n-6))$, and $\alpha$-linolenic acid (C18:3(n-3)) were evaluated. In addition, effects of cis/trans configuration of $\mathrm{C} 18$ fatty acids were analyzed. Therefore, effects of C18:1 fatty acids - oleic acid (C18:1), elaidic acid (C18:1(n-9)trans), and vaccenic acid (C18:1(n11)trans) -, and of C18:2 fatty acids - linoleic acid (C18:2(n-6)), c9, t11 CLA, and $t 10, c 12$ CLA - were examined.

As shown in figure 2, panel $A$, the SAFA lauric acid ( $+15 \%$ versus oleic acid) significantly elevated apoA-I concentrations in culture medium. Moreover, although apoA-I medium concentrations were higher after addition of the SAFAs caprylic acid ( $+12 \%$ versus oleic acid) and myristic acid $(+17 \%$ versus oleic acid), these elevations did not reach significance. In addition, no significant effects were found on apoA-I concentrations in culture medium after addition of palmitic acid ( $+7 \%$ versus oleic acid) and stearic acid $(+1 \%$ versus oleic acid).

With respect to the degree of saturation, both the $n-3$ PUFA $\alpha$-linolenic acid $(-10 \%$ versus oleic acid) as well as the $n-6$ PUFA linoleic acid $(+9.9 \%$ versus oleic acid) had no significant effects on apoA-I concentrations in culture medium as compared to oleic acid only.

Regarding cis/trans configurations (figure 2: panel C), an isomolar exchange of elaidic acid ( $+9.7 \%$ versus oleic acid) or vaccenic acid $(+3.5 \%$ versus oleic acid) did not significantly change apoA-I concentrations in culture medium. Also, an isomolar exchange of c9, t11 CLA (+3.2\% versus oleic acid), or $t 10, c 12$ CLA $(-3.3 \%$ versus oleic acid) had no significant effects on apoA-I medium concentrations (figure 2: panel D) 

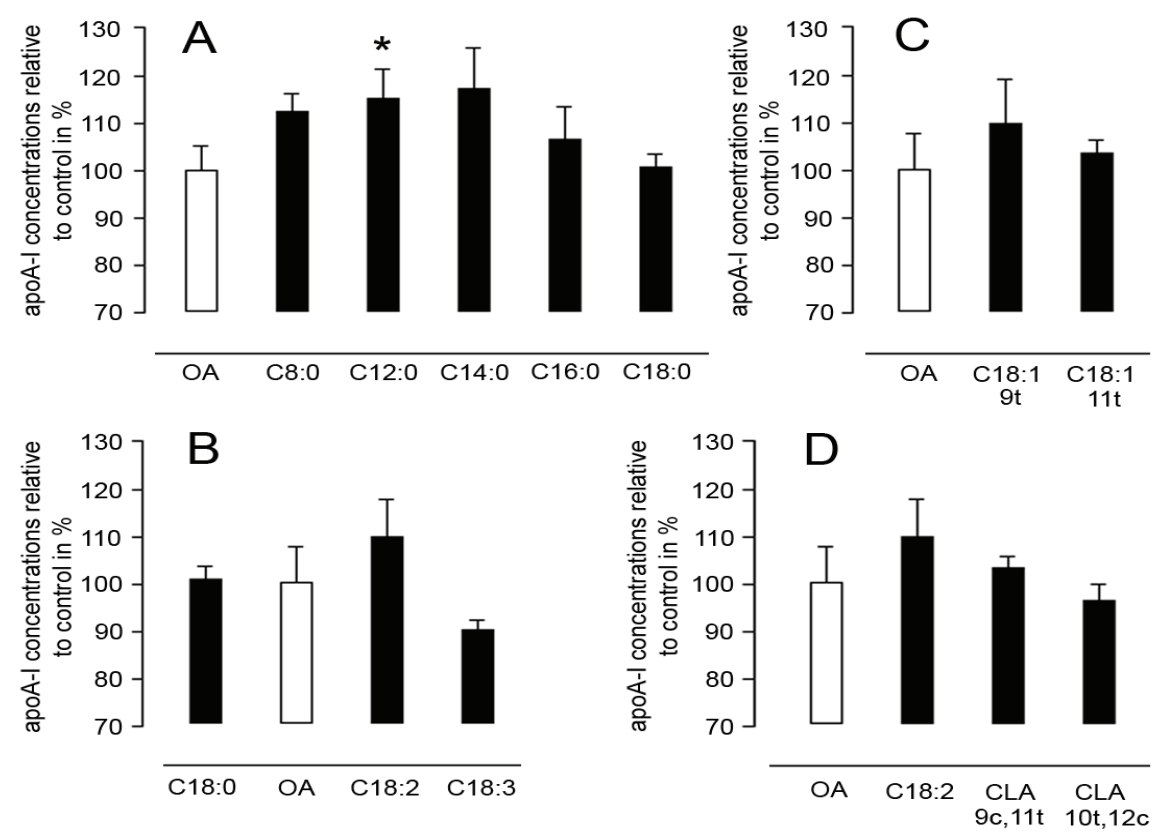

Figure 2. Effects of individual fatty acids ( $2 \mu \mathrm{M}$ of the fatty acid plus $158 \mu \mathrm{M}$ oleic acid) on apoA-I concentrations compared to oleic acid in differentiated CaCo-2 cells after 48 hours incubation, are shown in panels A-D.

Panel A: FFAs differ in chain-length. Panel B: C18 FFAs differ in the degree of saturation. Panel C: C18:1 FFAs differ in trans/cis configuration. Panel D: C18:2 FFAs differ in trans/cis configuration. Values are presented as mean $\pm \mathrm{SEM}$, and relatively compared to $160 \mu \mathrm{M}$ oleic acid. $\mathrm{N}=3$ of each individual condition. * $\mathrm{P}<0.05$ as compared to OA.

\section{Differential effects of individual fatty acids on apoA-I gene expression}

As compared to oleic acid, after 3 hours of incubation, apoA-I mRNA expression levels were increased by lauric acid (comparative threshold cycle value of $1.36 ; \mathrm{P}<0.05$ ) and by palmitic acid (comparative threshold cycle value of $1.18 ; \mathrm{P}<0.05)$, as shown in table 1 . In contrast, stearic acid (comparative threshold cycle value of $0.87 ; \mathrm{P}<0.05$ ), vaccenic acid (comparative threshold cycle value of $0.75 ; \mathrm{P}<0.05)$, linoleic acid (comparative threshold cycle value of $0.80 ; \mathrm{P}<0.05), c 9, t 11$ CLA (comparative threshold cycle value of $0.70 ; \mathrm{P}<0.05), t 10$, c12 CLA (comparative threshold cycle value of $0.62 ; \mathrm{P}<0.05$ ), and $\alpha$-linolenic acid (comparative threshold cycle value of $0.64 ; \mathrm{P}<0.05$ ) significantly lowered apoA-I mRNA expression as compared to oleic acid supplementation alone. The elevated apoA-I mRNA levels after lauric acid supplementation were in 
line with the observed elevating effect on apoA-I protein concentrations in culture medium. Although a close relationship between apoA-I protein and mRNA gene expression levels was not consistently present, apoA-I protein concentrations in the culture medium of individually fatty acids were strongly correlated with their comparative threshold cycle-values of apoA-I gene expression (Pearson correlation of $0.67 ; \mathrm{P}<0.05$ ).

Table 1. Quantification of the effects of individual FFAs on apoA-I gene expression levels compared to oleic acid.

\begin{tabular}{ll}
\hline FFA & apoA-I \\
\hline C18:1(n-9) & comparative threshold cycle value \\
C8:0 & $1.00 \pm 0.03$ \\
C12:0 & $1.01 \pm 0.05$ \\
C14:0 & $0.97 \pm 0.09 *$ \\
C16:0 & $1.18 \pm 0.02 *$ \\
C18:0 & $0.87 \pm 0.03 *$ \\
& \\
C18:1(n-9)t & $0.90 \pm 0.07$ \\
C18:1(n-11)t & $0.75 \pm 0.02 *$ \\
& \\
C18:2(n-6) & $0.80 \pm 0.03 *$ \\
CLA 9c, 11t & $0.70 \pm 0.03 *$ \\
CLA 10t, 11c & $0.63 \pm 0.06 *$ \\
& \\
C18:3(n-3) & $0.64 \pm 0.02 *$ \\
\hline
\end{tabular}

Values were normalized to cyclophillin $A$, and are expressed as mean comparative threshold cycle values \pm SEM, in which effects of oleic acid were set at 1 .

$\mathrm{N}=3$ of each individual fatty acid. $* \mathrm{P}<0.05$ as compared to oleic acid.

\section{Differential effects of individual fatty acids on PPAR activation in PPRE-luc reporter differentiated CaCo- 2 cells}

Since $\mathrm{CaCo}-2$ cells had to differentiate into small intestinal cells for a period of 21 days and transfection was done before differentiation, we checked first whether the PPRE-luc reporter was still present in the differentiated CaCo-2 cells. It appeared that the reporter functioned properly 21 days after transfection, as it responded adequately to the PPAR $\alpha$ agonist GW7647. The transfected and differentiated $\mathrm{CaCo}-2$ cells were then exposed to the fatty acids lauric acid, linoleic acid, and $\alpha$-linolenic acid, and the ability to increase 
luciferase activity was compared to oleic acid only. As shown in table 2, an isomolar exchange of $2 \mu \mathrm{M}$ lauric acid for oleic acid strongly elevated PPAR activation (fold change of 2.8 over oleic acid only; $\mathrm{P}=0.002$ ) in PPRE-luc differentiated $\mathrm{CaCo}-2$ cells. In addition, a similar isomolar exchange of stearic acid (fold change of 2.2; $\mathrm{P}=0.003$ ) as well as linoleic acid (fold change of 2.5; $\mathrm{P}=0.003$ ) and $100 \mathrm{nM}$ GW7647 (fold change of 2.3; $\mathrm{P}=0.008$ ) also elevated PPAR transactivation as compared to oleic acid.

Table 2. PPAR activation by individual FFAs relative to oleic acid.

\begin{tabular}{ll}
\hline Component & Luc expression compared to C18:1(n-9) in fold change \\
\hline C18:1(n-9) & $1.00 \pm 0.11$ \\
C12:0 & $2.76 \pm 0.23 *$ \\
C18:0 & $2.15 \pm 0.18 *$ \\
C18:2(n-6) & $2.54 \pm 0.09 *$ \\
GW7647 & $2.32 \pm 0.10 *$ \\
\hline Values are presented as mean fold changes \pm SEM. N $=4$ of each individual \\
component. Experiment performed in duplo in transient transfected and differentiated \\
CaCo-2 cells. * P $<0.01$ as compared to oleic acid.
\end{tabular}




\section{Discussion}

Elevating serum HDL concentrations, ultimately leading to an enhanced cholesterol efflux from peripheral tissues to the liver, is a challenging target to lower CHD risk. In this respect, increasing de novo apoA-I production is an attractive target ${ }^{16}$. Nutritional intervention studies have now shown that the dietary fatty acid composition affects serum apoA-I and HDL-C concentrations 7. Particularly the SAFA lauric acid was associated with an increase in serum apoA-I concentrations. The mechanism underlying these in vivo observed effects is unknown, but an increased de novo apoA-I production may be involved ${ }^{17}$. In the present in vitro studies, we have demonstrated that an isomolar exchange of $2 \mu \mathrm{M}$ lauric acid for oleic acid (in total $160 \mu \mathrm{M}$ FFA) did not only increase apoA-I mRNA expression, but also apoA-I protein production by enterocytes. Interestingly, the effect levelled off at higher concentrations and treatment with $250 \mu \mathrm{M}$ lauric acid had no effect on de novo apoA-I production in differentiated CaCo-2 cells as compared to $250 \mu \mathrm{M}$ oleic acid. Whether this means that also in vivo, the effect of lauric acid on intestinal apoA-I production is not linear with intake has never been investigated systematically. Interestingly, in the already mentioned metaanalysis ${ }^{7}$, only one study was included that was specifically designed to examine the effects of lauric acid on the serum lipoprotein profile ${ }^{18}$. Trilaureate intake was 16.9 en\%. That study, however, was not included in the final model for HDL-C and apoA-I, because results were considered as outliers for these two parameters. Whether this also suggests, that effects of extreme high intakes of lauric acid on HDL-C and apoA-I are not linear with intake, warrants further investigation. On the other hand, this suggestion is not supported by other studies, including two studies that were not included ${ }^{18-20}$ in the meta-analysis, even when lauric acid intake was as high as 11 en $\%{ }^{7}$.

As previously demonstrated by others ${ }^{21}$, fatty acids and their derivatives are natural PPAR $\alpha$ agonists, thereby affecting the transcription of PPAR $\alpha$ target genes, such as apoA-I. To confirm whether lauric acid is an efficient PPAR agonist, a PPRE-luc reporter was transfected into CaCo-2 cells. Indeed, the PPAR transactivation was strongly activated by lauric acid as compared to oleic acid. Moreover, stearic acid, linoleic acid as well as GW7647 elevated PPAR transactivation as compared to oleic acid. These effects however were not always translated into elevated apoA-I mRNA and/or protein levels. Based on the current data, it is tempting to suggest that PPAR $\alpha$ activation is involved, but that PPAR $\alpha$ activation alone is not enough to induce de novo apoA-I production. Therefore, other transcription factors and/or PPAR $\alpha$ cofactors should be considered in fatty acid mediated small intestinal apoA-I production, especially since the regulation of cofactors 
was essential for full or partial PPAR $\alpha$ activation ${ }^{22}$. We therefore speculate that - compared to other fatty acids - lauric acid not only activates PPAR $\alpha$, but also one or more essential co-factors involved in apoA-I production. Besides PPAR $\alpha$, fatty acids also activate transcription factor specific protein 1 (Sp1). Sp1 induces apoA-I gene expression by binding to an insulinresponsive core element (IRCE) in the apoA-I enhancer region ${ }^{23}$. However, in HepG2 cells, Sp1 activity was reduced when $250 \mu \mathrm{M}$ of myristic acid, palmitic acid, or stearic acid were used as compared to the control condition without added fatty acids. Consequently, $250 \mu \mathrm{M}$ of the fatty acids lowered apoA-I promoter activity ${ }^{24}$. Since we also observed that $250 \mu \mathrm{M}$ lauric acid resulted in lower apoA-I concentrations in culture medium of differentiated CaCo-2 cells as compared to $2 \mu \mathrm{M}$ of the fatty acids (figure $\mathbf{1}$ ), the effects of fatty acids on Sp1 activity may be different at lower concentrations.

Earlier studies have reported beneficial cardiovascular health effects for $c 9, t 11 \mathrm{CLA}{ }^{25}$. However, more recent studies showed that at current intakes effects of $c 9, t 11$ CLA and $t 10, c 12$ CLA on the serum lipoprotein profile are negligible ${ }^{26}$. If anything, the $t 10, c 12$ CLA isomer may even elevate serum TAG concentrations at high intakes ${ }^{27}$. Moreover, CLAs had no or even a slightly lowering effect on serum HDL-C levels ${ }^{28,29}$. This is in line with the results of our study, as neither one of the two CLA isomers significantly changed de novo apoA-I production in differentiated $\mathrm{CaCo}-2$ cells.

Elaidic acid and vaccenic acid, two trans MUFAs, did also not affect apoA-I protein production. At the transcriptional level, vaccenic acid as well as the CLA isomers even reduced apoA-I expression. Moreover, Lichtenstein and co-workers have shown that the reduction in serum apoA-I concentrations, associated with increased trans fatty acid intake, could be explained by an enhanced catabolism of HDL particles ${ }^{30}$. It should however be realized that the effect of trans fatty acids on apoA-I fractional catabolic rate was compared to that of SAFAs, and not to oleic acid as in our in vitro model. Moreover, others explained HDL-C decreasing effects by trans fatty acid elaidic acid as compared to palmitic acid on both an increased HDL clearance and an increased CETP activity as demonstrated in cebus monkeys ${ }^{31}$. Conclusively, this shows that in vivo decreases in serum apoA-I and HDL$C$ concentrations is probably not only related to a reduced apoA-I production, but also to an increased HDL catabolism and CETP activity.

With respect to the degree of saturation at a constant length of 18 carbon atoms, both the n-6 PUFA linoleic acid C18:2(n-6) as well as the $n-3$ PUFA $\alpha$-linolenic acid $(\mathrm{C} 18: 3(n-3))$ had no significant effect on apoA-I concentrations in culture medium as compared to oleic acid (C18:1(n-9)). Therefore, it is possible that the in vivo observed reductions in serum apoA-I by PUFAs as compared to MUFAs and SAFAs are not related to de novo apoAI production. Indeed, it has been found in cynomolgus monkeys that PUFAs 
enhanced apoA-I catabolism as compared to SAFAs ${ }^{32}$. This implies that besides apoA-I synthesis, apoA-I catabolic rate can also be an important factor in HDL metabolism and CHD risk. However, it should be mentioned that the atherogenic effect due to an elevated apoA-I catabolic rate might be overruled by elevating serum apoA-I concentrations ${ }^{33}$.

In summary, our results in differentiated $\mathrm{CaCo}-2$ cells suggest that the apoA-I elevating effects of dietary SAFA lauric acid is - at least partly related to an increased de novo apoA-I production in the small intestine. Mechanistically, PPAR activation might be involved, but is apparently not the only necessary transactivation signal. The PUFAs $\alpha$-linolenic acid and linoleic acid as well as trans fatty acids did not change de novo apoA-I production in our experimental model. Whether this suggest that these fatty acids more act on HDL catabolism needs further study. 


\section{References}

1. Lakka HM, Laaksonen DE, Lakka TA, et al. (2002). The metabolic syndrome and total and cardiovascular disease mortality in middle-aged men. Jama (288):2709-16.

2. Haffner SM. (2006). Relationship of metabolic risk factors and development of cardiovascular disease and diabetes. Obesity (Silver Spring) (14 Suppl 3):121S-127S.

3. Brewer HB, Jr. (2004). Focus on high-density lipoproteins in reducing cardiovascular risk. Am Heart J (148):S14-8.

4. Benoit $\mathrm{P}$, Emmanuel $\mathrm{F}$, Caillaud JM, et al. (1999). Somatic gene transfer of human ApoA-I inhibits atherosclerosis progression in mouse models. Circulation (99):105-10.

5. Rubin EM, Krauss RM, Spangler EA, Verstuyft JG, Clift SM. (1991). Inhibition of early atherogenesis in transgenic mice by human apolipoprotein AI. Nature (353):265-7.

6. Luc G, Bard JM, Ferrieres J, et al. (2002). Value of HDL cholesterol, apolipoprotein A-I, lipoprotein A-I, and lipoprotein A-I/A-II in prediction of coronary heart disease: the PRIME Study. Prospective Epidemiological Study of Myocardial Infarction. Arterioscler Thromb Vasc Biol (22):1155-61.

7. Mensink RP, Zock PL, Kester AD, Katan MB. (2003). Effects of dietary fatty acids and carbohydrates on the ratio of serum total to HDL cholesterol and on serum lipids and apolipoproteins: a meta-analysis of 60 controlled trials. Am J Clin Nutr (77):114655.

8. Inazu A, Brown ML, Hesler CB, et al. (1990). Increased high-density lipoprotein levels caused by a common cholesteryl-ester transfer protein gene mutation. N Engl J Med (323):1234-8.

9. Brunham LR, Kruit JK, Pape TD, Parks JS, Kuipers F, Hayden MR. (2006). Tissuespecific induction of intestinal ABCA1 expression with a liver $X$ receptor agonist raises plasma HDL cholesterol levels. Circ Res (99):672-4.

10. Dullens SP, Plat J, Mensink RP. (2007). Increasing apoA-I production as a target for CHD risk reduction. Nutr Metab Cardiovasc Dis (17):616-628.

11. Eggerman TL, Hoeg JM, Meng MS, Tombragel A, Bojanovski D, Brewer HB, Jr. (1991). Differential tissue-specific expression of human apoA-I and apoA-II. J Lipid Res (32):821-8

12. Swift LL, Jovanovska A, Kakkad B, Ong DE. (2005). Microsomal triglyceride transfer protein expression in mouse intestine. Histochem Cell Biol (123):475-82.

13. Miettinen TA, Siurala M. (1971). Bile salts, sterols, sterol esters, glycerides and fatty acids in micellar and oil phases of intestinal contents during fat digestion in man. Z Klin Chem Klin Biochem (9):47-52.
14. Gilde AJ, van der Lee KA, Willemsen $\mathrm{PH}$, et al. (2003). Peroxisome proliferator-activated receptor (PPAR) alpha and PPARbeta/delta, but not PPARgamma, modulate the expression of genes involved in cardiac lipid metabolism.[see comment]. Circulation Research (92):518-24.

15. Livak KJ, Schmittgen TD. (2001). Analysis of relative gene expression data using real-time quantitative PCR and the 2(-Delta Delta $\mathrm{C}(\mathrm{T})$ ) Method. Methods (25):402-8.

16. Rader DJ. (2006). Molecular regulation of HDL metabolism and function: implications for novel therapies. J Clin Invest (116):3090100.

17. Mooradian AD, Haas MJ, Wong NC. (2006). The Effect of Select Nutrients on Serum HighDensity Lipoprotein Cholesterol and Apolipoprotein A-I Levels. Endocr Rev.

18. Denke MA, Grundy SM. (1992). Comparison of effects of lauric acid and palmitic acid on plasma lipids and lipoproteins. Am J Clin Nutr (56):895-8.

19. Temme EH, Mensink RP, Hornstra G. (1996) Comparison of the effects of diets enriched in lauric, palmitic, or oleic acids on serum lipids and lipoproteins in healthy women and men Am J Clin Nutr (63):897-903.

20. de Roos N, Schouten E, Katan M. (2001). Consumption of a solid fat rich in lauric acid results in a more favorable serum lipid profile in healthy men and women than consumption of a solid fat rich in trans-fatty acids. J Nutr (131):242-5.

21. Murakami K, Ide $T$, Suzuki M, Mochizuki T, Kadowaki T. (1999). Evidence for direct binding of fatty acids and eicosanoids to human peroxisome proliferators-activated receptor alpha. Biochem Biophys Res Commun (260):609-13.

22. Duez $H$, Lefebvre $B$, Poulain $P$, et al. (2005) Regulation of human apoA-I by gemfibrozil and fenofibrate through selective peroxisome proliferator-activated receptor alpha modulation. Arterioscler Thromb Vasc Bio (25):585-91.

23. Lam JK, Matsubara S, Mihara K, Zheng XL, Mooradian AD, Wong NC. (2003). Insulin induction of apolipoprotein AI, role of Sp1. Biochemistry (42):2680-90.

24. Haas MJ, Horani MH, Wong NC, Mooradian AD. (2004). Induction of the apolipoprotein AI promoter by $\mathrm{Sp} 1$ is repressed by saturated fatty acids. Metabolism (53):1342-8.

25. Belury MA. (2002). Dietary conjugated linoleic acid in health: physiological effects and mechanisms of action. Annu Rev Nutr (22):505-31. 
26. Tricon S, Yaqoob P. (2006). Conjugated linoleic acid and human health: a critical evaluation of the evidence. Current Opinion in Clinical Nutrition \& Metabolic Care (9):10510.

27. Naumann E, Carpentier YA, Saebo A, et al. (2006). Cis-9, trans- 11 and trans-10, cis-12 conjugated linoleic acid (CLA) do not affect the plasma lipoprotein profile in moderately overweight subjects with LDL phenotype B. Atherosclerosis (188): 167-74.

28. Steck SE, Chalecki AM, Miller P, et al. (2007). Conjugated linoleic acid supplementation for twelve weeks increases lean body mass in obese humans. J Nutr (137):1188-93.

29. Tricon S, Burdge GC, Jones EL, et al. (2006). Effects of dairy products naturally enriched with cis-9,trans-11 conjugated linoleic acid on the blood lipid profile in healthy middle-aged men. Am J Clin Nutr (83):744-53.

30. Lichtenstein AH, Erkkila AT, Lamarche B, Schwab US, Jalbert SM, Ausman LM. (2003). Influence of hydrogenated fat and butter on CVD risk factors: remnant-like particles, glucose and insulin, blood pressure and Creactive protein. Atherosclerosis (171):97107.

31. Khosla P, Hajri T, Pronczuk A, Hayes KC. (1997). Replacing dietary palmitic acid with elaidic acid ( $t-C 18: 1$ delta9) depresses HDL and increases CETP activity in cebus monkeys. J Nutr (127):531S-536S.

32. Brousseau ME, Schaefer EJ, Stucchi AF, et al. (1995). Diets enriched in unsaturated fatty acids enhance apolipoprotein A-I catabolism but do not affect either its production or hepatic mRNA abundance in cynomolgus monkeys. Atherosclerosis (115):107-19.

33. Nissen SE, Tsunoda T, Tuzcu EM, et al. (2003). Effect of recombinant ApoA-I Milano on coronary atherosclerosis in patients with acute coronary syndromes: a randomized controlled trial. Jama (290):2292-3000. 


\section{Chapter 5}

\section{Effects of emulsified policosanols with different chain-lengths on cholesterol metabolism in heterozygous LDL-receptor deficient mice}

Stefan P.J. Dullens ${ }^{1}$, Ronald P. Mensink ${ }^{1}$, Marjolijn C.E. Bragt ${ }^{1}$, Arie K. Kies ${ }^{2}$, Jogchum Plat ${ }^{1}$

${ }^{1}$ Department of Human Biology, Nutrition and Toxicology

Research Institute Maastricht, Maastricht University, Maastricht, The Netherlands

${ }^{2}$ DSM Food Specialties, R\&D, Biochemistry and Nutrition Department, Delft, The Netherlands

J Lipid Res. 2008 Apr;49(4):790-6 


\section{Abstract}

A mixture of long-chain primary aliphatic saturated alcohols can be found in policosanols. Previous studies in humans and animals have shown that this compound improved lipoprotein profiles, however more recent placebocontrolled studies could not confirm these promising effects. Octacosanol (C28), the main component of sugar cane derived policosanol, is assumed as the bioactive component. This has however never been tested in an in vivo study that compared individual policosanol components in vivo side-by-side. We here present that none of the individual policosanol components (C24, $\mathrm{C} 26, \mathrm{C} 28$ or C30) as well as the natural policosanol mixture (all $30 \mathrm{mg} / 100 \mathrm{~g}$ diet) lowered serum cholesterol concentrations in heterozygous $\mathrm{LDLr}^{+/-}$mice. Moreover, there was no effect on gene expression profiles of LDLr, ABCA1, HMG CoA synthase 1 , and apoA-I in hepatic and small intestinal tissue of the female $\mathrm{LDLr}^{+/}$mice after the 7 weeks intervention period. Finally, none of the individual policosanols or their respective long-chain fatty acids or aldehydes affected de novo apoA-I protein production in vitro in HepG2 and differentiated CaCo- 2 cells. Therefore, we conclude that the evaluated individual policosanols as well as the natural policosanol mixture have no potential in reducing CHD risk through effects on serum lipoprotein concentrations. 


\section{Introduction}

Policosanol is a natural mixture of long-chain primary aliphatic saturated alcohols that is not only isolated from sugar cane wax (Saccharum officinarum $L$ ), but also from wheat germ, rice bran, or beeswax ${ }^{1-3}$. The policosanols derived from sugar cane may be an effective food ingredient or a dietary supplement to lower serum low-density lipoprotein cholesterol (LDLC) and total cholesterol (TC) concentrations in humans. As reviewed ${ }^{4}$, more than 50 human and animal studies have demonstrated strong reductions in serum total and LDL-C ranging between 17 to $21 \%$, and 21 to $29 \%$, respectively. Besides lowering the atherogenic LDL-C fraction, the policosanols also increased HDL-C concentrations by 8 to $15 \%{ }^{4}$. These promising effects on serum lipoprotein profiles, however, could not be confirmed in six more recent well controlled double blinded human intervention studies from Europe and USA ${ }^{5-10}$. One possible reason for these discrepancies might be a difference in composition between the originally used sugar cane derived policosanol mixture and the mixtures used in the later studies ${ }^{11}$. Also very long chain fatty acids and aldehydes with different chain-lengths are present in policosanol mixtures, although in minor amounts 12. Altogether, this implies that the composition of policosanol mixtures can vary considerably, which might relate to the discrepancy in outcomes between studies. Since octacosanol (C28) is the main component of the sugar cane derived policosanol mixture, this compound is generally assumed to be the bioactive component of the policosanol mixtures ${ }^{12}$. This latter assumption has however never been tested in a study that compared individual policosanol components in vivo side-by-side.

We evaluated the potential LDL-C lowering effects of the individual policosanol components in heterozygous LDL-receptor knock-out mice $\left(\mathrm{LDLr}^{+/-}\right)$. For this, we carried out two independent studies, in which the diets were enriched with $30 \mathrm{mg}$ per $100 \mathrm{~g}$ diet purified and emulsified tetracosanol (C24), hexacosanol (C26), octacosanol (C28), or triacontanol (C30). This policosanol diet was provided to the animals to reach a dose of approximately $50 \mathrm{mg} / \mathrm{kg} /$ day, which equals the doses used in previous animal studies that demonstrated effective effects of a natural policosanol mixture on cholesterol metabolism ${ }^{13-15}$. Effects of these policosanol-enriched diets were compared with that of a diet containing an emulsion of the natural policosanol mixture (Lesstanol ${ }^{60}$ ) that has been reported to effectively lower LDL-C in humans ${ }^{11}$, or with a control (empty emulsions). Since heterozygous $\mathrm{LDLr}^{+/-}$mice, as most rodent models, are not a suitable model to study HDL metabolism, we evaluated these effects in vitro in hepatic (HepG2 cells) and in small intestinal (fully differentiated $\mathrm{CaCo}-2$ cells) human cell models. Individual policosanols varying in chain-length (C24 to C30) and their respective long- 
chain fatty acids (tetracosanoic acid, hexacosanoic acid, octacosanoic acid, and melissic acid), and aldehydes (tetracosanal, hexacosanal, octacosanal, and triacontanal) were tested on de novo apoA-I production and on expression levels of a panel of cholesterol metabolism related genes. 


\section{Material and methods}

\section{Test products}

Tetracosanol, hexacosanol, octacosanol, triacontanol, tetracosanoic acid, hexacosanoic acid, octacosanoic acid, and melissic acid were purchased from Sigma (St. Louis, MO, USA), and all had a purity of $>95 \%$ as determined by gas chromatography (GC). The natural policosanol mixture Lesstanol $^{60}$ (a purity of $>97 \%$ as determined by GC) was obtained from Garuda International Inc. (Lemon cove, CA, USA). Tetracosanal, hexacosanal, octacosanal, and triacontanal were prepared by DSM Pharmaceutical Products (Geleen, The Netherlands). The purity of each of the four aldehyde products used was $>95 \%$, as determined using $1 \mathrm{H}$ NMR analysis.

\section{Animals and diets}

Experiments involving the use of animals were performed according to protocols approved by Maastricht University Health Sciences Animal Welfare Committee and in accordance with the guidelines established by the Dutch Council on Animal Care. Heterozygous $\mathrm{LDLr}^{+/-}$mice were obtained by breeding $\mathrm{LDLr}^{-/-}$male mice ${ }^{16}$ with $\mathrm{C} 57 \mathrm{BL} / 6$ female mice (Charles River Laboratories Inc., Wilmington, MA, USA). Seven and eight weeks old female and male heterozygous $\mathrm{LDLr}^{+/-}$mice were used for the dietary interventions. Animals had ad libitum access to semi-synthetic diets.

The feed (pellets) contained 37 percent of energy (en\%) fat with a Western-like fatty acid profile ( $26 \%$ palm oil, $10 \%$ coconut oil, $23 \%$ soy oil, $13 \%$ olive oil, and $28 \%$ cacao oil), 45 en\% carbohydrates (36 en $\%$ sucrose, and 9 en\% corn starch), and 19 en\% protein (casein), $0.25 \mathrm{~g}$ cholesterol, $0.25 \mathrm{~g}$ vitamin mixture, $0.25 \mathrm{~g}$ cholate, and $4.85 \mathrm{~g}$ mineral mixture per $100 \mathrm{~g}$ diet (Arie Blok diervoeding, Woerden, The Netherlands). This Western-like control diet was enriched with an amount of $0.03 \mathrm{~g}$ of the individual policosanols or natural policosanol mixture (Lesstanol ${ }^{60}$ ) per $100 \mathrm{~g}$ diet, which is comparable to amounts used in previous animal studies ${ }^{1,15}$. In this manner, mice consumed about $50 \mathrm{mg}$ policosanol per $\mathrm{kg}$ per day. Lesstanol ${ }^{60}$ contained 2.6\% tetracosanol (C24), 6.5\% hexacosanol (C26), $61.2 \%$ octacosanol (C28), and $16.8 \%$ triacontanol (C30). Other policosanols were present in smaller amounts. The total alcohol content was $97.4 \%$. To assure a homogenous distribution of policosanols within the diets they were incorporated into emulsions. These emulsions were prepared by DSM Nutritional Products (Kaiseraugst, Switzerland) and contained $3.0 \%$ (individual) policosanols, $1.0 \%$ Tween $20,70.0 \%$ glycerol, and $26.0 \%$ water. This emulsification step resulted in a strong reduction of the policosanol particle size from $30 \mu \mathrm{m}$ or larger, towards a mean particle size of $399 \mathrm{~nm}$, assuring a better distribution of the policosanols within the diets (figure $\mathbf{1}$ ). 
Next, these policosanol emulsions were incorporated into the mouse diets, first by mixing the policosanol emulsions into the fat phase, followed by blending this phase with the solid components to obtain a well-homogenized product. The control diet was prepared by mixing an empty emulsion into the feed, i.e. an emulsion without addition of a policosanol.

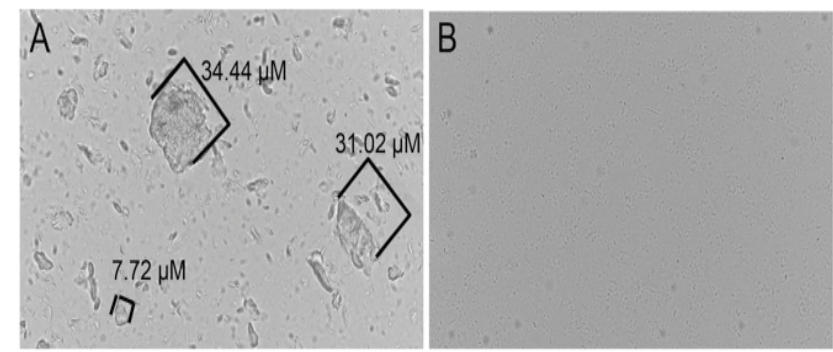

Figure 1. Policosanol solutions before (A) and after (B) emulsification.

\section{Experimental procedures of the animal studies}

In the first intervention study, the effects of policosanols-enriched diets, i.e. hexacosanol (C26), octacosanol (C28), triacontanol (C30), or Lesstanol ${ }^{60}$, on serum cholesterol concentrations were compared to the control diet. After a two-week run-in period, in which animals received the control diet, 48 female and 39 male mice were randomly allocated to one of the five intervention groups, as indicated in figure 2 (three mice per cage). For the next 7 weeks, one intervention group continued to use the control diet, whereas the other groups received one of the individual policosanol- or Lesstanol ${ }^{60}$-enriched diets. Animals were weighed in weeks 2, 3, 5, 7, and 9 (figure 2). At these time points, blood was sampled by orbital punction under anesthesia (1-2\% isofluran) for analysis of serum TC concentrations. At the end of week 9, animals were euthanized under anesthesia (1-2\% isofluran) by an aortic punction. Blood was sampled to determine lipoprotein profiles, and hepatic and small intestinal tissue (starting approximately $2 \mathrm{~cm}$ distal from stomach) was collected for gene expression analysis. Isolated tissues were first washed with cold phosphate buffered saline (PBS), snap frozen in liquid nitrogen, and stored at $-80{ }^{\circ} \mathrm{C}$ until analysis. 


\section{Design Study 1}

\begin{tabular}{|c|c|}
\hline \multirow{5}{*}{$\begin{array}{c}\begin{array}{c}\text { Control } \\
\text { diet }\end{array} \\
n=87 \\
(48 \text { female, } \\
39 \text { male) }\end{array}$} & Control diet ( $n=17 ; 9$ female, 8 male $)$ \\
\hline & Control diet + Hexacosanol $(n=18 ; 10$ female, 8 male $)$ \\
\hline & Control diet + Octacosanol ( $n=18 ; 10$ female, 8 male $)$ \\
\hline & Control diet + Triacontanol $(n=18 ; 10$ female, 8 male $)$ \\
\hline & Control diet + Lesstanol $(n=16 ; 9$ female, 7 male $)$ \\
\hline & 5 \\
\hline
\end{tabular}

\section{Design Study 2}

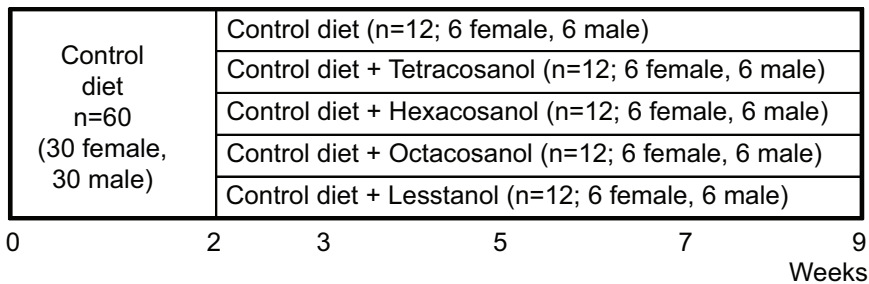

\section{Figure 2. Design of the animal studies.}

In study 1, 48 female and 39 male heterozygous $\mathrm{LDLr}^{+/-}$mice were included, whereas 30 female and 30 male heterozygous $\mathrm{LDLr}^{+/-}$mice were used in study 2 . Policosanol diets were prepared using policosanol emulsions to obtain a well-homogenized product. Targeted policosanol intake was $50 \mathrm{mg} / \mathrm{kg} /$ day. Policosanol emulsions were added to the Western-like control diets (contain 'empty' emulsion) containing $17.2 \mathrm{~g} / 100 \mathrm{~g}$ (or $37 \mathrm{en} \%$ ) fat and $0.25 \mathrm{~g} / 100 \mathrm{~g}$ cholesterol. During the run-in period of 2 weeks, animals received the Western-like control diet, The Western-like fat blend consisted of $26 \%$ palm oil, $10 \%$ coconut oil, $23 \%$ soy oil, $13 \%$ olive oil, and $28 \%$ cacao oil. Mice were weighted and blood was sampled during the indicated weeks, and euthanized at the end of week 9.

The aim of the second intervention study in heterozygous $\mathrm{LDLr}^{+/-}$mice was to confirm the results obtained from study 1 . In contrast to the first study, triacontanol (C30) was replaced with tetracosanol (C24) because promising results on serum cholesterol concentrations in humans were described for grain sorghum wax, which contains a high proportion of tetracosanol ${ }^{17}$. After a new breeding program, 30 female and 30 male heterozygous $\mathrm{LDLr}^{+/}$mice enrolled in a 2-week run-in period and received the control diet, containing an empty emulsion. Next, they were randomly allocated to one of five intervention groups. Again, one group (control) continued on this control diet, whereas the other intervention groups received tetracosanol-, hexacosanol-, octacosanol-, or Lesstanol ${ }^{60}$-enriched diets. Diets were prepared as described above. Blood sampling, weighing, and other measurements were performed as indicated for study 1 . 


\section{Measurements of serum lipoproteins and lipoprotein profiles}

After blood sampling at weeks 2, 3, 5, 7, and 9, serum TC concentrations were directly measured enzymatically with a commercial available kit (CHOD/PAP method; Roche Diagnostics, Basel, Switzerland). At the end of week 9, serum lipoprotein profiles were determined by means of fast-protein liquid chromatography (FPLC) as described before ${ }^{18}$. Briefly, $50 \mu$ of serum (pooled mice sera from six mice out of the same diet group) was loaded on a Superose-6PC 3.2/30 column (Amersham biosciences, Piscataway, NJ, USA) using PBS-EDTA as a mobile phase and automatically fractionated into 36 portions of $50 \mu \mathrm{l}$. TC concentrations were measured in all fractions enzymatically as described above.

\section{Gene expression in mice}

By using Trizol reagent (Invitrogen Life Technologies, Carlsbad, CA, USA), total RNA was isolated from liver and small intestine samples. Treatment of total RNA with RNase-free DNase (QIAGEN Benelux B.V., Venlo, The Netherlands) removed possible traces of contaminating DNA. Next, cDNA was synthesized, and real-time quantitative PCR (RT-q PCR) reactions were performed as previously described ${ }^{19}$. Taqman MGB probes (FAM ${ }^{\mathrm{TM}}$ dyelabeled) from Applied Biosystems (Foster City, CA, USA) were used to determine mice gene expression profiles. Taqman gene expression assays of apoA-I (Mm00437569_m1), LDLr (Mm00440169_m1), ABCA1 (Mm00442646_m1), HMG-CoA synthase-1 (Mm00524111_m1), and housekeeping gene cyclophillin A (Mm02342430_g1) were used. mRNA expression was expressed as comparative $\mathrm{Ct}$ values as described by others 20 .

\section{Cell lines and experimental procedures}

Human hepatoma cells (HepG2 cells; Mabtech, Nacka Strand, Sweden) were maintained in minimal essential medium (MEM) containing $2 \mathrm{mM}$ L-glutamine (Invitrogen Life Technologies, Carlsbad, CA, USA), supplemented with $10 \%$ ( $\mathrm{v} / \mathrm{v}$ ) fetal bovine serum (FBS), $1 \%$ ( $/ \mathrm{v}$ ) non-essential amino acids (NEAA), and $1 \%(\mathrm{v} / \mathrm{v})$ penicillin/streptomycin, at $37{ }^{\circ} \mathrm{C}$ in a humidified atmosphere of $5 \% \quad \mathrm{CO}_{2} / 95 \% \quad \mathrm{O}_{2}(\mathrm{v} / \mathrm{v})$. Experimental procedures were performed when approximately $90 \%$ confluent monolayers were reached. For this, 500.000 cells were seeded per well in 6-well-tissue-culture plates. Policosanol emulsions containing purified C24, C26, C28, or C30 policosanols were added to the cells, in a dose range of $0.5,5$, or $50 \mu \mathrm{g} / \mathrm{mL}$. These concentrations were in line with those used in earlier effective in vitro studies ${ }^{21}$. In line with the animal studies, Lesstanol ${ }^{60}$ was also included and the 'empty' emulsion (without policosanols) was used as control. In addition, $10 \mu \mathrm{M}$ 9-cis retinoid 
acid (RA) was included as positive control, as it elevates de novo apoA-I production ${ }^{22}$. Furthermore, the effects of fatty acids and aldehydes with chain-length $\mathrm{C} 24, \mathrm{C} 26, \mathrm{C} 28$, or C30, incorporated into the same emulsions, were evaluated. After 3 hours incubation, cell lysates were collected and used for RNA isolation followed by gene expression analysis of the genes HMG-CoA synthase 1, LDLr, apoB, ABCA1, ACAT1, and apoA-I, essentially as described above. Human probe sets of apoA-I (Hs00163641_m1), LDLr (Hs00181192_m1), apoB (Hs00181142_m1), ABCA1 (Hs00194045_m1), ACAT-1 (Hs00608002_m1), HMG-CoA synthase-1 (Hs00266810_m1), and the housekeeping gene cyclophillin A (Hs99999904_m1)), were used. To measure human apoA-I protein concentrations in culture medium of the HepG2 cells, these experiments were prolonged for 48 hours. ApoA-I was measured with an apoA-I sandwich ELISA (Mabtech, Nacka Strand, Sweden). In addition to the hepatic cell model, fully differentiated CaCo-2 cells - a model for the small intestine - were also used to evaluate effects of $0.5,5$, or $50 \mu \mathrm{g} / \mathrm{mL}$ Lesstanol $^{60}$ (as emulsions) on de novo apoA-I production.

\section{Statistics}

Data are presented as means \pm SEM. Differences between mean values in the different intervention groups (either from the mice or the cell studies) were tested by Kruskal-Wallis or Mann-Whitney U-test. 


\section{Results}

\section{Animal studies}

In study 1 , no significant differences between treatments were observed on absolute serum TC concentrations in week $9(P=0.67)$ and on changes in serum TC concentrations (change between week 2 and 9: $P=0.82$ ) in female heterozygous $\mathrm{LDLr}^{+/-}$mice (figure 3 ). However, significant effects on serum TC concentrations were observed in week 3 with Lesstanol ${ }^{60}(P=0.03)$, in week 5 with Lesstanol $^{60}(P=0.02)$, and in week 7 with triacontanol $(P=0.04)$, compared to control diet. Next, no changes in serum lipoprotein profiles were observed between the control diet and the $\mathrm{C}_{26}-$, C28-, or C30- policosanol formulations, or Lesstanol ${ }^{60}$ (figure 4). See supplementary figure for comparable data of serum TC concentrations in male heterozygous $\mathrm{LDLr}^{+/-}$ mice. Serum lipoprotein profiles in male heterozygous $\mathrm{LDLr}^{+/-}$mice were comparable to female heterozygous $\mathrm{LDLr}^{+/-}$mice (data not shown). Body weight development of the mice was not differently affected by treatment.
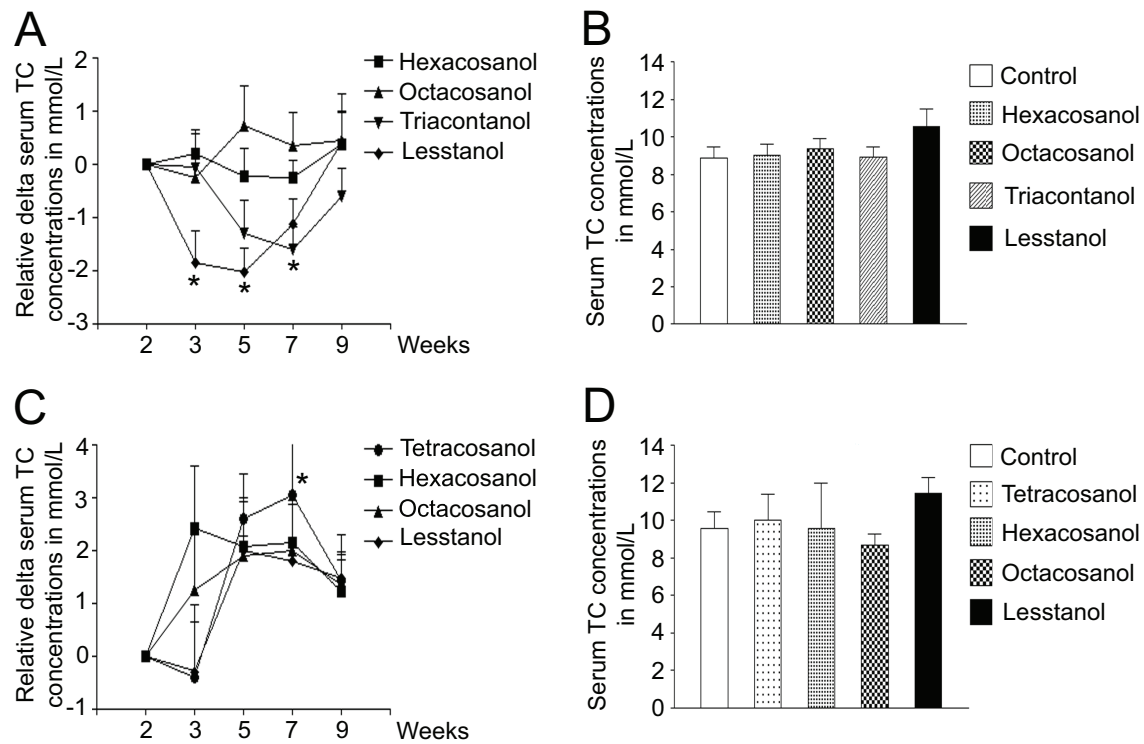

Figure 3. Serum TC concentrations in female heterozygous $\mathrm{LDLr}^{+/-} \mathrm{mice}$ as affected by different policosanols.

Panel A: Serum TC concentrations relative to the control treatment of study 1. Panel B: Serum TC concentrations at the end of week 9 of study 1 . Panel C: Serum TC concentrations relative to the control treatment of study 2. Panel D: Serum TC concentrations at the end of week 9 of study 2 . Values are means \pm SEM ( $N=48$ in study $1 ; \mathrm{N}=30$ in study 2 ). $* \mathrm{P}<0.05$. See supplementary figure for data in male heterozygous $\mathrm{LDLr}^{+/-}$mice. 
Also in study 2, there were no significant differences in the absolute TC concentrations at the end of week $9(P=0.23)$ or in changes in serum TC concentrations during the study $(P=0.43)$, between the different policosanol formulations (C24, C26, or $\mathrm{C} 28)$, Lesstanol ${ }^{60}$ or the control diet (figure 3 ). However, significant differences on serum TC concentrations were only observed in tetracosanol-treated female heterozygous LDLr $^{+/-}$mice in week 7 $(P=0.04)$, compared to the control group. As in study 1 , no effects on serum lipoprotein profiles were observed (figure 4). Comparable results were observed in male heterozygous $\mathrm{LDLr}^{+/-}$mice as shown in supplementary figure (data of serum TC concentrations). Serum lipoprotein profiles in male heterozygous $\mathrm{LDLr}^{+/-}$mice were comparable to female heterozygous $\mathrm{LDLr}^{+/-}$ mice (data not shown). In addition, body weight development of the mice was also not significantly affected by treatment.
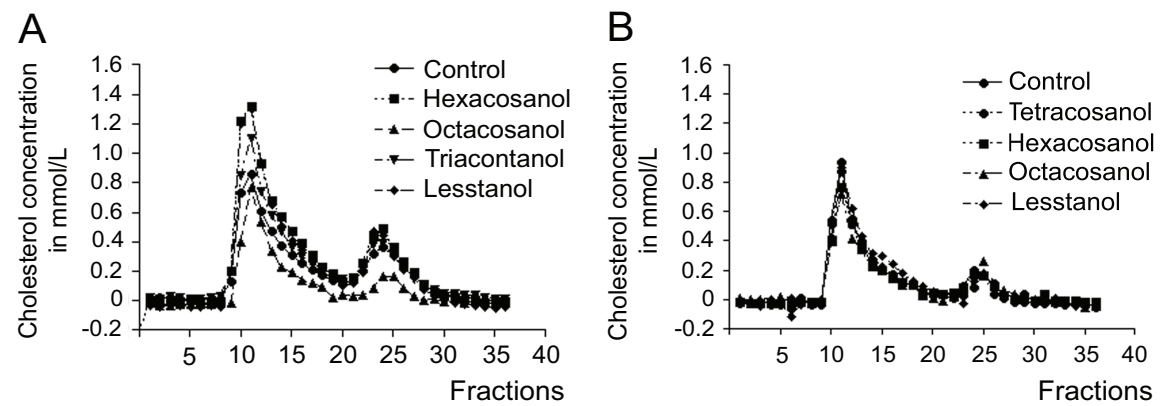

Figure 4. Serum lipoprotein profile of female heterozygous LDLr $^{+/-}$mice after a 9-week dietary intervention with policosanol-enriched diets.

Study 1 evaluated the effects of policosanol C26-, C28-, C30-, or Lesstanol ${ }^{60}$-enriched diets, versus a control diet (panel A). Effects of C24-, C26-, C28-, or Lesstanol ${ }^{60}$ enriched diets, versus a control diet were evaluated in study 2 (panel $B)$. ( $N=48$ in study $1 ; \mathrm{N}=30$ in study 2 ).

Effects of policosanol-enriched Western-like diet on hepatic and small intestinal gene expression in female heterozygous $\mathrm{LDLr}^{+/-}$mice

Gene expression profiles of LDLr, ABCA1, HMG CoA synthase 1, and apoA-I were determined in isolated hepatic and small intestinal tissue of female heterozygous $\mathrm{LDLr}^{+/-}$mice of study 2 . As shown in table $\mathbf{1}$, hepatic and small intestinal gene expression levels of LDLr, ABCA1, HMG CoA synthase 1, and apoA-I were not affected by a 7 weeks dietary intervention with the different policosanol emulsions as compared to the control diet. 
Table 1. Effects of different policosanol formulations on hepatic or small intestinal gene expression in female heterogous $\mathrm{LDLr}^{+/-}$mice.

\begin{tabular}{lcccc}
\hline \multicolumn{1}{c}{ ABCA1 } & HMG CoA Synth 1 & LDLr & ApoA-I \\
\hline Liver & & & & \\
\hline Treatment & & & & \\
Control & $1.00 \pm 0.14$ & $1.00 \pm 0.10$ & $1.00 \pm 0.17$ & $1.00 \pm 0.07$ \\
C24 & $0.98 \pm 0.15$ & $0.83 \pm 0.19$ & $1.39 \pm 0.17$ & $0.99 \pm 0.24$ \\
C26 & $0.99 \pm 0.16$ & $0.96 \pm 0.06$ & $1.13 \pm 0.22$ & $0.99 \pm 0.13$ \\
C28 & $0.80 \pm 0.19$ & $0.81 \pm 0.11$ & $1.13 \pm 0.29$ & $0.91 \pm 0.19$ \\
Lesstanol $^{60}$ & $0.79 \pm 0.25$ & $1.06 \pm 0.19$ & $0.66 \pm 0.11$ & $0.90 \pm 0.13$ \\
& & & & \\
\hline Small & & & & \\
intestine & & & & \\
\hline Treatment & & & & \\
Control & $1.00 \pm 0.10$ & $1.00 \pm 0.14$ & $1.00 \pm 0.24$ & $1.00 \pm 0.09$ \\
C24 & $1.20 \pm 0.18$ & $1.07 \pm 0.09$ & $0.97 \pm 0.13$ & $1.10 \pm 0.24$ \\
C26 & $1.07 \pm 0.36$ & $1.17 \pm 0.14$ & $0.90 \pm 0.29$ & $1.31 \pm 0.17$ \\
C28 & $1.01 \pm 0.31$ & $1.02 \pm 0.08$ & $1.28 \pm 0.13$ & $1.06 \pm 0.09$ \\
Lesstanol $^{60}$ & $0.84 \pm 0.24$ & $1.05 \pm 0.17$ & $1.08 \pm 0.22$ & $0.89 \pm 0.20$ \\
\hline
\end{tabular}

Results are expressed as mean \pm SEM of the Comparative Ct values in which the control group is set at 1 . ( $N=30$ in total or $\mathrm{N}=6$ animals in each diet group).

\section{Effects of policosanol emulsions on de novo apoA-I production in HepG2 and differentiated CaCo-2 cells}

After an incubation period of 48 hours with policosanol, policosanal, or policosanoic acid emulsions (C24, C26, C28, or C30; $0.5,5$, or $50 \mu \mathrm{g} / \mathrm{mL}$ ), or with Lesstanol $^{60}(0.5,5$, or $50 \mu \mathrm{g} / \mathrm{mL})$, no differences in apoA-I concentrations in cell culture medium were observed compared to control in HepG2 cells. In figure 5, results for the $5 \mu \mathrm{g} / \mathrm{mL}$ treatments are shown, but results for the other concentrations were similar. De novo apoA-I production was, however, increased by the positive control, i.e. $10 \mu \mathrm{M}$ RA $(+23 \%$, $\mathrm{P}=0.03$ ). Moderate apoA-I lowering effects were observed for C24 and C26 policosanols, policosanals, and policosanoic acids, but these effects were not significant. The effect of Lesstanol ${ }^{60}$ on de novo apoA-I production in fully differentiated $\mathrm{CaCo}-2$ cells was comparable to that in HepG2 cells (data not shown). 


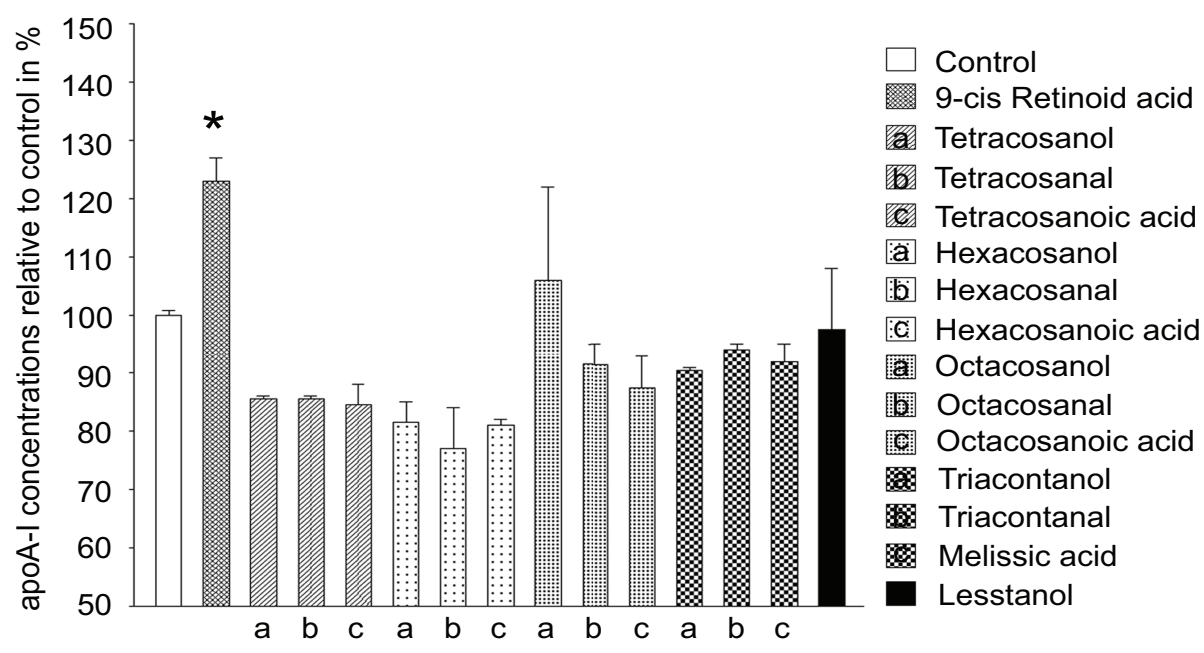

Figure 5. Effects of $5 \mu \mathrm{g} / \mathrm{mL}$ policosanol, policosanal, or policosanoic acid with chain-lengths of C24, C26, C28, or C30 on de novo apoA-I production in HepG2 cells.

$\mathrm{a}=$ policosanol, $\mathrm{b}=$ policosanal, $\mathrm{c}=$ policosanoic acid. Values are mean $\pm \mathrm{SEM}$, as percentage compared to the control. ${ }^{*} \mathrm{P}<0.05 \mathrm{vs}$. control. $\mathrm{N}=8$.

\section{Gene expression profiles of cholesterol-modulating genes in HepG2 cells}

In line with the absence of an effect on apoA-I protein secretion by HepG2 cells, Lesstanol ${ }^{60}$ did not affect apoA-I mRNA transcription as compared to the control. Also the gene expression of ACAT1 was not changed. Gene expressions of ABCA1, HMG CoA synthase 1, LDLr, and apoB were, however, dose-dependently elevated by Lesstanol $^{60}$, with $5 \mu \mathrm{g} / \mathrm{mL}$ giving the maximal response (table 2 ). An effect on gene expression of ABCA1 and HMG-CoA synthase 1 could also be shown for some of the individual policosanols or their respective metabolites (data not shown). This data sheds a light on the functional component within Lesstanol $^{60}$ responsible for the observed effect on elevated ABCA1 and HMG-CoA synthase 1 gene expression. Although concentrations of the individual policosanols applied to the cells were not identical to those used in the Lesstanol ${ }^{60}$ mixture, ABCA1 mRNA elevating effects (comparative threshold cycle value of 2.52 for $5 \mu \mathrm{g} / \mathrm{mL}$ Lesstanol ${ }^{60}$ ) were most likely ascribed to $\mathrm{C} 28$ policosanols, policosanals, and policosanoic acids, whereas the elevated HMG-CoA synthase 1 mRNA levels (comparative threshold cycle value of 1.80 for $5 \mu \mathrm{g} / \mathrm{mL}$ ) were mostly associated with C30 policosanols, policosanals, and policosanoic acids (data not shown). Moreover, gene expression levels of LDLr and ApoB were 
moderately elevated as compared to the control (comparative threshold cycle values of 1.52 and 1.56 for $5 \mu \mathrm{g} / \mathrm{mL}$, respectively).

Table 2. Comparative threshold cycle values of different policosanol formulations compared to control diet in HepG2 cells.

\begin{tabular}{lllll}
\hline & Control & $\begin{array}{l}\text { Lesstanol }^{60} \\
0.5 \mu \mathrm{gL} / \mathrm{mL}\end{array}$ & $\begin{array}{l}\text { Lesstanol }^{60} \\
5 \mu \mathrm{g} / \mathrm{mL}\end{array}$ & $\begin{array}{l}\text { Lesstanol }^{60} \\
50 \mu \mathrm{g} / \mathrm{mL}\end{array}$ \\
\hline ABCA1 & $1.00 \pm 0.17$ & $2.41 \pm 0.00$ & $2.52 \pm 0.26$ & $1.92 \pm 0.08$ \\
HMG-CoA synthase 1 & $1.00 \pm 0.00$ & $1.83 \pm 0.08$ & $1.80 \pm 0.01$ & $1.69 \pm 0.04$ \\
LDLr & $1.00 \pm 0.00$ & $1.38 \pm 0.01$ & $1.52 \pm 0.05$ & $1.31 \pm 0.06$ \\
apoB & $1.00 \pm 0.02$ & $1.27 \pm 0.04$ & $1.56 \pm 0.05$ & $1.58 \pm 0.02$ \\
ACAT1 & $1.00 \pm 0.03$ & $1.13 \pm 0.10$ & $0.98 \pm 0.02$ & $0.91 \pm 0.03$ \\
apoA-I & $1.00 \pm 0.06$ & $1.27 \pm 0.02$ & $1.21 \pm 0.03$ & $1.21 \pm 0.07$ \\
\hline
\end{tabular}

Results are expressed as mean \pm SEM of the comparative threshold cycle values, in which the control is set at $1 . \mathrm{N}=8$. 


\section{Discussion}

In the past two decades, an impressive amount of data from various animal and human intervention studies have suggested that policosanols have strong LDL-C lowering and HDL-C elevating effects ${ }^{4}$. However, all these studies have used a natural mixture composed of policosanols varying in chainlength. Also other constituents, like very long-chain fatty acids and aldehydes, were present. Therefore, the bioactive component remained to be identified. We tested, therefore, the effects of the individual policosanol components in heterozygous $\mathrm{LDLr}^{+/-}$mice. None of the evaluated individual policosanols, including the natural policosanol mixture (Lesstanol ${ }^{60}$ ), however, effectively lowered serum TC concentrations, or changed the serum lipoprotein profiles. Also human hepatic or small intestinal cell lines did not suggest that these compounds affected cholesterol metabolism. These results are in line with more recent human intervention studies in non-Cuban populations ${ }^{6-8,23}$, or in hamsters ${ }^{24}$.

Besides lowering serum TC and LDL-C concentrations, policosanols have also been suggested to elevate serum HDL-C concentrations ${ }^{4}$. An increase in de novo apoA-I production is one of the potential mechanisms by which serum HDL-C concentrations may be elevated. We recently showed that synthetic ligands as well as specific dietary fatty acids are able to elevate de novo apoA-I production in human hepatic (HepG2 cells) and small intestinal cell lines (fully differentiated CaCo-2 cells) ${ }^{23}$. However, in the same cell models, no effects of either one of the policosanols on de novo apoA-I production was observed, while retinoid $X$ receptor ( $R X R$ ) agonist 9-cis retinoid acid increased apoA-I concentrations in culture medium. This indicates that if policosanols do elevate HDL-C concentrations, this is not regulated at the level of de novo apoA-I production.

ABCA1 gene expression was strongly elevated in HepG2 cells treated with Lesstanol ${ }^{60}$. ABCA1 plays an important role in regulating serum HDL-C concentrations. In contrast to the cell experiments, however, none of the policosanols were able to change ABCA1 gene expression in the liver or the small intestine in the in vivo experiments in heterozygous $\mathrm{LDLr}^{+/-}$mice. Except for differences between the models used, this may also be related to the fact that the bioavailability of these components from the gastrointestinal tract into the circulation in the animals is extremely low ${ }^{1}$. Generally, absorption of nutrients with long-chain carbon backbones and a high degree of saturation is low ${ }^{25-27}$. Therefore, policosanol concentrations reaching the liver in vivo are most likely lower than those used in cell culture studies. Therefore, earlier observations in rat hepatoma cells ${ }^{21}$ showing that both triacontanol and the natural policosanol mixture but not hexacosanol, and octacosanol lowered cholesterol biosynthesis by activating AMP-kinase but 
without reducing HMG-CoA reductase enzyme levels, might be of less importance for the in vivo situation. However, the finding that the inhibiting effect of triacontanol on cholesterol biosynthesis in vitro in rat hepatoma cells is most likely localized above the rate-limiting HMG-CoA reductase step [21] is in line with our finding that HMG-CoA synthase mRNA expression was not lowered by triacontanol, triacontanal or melissic acid in HepG2 cells.

In conclusion, in line with recent observations in human intervention studies ${ }^{1,6-8,10}$, we were not able to show a reduction in serum TC or an improvement in lipoprotein profiles for any of the evaluated policosanols, nor for the natural policosanol mix (Lesstanol ${ }^{60}$ ) in heterozygous $\mathrm{LDLr}^{+/-}$mice. Furthermore, we could not demonstrate that policosanols or one of its metabolites elevated de novo apoA-I production, one of the key players in HDL metabolism, in HepG2 or in fully differentiated CaCo-2 cells. Therefore, we conclude that the evaluated individual policosanols as well as the natural policosanol mixture (Lesstanol ${ }^{60}$ ) have no potential in reducing CHD risk through effects on serum lipoprotein concentrations.

\section{Acknowledgements}

The authors thank Jacquelien Numann for practical assistance in the studies and for analysis, Patrick van Gorp for assistance in FPLC analysis, and Georgios Sarakinos for production of the aldehydes. The authors thank DSM Food Specialties for financial support and for providing the test products. 


\section{References}

1. Marinangeli $C P$, Kassis $A N$, Jain $D$, Ebine $N$, Cunnane SC, Jones PJ. (2007). Comparison of composition and absorption of sugarcane policosanols. Br J Nutr (97):381-8.

2. Irmak S, Dunford NT. (2005). Policosanol contents and compositions of wheat varieties. J Agric Food Chem (53):5583-6.

3. Hargrove JL, Greenspan P, Hartle DK. (2004). Nutritional significance and metabolism of very long chain fatty alcohols and acids from dietary waxes. Exp Biol Med (Maywood) (229):215-26.

4. Gouni-Berthold I, Berthold HK. (2002). Policosanol: clinical pharmacology and therapeutic significance of a new lipidlowering agent. Am Heart J (143):356-65.

5. Lin $Y$, Rudrum $M$, van der Wielen RP, et al. (2004). Wheat germ policosanol failed to lower plasma cholesterol in subjects with normal to mildly elevated cholesterol concentrations. Metabolism (53):1309-14.

6. Greyling A, De Witt C, Oosthuizen W, Jerling JC. (2006). Effects of a policosanol supplement on serum lipid concentrations in hypercholesterolaemic and heterozygous familial hypercholesterolaemic subjects. $\mathrm{Br}$ J Nutr (95):968-75.

7. Berthold HK, Unverdorben S, Degenhardt R, Bulitta M, Gouni-Berthold I. (2006). Effect of policosanol on lipid levels among patients with hypercholesterolemia or combined hyperlipidemia: a randomized controlled trial. Jama (295):2262-9.

8. Kassis AN, Jones PJ. (2006). Lack of cholesterol-lowering efficacy of Cuban sugar cane policosanols in hypercholesterolemic persons. Am J Clin Nutr (84):1003-8.

9. Dulin MF, Hatcher LF, Sasser HC, Barringer TA. (2006). Policosanol is ineffective in the treatment of hypercholesterolemia: a randomized controlled trial. Am J Clin Nutr (84):1543-8.

10. Cubeddu LX, Cubeddu RJ, Heimowitz T, Restrepo B, Lamas GA, Weinberg GB. (2006). Comparative lipid-lowering effects of policosanol and atorvastatin: a randomized, parallel, double-blind, placebo-controlled trial. Am Heart J (152): 982 e1-5.

11. Castano G, Fernandez L, Mas R, et al. (2002). Comparison of the efficacy, safety and tolerability of original policosanol versus other mixtures of higher aliphatic primary alcohols in patients with type II hypercholesterolemia. Int J Clin Pharmacol Res (22):55-66.

12. Singh H, Derwas N, A P. (1987). Very long chain fatty acid beta-oxidation by rat liver mitochondria and peroxisomes. Arch Biochem Biophys (259):382-390.

13. Noa M, Mas R, de la Rosa MC, Magraner J. (1995). Effect of policosanol on lipofundininduced atherosclerotic lesions in rats. J Pharm Pharmacol (47):289-91.
14. Menendez R, Arruzazabala L, Mas R, et al. (1997). Cholesterol-lowering effect of policosanol on rabbits with hypercholesterolaemia induced by a wheat starch-casein diet. Br J Nutr (77):923-32.

15. Menendez R, Marrero D, Mas R, Fernandez I, Gonzalez L, Gonzalez RM. (2005). In vitro and in vivo study of octacosanol metabolism. Arch Med Res (36): 113-9.

16. Ishibashi S, Brown MS, Goldstein JL, Gerard RD, Hammer RE, Herz J. (1993). Hypercholesterolemia in low density lipoprotein receptor knockout mice and its reversal by adenovirus-mediated gene delivery. J Clin Invest (92):883-93.

17. Hartle DK JL, Greenspan P. (2005). Nutraceutical use of grain sorghum wax lowers serum cholesterol in humans. FASEB (76.2): A89.

18. Ghesquiere SA, Gijbels MJ, Anthonsen M, et al. (2005). Macrophage-specific overexpression of group IIa sPLA2 increases atherosclerosis and enhances collagen deposition. J Lipid Res (46):201-10.

19. Plat J, Mensink RP. (2002). Relationship of genetic variation in genes encoding apolipoprotein A-IV, scavenger receptor BI, HMG-COA reductase, CETP and apolipoprotein $\mathrm{E}$ with cholesterol metabolism and the response to plant stanol ester consumption. Eur J Clin Invest (32):242-50.

20. Livak KJ, Schmittgen TD. (2001). Analysis of relative gene expression data using real-time quantitative PCR and the 2(-Delta Delta C(T)) Method. Methods (25):402-8.

21.Singh DK, Li L, Porter TD. (2006). Policosanol inhibits cholesterol synthesis in hepatoma cells by activation of AMP-kinase. J Pharmacol Exp Ther (318):1020-6.

22. Giller T, Hennes U, Kempen HJ. (1995). Regulation of human apolipoprotein A-I expression in Caco-2 and HepG2 cells by alltrans and 9-cis retinoic acids. J Lipid Res (36): 1021-8.

23. Dullens SPJ, Mensink RP, Plat J. (2007). Differential effects of individual fatty acids on de novo apoA-I production in differentiated CaCo-2 cells. Atheroscler Suppl (8):223.

24. Kassis AN, Marinangeli CP, Jain D, Ebine $N$, Jones PJ. (2007). Lack of effect of sugar cane policosanol on plasma cholesterol in golden syrian hamsters. Atherosclerosis (194):1538.

25. Jones PJ, Pencharz PB, Clandinin MT. (1985). Absorption of $13 \mathrm{C}$-labeled stearic, oleic, and linoleic acids in humans: application to breath tests. J Lab Clin Med (105):647-52.

26. Sallee VL, Dietschy JM. (1973). Determinants of intestinal mucosal uptake of short- and medium-chain fatty acids and alcohols. J Lipid Res (14):475-84.

27. Bernard A, Carlier H. (1991). Absorption and intestinal catabolism of fatty acids in the rat: effect of chain length and unsaturation. Exp Physiol (76):445-55 


\section{Supplemental data}
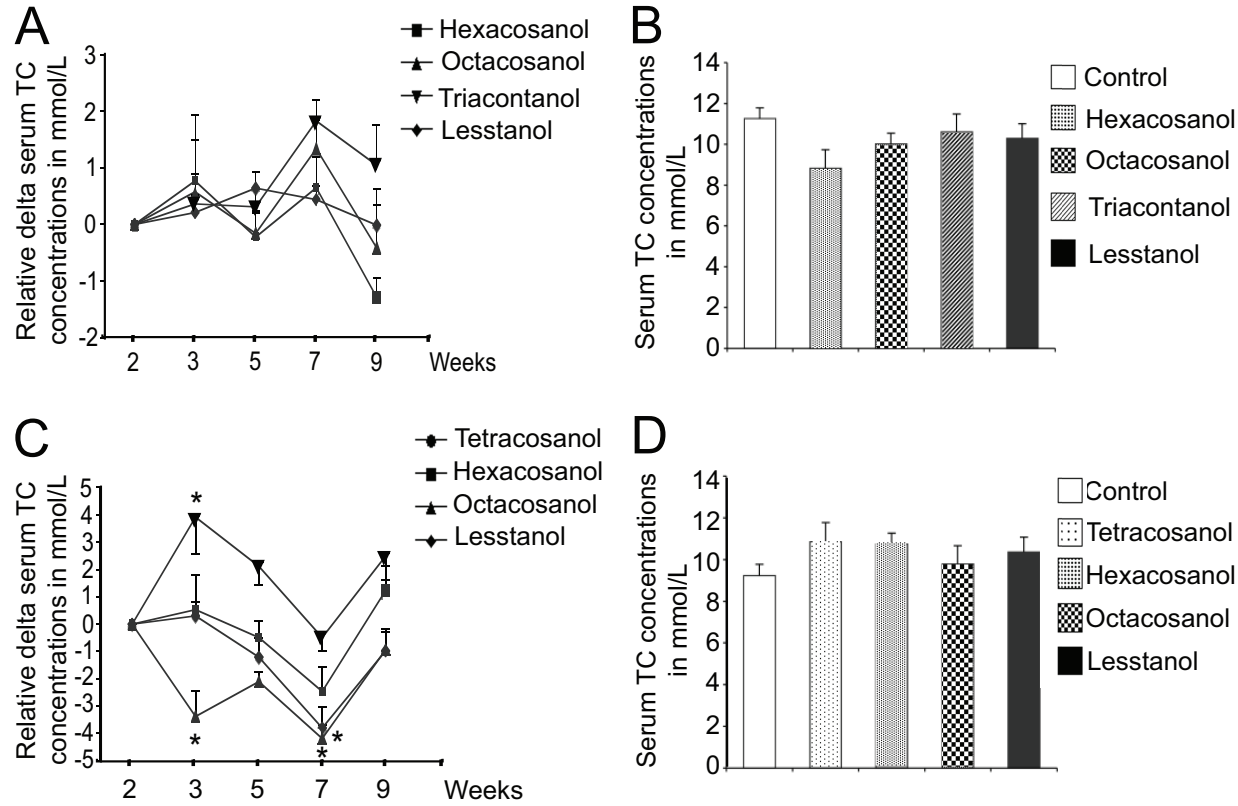

Supplemental data: figure 1 . Serum TC concentrations in male heterozygous LDLr $^{+/-}$mice as affected by different policosanols.

Panel A: Serum TC concentrations relative to the control treatment of study 1 . Panel B: Serum TC concentrations at the end of week 9 of study 1. Panel C: Serum TC concentrations relative to the control treatment of study 2. Panel D: Serum TC concentrations at the end of week 9 of study 2 . Values are means \pm SEM $(N=39$ in study $1 ; \mathrm{N}=30$ in study 2 ). ${ }^{*} \mathrm{P}<0.05$. 


\section{Chapter 6}

\section{Identification of regulatory factors for apoA-I production by enterocytes and hepatocytes}

Stefan P.J. Dullens ${ }^{1}$, Stan Gaj ${ }^{1,2,3}$, Ronald P. Mensink ${ }^{1}$, Jogchum Plat ${ }^{1,3}$

${ }^{1}$ Department of Human Biology, Nutrition and Toxicology Research Institute Maastricht, Maastricht University, Maastricht, The Netherlands

${ }^{2}$ Nutrigenomics Consortium, Top Institute Food and Nutrition, Wageningen, The Netherlands

${ }^{3}$ Department of Bioinformatics, BiGCaT Bioinformatics, Maastricht University, Maastricht, The Netherlands

In preparation 


\section{Abstract}

It is generally accepted that de novo apoA-I production is mediated by the transcription factor PPAR $\alpha$. Although fenofibric acid (FeAc) and GW7647 are both PPAR $\alpha$ agonists, FeAc lowered, whereas GW7647 elevated de novo apoA-I production both in HepG2 cells and in enterocyte-like CaCo-2 cells. This observation may suggest that besides activation of PPAR $\alpha$ additional factors involved in apoA-I transcription play a role. These factors are potential candidates that can be used in regulating de novo apoA-I production when aiming a lowering CVD risk. To identify factors that are differently expressed we compared gene expression profiles of FeAc- and GW7647-treated HepG2 cells as well as of differentiated CaCo- 2 cells after 3 hours incubation. For this, 22K Agilent Human 1A oligo nucleotide V2 microarrays were used. The final data-set contained 63 genes that were differentially expressed after FeAc and GW7647 treatment in both cell lines (an absolute fold change of $\geq 1.2$ and a $P$-value of $P \leq 0.05$ ). As verified by RTq-PCR, gene expression of ATF3, C/EBP $\beta$, GDF15, and NF-IL3 were differently upregulated $(P<0.05)$ in both cell lines. Gene expression of DDIT3 and DDIT4 were only significantly affected in HepG2 cells.

Although, in theory all six selected factors might be involved in de novo apoA-I production, we here now postulate the hypothesis that besides PPAR $\alpha$, C/EBP $\beta$ plays a crucial role that might explain the different effects on de novo apoA-I production between FeAc and GW7647. In this respect, FeAc but not GW7647 activates the transcription factor C/EBP $\beta$, which has a binding-site at the apoA-I promoter site. C/EBP $\beta$ may prevent PPAR $\alpha$ to enhance the apoA-I gene expression. 


\section{Introduction}

Human intervention trials have demonstrated that fibrates, such as fenofibrate, elevate serum high-density lipoprotein cholesterol (HDL-C) as well as apolipoprotein A-I (apoA-I) concentrations, and lower elevated triacylglycerol (TAG) concentrations ${ }^{1}$. Obviously, these changes are expected to lower cardiovascular risk. However, a recent clinical endpoint trail (FIELD study) showed that in this respect fenofibrate was less effective than a priori anticipated ${ }^{2}$. These observations have contributed to the current perception that fibrate-treatment is especially effective for subjects with low HDL-C and elevated TAG concentrations ${ }^{3}$.

Fibrates are thought to elevate HDL-C through effects on the transcription factor peroxisome proliferator-activated receptor alpha (PPAR $\alpha$ ), thereby enhancing de novo apoA-I production in the liver and/or in the small intestine. This stimulates the production of pre- $\beta-\mathrm{HDL}$ particles, which have the capacity to take up large amounts of cholesterol from the vessel walls, thereby increasing the reverse cholesterol transport (RCT) pathway. The effectiveness of selectively increasing apoA-I production on the process of atherogenesis has been shown by intravenous infusion of lipidpoor apoA-I-like particles in humans ${ }^{4}$ and in human apoA-I transgenic mice 5,6 . Thus, in vivo enhancement of apoA-I production may be a promising approach to reduce cardiovascular risk ${ }^{7}$.

Although fibrates activate PPAR $\alpha$, Duez and coworkers ${ }^{8}$ have shown that not all fibrates are equally effective. Some fibrates are full (fenofibrate) and others are partial (gemfibrozil) PPAR $\alpha$ agonists. This difference depends on the potential to activate or repress additional co-factors (activator or repressor to a transcription factor). Indeed, activation of the cofactor DRIP205, which modulates the activation of the PPAR $\alpha / R X R \alpha$ heterodimer, was demonstrated in response to fenofibrate treatment but not to gemfibrozil, in transient human apoA-I PPAR response element (hapoA-IPPRE) transfected Cos-7 cells ${ }^{8}$. It is well possible that additional (co)factors, and/or transcription factors, all part of the yet not fully identified transcription factor complex, are also participating in this complex mechanism.

Fenofibric acid (FeAc) - the active form of fenofibrate - and GW7647 are both PPAR $\alpha$ agonists. We have previously demonstrated that both components transactivate PPRE in hepatocytes (HepG2 cells) and in enterocytes (differentiated $\mathrm{CaCo}-2$ cells), but that FeAc strongly decreased de novo apoA-I production, when compared to GW7647, which increased apoA-I production (see chapter 3 ). We therefore decided to compare gene expression profiles of FeAc- and GW7647-treated HepG2 cells and subtract these profiles from each other to detect PPAR $\alpha$-specific signatures, consisting 
of cofactors or transcription factors that may act as repressors or activators in PPAR $\alpha$ target gene regulation and might be essential in de novo apoA-I production. A similar approach was applied for FeAc- and GW7647-treated differentiated CaCo-2 cells. We were especially searching for genes that were differentially expressed during FeAc- and GW7646-treatment in both cell lines to increase the chance of successful gene identification. 


\section{Materials and methods}

\section{Materials}

Fenofibric acid was kindly provided by A. Edgard (Fournier, Dijon, France). The specific synthetic PPAR $\alpha$ agonist GW7647 was purchased from Sigma (St. Louis, MO, USA). Micro-arrays 22K Agilent Human 1A oligo nucleotide V2 micro-arrays (Agilent Technologies, Santa Clara, CA, USA) were used in this study.

\section{Cell culture}

CaCo-2 cells were purchased from European Collection of Cell Cultures (ECACC, Poole, UK) and cultured in growth medium DMEM at $37^{\circ} \mathrm{C}$ in a humidified atmosphere of $5 \% \mathrm{CO}_{2} / 95 \% \mathrm{O}_{2}(\mathrm{v} / \mathrm{v})$. Medium was supplemented with $10 \%(\mathrm{v} / \mathrm{v})$ FBS, $1 \%(\mathrm{v} / \mathrm{v})$ non essential amino acids (NEAA), $1 \%(\mathrm{v} / \mathrm{v}$ ) sodium pyruvate, and $1 \%(\mathrm{v} / \mathrm{v})$ penicillin/streptomycin. All supplements were obtained from Invitrogen Life Technologies (Carlsbad, CA, USA). For each experimental condition, CaCo-2 cells were seeded in 6-well-tissue-culture plates (Corning, Aston, MA, USA) at a density of $5 \times 10^{5}$ cells per well. Every 2 or 3 days cell culture medium was renewed. After 21 days, confluent and fully differentiated cell monolayers were exposed to $100 \mathrm{nM}$ GW7647 or $0.6 \mathrm{mM} \mathrm{FeAc}$ in triplo for an incubation period of 3 hours to determine gene expression profiles, and for 48 hours to determine apoA-I culture medium concentrations. In contrast to GW7647, FeAc did not dissolve in culture medium. Therefore, FeAc was first added to culture medium and sonificated for 30 minutes at $47 \mathrm{kHz}$ (Branson 2000, Danbury, CL, USA) to obtain a wellhomogenized suspension before it was supplied to the cells. HepG2 cells were kindly provided by Mabtech (Nacka Strand, Sweden) and grown in MEM (Invitrogen Life Technologies, Carlsbad, CA, USA), supplemented with $10 \%$ (v/v) FBS, 1\% (v/v) NEAA, 1\% (v/v) penicillin/streptomycin, and $2 \mathrm{mM} \mathrm{L-}$ glutamine. HepG2 cells were also grown in 6-well-tissue-culture plates, in which $5 \times 10^{5}$ cells were seeded per well. When monolayers of HepG2 cells reached a confluence of approximately $90 \%$, cells were incubated with the components as described above.

Cell culture medium was collected from treated differentiated CaCo-2 cells and HepG2 cells for analysis of human apoA-I protein concentrations with an apoA-I sandwich ELISA (Mabtech, Nacka Strand, Sweden). The apoAI calibration curve was obtained with purified human apoA-I from Sigma (St. Louis, MO, USA). The detection limit of this sandwich ELISA was $1.3 \mathrm{ng} / \mathrm{mL}$ and the between run variation coefficient was less than $5 \%$. Samples were analyzed in duplo on one ELISA plate. 


\section{RNA isolation and Agilent hybridization}

After culture medium was removed, cell lysates were obtained by adding $500 \mu \mathrm{l}$ nucleic acid purification lysis buffer (Applied Biosystems, Warrington, UK) at the monolayer of cells. Total RNA was isolated from $150 \mu$ l cell lysate with an ABI Prism 6100 Nucleic Acid Prep Station according to manufacturer's protocol (Applied Biosystems, Warrington, UK). During this procedure, DNA was removed with Absolute RNA Wash Solution (Applied Biosystems, Warrington, UK). Finally, total RNA was eluted in $150 \mu$ l elution buffer (Applied Biosystems, Warrington, UK). Next, total RNA of all triplo samples of fenofibric acid-treated cells was fluorescently Cy5-labeled, whereas total RNA of the triplo GW7647-treated cells was fluorescently Cy3-labeled. FeAc- and GW7647-labeled total RNA were paired hybridized on 22K Agilent Human 1A oligo nucleotide V2 micro-arrays (Agilent Technologies, Santa Clara, CA, USA). In addition, all paired samples were hybridized on a second Agilent micro-array, in which the RNA samples were labelled with the opposite dye (dye-flip). In this setup, 6 micro-arrays were used to make the comparison between FeAc and GW7647 in HepG2 cells and 6 micro-arrays for differentiated $\mathrm{CaCo}-2$ cells. Hybridization and image scanning procedures were performed at the Microarray Facility, Leuven University, Leuven, Belgium.

\section{Micro-array image and data analysis}

Agilent images were converted into tab-delimited text-files using the Agilent G2567AA Feature Extraction Software v8.5 (Agilent Technologies, Santa Clara, CA, USA) using the default parameters, as defined by the Agilent Human 1Av2 protocol. Next, the text-files were imported into R 2.5.1, using the Bioconductor "limma" package build 2.8.1 for statistical analysis 9, 10 . During data import, values for control spots and spots that did not meet our quality criteria, were flagged. These quality criteria included: 1) each fluorescent spot had to consist of at least 55 pixels, 2) the backgroundcorrected spot intensity (MeanSignal - BGUsed) had to be greater than $2.6 \mathrm{x}$ SD of the measured background, and 3) the fluorescent spot intensity was not saturated for both channels. If both channels were saturated, it was not possible to calculate a fold change.

Next, the background corrected intensities of all twelve micro-arrays were normalized using the LOESS algorithm (within-array), followed by an aquantile normalization step (between-array) 11, 12. Then, an additional quality check was implemented to verify the consistency of the signal intensity differences between the two dyes on their dye-flip counterpart arrays. This was done for each array reporter by subtracting its background corrected mean log signal of the red (Cy5-labeled) channel with the green (Cy3-labeled) signal of its dye-flip counterpart. This was also done for the 
opposite channels. The resulting values were then plotted (see supplemental data: files 1 and 2 ). These values were expected to be highly centred around 0 , since both signal intensities were derived from the same sample. Small deviations in this number can be explained by technical variation and/or dye-specific variation. For one micro-array of differentiated CaCo-2 treated cells this spread was very large. Therefore, this specific micro-array was excluded from further analysis (including normalization), meaning that only five of the six micro-arrays of treated CaCo-2 cells were finally used.

For the remaining micro-arrays, each array-reporter-intensity was fitted to a linear model including a 'dye-effect' intercept, followed by calculating the moderated t-statistics using the "limma" functions Imfit and eBayes. This procedure resulted in a gene list for each cell line, which were exported out of $\mathrm{R}$ as a tab-delimited text file and imported into Microsoft Excel. Next, these gene lists were filtered based on significant P-values $(P<0.05)$ and on absolute fold changes $(|F C| \geq 1.2)$. The resulting lists were: a) manually compared to each other to find biologically interesting genes, $b$ ) used as input for pathway- and GO analysis (GenMAPP v2.1/GO-elite v1.17 beta) for pathway analysis.

To ensure reporter specificity (i.e. include information whether a microarray reporter sequence detected one or more gene product(s)), we reannotated all Agilent micro-array reporters using our annotation procedures

13. All nonspecific reporters were included in the pathway analysis step, but were flagged to prevent incorrect interpretation. Also, this procedure allowed us to use tools such as GenMAPP/GO-Elite, since these programs do not accept Agilent reporter identifiers.

\section{Pathway and Gene Ontology analysis}

For biological pathway analysis the GenMAPP v2.1 program was used ${ }^{14}$. First, all gene expression values, obtained from differentiated $\mathrm{CaCo}-2$ cells and HepG2 cells, were combined into a master list. This master list showed for each reporter the individual gene expression values for each cell-line experiment (FeAc versus GW7647). Together with its associated p-value and FDR-value, these data were imported in GenMAPP using the "HsStd_20060526" gene database. Since GenMAPP does not accept Agilent reporter IDs as input, the Agilent reporters were converted to either a UniProt or an EnsEMBL ID. In this procedure, we used our annotation procedures prior to import. After the data was imported, the MAPPFinder program was run to detect significantly changed pathways (z-scores) in either differentiated CaCo-2 or HepG2 cells treated with FeAc versus GW7647 using fold change $(|F C| \geq 1.2)$ and $p$-value criteria $(P<0.05)$. For pathway analysis the "Hs_Contributed_20070308" pathway set was used. Additionally, 
we compared the outcome of GenMAPP with the outcome of GO-Elite v1.17 on the biological pathway level. This was done since GO-Elite uses a more up-to-date gene database (derived from EnsEMBL human build 48) and adds a random permutation test ( 2.000 cycles) for each pathway found in the list.

GO-Elite was primarily used for the Gene Ontology (GO) analysis. First, criteria-specific gene lists were created in which the reporters were annotated with only EnsEMBL IDs. If the reporter was not annotated or was linked to more than four different EnsEMBL genes, it was left out of the analysis. Next, these lists were imported into GO-Elite. The outcome is nearly identical to the MAPPFinder approach, except that the GO-term lists are now less redundant. This redundancy decrease is obtained by considering the relative position and empirically derived over-representation score of significant GO terms within the GO hierarchy, were the highest scoring terms at each trunk and branch in the hierarchy are chosen to identify a minimal set of required terms corresponding to related GO categories. The GO-database used was of build 1.1 (downloaded on $28^{\text {th }}$ December 2007).

\section{Real-time quantitative RT-PCR analysis}

Differences in expression of genes selected from the micro-array experiments were confirmed by real-time quantitative PCR (RTq-PCR) analysis with predesigned and optimized Taqman gene expression assays from Applied Biosystems (Warrington, UK). RTq-PCR was performed on a Taqman ABI7000 (Applied Biosytems, Warrington, UK). All reagents necessary for running a Taqman RTq-PCR assay were purchased from Applied Biosystems (Warrington, UK). Gene expression levels of ATF3 (Hs00231069_m1), CEBP $\beta$ (Hs00942496_s1), DDIT3 (Hs99999172_m1), DDIT4 (Hs01111686_g1), GDF15 (Hs00171132_m1), NFIL3 (Hs00993282_m1), PPAR $\alpha$ (Hs00231882_m1), and the housekeeping gene PPIA (Hs99999904_m1) were determined. Relative mRNA quantification was performed as described earlier ${ }^{15}$.

\section{Statistical analysis}

RTq-PCR values are shown as mean \pm SEM. Differences on apoA-I protein concentrations between FeAc and GW7647 (delta threshold cycles), or differences between HepG2 cells and differentiated CaCo-2 cells (relative fold changes between FeAc and GW7647), were tested by student's t-test. 


\section{Results}

Effects of fenofibric acid compared to GW7647 on de novo apoA-I production

As shown in figure 1, effects of FeAc and GW7647 on apoA-I concentrations in culture medium were different in HepG2 and in differentiated $\mathrm{CaCo}-2$ cells after 48 hours incubation. Compared to GW7647, FeAc $(0.6 \mathrm{mM})$ significantly decreased $(-40 \%)$ apoA-I concentrations in differentiated $\mathrm{CaCo}-2$ cells, as well as in HepG2 cells $(-48 \%)$. These differential effects on de novo apoA-I production induced by known PPAR $\alpha$ agonists, raised the question whether we could identify co-factors or transcription factors involved in apoA-I production that are differentially regulated by FeAc and GW7647.

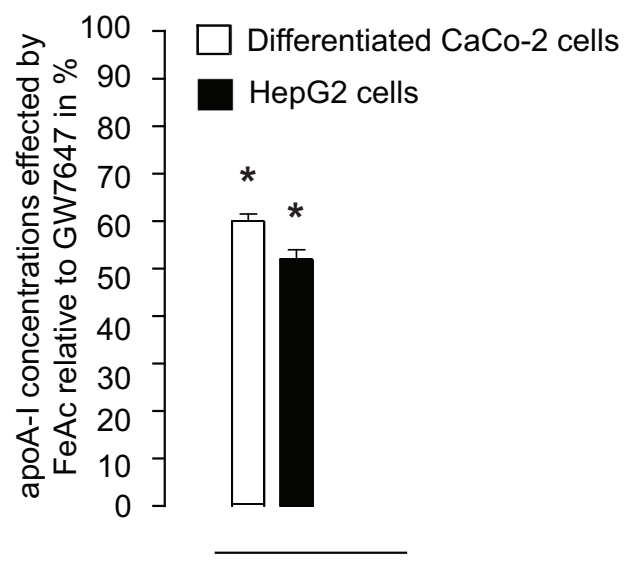

Figure 1. Effects of fenofibric acid compared to GW7647 on de novo apoA-I production in differentiated CaCo-2 cells and HepG2 cells after 48 hours of incubation.

Values are presented as mean \pm SEM as percentage of control values. $\mathrm{N}=2$. $* \mathrm{P}<0.05$ : Statistically different between FeAc and GW7647. 


\section{Genes differentially expressed between fenofibric acid and GW7647}

After 3 hours treating HepG2 cells and differentiated CaCo-2 cells with FeAc $(0.6 \mathrm{mM})$ or GW7647 (100nM), gene expression profiles were determined. These gene expression profiles showed the differences between FeAc-versus GW7647-affected genes. After normalisation, 19025 genes that were expressed differently after FeAc treatment, as compared to GW7647 treatment, could be identified and quantified for HepG2 cells. In differentiated CaCo-2 cells this was the case for 19910 genes. After applying the inclusion criteria, i.e. a minimal absolute fold change of $\geq 1.2$ and a $P$-value of $P<0.05$, we obtained the final set of differentially expressed genes after FeAc and GW7647 treatment. This resulted in 473 up-regulated genes and 396 downregulated genes for HepG2 cells, and 238 up-regulated genes and 222 downregulated genes for differentiated $\mathrm{CaCo}-2$ cells. From this data set, 63 genes were differentially expressed in both cell lines, as presented in the Venn diagrams (figure 2). These 63 genes are listed in table 1.

Diff. CaCo-2 HepG2

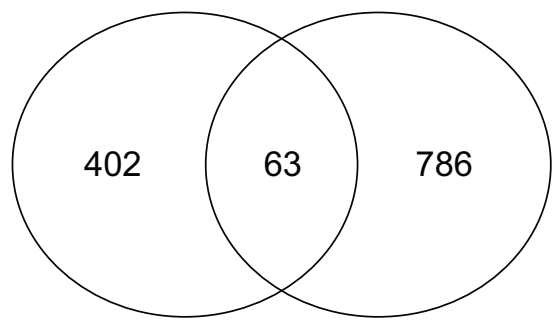

Fold change $\mathrm{IFCl} \geq 1.2$ and $\mathrm{P}<0.05$

Figure 2. Venn diagrams showing numbers of differentially expressed genes in HepG 2 cells and in differentiated CaCo-2 cells after 3 hours of incubation with fenofibric acid or GW7647.

FeAc versus GW7647 gene expression profiles of both cell lines were separately loaded into GO-ELite and GenMAPP. Biological pathways that had a $z$-score of $\geq 1$ in one of the cell lines, such as the MAPK signalling pathway (KEGG), adipogenesis, and hypertrophy, are presented in table 2. Affected genes within these pathways are included in supplemental data: file 3 . In addition to biological pathways, we also generated an additional list of transcription factors, which had - conform to the inclusion criteria - a minimal absolute fold change of $\geq 1.2$ and a $P$-value of $P<0.05$ (table 3 ). Since this is not an official GenMAPP pathway, we do not have a z-score for this selected 
group of transcription factors. Within this group, the expression of genes encoding for ATF3, DDIT4, GDF15, C/EBP $\beta$, NF-IL3 and PPAR $\alpha$ was strongly up-regulated after FeAc as compared to GW7647 treatment in both cell lines.

Since we demonstrated that GW7647 and FeAc had contrasting effects on apoA-I culture medium concentrations both in HepG2 cells and in differentiated $\mathrm{CaCo}-2$ cells after 48 hours incubation, it was unexpected that we did not find a significant effect on apoA-I gene expression after 3 hours incubation. Although we have not verified this, it might be that apoA-I transcription is only elevated after incubation periods longer than 3 hours. 
Table 1. Differentially expressed genes by fenofibric acid versus GW7647 in HepG2 cells and in differentiated $\mathrm{CaCo}-2$ cells (Part A).

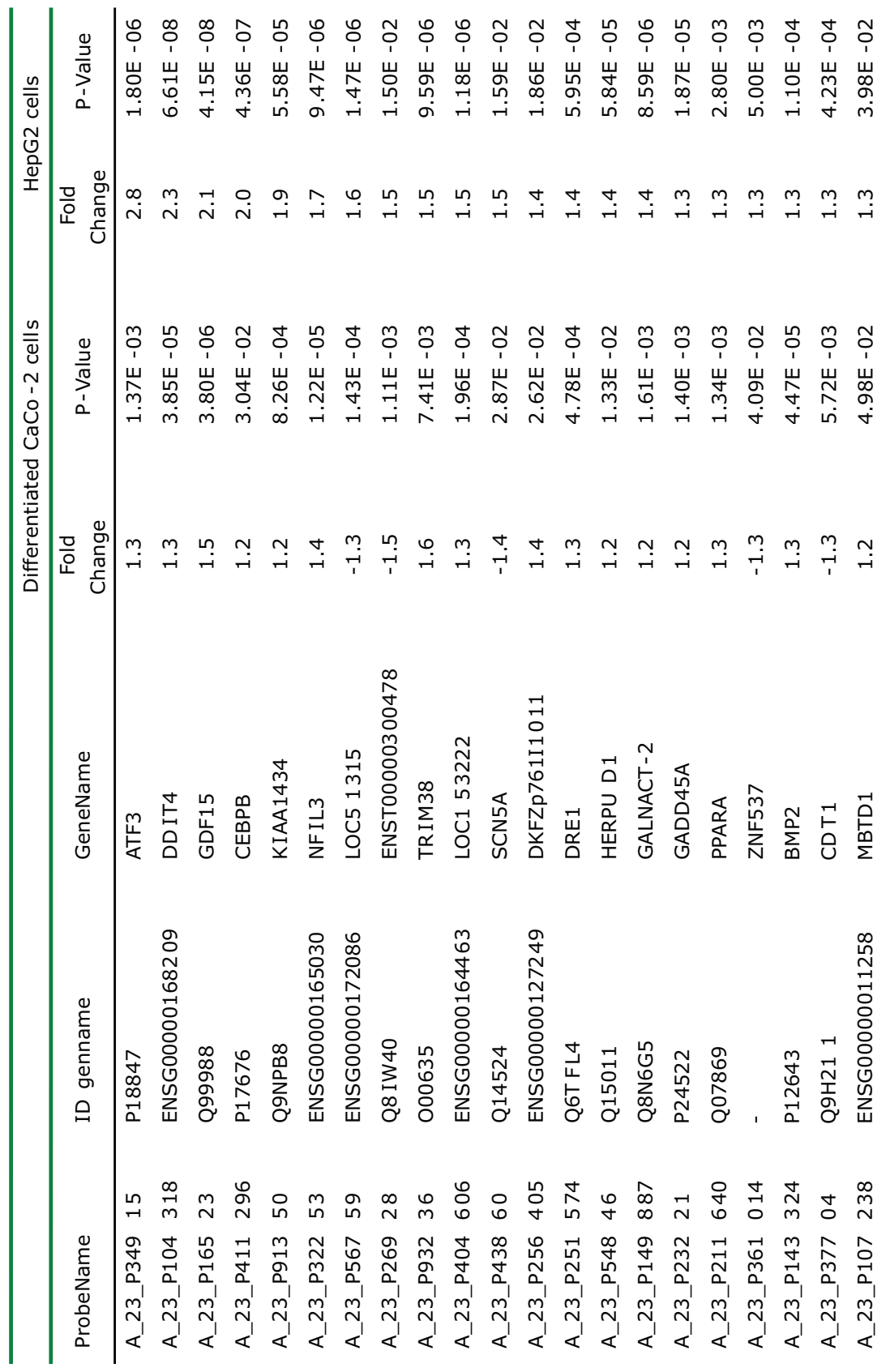


Table 1. Differentially expressed genes by fenofibric acid versus GW7647 in HepG2 cells and in differentiated CaCo-2 cells (Part B).

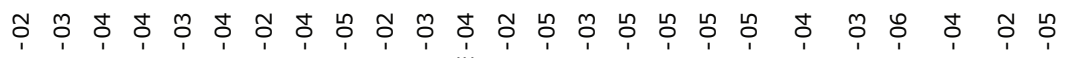

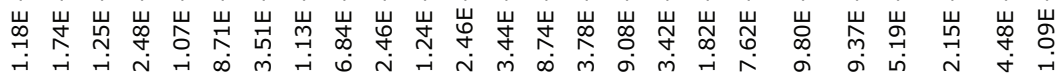

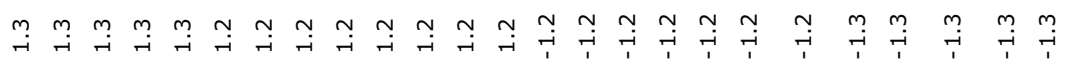

mon

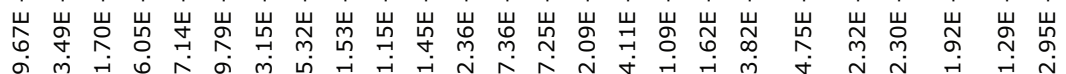

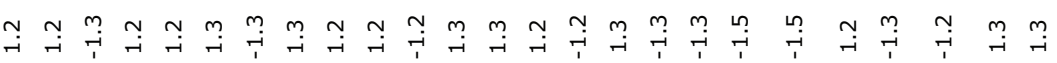

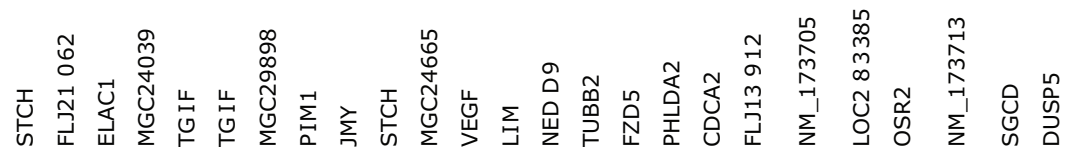

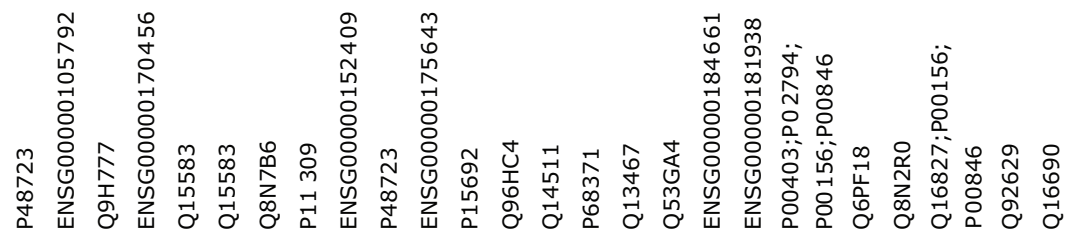

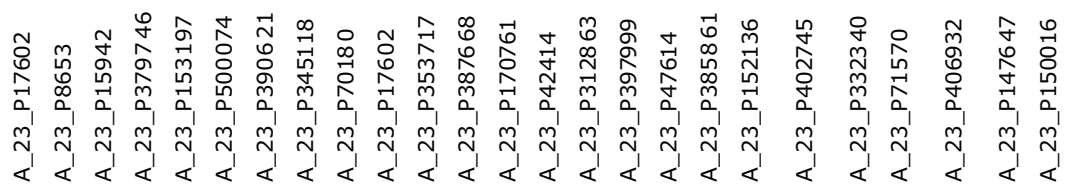


Table 1. Differentially expressed genes by fenofibric acid versus GW7647 in HepG2 cells and in differentiated CaCo- 2 cells (Part C).

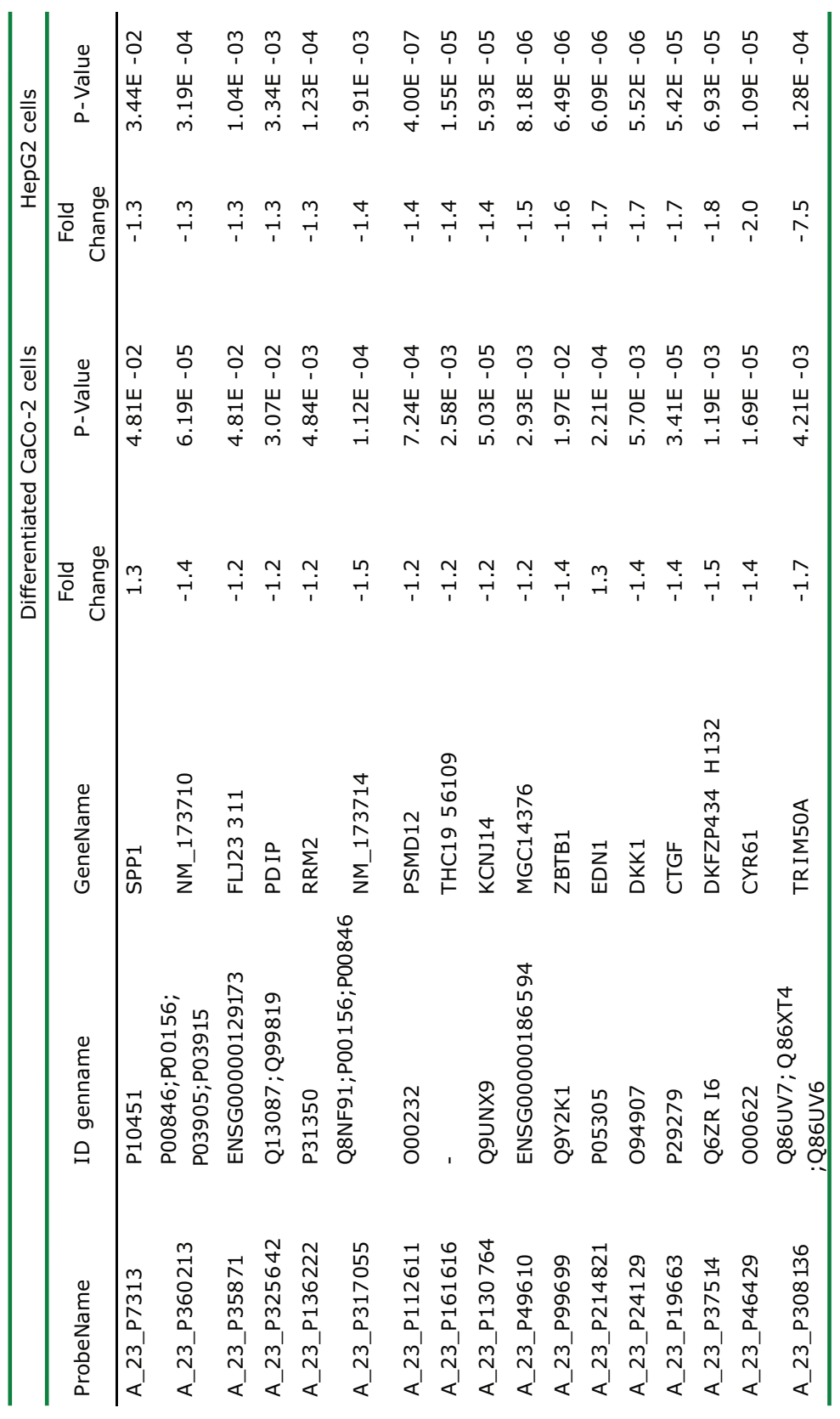


Table 2. Differentially affected GenMAPP v2.1 pathways by fenofibric acid versus GW7647 in HepG2 cells and in differentiated CaCo-2 cells (Part A).

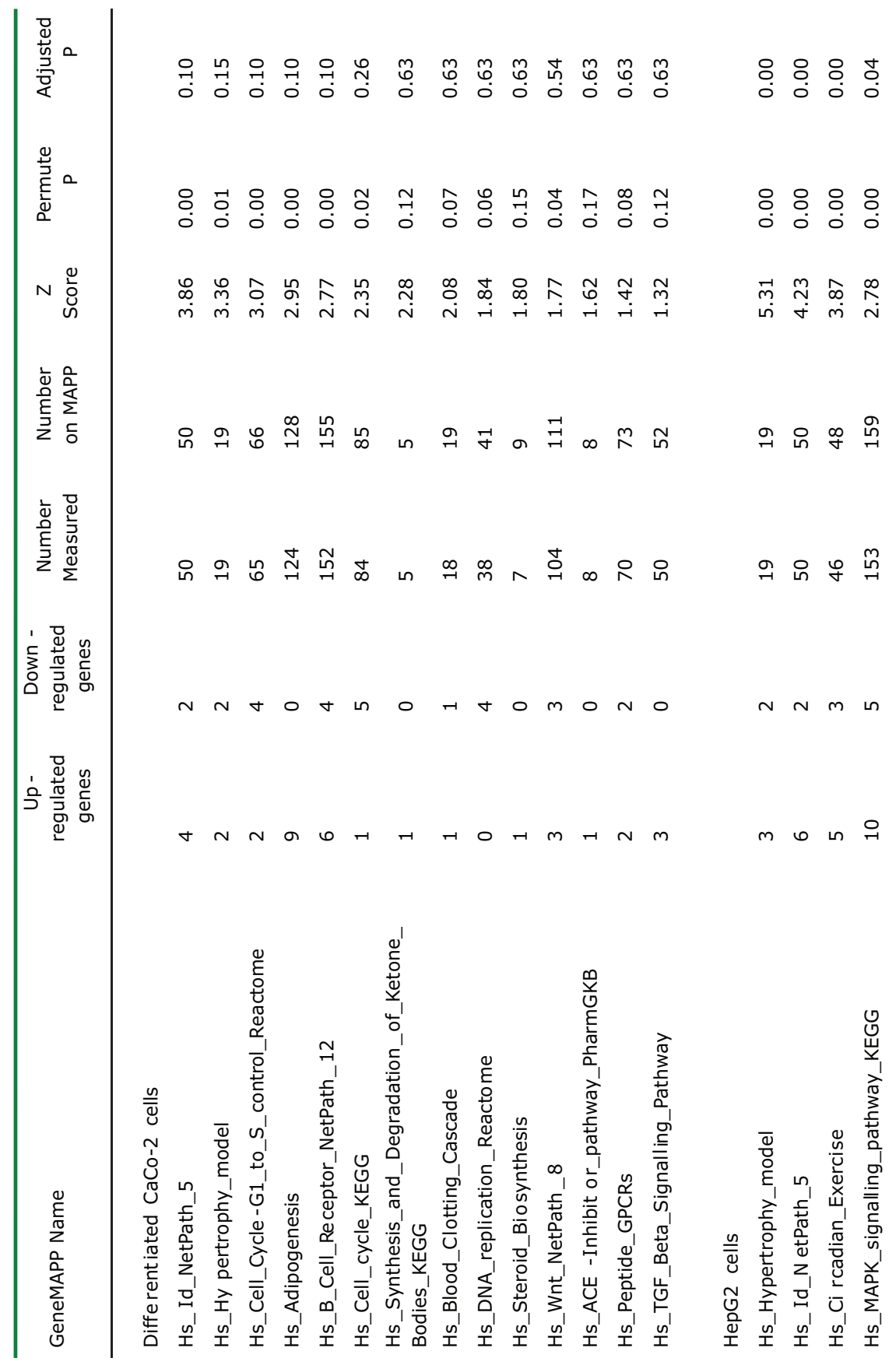


Table 2. Differentially affected GenMAPP v2.1 pathways by fenofibric acid versus GW7647 in HepG2 cells and in differentiated CaCo-2 cells (Part B).

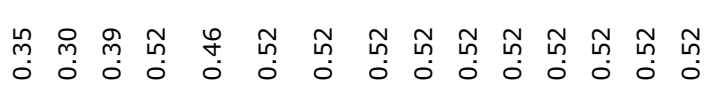

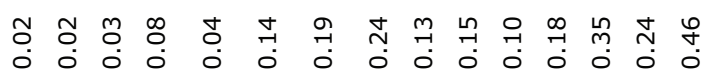

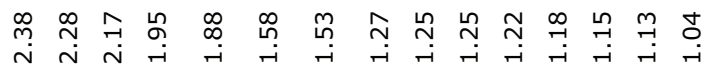

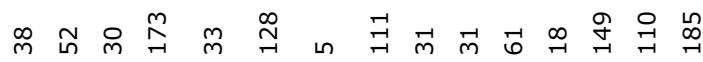

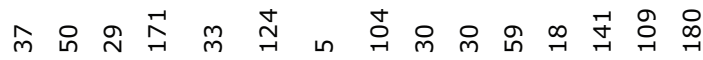

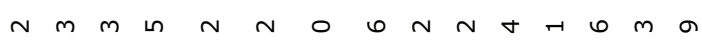

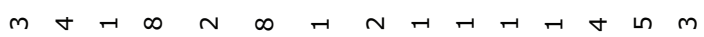

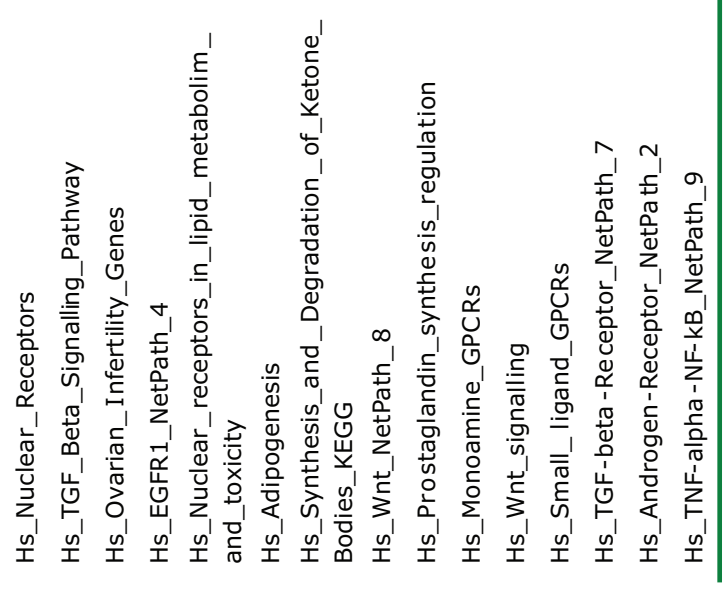


Table 3. Differentially expressed genes of selected transcription factors by fenofibric acid versus GW7647 in HepG2 cells and/or in differentiated CaCo-2 cells present in human GenMAPP v2.1 pathways.

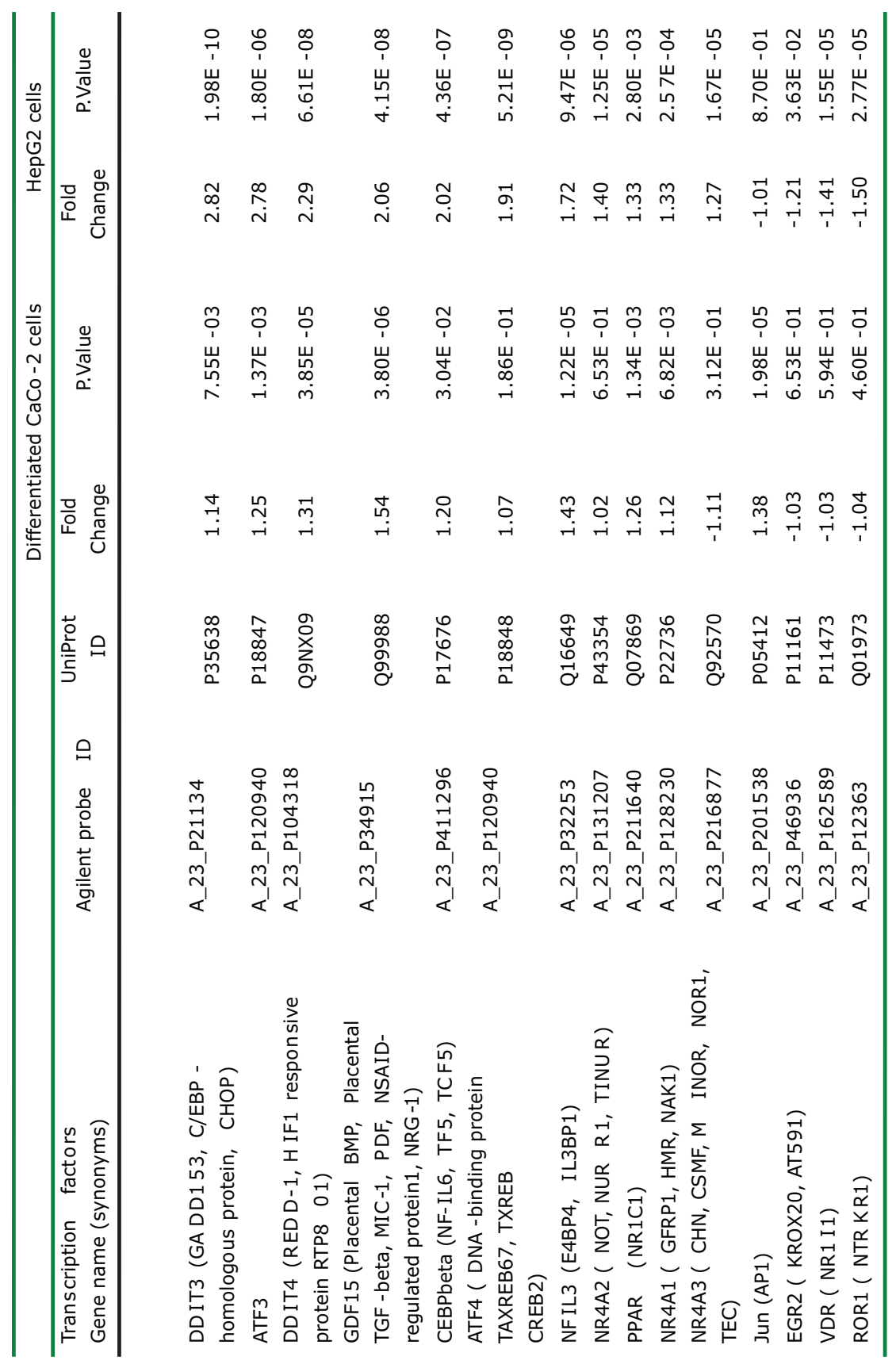




\section{Verification of micro-array results}

As determined by the micro-array data analysis, gene expression after FeAc treatment, as compared to GW7647 treatment, was differently affected in HepG2 cells and/or in differentiated CaCo-2 cells for ATF3, C/EBP $\beta$, DDIT3, DDIT4, GDF15, NF-IL3, and PPAR $\alpha$. After RTq-PCR, differences in expressions of ATF3, C/EBP $\beta$, GDF15, and NF-IL3 after FeAc and GW7647 treatment reached statistical significance in both cell lines as shown in figure $\mathbf{3}$ $(P<0.05)$. Gene expression of DDIT3 and DDIT4 were only significantly affected in HepG2 cells. Furthermore, in HepG2 cells FeAc reduced PPAR $\alpha$ gene expression (a relative fold change of 0.68 ) as compared to the effect of GW7647, whereas PPAR $\alpha$ gene expression was elevated (a relative fold change of 1.33) in differentiated CaCo-2 cells. However, changes between treatments were not significantly different.

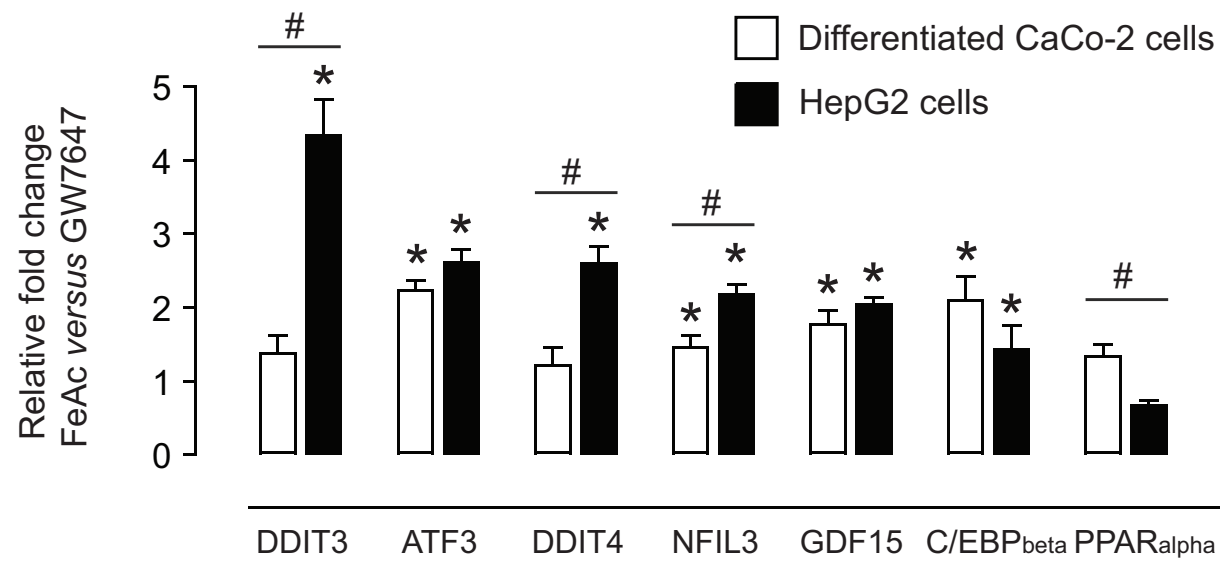

Figure 3. Relative fold changes of selected transcription factors affected by fenofibric acid versus GW7647, as measured by RTq-PCR.

Values are presented as mean $+/-\mathrm{SEM} . \mathrm{N}=3 . * \mathrm{P}<0.05$. The relative fold change of a selected transcription factor was statistically different affected by FeAc compared to GW7647. Statistical differences of relative fold changes between differentiated CaCo-2 and HepG2 cells (\# $\mathrm{P}<0.05)$. 


\section{Putative apoA-I regulatory mechanism of fenofibric acid versus GW7647}

Since FeAc and GW7647 are both PPAR $\alpha$ agonists inducing PPAR $\alpha$ activation (data not shown) with contrasting effects on de novo apoA-I production in hepatocytes as well as in enterocytes, it is tempting to suggest that other transcription factors and/or PPAR $\alpha$ co-factors, besides PPAR $\alpha$, are involved. We here postulate the hypothesis that differences on C/EBP $\beta$ activity might explain the observed differential effects on apoA-I protein concentrations between FeAc and GW7647. More into detail, a C/EBP binding-site was previously identified at site $B$ of the apoA-I promoter ${ }^{16}$, and binding of $\mathrm{C} / \mathrm{EBP} \beta$ may reduce apoA-I gene expression. Indeed, the transcription factor C/EBP $\beta$ can act as a repressor as earlier shown for fibrinogen 17 . Furthermore, within regulatory regions of the apoA-I gene no binding sites have been reported for the other differentially expressed transcription factors that were identified in the micro-array data set. This suggests that C/EBP $\beta$ is the most likely candidate out of the list of 63 differentially expressed genes as identified in both HepG2 and in differentiated CaCo-2 cells (table 1 ). Therefore, we hypothesize that the FeAc induced activation of C/EBP $\beta$ can bind to site $B$ at the apoA-I promoter site and consequently prevents PPAR $\alpha$ mediated apoA-I elevation (figure 4A). Since GW7647 does not activate $\mathrm{C} / \mathrm{EBP} \beta$ no repression of apoA-I transcription occurred. Furthermore, recent studies have demonstrated that dual PPAR $\alpha / \gamma$ agonists stimulated apoA-I production in HepG2 cells (pioglitazone ${ }^{18}$ ) and elevated serum apoA-I levels in vivo in non-diabetic insulin resistant subjects (tesaglitazar ${ }^{19}$ ). This might be explained by observations that PPAR $\gamma$ can bind to $C / E B P \beta$, which results into the formation of the complex PPAR $\gamma$-C/EBP $\beta$ thereby inactivating C/EBP $\beta$ (figure 4C) ${ }^{20}$. Although this does not prove that PPAR $\gamma$ activation can play an essential role in apoA-I synthesis, results are suggestive. Therefore, we further hypothesize that simultaneous activation of PPAR $\alpha$ and PPAR $\gamma$ enhances apoA-I gene expression and consequently results in elevated serum apoA-I levels (figure 4B). To confirm or refuse the hypothesis that PPAR activation is quantitatively important, more side-by-side studies on the effects on PPAR $\alpha$ and a dual PPAR $\alpha / \gamma$ agonists on changes in apoA-I concentrations and gene expression are needed. 

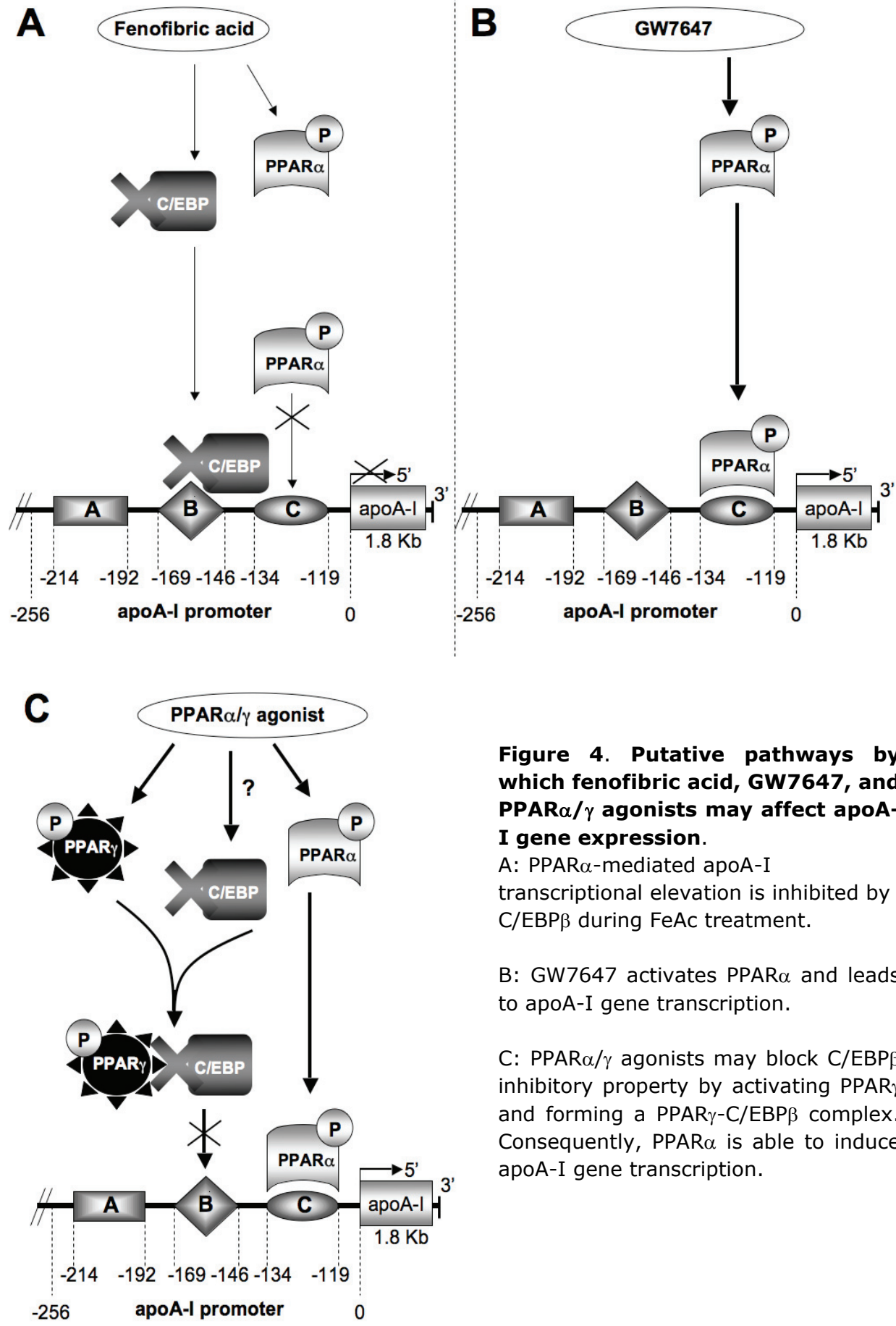

Figure 4. Putative pathways by which fenofibric acid, GW7647, and PPAR $\alpha / \gamma$ agonists may affect apoAI gene expression.

A: PPAR $\alpha$-mediated apoA-I transcriptional elevation is inhibited by C/EBP $\beta$ during FeAc treatment.

B: GW7647 activates PPAR $\alpha$ and leads to apoA-I gene transcription.

C: PPAR $\alpha / \gamma$ agonists may block C/EBP $\beta$ inhibitory property by activating PPAR $\gamma$ and forming a PPAR $\gamma-\mathrm{C} / \mathrm{EBP} \beta$ complex. Consequently, PPAR $\alpha$ is able to induce apoA-I gene transcription. 
In summary, we hypothesize that FeAc activates not only PPAR $\alpha$ but also C/EBP $\beta$, which blocked PPAR $\alpha$-mediated apoA-I elevation in both cell models. Furthermore, PPAR $\gamma$ may prevent the apoA-I inhibitory effects of $C / E B P \beta$, which may explain the promising effects of PPAR $\alpha / \gamma$ dual agonists on apoA-I production. Although PPAR $\alpha / \gamma$ dual agonists are promising, most PPAR $\alpha / \gamma$ dual agonists were suspended during the clinical trails due to side effects. 


\section{Discussion}

It is generally accepted that PPAR $\alpha$ agonists elevate apoA-I gene expression. However, not all PPAR $\alpha$ agonists have similar effects ${ }^{8}$. In this study, we have comprehensively analysed gene expression profiles of HepG2 cells and of differentiated $\mathrm{CaCo}-2$ cells, which were treated with two different PPAR $\alpha$ agonists, i.e. FeAc and GW7647. We found that FeAc lowered de novo apoA-I production in vitro in hepatocytes as well as in enterocytes when compared with GW7647 (figure 1 and also see chapter 3). This may indicate that additional (co)factors or transcription factors collaborating with PPAR $\alpha$ are involved. RTq-PCR assays confirmed findings from micro-array analysis that FeAc up-regulated gene expression of ATF3, C/EBP $\beta$, GDF15, and NF-IL3 as compared to GW7647 both in HepG2 cells and differentiated CaCo-2 cells.

Of all differentially regulated transcription factors identified during the micro-array analysis, a binding site at the apoA-I promoter region has only been demonstrated for $C / E B P \beta$, i.e. within site $B{ }^{16}$. This implies a potential role for $C / E B P \beta$ on apoA-I transcription. Indeed, inhibitory effects of C/EBP $\beta$ have previously been described for the expression of another PPAR $\alpha$ target gene, i.e. fibrinogen ${ }^{17}$. Therefore, we postulate the hypothesis that C/EBP $\beta$ plays a crucial role to explain the differences between GW7647 and FeAc on apoA-I synthesis. More into detail, FeAc simultaneously activate PPAR $\alpha$ and $\mathrm{C} / \mathrm{EBP} \beta$. Activated $\mathrm{C} / \mathrm{EBP} \beta$ binds to its binding site at the apoA-I promoter and prevents apoA-I elevation mediated by PPAR $\alpha$. Furthermore, since PPAR $\alpha / \gamma$ agonists strongly elevated the apoA-I production, we further hypothesize an alternative pathway possibility to enhance the apoA-I production, in which activation of PPAR $\gamma$ plays a major role. Activated PPAR $\gamma$ is able to form C/EBP $\beta$-PPAR $\gamma$ complexes, which prevents C/EBP $\beta$ repressing effects on apoAI gene expression. This is in contrast to the effect of FeAc, which only activated PPAR $\alpha$ and C/EBP $\beta$, but not PPAR $\gamma$. However, this assumption needs to be verified in future experiments, for example, by examining effects of FeAc during C/EBP $\beta$ silencing experiments or in C/EBP $\beta$ knockout animal models. Moreover, within this regulatory mechanism, C/EBP $\beta$ may also interact with ATF3 during the latter stages of the repressing response, as demonstrated in C/EBP $\beta$ siRNA-treated HepG2 cells ${ }^{22}$. Interestingly, ATF3 was also differentially expressed in FeAc- and GW7647-treated cells. ATF3 known as stress-inducible gene - is a member of the ATF/CREB (CAMPresponse-element-binding protein) family of transcription factors, and is mainly indicated as a repressor ${ }^{23}$. Whether ATF3 is also involved in apoA-I transcription is however unknown, but based on our observations is at least worth exploring.

Our hypothesis suggests that PPAR $\alpha / \gamma$ dual agonists may have a more pronounced effect on de novo apoA-I production than selective PPAR $\alpha$ 
activation. Indeed, pioglitazone ${ }^{18}$ elevated de novo apoA-I production in HepG2 cells. In addition, tesaglitazar ${ }^{19}$ elevated serum apoA-I levels in nondiabetic subjects with insulin resistance as well as serum HDL-C concentrations, whereas effects of FeAc on apoA-I were in general less or even not present ${ }^{2,24}$. However, to the best of our knowledge, a placebocontrolled intervention study that has compared the effects of a PPAR $\alpha$ specific agonist side-by-side with a PPAR $\alpha / \gamma$ dual agonist on de novo apoA-I production or on serum apoA-I concentrations has not been conducted to confirm this assumption.

Besides C/EBP $\beta$ and ATF3, a third interesting candidate gene, i.e. GDF15, was upregulated by FeAc as compared to GW7647. As extensively commented by Ago and Sadoshima ${ }^{25}$, GDF15 - a TGF-beta superfamily protein - has been postulated as cardio-protective, anti-inflammatory, antiapoptotic, and anti-growth/hypertrophic. Whether GDF15 plays a role in HDL metabolism, for example by interfering in pathways regulating apoA-I transcription/translation, is unknown.

One remark that has to be made regarding our study design, concerns the fact that it does not include a comparison of gene expression profiles between treated and untreated cells. Therefore, there will be a substantial number of genes that are comparably affected by both agonists, either up- or down-regulated, which will consequently not be identified as differentially expressed as compared to the untreated condition. This also implies that the direction of the affected genes by FeAc and GW7647, as compared to a baseline condition, could not be determined by the current approach.

Moreover, this study focused only on co-factors and transcription factors that were differentially expressed by FeAc and GW7467 in both cell lines. Thus, tissue-specific effects were not evaluated into detail. Nevertheless, the information provided in the Venn diagrams (figure 2) outside the overlapping part contains the differentially expressed tissuespecific target genes. Further research is needed to explore these potential tissue-specific effects.

In conclusion, FeAc induced gene expression of various transcription factors and/or cofactors, such as ATF3, C/EBP $\beta$, GDF15, and NF-IL3, as compared to GW7647 in both cell models. Although, in theory all of these factors might be involved in de novo apoA-I production, we here now postulate the hypothesis that PPAR $\alpha$, and C/EBP $\beta$ play a crucial role that might explain the different effects on de novo apoA-I production between GW7647 and FeAc. Based on our hypothesized models, PPAR $\alpha / \gamma$ dual agonists might have a more pronounced effect on serum apoA-I concentrations than selective PPAR $\alpha$ agonists. However, further research is needed to confirm and extend the postulated regulatory model more into detail. 


\section{References}

1. Despres JP. (2001). Increasing high-density lipoprotein cholesterol: an update on fenofibrate. Am J Cardiol (88):30N-36N.

2. Keech A, Simes RJ, Barter P, et al. (2005). Effects of long-term fenofibrate therapy on cardiovascular events in 9795 people with type 2 diabetes mellitus (the FIELD study): randomised controlled trial. Lancet (366):1849-61.

3. Robins SJ, Bloomfield HE. (2006). Fibric acid derivatives in cardiovascular disease prevention: results from the large clinical trials. Curr Opin Lipidol (17):431-9.

4. Nissen SE, Tsunoda T, Tuzcu EM, et al. (2003). Effect of recombinant ApoA-I Milano on coronary atherosclerosis in patients with acute coronary syndromes: a randomized controlled trial. Jama (290):2292-300.

5. Rubin EM, Krauss RM, Spangler EA, Verstuyft JG, Clift SM. (1991). Inhibition of early atherogenesis in transgenic mice by human apolipoprotein AI. Nature (353):265-7.

6. Garber DW, Datta G, Chaddha M, et al. (2001). A new synthetic class A amphipathic peptide analogue protects mice from dietinduced atherosclerosis. J Lipid Res (42):54552.

7. Rader DJ. (2006). Molecular regulation of HDL metabolism and function: implications for novel therapies. J Clin Invest (116):3090100.

8. Duez $H$, Lefebvre $B$, Poulain $P$, et al. (2005). Regulation of human apoA-I by gemfibrozi and fenofibrate through selective peroxisome proliferator-activated receptor alpha modulation. Arterioscler Thromb Vasc Biol (25):585-91.

9. Smyth GK. (2005). Bioinformatics and Computational Biology Solutions Using $\mathrm{R}$ and Bioconductor. Springer, New York 397-420.

10. Smyth GK, Yang YH, Speed T. (2003). Statistical issues in cDNA micro-array data analysis. Methods Mol Biol (224):111-36.

11. Bolstad BM, Irizarry RA, Astrand M, Speed TP. (2003). A comparison of normalization methods for high density oligonucleotide array data based on variance and bias. Bioinformatics (19): 185-93.

12. Yang $\mathrm{YH}$, Dudoit $\mathrm{S}$, Luu $\mathrm{P}$, et al. (2002). Normalization for cDNA micro-array data: a robust composite method addressing single and multiple slide systematic variation. Nucleic Acids Res (30): e15.

13. Gaj S, van Erk A, van Haaften RI, Evelo CT. (2007). Linking micro-array reporters with protein functions. BMC Bioinformatics (8): 360 .

14. Salomonis N, Hanspers $\mathrm{K}$, Zambon AC, et al. (2007). GenMAPP 2: new features and resources for pathway analysis. BMC Bioinformatics (8):217.
15. Livak KJ, Schmittgen TD. (2001). Analysis of relative gene expression data using real-time quantitative PCR and the 2(-Delta Delta C(T)) Method. Methods (25):402-8.

16. Zannis VI, Kan HY, Kritis A, Zanni EE, Kardassis D. (2001). Transcriptional regulatory mechanisms of the human apolipoprotein genes in vitro and in vivo. Curr Opin Lipidol (12):181-207.

17. Gervois P, Vu-Dac N, Kleemann R, et al. (2001). Negative regulation of human fibrinogen gene expression by peroxisome proliferator-activated receptor alpha agonists via inhibition of CCAAT box/enhancer-binding protein beta. J Biol Chem (276):33471-7.

18. Qin S, Liu T, Kamanna VS, Kashyap ML. (2007). Pioglitazone stimulates apolipoprotein A-I production without affecting HDL removal in HepG2 cells: involvement of PPAR-alpha. Arterioscler Thromb Vasc Biol (27):2428-34.

19. Schuster H, Fagerberg B, Edwards S, et al. (2007). Tesaglitazar, a dual peroxisome proliferator-activated receptor alpha/gamma agonist, improves apolipoprotein levels in non-diabetic subjects with insulin resistance. Atherosclerosis.

20. Wang LH, Yang $X Y$, Zhang $X$, Farrar WL. (2007). Inhibition of adhesive interaction between multiple myeloma and bone marrow stromal cells by PPARgamma cross talk with NF-kappaB and C/EBP. Blood (110):4373-84.

21.Schoonjans K, Peinado-Onsurbe J, Lefebvre AM, et al. (1996). PPARalpha and PPARgamma activators direct a distinct tissue-specific transcriptional response via a PPRE in the lipoprotein lipase gene. Embo J (15): $5336-48$

22. Thiaville MM, Dudenhausen EE, Zhong C, Pan YX, Kilberg MS. (2007). Deprivation of protein or amino acid induces C/EBPbeta synthesis and binding to amino acid response elements, but its action is not an absolute requirement for enhanced transcription. Biochem J.

23. Hai T, Hartman MG. (2001). The molecular biology and nomenclature of the activating transcription factor/cAMP responsive element binding family of transcription factors: activating transcription factor proteins and homeostasis. Gene (273):1-11.

24. Hiukka $A$, Leinonen $E$, Jauhiainen $M$, et al. (2007). Long-term effects of fenofibrate on VLDL and HDL subspecies in participants with type 2 diabetes mellitus. Diabetologia (50):2067-75.

25. Ago T, Sadoshima J. (2006). GDF15, a cardioprotective TGF-beta superfamily protein.[comment]. Circulation Research (98):294-7. 


\section{Supplemental data (1-3)}
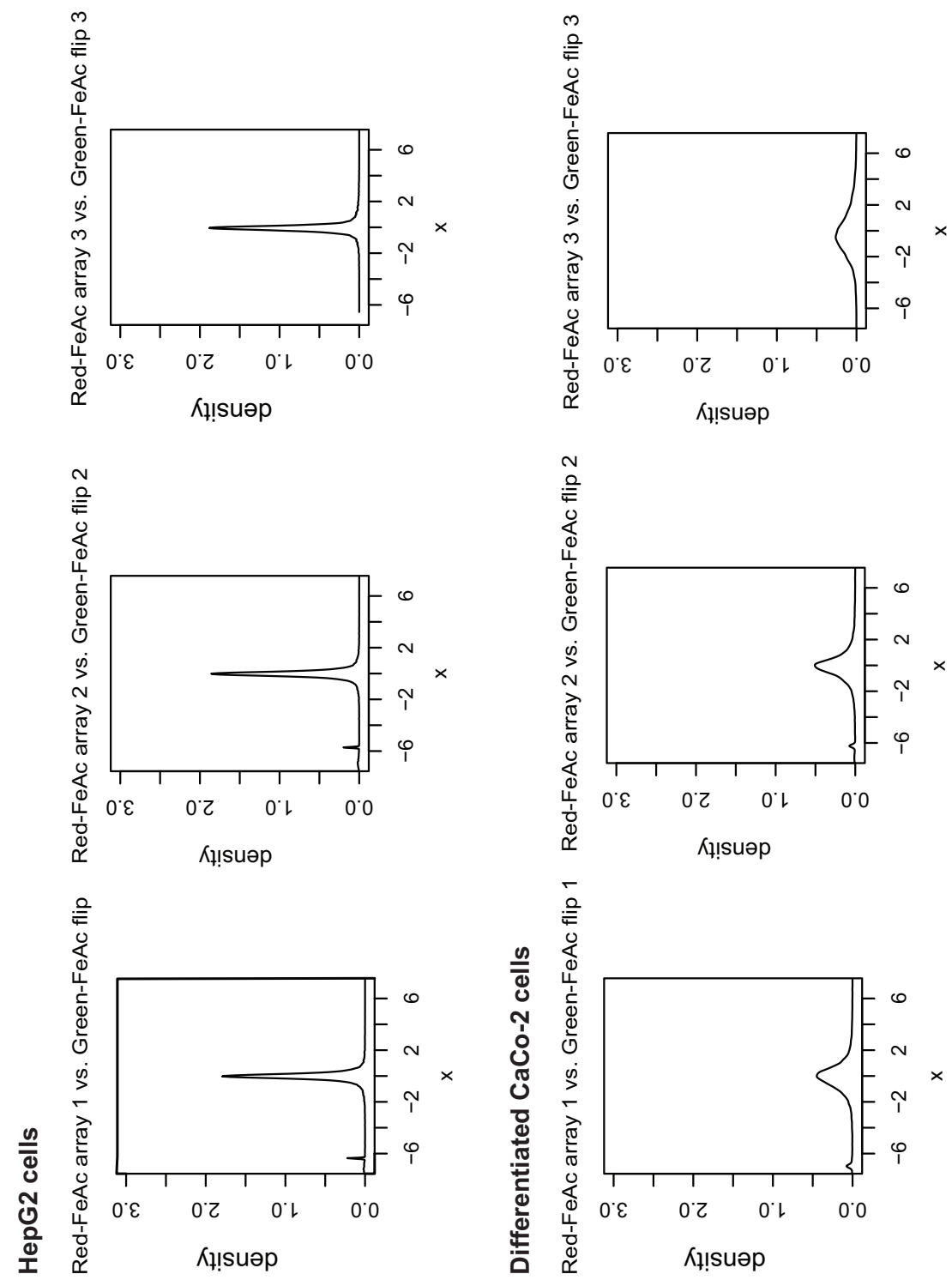

Supplemental data 1: figure 1. Quality check of the Agilent micro-arrays to verify the consistency of the signal intensity differences between the red and green dye of FeAc labelled samples in HepG2 and in differentiated CaCo-2 cells. 

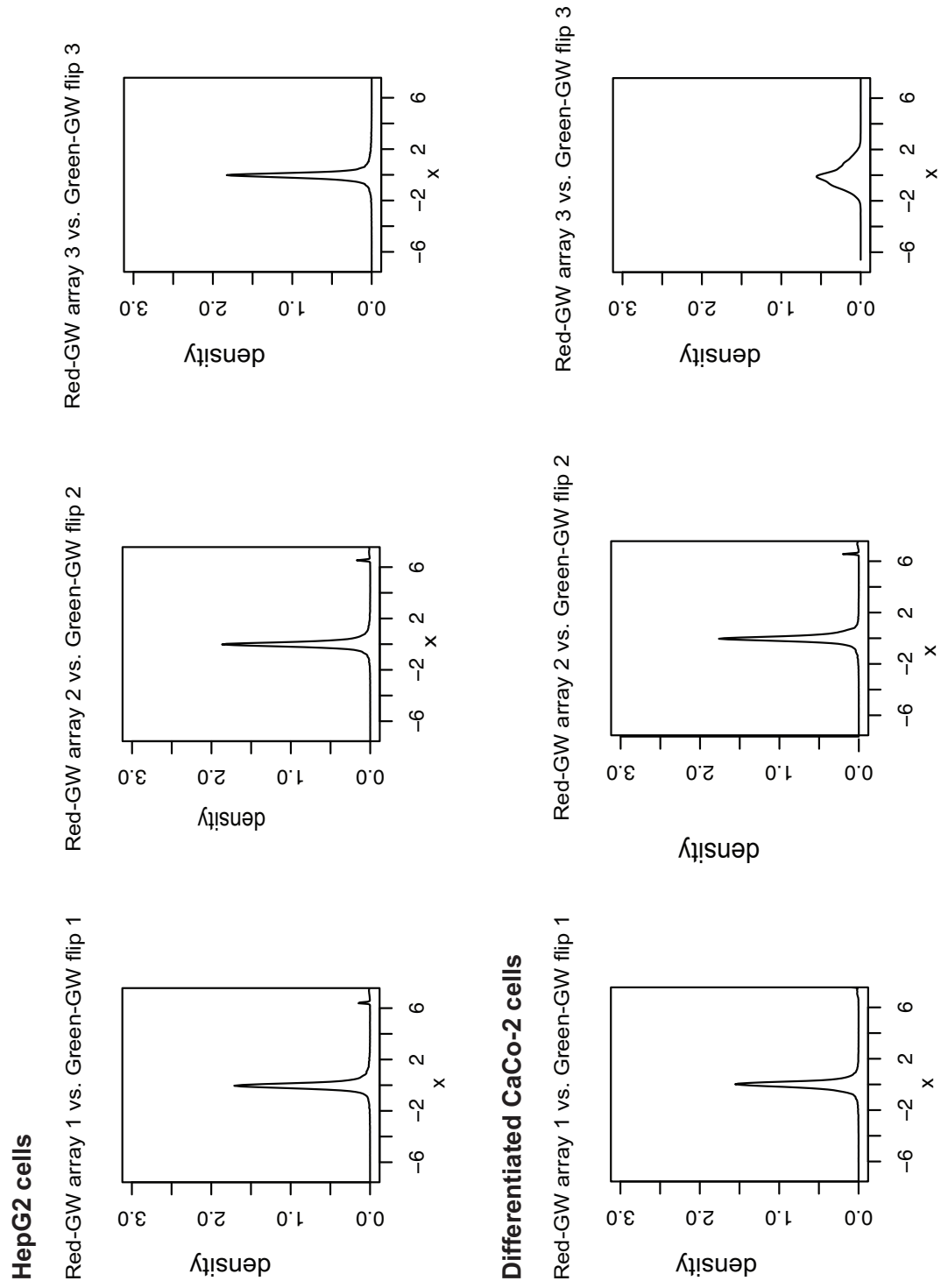

Supplemental data 2: figure 2. Quality check of the Agilent micro-arrays to verify the consistency of the signal intensity differences between the red and green dye of GW7647 labelled samples in HepG2 and in differentiated CaCo-2 cells. 
Supplemental data 3: table 1. Differentially expressed genes by fenofibric acid versus GW7647 in HepG2 cells and/or in differentiated CaCo-2 cells present in affected human GenMAPP v2.1 pathways (Part A).

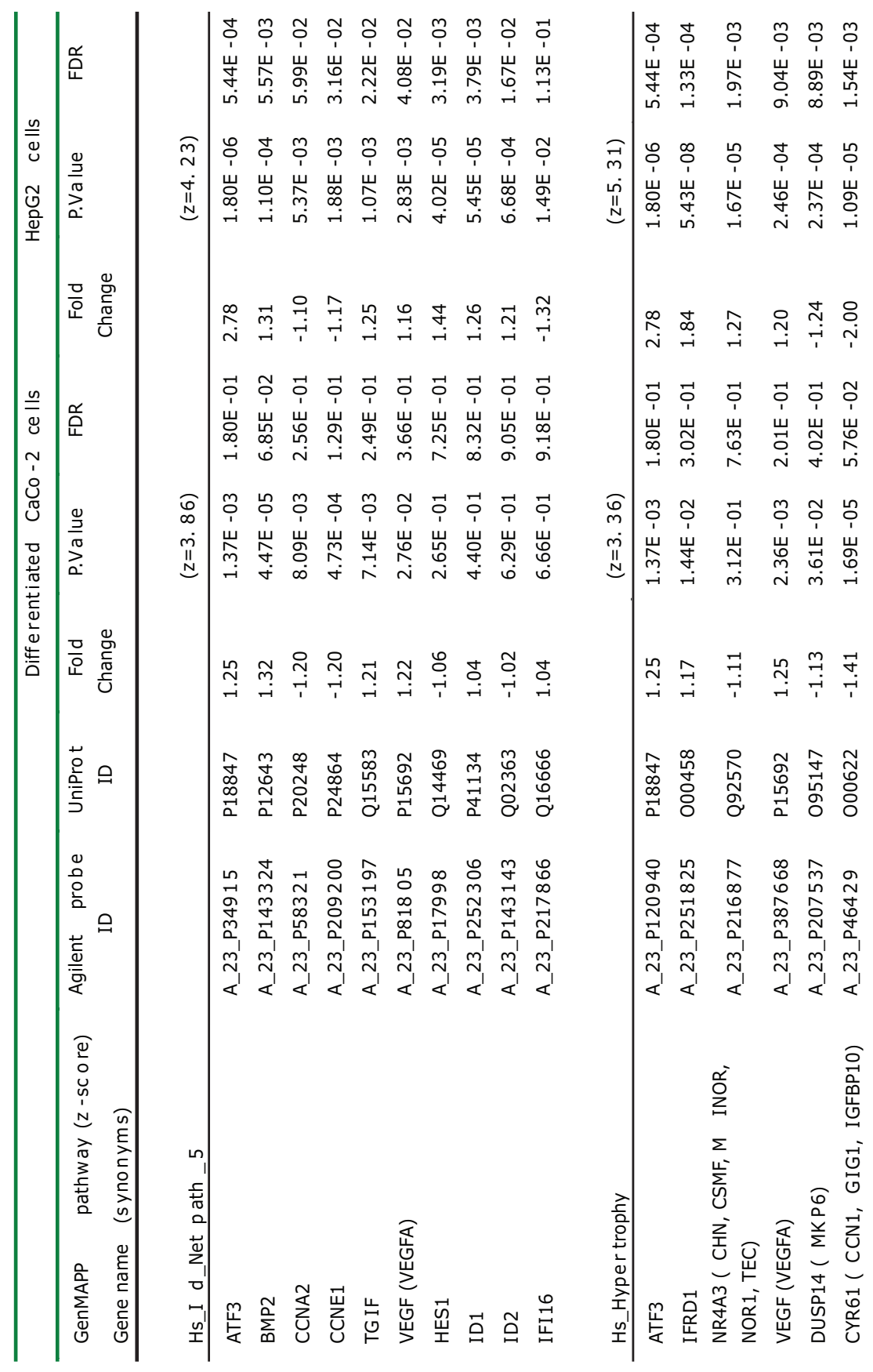


Supplemental data 3: table 1. Differentially expressed genes by fenofibric acid versus GW7647 in HepG2 cells and/or in differentiated CaCo- 2 cells present in affected human GenMAPP v2.1 pathways (Part B).

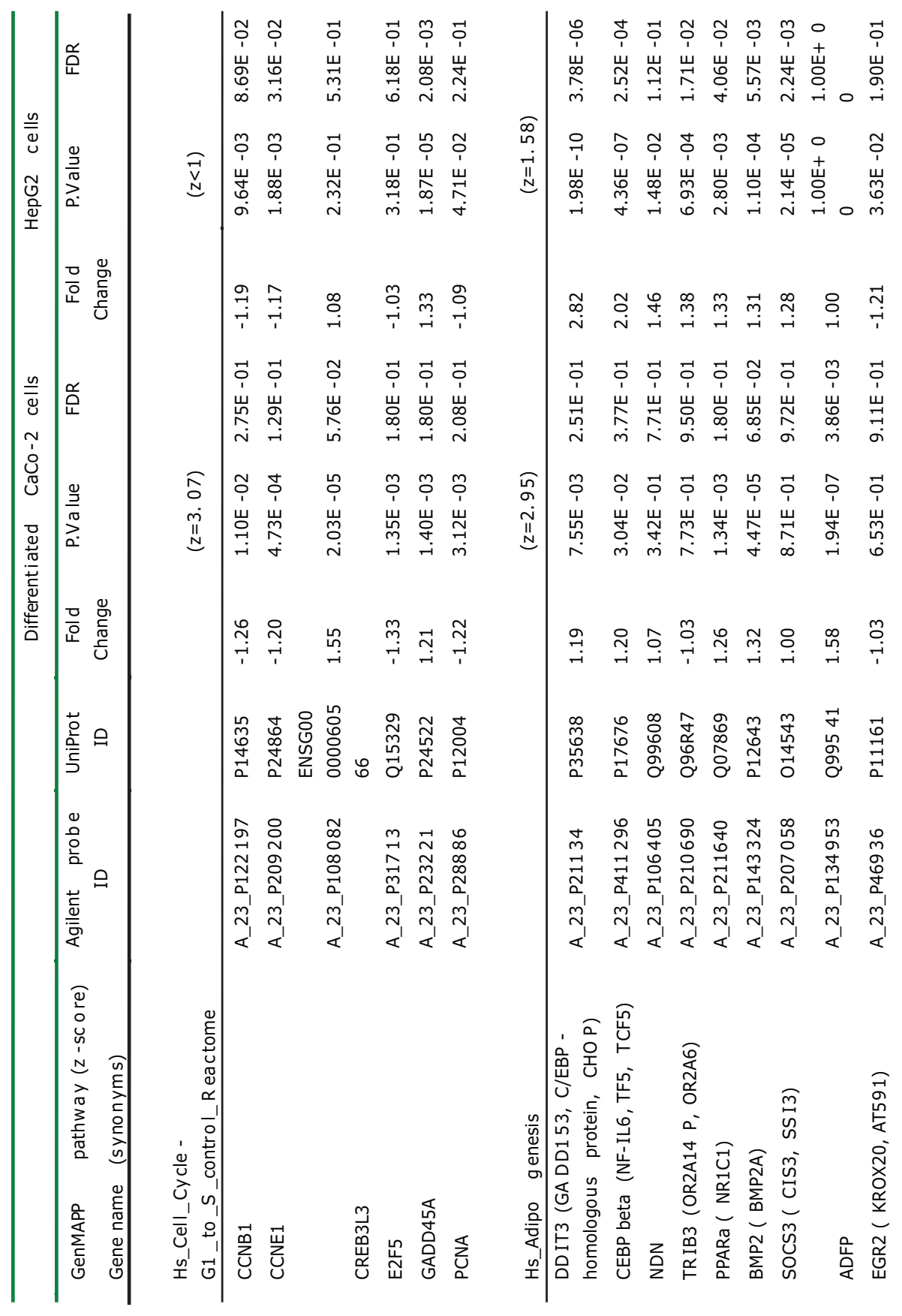


Supplemental data 3: table 1. Differentially expressed genes by fenofibric acid versus GW7647 in HepG2 cells and/or in differentiated CaCo- 2 cells present in affected human GenMAPP v2.1 pathways (Part C).

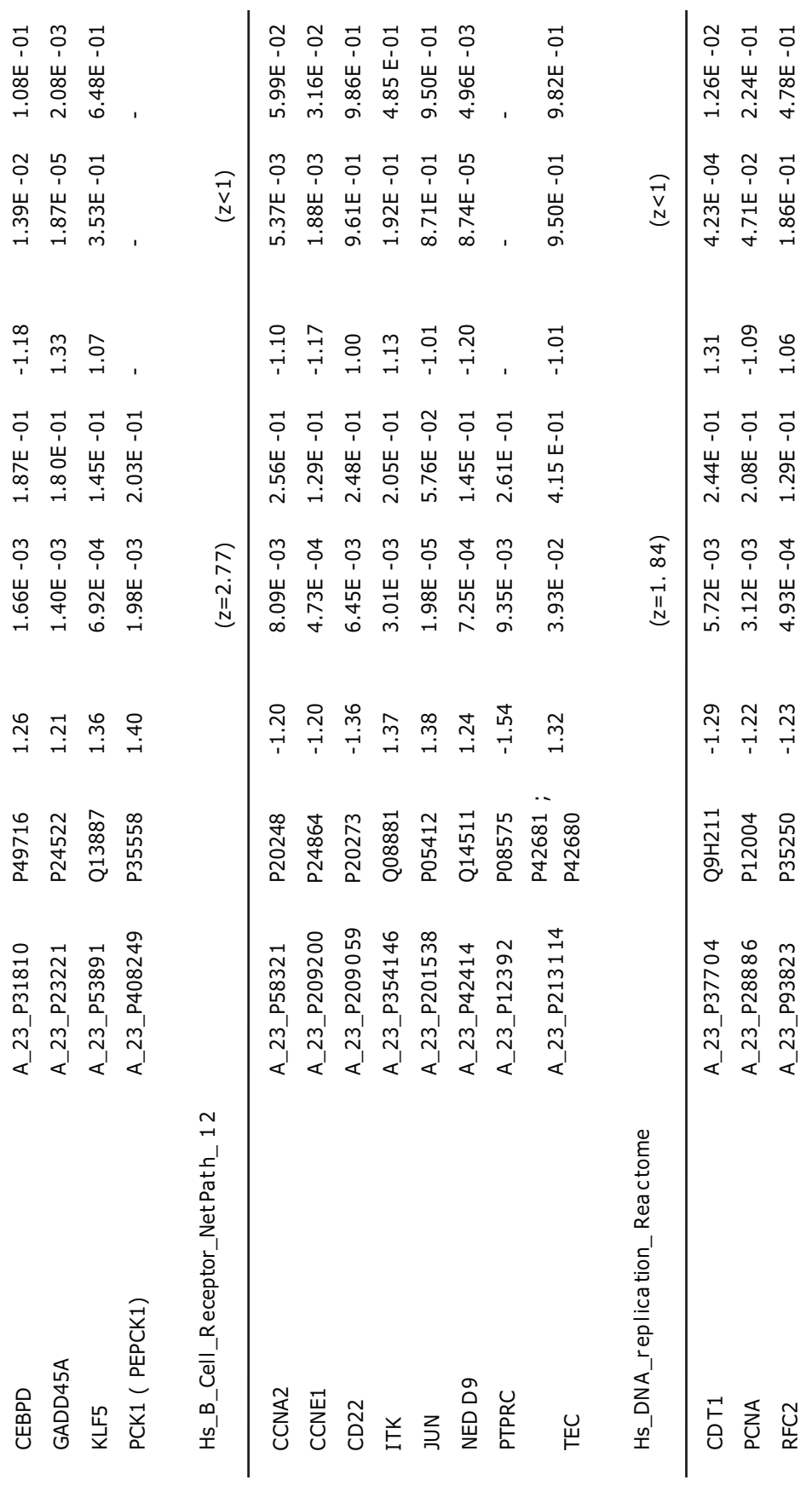


Supplemental data 3: table 1. Differentially expressed genes by fenofibric acid versus GW7647 in HepG2 cells and/or in differentiated CaCo-2 cells present in affected human GenMAPP v2.1 pathways (Part D).

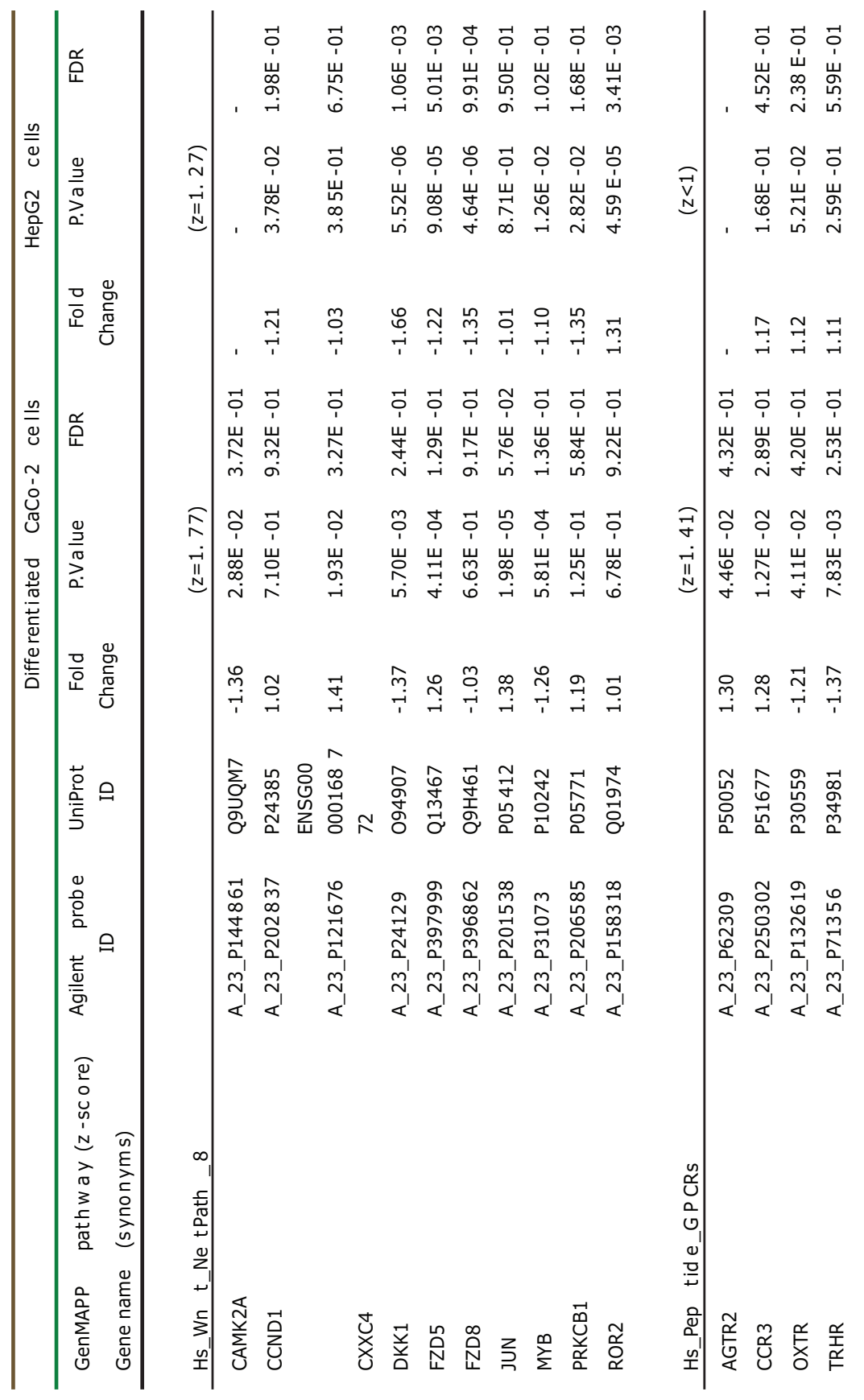


Supplemental data 3: table 1. Differentially expressed genes by fenofibric acid versus GW7647 in HepG2 cells and/or in differentiated CaCo-2 cells present in affected human GenMAPP v2.1 pathways (Part E).

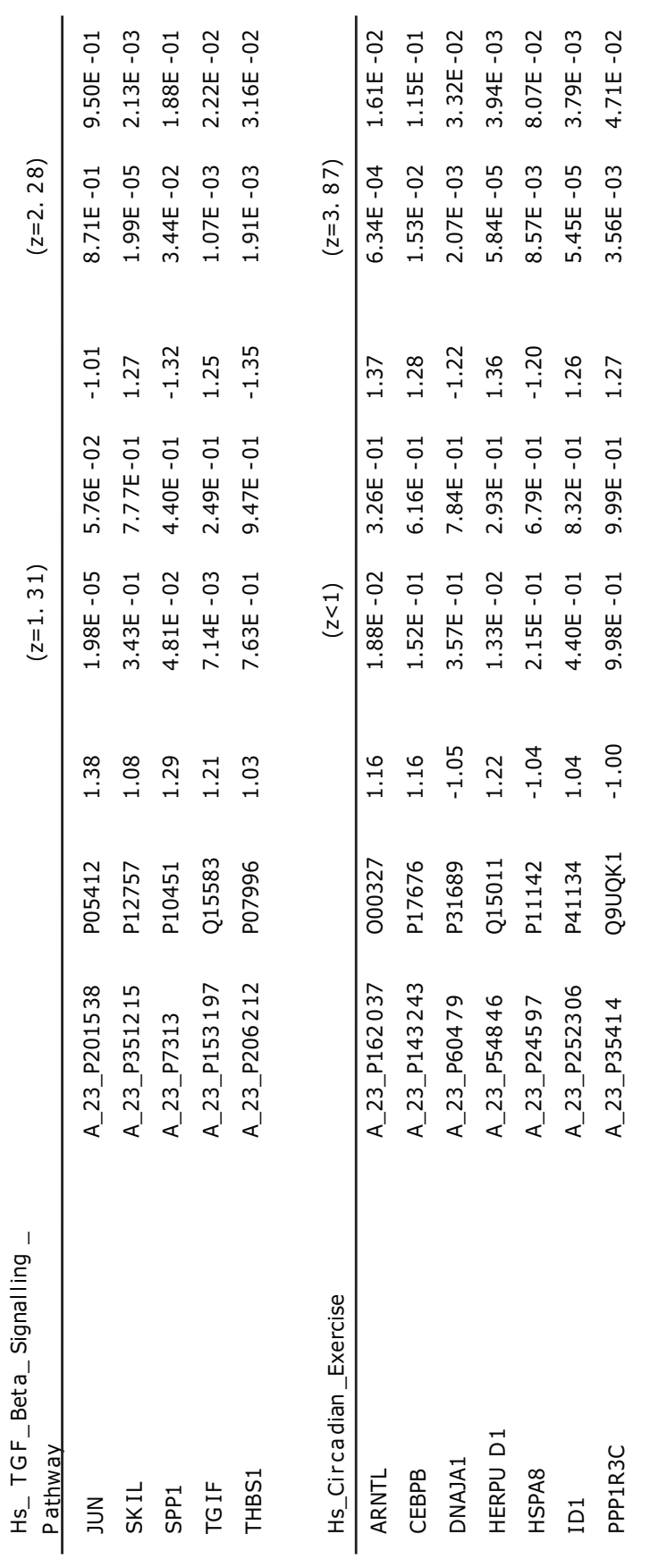


Supplemental data 3: table 1. Differentially expressed genes by fenofibric acid versus GW7647 in HepG2 cells and/or in differentiated CaCo- 2 cells present in affected human GenMAPP v2.1 pathways (Part F).

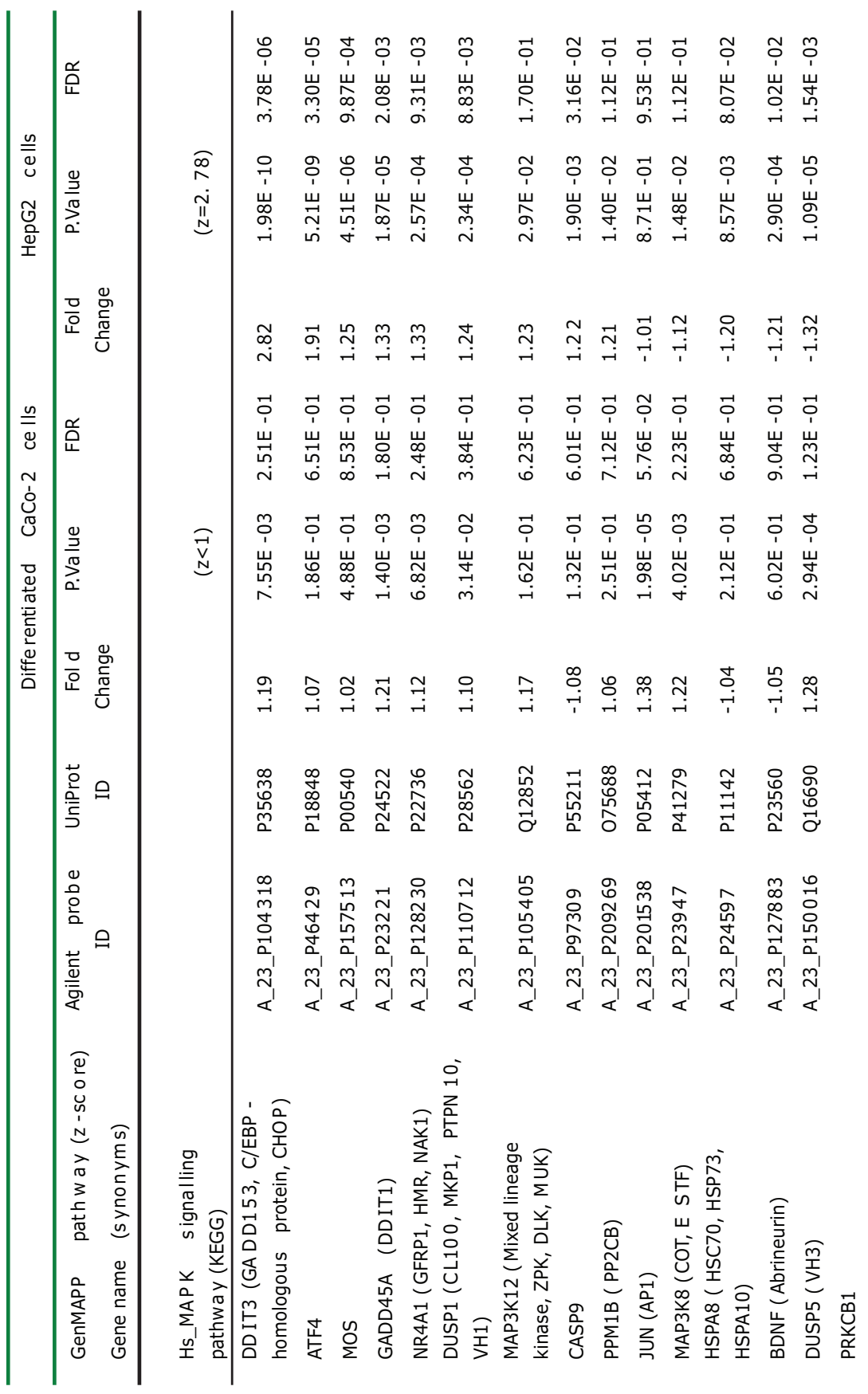


Supplemental data 3: table 1. Differentially expressed genes by fenofibric acid versus GW7647 in HepG2 cells and/or in differentiated CaCo-2 cells present in affected human GenMAPP v2.1 pathways (Part G).

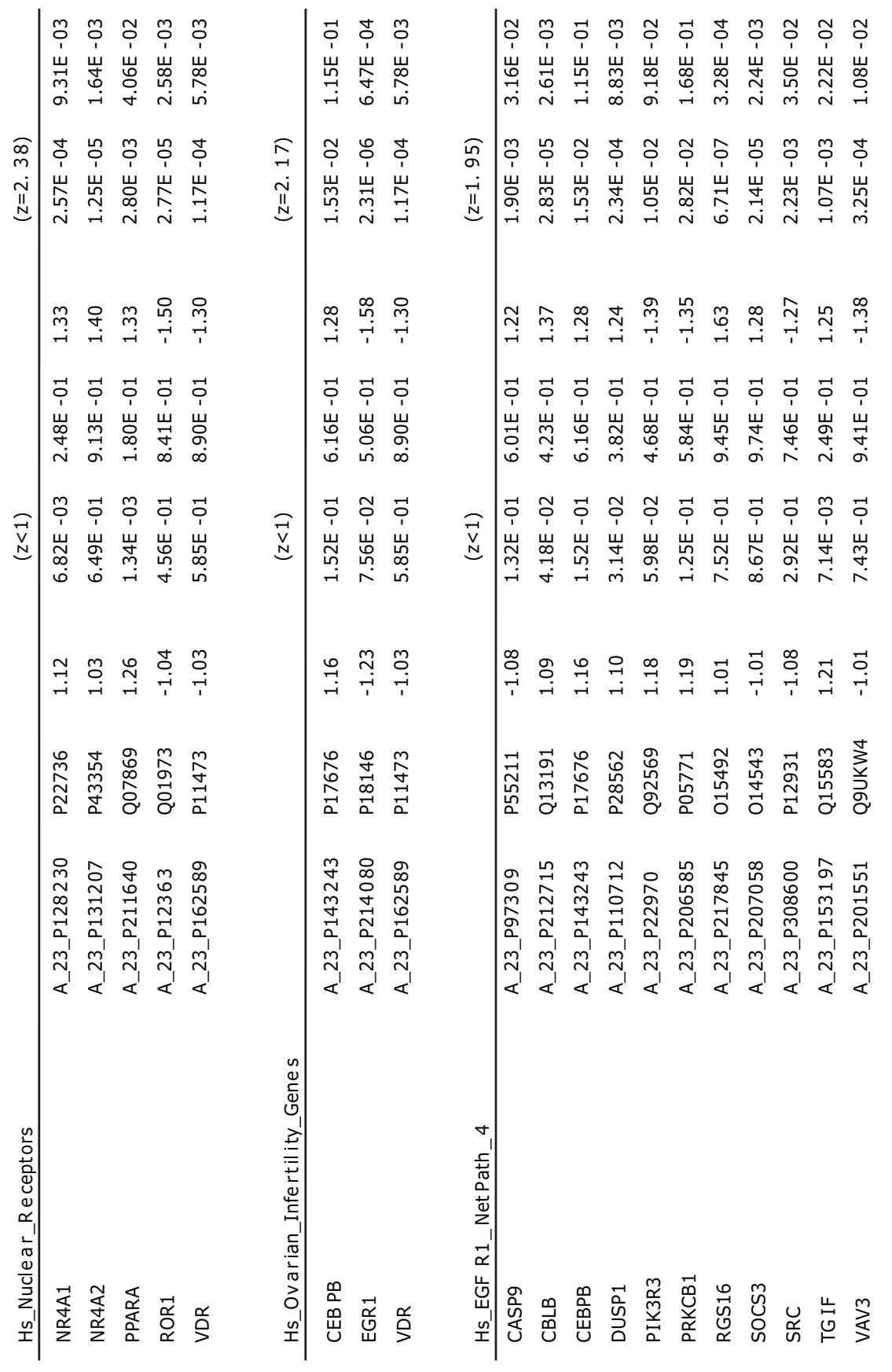


Supplemental data 3: table 1. Differentially expressed genes by fenofibric acid versus GW7647 in HepG2 cells and/or in differentiated CaCo-2 cells present in affected human GenMAPP v2.1 pathways (Part $\mathrm{H}$ ).

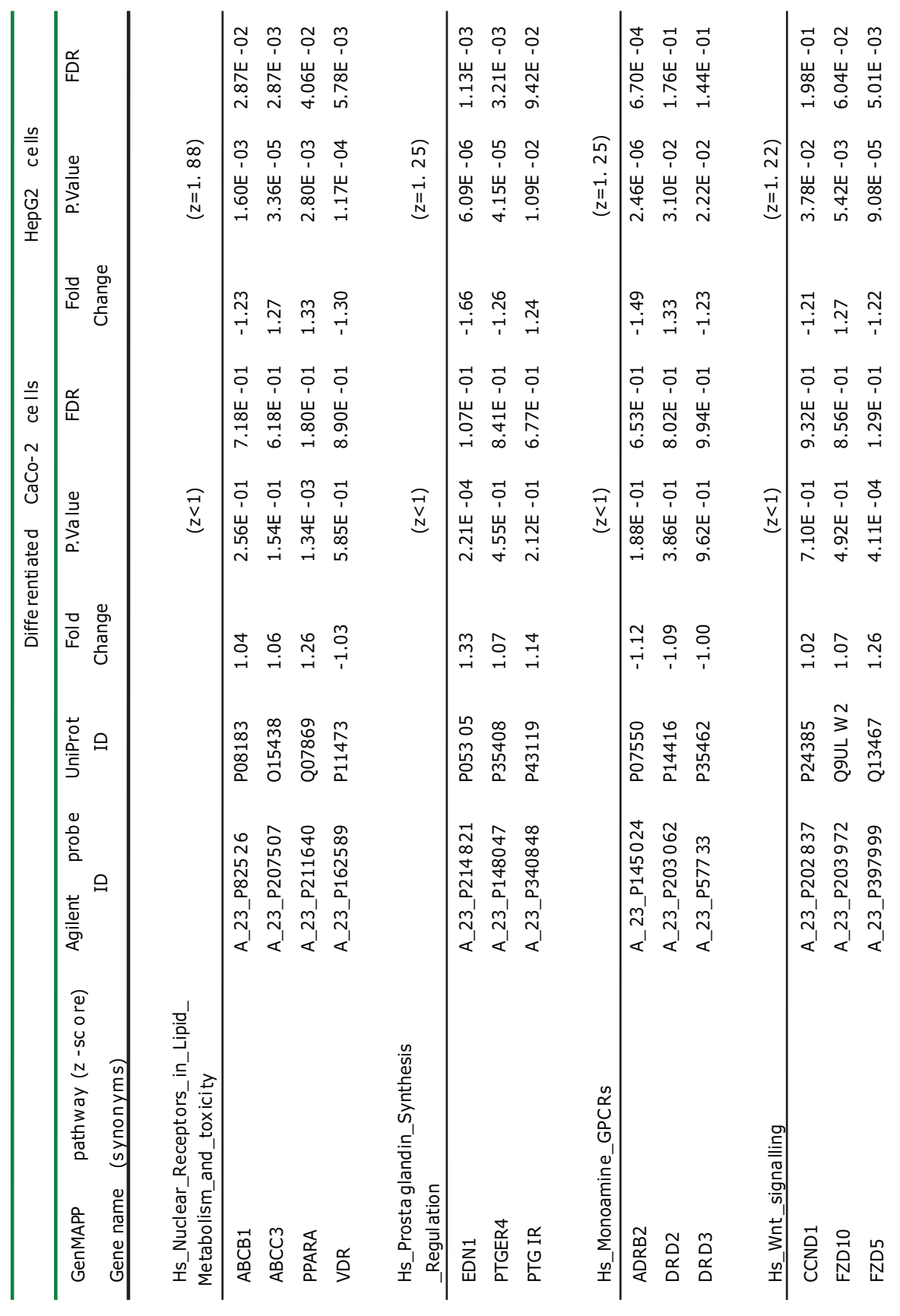


Supplemental data 3: table 1. Differentially expressed genes by fenofibric acid versus GW7647 in HepG2 cells and/or in differentiated CaCo- 2 cells present in affected human GenMAPP v2.1 pathways (Part I).

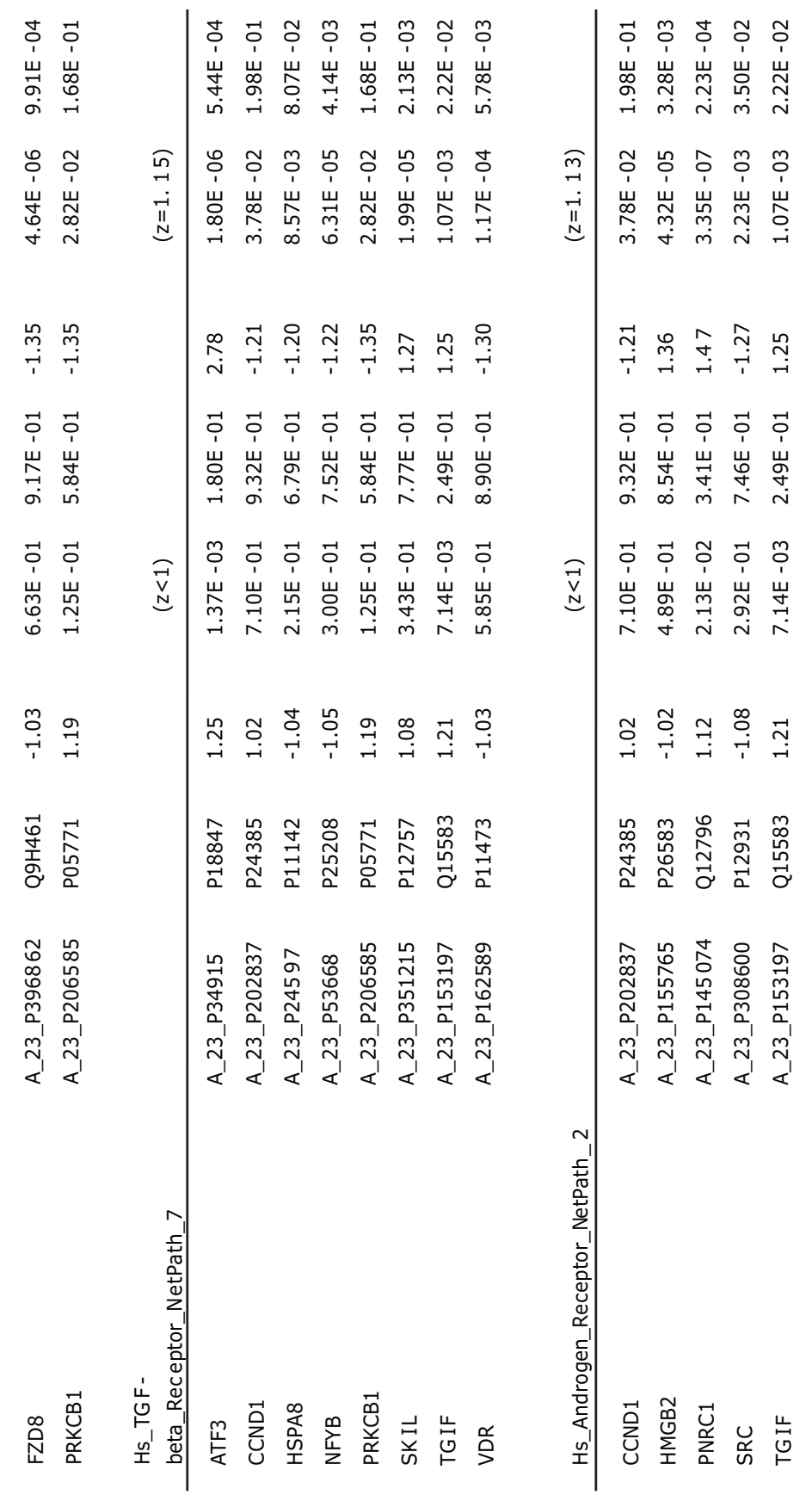


Supplemental data 3: table 1. Differentially expressed genes by fenofibric acid versus GW7647 in HepG2 cells and/or in differentiated CaCo- 2 cells present in affected human GenMAPP v2.1 pathways (Part J).

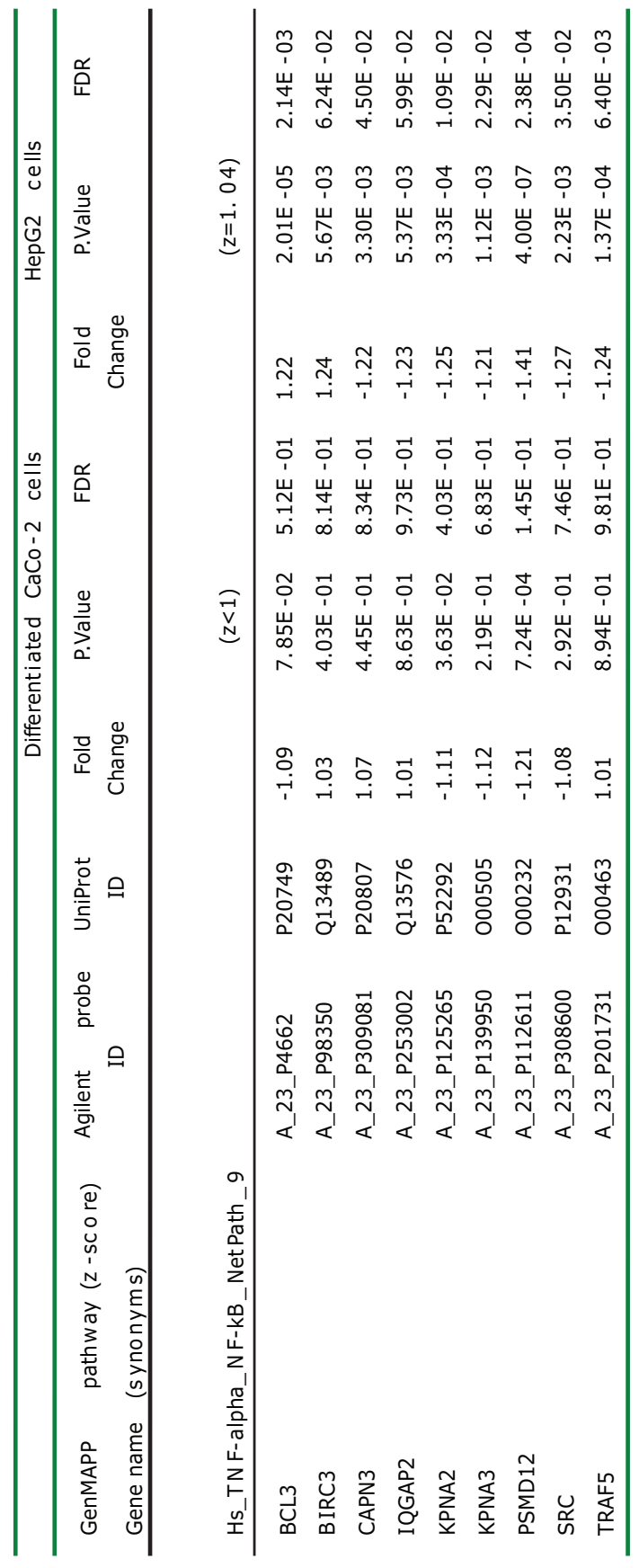


Chapter 7

General discussion 


\section{Introduction}

Although various cholesterol-lowering agents (e.g. statins and fibrates) and other therapies have been successfully developed during the last decades, CHD is still a major health problem in western and developed countries. To lower CHD risk, interventions were predominantly focused on reducing serum LDL-C concentrations. Although this is still a relevant strategy, additional strategies are urgently needed to counter this health problem more effectively. In this view, elevating serum HDL-C levels has been postulated as a promising anti-atherosclerotic approach ${ }^{1}$. To elevate HDL-C levels, various approaches have been suggested and used more or less successfully. Examples are CETP inhibition, niacin treatment, increasing ABCA1 expression, HDL remodelling, and elevating de novo apoA-I production ${ }^{2-5}$. It is important to emphasize that increasing HDL-C concentrations will not by definition reduce CHD risk. For example, in subjects with familial hypercholesterolemia treatment with the CETP inhibitor torcetrapib (in combination with atorvastatin) strongly elevated HDL-C levels as compared to treatment with atorvastatin alone as expected. However, torcetrapib increased the risk of cardiovascular events and death from any cause and was not effective in reducing the yearly rate of change in the maximum intima-media thickness of 12 carotid segments ${ }^{6,7}$. Elevating HDL-C levels by decreasing CETP activity is now under consideration, in which the question "Was it the molecule torcetrapid or the mechanism that failed to reduce CHD risk?" needs to be answered $^{8}$. It has been postulated that the small increase of $2.8 \mathrm{~mm} \mathrm{Hg}$ in average systolic blood pressure may have caused this undesirable outcome. However, it is also possible that other factors have contributed to this undesirable outcome. Another explanation, for example, might relate to the fact that CETP inhibition particularly increases mature HDL-C particles, which lack in theory the capacity to incorporate large amounts of cholesterol from the vessel wall. As a consequence, elevated serum HDL-C concentrations through the use of a CETP-inhibitor may not substantially enhance the reverse cholesterol efflux (RCT), thereby reducing cardiovascular risk. Therefore, elevating serum HDL-C concentrations is a promising approach, but the HDL-C elevating approach should be chosen carefully to reduce cardiovascular risk successfully. In this respect, we postulate that elevating de novo apoA-I production, which consequently results in more premature HDL particles, is one of the most promising approaches at this moment ${ }^{5}$. Therefore, the experiments described in this thesis focused on regulatory mechanisms behind de novo apoA-I production, and on the potential apoA-I elevating effects of nutritional agents. This chapter will provide the main conclusions of the studies as reported in this thesis, discuss critically the relevance of the findings, and include recommendations for future research. 


\section{Differentiated CaCo- 2 cells as an enterocyte cell model}

Since our primary interest lies in elevating de novo apoA-I production by means of nutritional interventions, understanding effects of specific nutrients is of utmost importance. When considering dietary effects, the intestine is of particular importance. Furthermore, small intestinal apoA-I production might be especially relevant for dietary components characterized by a low bioavailability. More specifically, components can be taken up by the enterocytes, giving rise to high local concentrations, but do not appear in the circulation, since they are secreted back into the lumen or end up in the faeces after renewal of the mucosal enterocyte lining ${ }^{9}$. Under these conditions, the dietary component may still affect apoA-I synthesis and secretion within the enterocyte, but not or to a much lower extent within the hepatocyte. These components may therefore still influence de novo apoA-I production and as such serum HDL-C concentrations. For these reasons, we evaluated differentiated $\mathrm{CaCo}-2$ cells for its suitability as an enterocyte cell model to study apoA-I production. As described in chapter $\mathbf{3}$, the RXR $\alpha$ agonist 9-cis retinoid acid and the PPAR $\alpha$ agonist GW7647 elevated, whereas the PPAR $\alpha$ agonist fenofibric acid and the FXR agonist CDCA decreased apoAI concentrations in culture medium of differentiated $\mathrm{CaCo}-2$ cells as well as in HepG2 cells. The observed effects on apoA-I concentrations in both HepG2 cells as well as in differentiated $\mathrm{CaCo}-2$ cells were strongly correlated (correlation coefficient of 0.68: $P=0.037$ ). Eventually, we concluded that differentiated $\mathrm{CaCo}-2$ cells are a suitable cell model to study the effects of potential (nutritional) components on de novo apoA-I production of the small intestine. However, despite similarities between hepatic and small intestinal regulation, we also postulated tissue-specific regulation. ApoA-I production in the small intestine, for example, may also depend on the activation of the apoC-III enhancer, which is not essential for hepatocytes but may play an important role in enterocytes, as demonstrated in vitro ${ }^{10}$.

Differentiated $\mathrm{CaCo}-2$ cells are probably the most suitable cell model to study apoA-I regulatory effects in enterocytes. Culturing CaCo-2 cells, however, is very laborious since they have to be pre-cultured for 21 days to differentiate fully into enterocytes. Therefore, it would be interesting to evaluate other enterocyte cell models. In this view, we examined the enterocyte cell line INT407. ApoA-I mRNA expression as well as apoA-I protein levels were however undetectable (data not shown). Besides testing other new enterocyte cell models, immortalisation of human primary enterocytes might be another interesting approach. Immortalisation of human primary hepatocytes has previously been successful ${ }^{11,12}$, and this may therefore also be possible with human primary enterocytes. Nevertheless, despite these obvious drawbacks, differentiated $\mathrm{CaCo}-2$ cells 
are a suitable small intestinal cell model to study the effects of (nutritional) components on de novo apoA-I production.

\section{Nutrients and beyond de novo apoA-I production}

There is an urgent need for identification of functional ingredients that can be incorporated into foods to manage HDL metabolism by elevating apoA-I production and consequently the blood lipid profile in a favourable manner.

Since we have postulated that differentiated CaCo-2 cells are an appropriate enterocyte cell model, we examined the effects of different fatty acids on apoA-I production (see chapter 4). In chapter 4, we treated the cells with a total fatty acid content of $160 \mu \mathrm{M}$ and concluded that at least the SAFA lauric acid ( $2 \mu \mathrm{M}$ lauric acid with $158 \mu \mathrm{M}$ oleic acid) elevated de novo apoA-I production in differentiated $\mathrm{CaCo}-2$ cells, both at transcriptional (3 hours incubation) and at protein (48 hours incubation) level, as compared to $160 \mu \mathrm{M}$ oleic acid. This suggests that at least a part of the apoA-I and HDL-C elevating effects by lauric acid (compared to oleic acid), as estimated by a meta-analysis of controlled human intervention trials ${ }^{13}$, might be explained by an increased small intestinal de novo apoA-I production. Interestingly, apoA-I elevating effects were most strongly observed at the lowest lauric acid concentration of $2 \mu \mathrm{M}$ with $158 \mu \mathrm{M}$ oleic acid, whereas apoA-I elevating effects levelled-off when higher lauric acid concentrations $(4,8,16$, and 32 $\mu \mathrm{M})$ were exchanged for oleic acid. Whether this means that lauric acid activates regulatory pathways with an inhibitory effect remains to be evaluated. Although previous human intervention studies have already demonstrated that serum HDL-C and apoA-I concentrations were elevated by increased lauric acid consumption ${ }^{14-16}$, further research is needed to estimate its most effective dietary intake to enhance de novo apoA-I production. Moreover, since an enriched diet to $4 \%$ of energy with lauric acid had a minimal impact on serum lipid concentrations as compared to the 2-wk baseline period with MUFAs (mainly oleic acid) in healthy young women ${ }^{17}$, HDL-C and apoA-I elevating effects by lauric acid might be less effective in normolipidemic subjects. However, lauric acid treatment might be still effective in subjects with low HDL-C levels, in which de novo apoA-I production is reduced. Importantly, it should be realized that the SAFA lauric acid also increases serum LDL-C concentrations as compared to carbohydrates or oleic acid. However, the overall effect is a decrease in the ratio of TC/HDL-C, which may beneficially affect CHD risk. Moreover, it would also be interesting to study the effects of lauric acid versus oleic acid on hepatic de novo apoA-I production to estimate the possible contribution of the liver versus the small intestine. Nevertheless, the key finding is that 
lauric acid elevated the apoA-I production, at least in enterocytes, which may contribute to higher serum apoA-I and HDL-C concentrations on lauric acidrich diets, as previously observed in human intervention studies. Main dietary sources of lauric acid are coconut oil and palm kernel oil are. In this respect, consuming pure lauric acid containing supplements or adding pure lauric acid as a functional food ingredient might be an interesting approach. However, effects of lauric acid on cardiovascular outcomes should be extensively examined in long-term clinical studies.

As already indicated at chapter 1, policosanols have been postulated in literature as a potential functional food ingredient, which was claimed to lower serum TC and LDL-C levels and to elevate strongly serum HDL-C concentrations. Since the functional policosanol constituent was not yet determined, we examined the effects of different emulsified policosanols, i.e. the natural policosanol mixture (Lesstanol ${ }^{60}$ ) and various individual policosanols components, on de novo apoA-I production and on other markers that are related to cholesterol metabolism. This study, which included both in vitro (HepG2 cells and differentiated CaCo-2 cells) as well as in vivo (heterozygous $\mathrm{LDLr}^{+/-}$mice) studies, is described in chapter 5 . We demonstrated that none of the individual policosanol components (C24, C26, $\mathrm{C} 28$, and $\mathrm{C} 30$ ) as well as the natural policosanol mixture Lesstanol $^{60}$ (all 30 $\mathrm{mg} / 100 \mathrm{~g}$ diet) lowered serum TC concentrations in heterozygous $\mathrm{LDLr}^{+/-}$ mice. Moreover, there was no effect on gene expression profiles of LDLr, ABCA1, HMG CoA synthase 1, and apoA-I, in hepatic and small intestinal tissue of the female heterozygous $\mathrm{LDLr}^{+/-}$mice after the 7 weeks intervention period. Finally, none of the individual policosanols or their respective very long-chain fatty acids or aldehydes elevated de novo apoA-I production in HepG2 cells or in differentiated $\mathrm{CaCo}-2$ cells. Therefore, we concluded that the evaluated individual policosanols as well as the natural policosanol mixture Lesstanol ${ }^{60}$ have no potential in reducing CHD risk through effects on serum lipoprotein concentrations.

As demonstrated in HepG2 cells and differentiated $\mathrm{CaCo}-2$ cells (chapter 3), 9-cis retinoid acid, an effective $\mathrm{RXR} \alpha$ agonist, strongly elevated apoA-I concentrations in culture medium of both cell lines. Based on this result, it is tempting to suggest that vitamin $A$ increases de novo apoA-I production in vivo, and might increases de novo HDL particle production ${ }^{18}$. The average vitamin A intake estimated of the Dutch population is slightly below the recommended daily intake, i.e. for adult men 830 retinol equivalents (RE) in stead of $1000 \mathrm{RE}$, and for adult women $650 \mathrm{RE}$ in stead of 800 RE ${ }^{18}$. Furthermore, analyses obtained from the Dutch National Food consumption Survey (1997-1998) indicated that 17 to 30 percent of the adults had an inadequate vitamin $A$ intake to maintain sufficient vitamin $A$ stores in the liver. Furthermore, a substantial proportion of these individuals 
had a vitamin A intake level far below the recommended daily intake as estimated by the Nusser method ${ }^{18}$. Considering a vitamin A deficiency in the Dutch population, the health consequence of the current low vitamin A intake on, for example, serum HDL-C concentrations should be investigated more adequately. With respect to vitamin A, different types can be distinguished, i.e. retinol (an alcohol), retinal (an aldehyde), and retinoic acid (an acid). Although vitamin $A$ can be consumed in all three forms, it can also be processed from $\beta$-carotene in the gut. This process is facilitated by $\beta$-carotene dioxygenase. Although the effects of vitamin $A$ or retinoid monotherapy on serum apoA-I and HDL-C concentrations in humans have to our knowledge never been evaluated, it might be an important component in our diet to achieve HDL elevation to prevent CHD.

Other agents, which have not been examined in this thesis, might also be of interest. For example, niacin, also known as nicotinic acid or vitamin $B_{3}$, has been suggested to be the nutritional component with the largest elevating effect on serum HDL-C concentrations ${ }^{19}$. In fact, in humans niacin did not only raise serum HDL-C levels, but also favourably altered serum TC, LDL-C and TAG levels ${ }^{20}$. In this view, several clinical trials have demonstrated that treatment with niacin mono-therapy, or dual-therapy with other lipid lowering agents, significantly reduced mortality and coronary events in humans, and retards total mortality and induce regression of coronary atherosclerosis ${ }^{20}$. Therefore, niacin promised to become a powerful agent in the battle against atherosclerotic diseases. However, due to major side effects, such as hepatotoxicity and flushing, niacin was for a long-time of limited clinical use. However, a new formulation of niacin (inositol hexanicotinate) with an extended-release in the gut, counteracts these major side effects ${ }^{21}$. Additional clinical studies however are required to examine the potency of this new niacin variant on lipoproteins and CHD risk reduction. Mechanistically, it has been suggested that niacin acts on G-protein-couples receptor GPR109A and GPR109B, decreases apoB secretion, inhibits diacylglycerol acyltransferase 2 (DGAT2) activity, inhibits LDL oxidation, retards endothelial reactive oxygen species (ROS) production, and reduces the surface expression of $\beta$-chain of ATP synthase that consequently decreases the hepatic HDL-apoA-I holo-particle uptake, as demonstrated in vitro ${ }^{22}$. Moreover, niacin did not affect the hepatic uptake of cholesterol esters or de novo apoA-I production. This latter aspect is interesting since it suggests that niacin did not affect the RCT. However, effects of niacin on apoA-I production in the enterocyte have not been examined.

Thus, major (e.g. fatty acids) and minor (e.g. vitamins) dietary constituents participate in the regulation of apoA-I and/or HDL metabolism. In this view, amino acids might also be interesting. Approximately 300 amino acids are present in various animal, plant and microbial systems, but only 20 
amino acids serve as building blocks for proteins ${ }^{23}$. With respect to de novo apoA-I production, various amino acids $(27.7 \mathrm{mM})$ were found to elevate apoA-I in HepG2 cells after 24 hours incubation as compared to a basal concentration of essential amino acids $(3.46 \mathrm{mM}){ }^{24}$. These effects could not be explained by differences in chemical structure (aliphatic, aromatic, neutral polar, acidic, basic, or sulfur-containing amino acids, or imino acid) ${ }^{24,25}$. More into detail, strong apoA-I elevating effects, as measured in culture medium of HepG2 treated cells, were found for serine, valine, arginine, threonine, tryptophan, and phenylalanine, whereas asparagine, histidine, proline, leucine, isoleucine, alanine, glycine, lysine, methionine, glutamine, and cysteine had no effect on apoA-I culture medium levels ${ }^{24}$. Interestingly, all these tested amino acids had decreasing effects on apoB secretion compared to the control condition that contained $3.46 \mathrm{mM}$ essential amino acids. Furthermore, anti-atherogenic effects of amino acids have been postulated, since L-aspartate and L-glutamate inhibited fatty streak initiation in cholesterol-fed New Zealand white rabbits ${ }^{25}$. This inhibition was explained by an increase of serum HDL-C concentrations in amino acid-treated animals. However, in these animals serum apoA-I levels were not affected. Mechanistically, not much is known concerning the effects of amino acids on apoA-I metabolism. During amino acid deprivation, amino acid response elements (AAREs) become activated and induce AARE target genes. Although AAREs have not yet been determined in apoA-I regulatory regions, activation of AAREs elevated gene expression of C/EBP $\beta{ }^{26}$. As described in chapter $\mathbf{6}$, FeAc differently affected C/EBP $\beta$ gene expression as compared to GW7647. In addition, amino acid deprivation also induced gene expression of C/EBP homologous protein (CHOP or DDIT3), while ATF3 and ATF4 seem to be involved as well ${ }^{27}$. This suggests that the mechanism by which amino acids regulates de novo apoA-I production, might be related to the mechanism by which FeAc regulates the apoA-I production (chapters 3 and $\mathbf{6}$ ). 


\section{Regulatory factors that enhance apoA-I gene expression}

As extensively described in chapter 2, various transcription factors, such as PPAR $\alpha, R X R \alpha$, and SP1 have been identified to play a role in apoA-I gene expression ${ }^{28}$. However, there is a need to better understand the mechanism or pathways involved in apoA-I transcriptional regulation.

Fatty acids, in particular PUFAs, are generally accepted as PPAR $\alpha$ ligands. In this view, PUFAs and other fatty acids should consequently enhance de novo apoA-I production, since apoA-I was identified by others as a target gene of transcription factor PPAR ${ }^{29}$. However, as we have demonstrated in HepG2 cells and in differentiated CaCo-2 cells (chapter 4), fatty acids did differently affect de novo apoA-I production. More into detail, particularly the SAFA lauric acid elevated apoA-I mRNA (after 3 hours incubation) and protein (after 48 hours incubation) levels, whereas MUFAs and PUFAs had no or apoA-I decreasing effects. Furthermore, since not only lauric acid, but also stearic acid, and linoleic acid elevated the PPRE activity, but only lauric acid elevated apoA-I production, we concluded that although PPAR $\alpha$ might be involved in de novo apoA-I production, it is apparently not the only critical factor. Which additional transcription factor or cofactor is activated or inhibited by lauric acid, is currently not known. Maybe there is a regulatory function for the transcription factors PPAR $\gamma$ and C/EBP $\beta$, as we have postulated in chapter 6. In chapter 6, we compared gene expression profiles of HepG2 and differentiated CaCo-2 cells that were treated with the PPAR $\alpha$ agonists FeAc and GW7647. In chapter 3 and 6, we have demonstrated that GW7647 increased de novo apoA-I production in HepG2 cells and in differentiated $\mathrm{CaCo}-2$ cells after 48 hours incubation, whereas PPAR $\alpha$ agonist FeAc had apoA-I decreasing effects. In line with the hypothesis based on the results of the fatty acid experiment we postulate that PPAR $\alpha$-mediated cofactors or other transcriptional factors should be involved in de novo apoA-I production. As determined by Agilent microarrays and confirmed by RTq-PCR, gene expression of ATF3, GDF15, C/EBP $\beta$, and NF-IL3A were differentially affected between FeAc and GW7647 in both cell lines. Although even more regulatory mechanisms might be involved, in chapter 6 we hypothesize that FeAc activates both PPAR $\alpha$ and transcription factor $C / E B P \beta$. Activated $C / E B P \beta$ may bind to site $B$ at the apoA-I promoter region. Activated $\mathrm{C} / \mathrm{EBP} \beta$ might repress the apoA-I gene expression by blocking the binding-site (site C) of PPAR $\alpha$. Consequently, activated PPAR $\alpha$ can not enhance the apoA-I gene expression, which might finally result in lower apoA-I protein levels. This might explain the observed reduced de novo apoA-I production by FeAc treatment as compared to GW7647 observed in HepG2 cells and in differentiated CaCo-2 cells. 
PPAR $\alpha$ agonists, such as fibrates, primarily improve dyslipidemia, whereas PPAR $\gamma$ agonists, e.g. thiazolidinediones, improve insulin resistance. Therefore, PPAR $\alpha / \gamma$ dual agonists can be regarded as promising agents to lower CHD risk, especially in patients with the metabolic syndrome. Indeed, $\operatorname{PPAR} \alpha / \gamma$ dual agonists, such as tesaglitazar and pioglitazone were very effective in elevating serum HDL-C and/or apoA-I levels, which was confirmed both in vitro and in vivo ${ }^{30,31}$. Moreover, activated PPAR $\gamma$ can bind to $C / E B P \beta$, and forms PPAR $\gamma$-C/EBP $\beta$ complexes ${ }^{32}$. This complex prevents C/EBP $\beta$ to bind to its apoA-I binding-site, and PPAR $\alpha$-mediated apoA-I gene expression should be not inhibited by C/EBP $\beta$. Although PPAR $\alpha / \gamma$ dual agonists are promising, various PPAR $\alpha / \gamma$ dual agonists, i.e. muraglitazar, tesaglitazar, ragaglitazar, imiglitazar, and KRP-297, were suspended after performing clinical trails due to unacceptable side effects ${ }^{33}$. In addition, little evidence of major improvements on cardiovascular outcomes by PPAR $\alpha / \gamma$ dual agonists is available, and therefore their relevance to reduce CHD risk remains to be proven. If adverse effects of PPAR $\alpha / \gamma$ dual agonists are not present or can be overruled in humans, this approach might be valuable. With respect to apoA-I production, their effectiveness might relate to its ability to inactivate C/EBP $\beta$, but this should be confirmed in future studies. 


\section{The main findings and conclusions}

This thesis contains several in vitro and in vivo studies that describe the effects of specific (dietary) compounds, and postulates a new regulatory mechanism on de novo apoA-I production. Elevating de novo apoA-I production is an anti-atherogenic strategy that should induce the formation of new HDL particles and should consequently reduce CHD risk in humans. From our studies we conclude:

1) Differentiated CaCo-2 cells are a suitable model to study de novo small intestinal apoA-I production in vitro enabling the possibility to screen for potential bioactive dietary components. This cell model may also be used in tracing tissue specific effects.

2) Elevated serum apoA-I concentrations after consumption of higher amounts of the SAFA lauric acid might - at least partly - be related to an increased small intestinal de novo apoA-I production. Mechanistically, PPAR $\alpha$ activation seems to be involved, but is apparently not the only necessary transactivation signal.

3) None of the individual policosanol components (C24, C26, C28, or C30) as well as the natural policosanol mixture Lesstanol ${ }^{60}$ (all $30 \mathrm{mg} / 100 \mathrm{~g}$ diet) lowered serum total cholesterol concentrations in heterozygous $\mathrm{LDLr}^{+/-}$ female or male mice after a 7 weeks intervention period. Moreover, there was no effect on gene expression profiles of LDLr, ABCA1, HMG CoA synthase 1 , and apoA-I in hepatic and small intestinal tissue of the heterozygous female $\mathrm{LDLr}^{+/-}$mice. Finally, none of the individual very long-chain fatty alcohols or their respective fatty acids or fatty aldehydes affected de novo apoA-I protein production in vitro in HepG2 and differentiated CaCo- 2 cells. Therefore, we conclude that the evaluated individual policosanols as well as the natural policosanol mixture Lesstanol ${ }^{60}$ have no potential in reducing $\mathrm{CHD}$ risk through effects on serum lipoprotein concentrations.

4) In contrast to the PPAR $\alpha$ agonist GW7647, fenofibric acid (FeAc) lowered apoA-I concentrations in culture medium, both in HepG2 cells and in differentiated CaCo-2 cells. After 3 hours incubation, FeAc induced gene expression of various transcription factors, such as ATF3, C/EBP $\beta$, GDF15, and NF-IL3A, in both cell lines as compared to GW7647. In theory all of these factors might be involved in de novo apoA-I production, but we hypothesize that the differences on de novo apoA-I production between FeAc and GW7647 is mainly explained by the difference in activation of the transcription factor $\mathrm{C} / \mathrm{EBP} \beta$. 


\section{References}

1. Rader DJ. (2006). Molecular regulation of HDL metabolism and function: implications for novel therapies. J Clin Invest (116):3090100.

2. Klerkx AH, El Harchaoui K, van der Steeg WA, et al. (2006). Cholesteryl ester transfer protein (CETP) inhibition beyond raising highdensity lipoprotein cholesterol levels: pathways by which modulation of CETP activity may alter atherogenesis. Arterioscler Thromb Vasc Biol (26):706-15.

3. Lee JY, Parks JS. (2005). ATP-binding cassette transporter $\mathrm{AI}$ and its role in $\mathrm{HDL}$ formation. Curr Opin Lipidol (16):19-25.

4. Rye KA, Barter PJ. (2004). Formation and metabolism of prebeta-migrating, lipid-poor apolipoprotein A-I. Arterioscler Thromb Vasc Biol (24):421-8.

5. Dullens SP, Plat J, Mensink RP. (2007). Increasing apoA-I production as a target for CHD risk reduction. Nutr Metab Cardiovasc Dis (17):616-628.

6. Kastelein JJ, van Leuven SI, Burgess L, et al. (2007). Effect of torcetrapib on carotid atherosclerosis in familial hypercholesterolemia. $\mathrm{N}$ Engl J Med (356):1620-30.

7. Barter PJ, Caulfield M, Eriksson $M$, et al. (2007). Effects of torcetrapib in patients at high risk for coronary events. N Engl J Med (357):2109-22.

8. Tall AR, Yvan-Charvet L, Wang N. (2007). The failure of torcetrapib: was it the molecule or the mechanism? Arterioscler Thromb Vasc Biol (27):257-60.

9. Marinangeli $C P$, Kassis $A N$, Jain $D$, Ebine N, Cunnane SC, Jones PJ. (2007). Comparison of composition and absorption of sugarcane policosanols. Br J Nutr (97):381-8.

10. Zannis VI, Liu T, Zanni M, Kan HY, Kardassis D. (2003). Regulatory gene mutations affecting apolipoprotein gene expression: functions and regulatory behavior of known genes may guide future pharmacogenomic approaches to therapy. Clin Chem Lab Med (41):411-24

11. Schippers IJ, Moshage $\mathrm{H}$, Roelofsen $\mathrm{H}$, et al. (1997). Immortalized human hepatocytes as a tool for the study of hepatocytic (dedifferentiation. Cell Biol Toxicol (13):375-86.

12. Cascio SM. (2001). Novel strategies for immortalization of human hepatocytes. Artif Organs (25):529-38.

13. Mensink RP, Zock PL, Kester AD, Katan MB. (2003). Effects of dietary fatty acids and carbohydrates on the ratio of serum total to HDL cholesterol and on serum lipids and apolipoproteins: a meta-analysis of 60 controlled trials. Am J Clin Nutr (77):114655.

14. Denke MA, Grundy SM. (1992). Comparison of effects of lauric acid and palmitic acid on plasma lipids and lipoproteins. Am J Clin Nutr (56):895-8.
15. de Roos N, Schouten E, Katan M. (2001). Consumption of a solid fat rich in lauric acid results in a more favorable serum lipid profile in healthy men and women than consumption of a solid fat rich in trans-fatty acids. J Nutr (131):242-5

16. Temme EH, Mensink RP, Hornstra G. (1996). Comparison of the effects of diets enriched in lauric, palmitic, or oleic acids on serum lipids and lipoproteins in healthy women and men. Am J Clin Nutr (63):897-903.

17. Schwab US, Niskanen LK, Maliranta HM, Savolainen MJ, Kesaniemi YA, Uusitupa MI. (1995). Lauric and palmitic acid-enriched diets have minimal impact on serum lipid and lipoprotein concentrations and glucose metabolism in healthy young women. J Nutr (125):466-73.

18. Waijers P, Feskens E. (2004). RIVM rapport 350010002/2004: Vitamine A voorziening van de Nederlandse bevolking. 1--47.

19. Barter P, Kastelein J, Nunn A, Hobbs R. (2003). High density lipoproteins (HDLs) and atherosclerosis; the unanswered questions. Atherosclerosis (168): 195-211.

20. Meyers CD, Kamanna VS, Kashyap ML. (2004). Niacin therapy in atherosclerosis. Curr Opin Lipidol (15):659-65.

21. Guyton JR. (2007). Niacin in cardiovascular prevention: mechanisms, efficacy, and safety. Curr Opin Lipidol (18):415-20.

22. Kamanna VS, Kashyap ML. (2007). Nicotinic acid (niacin) receptor agonists: will they be useful therapeutic agents? Am J Cardiol (100):S53-61.

23. Young VR, Yu YM, Borgonha S. (2000). Proteins, peptides and amino acids in enteral nutrition: overview and some research challenges. Nestle Nutr Workshop Ser Clin Perform Programme (3):1-20; discussion 203.

24. Cianflone K, Zhang Z, Vu H, KohenAvramoglu $R$, Kalant $D$, Sniderman AD. (1996). The effect of individual amino acids on $A$ poB100 and $L p(a)$ secretion by HepG2 cells. J Biol Chem (271):29136-45.

25. Yanni AE, Perrea DN, Yatzidis HA. (2005). Effect of antiatherogenic L-aspartate and Lglutamate on serum lipoproteins cholesterol and apolipoproteins $A-1$ and $B$ in rabbits fed with high cholesterol diet. Nutr Metab Cardiovasc Dis (15):161-5.

26. Thiaville MM, Dudenhausen EE, Zhong C, Pan YX, Kilberg MS. (2008). Deprivation of protein or amino acid induces C/EBPbeta synthesis and binding to amino acid response elements, but its action is not an absolute requirement for enhanced transcription. Biochem J (410):473-84.

27. Cherasse $\mathrm{Y}$, Maurin AC, Chaveroux C, et al. (2007). The p300/CBP-associated factor (PCAF) is a cofactor of ATF4 for amino acidregulated transcription of $\mathrm{CHOP}$. Nucleic Acids Res (35): 5954-65. 
28. Zannis VI, Kan HY, Kritis A, Zanni EE, Kardassis D. (2001). Transcriptional regulatory mechanisms of the human apolipoprotein genes in vitro and in vivo. Curr Opin Lipidol (12):181-207.

29. Schoonjans K, Staels B, Auwerx J. (1996). Role of the peroxisome proliferator-activated receptor (PPAR) in mediating the effects of fibrates and fatty acids on gene expression. J Lipid Res (37):907-25.

30. Schuster H, Fagerberg B, Edwards S, et al. (2007). Tesaglitazar, a dual peroxisome proliferator-activated receptor alpha/gamma agonist, improves apolipoprotein levels in non-diabetic subjects with insulin resistance. Atherosclerosis.

31. Qin S, Liu T, Kamanna VS, Kashyap ML. (2007). Pioglitazone stimulates apolipoprotein A-I production without affecting HDL removal in HepG2 cells: involvement of PPAR-alpha. Arterioscler Thromb Vasc Biol (27):2428-34.

32. Wang LH, Yang $X Y$, Zhang $X$, Farrar WL. (2007). Inhibition of adhesive interaction between multiple myeloma and bone marrow stromal cells by PPAR $\{$ gamma $\}$ cross talk with NF-\{kappa\}B and C/EBP. Blood (110):4373-84.

33. Fievet C, Fruchart JC, Staels B. (2006). PPARalpha and PPARgamma dual agonists for the treatment of type 2 diabetes and the metabolic syndrome. Curr Opin Pharmacol (6):606-14.

34.RIVM. Internet: http://www.rivm.nl. Assed on April 2008.

35. Nederlandse, Hartstichting. Internet:http://www.hartstichting.nl. Assed on April 2008.

36. Berliner JA, Navab M, Fogelman AM, et al. (1995). Atherosclerosis: basic mechanisms. Oxidation, inflammation, and genetics. Circulation (91):2488-96.

37. Fruchart JC, Nierman MC, Stroes ES, Kastelein JJ, Duriez P. (2004). New risk factors for atherosclerosis and patient risk assessment. Circulation (109): III15-9.

38. Tegos TJ, Kalodiki E, Sabetai MM, Nicolaides AN. (2001). The genesis of atherosclerosis and risk factors: a review. Angiology (52):8998.

39. Fuster V, Badimon L, Badimon JJ, Chesebro JH. (1992). The pathogenesis of coronary artery disease and the acute coronary syndromes (1). N Engl J Med (326):24250,310-318.

40. Danielsson H, Sjovall J. (1975). Bile acid metabolism. Annu Rev Biochem (44):233-53. 




\section{Summary/Samenvatting}




\section{Summary}

In many developed countries, coronary heart disease (CHD) is the most frequent cause of death. The primary cause of $\mathrm{CHD}$ is the process of atherosclerosis occurring in the vessel wall. Atherosclerosis is a progressive disease and is strongly associated with a disturbed lipid profile, also known as dyslipidemia. Dyslipidemia can be characterised by 1) elevated low-density lipoprotein cholesterol (LDL-C), 2) elevated triacylglycerol (TAG), and 3) lowered high-density lipoprotein cholesterol (HDL-C) serum concentrations. Therefore, anti-atherosclerotic approaches focus on the development of agents that lower serum LDL-C and TAG concentrations, and/or elevate serum HDL-C concentrations. One of the most promising approaches to elevate serum HDL-C concentrations is by enhancing de novo apoA-I production. ApoA-I is the main protein constituent of an HDL particle and predominantly produced by hepatocytes and enterocytes in humans. To study regulatory mechanisms and effects of (nutritional) components on de novo apoA-I production in human enterocytes, we evaluated effects of various (pharmacological) components in differentiated CaCo-2 cells (an enterocyte cell model) and in HepG2 cells (a hepatic cell model), as described in chapter 3. We found a strong significant correlation on de novo apoA-I production between the effects of the evaluated agents in differentiated CaCo-2 cells and in HepG2 cells. Therefore, we concluded that differentiated CaCo-2 cells are a suitable enterocyte cell model to study de novo apoA-I production in vitro. Furthermore, we postulated the existence of tissuespecific effects, since apoA-I gene expression in enterocytes is regulated by both similar and different promoter/enhancer regions as compared to apoA-I gene expression in hepatocytes. In chapter 4, we examined the effects of fatty acids that differ in chain-length, degree of saturation, and cis/trans configuration on de novo apoA-I production in differentiated $\mathrm{CaCo}-2$ cells. We concluded that lauric acid elevated de novo apoA-I production, both at the level of gene expression (after 3 hours incubation) and protein synthesis (after 48 hours incubation). Therefore, we concluded that HDL-C and apoA-I elevating effects by the SAFA lauric acid, as earlier observed in human intervention studies, might - at least partly - be explained by an enhanced de novo apoA-I production in enterocytes. Interestingly, the strongest apoA-I elevating effect by lauric acid was achieved by the lowest replacement. Furthermore, the PUFAs linoleic acid and $\alpha$-linolenic acid, but also cis/trans configurations of $\mathrm{C} 18: 1$ and C18:2 fatty acids, had no clear effects on the apoA-I production in this cell model.

In chapter 6, we tried to elucidate a part of the apoA-I transcriptional mechanism. As described in chapter 3, PPAR $\alpha$ agonists fenofibric acid (FeAc) and GW7647 had opposite effects on de novo apoA-I production as measured 
in apoA-I culture medium concentrations after 48 hours incubation. These effects were observed both in HepG2 cells and in differentiated CaCo-2 cells. Agilent microarrays were used to determine expression profiles of genes that were differentially affected by FeAc and GW7647 after 3 hours incubation. Our main goal was to identify differentially regulated transcription factors or cofactors that might be involved in de novo apoA-I production. After 3 hours incubation, FeAc induced gene expression of various transcription factors and cofactors, such as ATF3, C/EBP $\beta$, GDF15, and NF-IL3A, as compared to GW7647. These differences were observed in both cell lines and confirmed by RTq-PCR. In theory, all of these factors might be involved in regulating the apoA-I gene expression and explain the difference between FeAc and GW7647 on de novo apoA-I production. However, we postulated the hypothesis that the difference on de novo apoA-I production between FeAc and GW7647 is mainly explained by the differences in activation of transcription factor C/EBP $\beta$. However, further research is needed to confirm this hypothesis.

A natural policosanol mixture has been postulated as LDL-C lowering and HDL-C elevating nutrient. However, which policosanol constituent in the natural mixture is responsible for these favourable effects is not known. Therefore, we examined (chapter 5) the effects of different emulsified policosanol components side-by-side versus a natural policosanol mixture on 1) serum total cholesterol concentrations, 2) lipoprotein profiles, and 3) gene expression levels of several genes involved in cholesterol metabolism in both liver and small intestinal tissue of heterozygous $\mathrm{LDLr}^{+/-}$mice. In addition, individual policosanols, i.e. very long-chain fatty alcohols (C24, C26, C28, and ( 30 ), and their respective very long-chain fatty acids and aldehydes, were evaluated for their capacity to increase de novo apoA-I production in HepG2 cells. Since for all of the components studied, no effects were observed both in vitro and in vivo, we concluded that policosanols have no potential in reducing CHD risk through effects on serum lipoprotein concentrations.

Based on the studies described in this thesis, we conclude that the SAFA lauric acid is a potential nutritional agent to elevate de novo apoA-I production in human enterocytes Furthermore, we hypothesized that the transcription factor C/EBP $\beta$ might be an important factor in regulating apoA-I production in both human hepatocytes and enterocytes. Nevertheless, the exact regulatory mechanisms, by which various apoA-I elevating agents act, are still poorly understood and need further investigation. Finally, we concluded that policosanols do not have any effects on cholesterol metabolism and therefore do not reduce CHD risk. 


\section{Samenvatting}

Hart- en vaatziekten (HVZ) is één van de belangrijkste doodsoorzaken in westerse landen. De belangrijkste oorzaak van HVZ is de ontwikkeling van aderverkalking, oftewel atherosclerose. Atherosclerose is een progressieve ziekte en is sterk geassocieerd met een verstoord lipidenprofiel, oftewel dyslipidemie. Een dyslipidemie wordt gekenmerkt door 1) verhoogde lagedichtheid lipoproteïne cholesterol (LDL-C), 2) verhoogde triacylglyceriden (TAG) en 3) verlaagde hoge-dichtheid lipoproteïne cholesterol (HDL-C) serum concentraties. Om atherosclerose te bestrijden zijn de meeste studies vooral gericht op stoffen die in staat zijn om LDL-C en TAG concentraties te verlagen en/of HDL-C concentraties te verhogen. Verschillende strategieën zijn ontwikkeld om HDL-C serum concentraties te verhogen. Een veelbelovende strategie is het verhogen van de novo apoA-I productie - een belangrijk eiwit dat voorkomt in een HDL deeltje - in lever- en/of darmcellen. Om mechanismen en effecten van (voedings)componenten te bestuderen op de novo apoA-I productie in humane dunne darmcellen (enterocyten), hebben we farmacologische stoffen in gedifferentieerde $\mathrm{CaCo}-2$ cellen - een celmodel voor de enterocyt - vergeleken met de effecten van dezelfde stoffen in HepG2 cellen - een celmodel voor de humane lever. Deze resultaten zijn beschreven in hoofdstuk 3. Wij vonden een sterke significante correlatie tussen de effecten van de bestudeerde stoffen op de novo apoA-I productie in gedifferentieerde $\mathrm{CaCo}-2$ en HepG2 cellen. Daaruit concludeerden wij dat gedifferentieerde $\mathrm{CaCo-2}$ cellen een bruikbaar celmodel zijn om de novo apoA-I productie in vitro te bestuderen. Daarnaast veronderstelden wij ook weefselspecifieke effecten in de dunne darm en in de lever, omdat de apoA-I genexpressie in enterocyten, ten opzichte van die in hepatocyten, gereguleerd wordt door dezelfde maar ook door andere promoter/enhancer regionen. In hoofdstuk 4 zijn de effecten van verschillende vetzuren op de novo apoA-I productie in gedifferentieerde CaCo-2 cellen beschreven. Deze vetzuren verschilden in ketenlengte, mate van verzadiging en cis/trans configuratie. Wij concludeerden dat het uitwisselen van een kleine hoeveelheid oliezuur voor het verzadigd vetzuur laurinezuur, vergeleken met alleen oliezuur, de de novo apoA-I productie verhoogt op zowel mRNA (na 3 uur incubatie) als op eiwit (na 48 uur incubatie) niveau. Daarom concludeerden wij dat HDL-C en apoA-I verhogende effecten, zoals eerder gevonden in humane studies, ten minste gedeeltelijk verklaard kunnen worden door een verhoogde de novo apoA-I productie in de darm. Opmerkelijk was de waarneming dat het apoA-I verhogende effect het sterkst was bij de laagste laurinezuur concentratie. Verder hadden de meervoudige onverzadigde vetzuren linolzuur en alpha-linoleenzuur, maar ook cis/trans 
configuraties van C18:1 en C18:2 vetzuren, geen duidelijke effecten op de novo apoA-I productie in dit celmodel.

In hoofdstuk 6 hebben we getracht om een deel van het mechanisme op te helderen, waardoor de apoA-I productie wordt verhoogd. Zoals beschreven in hoofdstuk 3, hebben de PPAR $\alpha$ agonisten fenofibric acid (FeAc) - het actieve bestanddeel van fenofibraat - en GW7647 na 48 uur incubatie tegengestelde effecten op de novo apoA-I productie. Deze respectievelijk verlagende en verhogende effecten werden waargenomen in zowel HepG2 als in gedifferentieerde CaCo-2 cellen. Om de genexpressie profielen van met FeAc en GW7647 gestimuleerde cellen te bepalen, werden Agilent microarrays gebruikt. De verkregen genexpressie profielen van beide PPAR $\alpha$ agonisten werden met elkaar vergeleken om transcriptiefactoren of cofactoren te identificeren welke betrokken kunnen zijn in de novo apoA-I synthese. $\mathrm{Na} 3$ uur incubatie induceerde FeAc verschillende transcriptiefactoren en/of cofactoren in vergelijking met GW7647, o.a. ATF3, C/EBP $\beta$, GDF15 en NF-IL3A. De genexpressie van deze genen was verhoogd in beide cellijnen en werd tevens bevestigd door RTq-PCR. In theorie kunnen al deze "upgereguleerde" genen betrokken zijn bij de genexpressie regulatie van apoA-I en zou daarmee het verschil kunnen verklaren tussen FeAc en GW7647 op de de novo apoA-I productie. Wij veronderstelden echter de hypothese dat het verschil op de novo apoA-I productie verklaard kan worden door een verschil in activatie van de transcriptie factor C/EBP $\beta$. Echter meer onderzoek is nodig om deze hypothese te bevestigen.

Andere studies hebben gesuggereerd dat een natuurlijk mengsel van verschillende typen policosanolen $\mathrm{LDL}-\mathrm{C}$ verlagende en $\mathrm{HDL}-\mathrm{C}$ verhogende eigenschappen heeft. Echter het is niet bekend welk policosanol bestanddeel in het natuurlijke policosanol mengsel hiervoor verantwoordelijk is. Daarom hebben wij in hoofdstuk 5 in lever en in dunne darmweefsel van heterozygote $\mathrm{LDLr}^{+/-}$muizen de effecten van verschillende geëmulsificeerde policosanol bestanddelen vergeleken met die van een natuurlijk policosanol mengsel op 1) serum totaal cholesterol concentraties, 2) het lipidenprofiel, en 3) het genexpressie profiel van verschillende genen betrokken bij het cholesterolmetabolisme. Verder hebben we de effecten onderzocht op de novo apoA-I productie in HepG2 cellen van individuele policosanolen. Deze policosanolen bestonden uit zeer lange keten vet-alcoholen (C24, C26, C28 en C30) en de hiervan afgeleide aldehyden en vetzuren. Omdat we geen gunstige effecten van zowel de individuele policosanol componenten als van het natuurlijke policosanol mengsel konden waarnemen in zowel de in vitro als in vivo studies, concludeerden wij dat policosanolen geen gunstig effect hebben om het risico op HVZ te verlagen door gunstige effecten op het cholesterolmetabolisme. 
Gebaseerd op de studies die beschreven staan in dit proefschrift concludeerden wij dat het verzadigd vetzuur laurinezuur mogelijk een voedingscomponent is om de novo apoA-I productie in humane dunne darmcellen te verhogen. Verder denken wij dat de transcriptiefactor C/EBP $\beta$ een belangrijke apoA-I regulerende factor is in zowel humane lever- als in dunne darmcellen. Echter de mechanismen waardoor de apoA-I productie kan worden verhoogd zijn nog niet volledig opgehelderd en daarom is verder onderzoek nodig. Tot slot kunnen wij concluderen dat policosanolen geen effect hebben op het cholesterolmetabolisme en verlaagt daarom niet het risico op het krijgen van HVZ. 


Dankwoord 


\section{Dankwoord}

Mede dankzij vele personen is dit proefschrift met succes afgerond en kan ik terugkijken naar een mooie en vooral leerzame periode.

Als eerste wil ik mijn promotors Prof. dr. ir. Ronald P. Mensink, Prof. dr. Edwin C.M. Mariman en copromotor Dr. Jogchum Plat bedanken. Beste Jogchum, ik had me geen betere begeleider kunnen wensen. Zowel op wetenschappelijk als op sociaal vlak heb ik zeer veel bewondering voor je. Bedankt dat jij altijd voor me klaar stond. Beste Ronald, promoveren onder jouw kritisch oog heb ik als een voorrecht ervaren. Ik denk dat ik mede door jouw toezien een betere wetenschapper ben geworden. Bedankt voor de fijne samenwerking. Beste Edwin, we kunnen het goed met elkaar vinden. Helaas hebben we (te) weinig gebruik gemaakt van proteomics, maar er liggen nog vele interessante vraagstellingen in jouw vakgebied die klaar liggen om aangepakt te worden.

Leden van de beoordelingscommissie, Prof. dr. Jan F.C. Glatz, Prof. dr. em. Gerard Hornstra, Prof. dr. Folkert Kuipers, Prof. dr. ir. Wim H.M. Saris en Dr. ir. Peter L. Zock, wil ik bedanken voor het beoordelen van dit proefschrift.

Humane Biologie is inmiddels uitgegroeid tot een enorme afdeling. Iedereen waarmee ik een gezellig praatje maakte of waarmee ik samenwerkte wil ik bij deze hartelijk bedanken. Toch wil ik een aantal mensen met nadruk in het zonnetje zetten. De middenlobbers Arienne, Carla, Chantal, Chris, Elke, Florence, Julia, Julian, Kirsten, Leonie, Marjolijn, Martine, Maurice, Noud, Pascal, Ruth, en Stan. Een zeer diverse groep waarin iedereen een steentje heeft bijgedragen aan de mooie tijd bij HB. Met name de vele koffie-rondes waren altijd weer een succes om de sociale band aan te wakkeren. Ondanks mijn verhuizing naar de $1^{\text {ste }}$ verdieping, ging dat vrijwel niet ten koste van de koffierondes. Beneden trof ik mijn lotgenoten. Iedereen in zijn of haar laatste fase van het promotie-traject. Dit was voor mij een succesvolle zet, zoals ook reeds anderen beschreven in hun dankwoord. Lydia, ik had dikwijls de tranen in mijn ogen van het lachen, mijn dank hiervoor en veel succes met je gezinnetje en je carrière in Zweden. Johan J, Mandy, en Myriam A., jullie heb ook zorggedragen bij het verlichten van stressvolle dagen. En uiteindelijk heb ik dan samen met Chantal en Julian de laatste loodjes met plezier samen doorbracht op niveau 0. Ook op dit niveau, kon ik bij jullie altijd terecht en heb ik met plezier naar het einde van dit traject gewerkt. Natuurlijk wil ik ook ex-HB's en ex-kamergenoten bedanken. Myriam T. en Jacquelien wil ik graag bedanken voor de humor en de vele luchtige en relativerende gesprekken in de eerste 2 jaar. Myriam T., heel veel succes met het voltooien van je opleiding als klinisch chemicus. De bezoekjes samen met je man Gert-Jan en je broer Martijn zijn steeds gezellig. Jacquelien, je hebt me ook vele uurtjes ondersteund bij het uitvoeren 
celexperimenten en het opzetten van de apoA-I ELISA. Ook heb je een deel voor je rekening genomen tijdens de muizenstudie. Met plezier heb ik met je samengewerkt en ik hoop dan ook dat jij ooit weer actief wordt in de wetenschap. Ook Maurice, Martine en Stan wil ik expliciet bedanken voor de fijne samenwerking en voor het vakkundig uitvoeren van de experimenten cq data verwerking.

Paul en Loek, fascinerend hoe jullie de taal der computers beheersen. Als de computerproblemen me te veel werden, stonden jullie altijd klaar voor wijze raad of loste jullie de problemen vrijwel direct op. Ook het secretariaat, Claudia, Desiree, Ilona, Larisa, en Kerstin, verdient een welverdiende pluim. Altijd behulpzaam en vriendelijk.

Ook buiten de HB wil ik een aantal mensen bedanken die bijzonder hebben bijgedragen aan de ontspanning naast de wetenschap. Jill, onze gesprekken waren altijd heel gezellig en ik ben blij dat ik je heb leren kennen, je bent een beste vriendin en een grootse wetenschapper. Eva\&Borja, ook jullie zijn fantastische vrienden. Bedankt voor jullie hartelijke vriendschap en de gezellige avonden. Eva succes met jouw promotie! Geert\&Veerle, Mark\&Debby, Ramon\&Mariska, en Sven\&Karolien, bedankt voor de ontspannende uitjes, van het uittrekken van een boom in de voortuin tot het drinken van een pintje. Ik heb er veel van genoten en hoop dat er nog vele avonden zullen volgen.

Richard, Allard en Harry, bedankt voor de prettige samenwerking tijdens het uitvoeren van de muizenstudies en het gebruik van de broedmachine. Ook wil ik Chiel bedanken voor het gebruik van de broedmachines van de afdeling anatomie\&embryologie. Het heeft geresulteerd in topdieren!

Leden van PROVUM, NUTRIM, en IPC, bedankt voor de leerzame en gezellige momenten. Met veel plezier heb ik genoten van de gedrevenheid waarmee jullie de belangen van promovendi behartigen.

Eric, beste neef, dankzij jouw creativiteit is mijn promotieboekje voorzien van een geweldige kaft. Bedankt!

Beste Pascal, bedankt dat je mijn paranimf wilt zijn! Ondanks dat ik naar de $1^{\text {ste }}$ verdieping vertrok, kwam je altijd gezellig buurten. Bedankt voor alles! Veel succes met jouw laatste loodjes. Beste Monique, met trots mijn zus, ver weg maar toch ook altijd dichtbij Ook jij zal mij ondersteunen als paranimf, bedankt.

Familie is voor mij altijd belangrijk geweest. Pa en Ma, met trots wil ik jullie bedanken voor de mogelijkheden en de nodige steun die jullie mij hebben gegeven. Ook mijn zussen Monique en Kristel, en mijn boer François, dank voor jullie interesse en steun, maar vooral bedankt voor wie jullie zijn. Natuurlijk wil ik hierbij de partners Bas, Mark, en Mariska niet vergeten in te betrekken. Oma Eijssen, altijd "koppie koppie!", en dus zal je ook nu het een 
en het ander begrijpen van dit proefschrift. Altijd zeer gezellig als we weer bij elkaar zijn. Bert\&Katelein, Karen\&Chris met de kleintjes Romina en mijn lief petekindje Eleni, bedankt dat jullie mij helemaal hebben opgenomen in jullie familie. Meter (Oma De Lombaerde), Annemarie\&Frank, ongelooflijk hoe jullie mij en Femke altijd als koningen behandelen in hartje Brugge. Deze enorme gastvrijheid geeft ons altijd een heerlijk vakantiegevoel. Tevens wil ik alle andere familieleden bedanken die geïnteresseerd naar me luisterde als ik weer eens met vol enthousiasme sprak over mijn onderzoek of andere zaken.

Tijdens mijn onderzoeksperiode heb ik veel geleerd en ontdekt. Maar de grootste en belangrijkste ontdekking vond echter plaats tijdens de cursus "Proefdierkunde" in juni 2004. Lieve Femke, ik kan niet half in woorden uitdrukken hoe gelukkig jij me maakt. Je bent mij steun en toeverlaat. Bedankt dat jij aan mijn zijde wilt staan. 




\section{List of publications}

\section{Full papers}

Schneider B, Gerdsen R, Plat J, Dullens S, Bjorkhem I, Diczfalusy U, Neuvonen PJ, Bieber T, von Bergmann K, Lutjohann D. Effects of high-dose itraconazole treatment on lipoproteins in men. Int J Clin Pharmacol Ther. 2007 Jul;45(7):377-84.

Dullens SPJ, Plat J, Mensink RP. Increasing apoA-I production as a target for CHD risk reduction. Nutr Metab Cardiovasc Dis. 2007 Oct;17(8):616-28.

Plat J, Dullens SPJ, Mensink RP. Policosanol als cholesterolverlagend voedingscomponent: waarheid of illusie? Voeding NU. 2007 Nov;11:14-16.

Dullens SPJ, Mensink RP, Bragt MC, Kies AK, Plat J. Effects of emulsified policosanols with different chain lengths on cholesterol metabolism in heterozygous LDL receptor-deficient mice.J Lipid Res. 2008 Apr;49(4):790-6.

Dullens SPJ, Mensink RP, Plat J. Differentiated CaCo-2 cells as an additional model besides HepG2 cells to evaluate interventional effects on de novo apoA-I production. Submitted.

Dullens SPJ, Mensink RP, Plat J. Effects of individual SAFAs, MUFAs, and PUFAs as compared to oleic acid on de novo intestinal apoA-I production. Submitted.

Dullens SPJ, Mensink RP, Gaj S, Plat J. Regulated genes by PPARalpha agonist fenofibric acid in hepatic and small intestinal apoA-I production. In preparation.

\section{Abstracts}

Dullens SPJ, Mensink RP, Mariman ECM, Plat J. Not only activation of PPARalpha, but also of another - so far unknown factor - is needed to increase apoA-I synthesis by fenofibric acid. Atherosclerosis 2005;6(1):S200.

Dullens SPJ, Mensink RP, Plat J. Differential effects of individual fatty acids on de novo apoA-I production in differentiated $\mathrm{CaCo}-2$ cells. Atherosclerosis 2007;8(1):S906. 


\section{Curriculum Vitae}

Stefan Philomina Joseph Dullens was born on august $12^{\text {th }} 1978$ in Heerlen, the Netherlands. In 1996, he graduated from secondary school and continued his education to study Chemical and Medical Laboratory Technology at Hogeschool Zuyd in Heerlen. He graduated in 2000 and started to study Medical Biology at the VU University in Amsterdam. To differentiate as a Medical Biologist he completed an internship of 10 months at Crucell NV in Leiden. During this internship, he completed to generate new fiber-chimeric adenoviral vectors of serotype Ad5 and Ad35 with the PER.C6 ${ }^{\circ}$ technology. In 2003, he graduated as MSc in Medical Biology and started as a PhDstudent at the department of Human Biology of the Faculty of Health, Medicine and Life Sciences at Maastricht University, under supervision of Dr. J. Plat, Prof. dr. E.C.M. Mariman, and Prof. dr. ir. R. P. Mensink. From 2003 to 2007, he performed cell-based as well as animal studies, which are described in this thesis. In June 2007, he was granted with a Young Investigator Award for his poster presentation "Differential effects of individual fatty acids on de novo apoA-I production in differentiated CaCo-2 cells" at the $76^{\text {th }}$ European Atherosclerosis Society (EAS) in Helsinki, Finland. 